\title{
Improving outcomes in gastric cancer surgery
}

Citation for published version (APA):

Tegels, J. J. W. (2019). Improving outcomes in gastric cancer surgery. [Doctoral Thesis, Maastricht University]. Maastricht University. https://doi.org/10.26481/dis.20190118jt

Document status and date:

Published: 01/01/2019

DOI:

10.26481/dis.20190118jt

Document Version:

Publisher's PDF, also known as Version of record

\section{Please check the document version of this publication:}

- A submitted manuscript is the version of the article upon submission and before peer-review. There can be important differences between the submitted version and the official published version of record.

People interested in the research are advised to contact the author for the final version of the publication, or visit the DOI to the publisher's website.

- The final author version and the galley proof are versions of the publication after peer review.

- The final published version features the final layout of the paper including the volume, issue and page numbers.

Link to publication

\footnotetext{
General rights rights.

- You may freely distribute the URL identifying the publication in the public portal. please follow below link for the End User Agreement:

www.umlib.nl/taverne-license

Take down policy

If you believe that this document breaches copyright please contact us at:

repository@maastrichtuniversity.nl

providing details and we will investigate your claim.
}

Copyright and moral rights for the publications made accessible in the public portal are retained by the authors and/or other copyright owners and it is a condition of accessing publications that users recognise and abide by the legal requirements associated with these

- Users may download and print one copy of any publication from the public portal for the purpose of private study or research.

- You may not further distribute the material or use it for any profit-making activity or commercial gain

If the publication is distributed under the terms of Article $25 \mathrm{fa}$ of the Dutch Copyright Act, indicated by the "Taverne" license above, 


\title{
Improving outcomes in gastric cancer surgery
}

\author{
Juul Tegels
}


ISBN 978-94-6323-459-7

Design and layout by the author

Printed by Gildeprint

(C) 2019 Juul Tegels

All rights reserved. No part of this thesis may be reproduced or transmitted in any form, by any means, electronic or mechanical, including photocopying, recording or any information storage or retrieval system, without prior permission in writing of the author, or when appropriate, of the publisher of the articles.

Publication of this thesis was financially supported by Vakgroep Heelkunde-Zuid Limburg, Maastricht University and Maastricht UMC+. 


\title{
Improving outcomes in gastric cancer surgery
}

\author{
PROEFSCHRIFT
}

ter verkrijging van de graad van doctor aan de Universiteit Maastricht, op gezag van Rector Magnificus, Prof. Dr. Rianne M. Letschert

volgens het besluit van het College van Decanen, in het openbaar te verdedigen

op vrijdag 18 januari 2019, om 12.00 uur

door

Juul Jeanne Wilhelmus Tegels

geboren 25 Augustus 1988 te Swalmen 


\title{
Promotor
}

Prof. dr. C.H.C. Dejong

\section{Co-promotor}

Dr. J.HM.B. Stoot

\section{Beoordelingscommissie}

Prof. dr. N.D. Bouvy (voorzitter)

Prof. dr. H.I. Grabsch

Prof. dr. R. van Hilligersberg, Universitair Medisch Centrum Utrecht

Prof. dr. ir. M.P. Weijenberg

Dr. B. Wijnhoven, Erasmus Medisch Centrum, Rotterdam

\author{
Paranimfen \\ Jasper Kox \\ Luuk Theelen
}




\section{Table of contents}

Chapter 1

General introduction and outline

6

Part 1

Overview of advances in gastric cancer surgery

Chapter 2

Improving the outcome in gastric cancer surgery

Part 2

Preoperative risk prediction

Chapter 3 Value of geriatric frailty and nutritional status assessment in predicting postoperative mortality in gastric cancer surgery

Chapter $4 \quad$ Sarcopenia is highly prevalent in patients undergoing surgery for gastric cancer but not associated with worse outcomes

\section{Part 3}

Laparoscopic surgery for gastric cancer and its cost aspects

Chapter 5 Introduction of laparoscopic gastrectomy for gastric cancer in a Western tertiary referral centre: a prospective cost analysis during the learning curve

Part 4

Quality of life after gastric cancer surgery

Chapter 6 Factors Influencing Health-Related Quality of

Life after Gastrectomy for Cancer

Chapter 7

General discussion and summary

Dutch summary

134

Valorization

142

Acknowledgements

146

List of publications

150

Curriculum vitae

153 


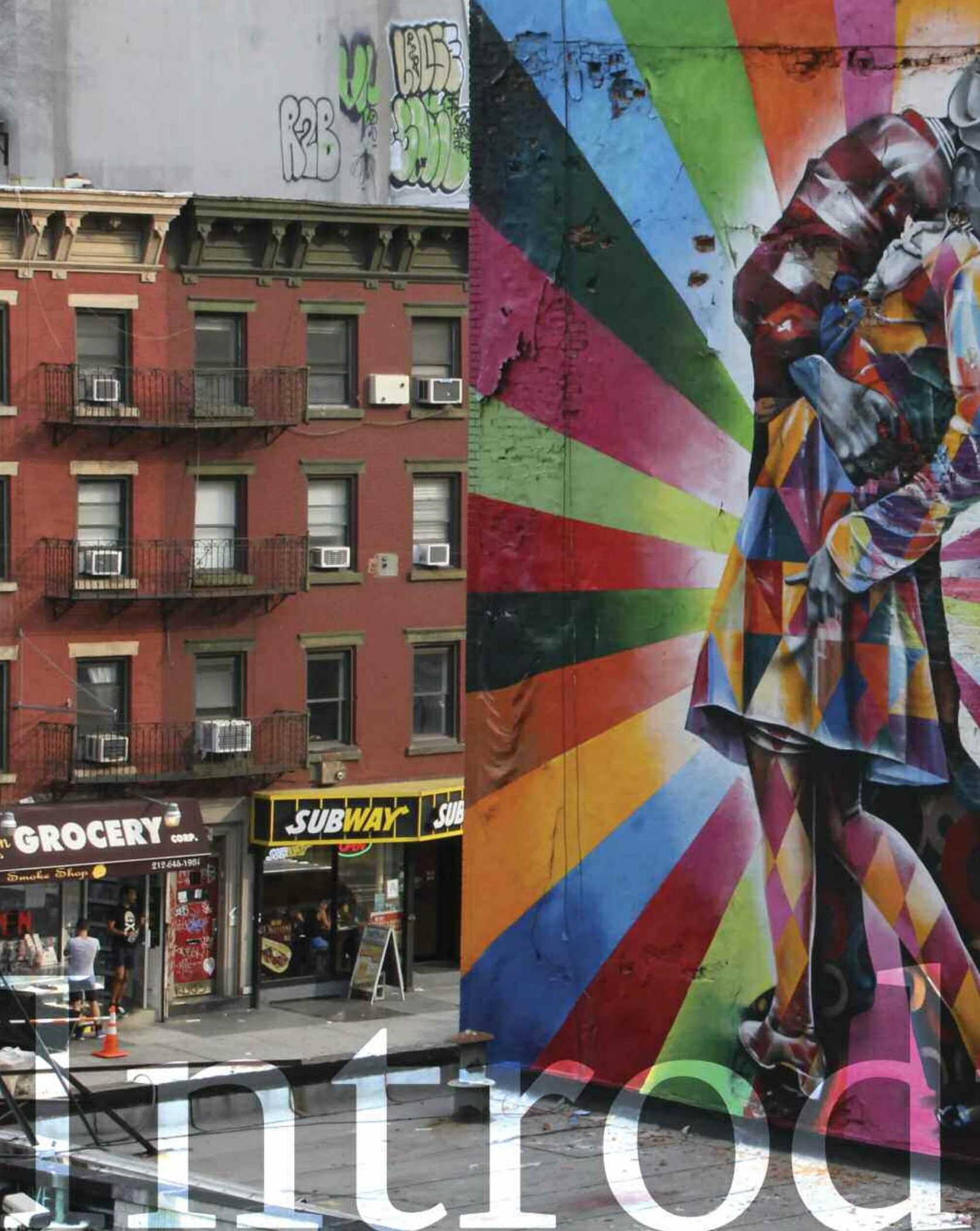




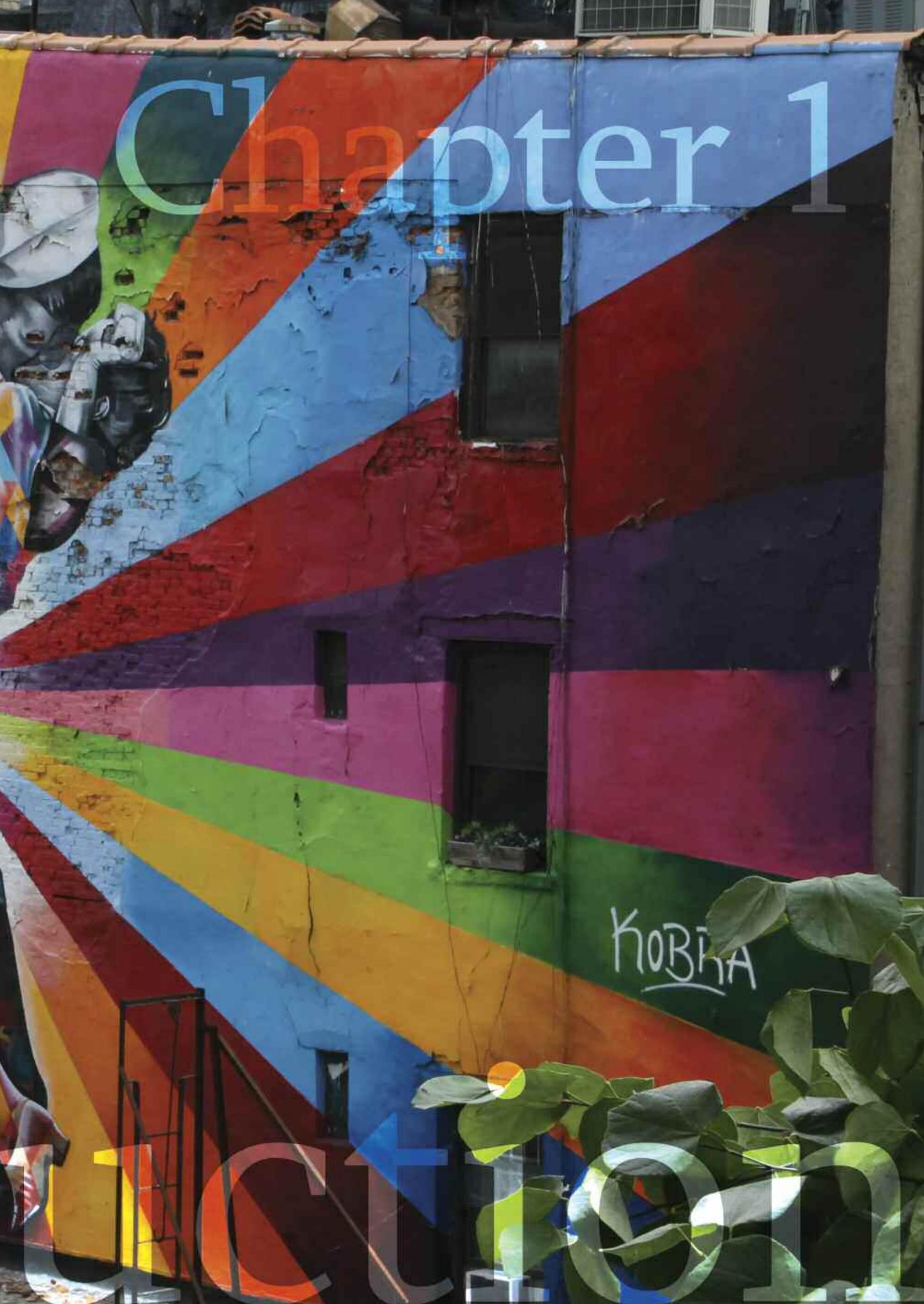




\section{An introduction to gastric cancer}

Worldwide, gastric cancer represents a major health problem as one of the leading causes of cancer-related deaths. For example in 2012, 951,600 cases and 723,100 deaths have been estimated to have occurred worldwide [1]. Major worldwide differences in gastric cancer incidence rates exist with the highest reported incidence in men in Japan and Korea, at 66.7/100,000 and 64.6/100,000 respectively. Much lower rates are observed in men in the United States (5.3 to $10.4 / 100,000)$, U.K. $(8.9 / 100,000)$ and the Netherlands $(9.3 / 100,000)$. There is also an almost universal male predominance with a male to female ratio of approximately $3: 2[1]$.

Surgery is the only treatment that can offer cure or long term survival for gastric cancer patients. However, especially in Western countries where incidences are much lower, gastric cancer is often not diagnosed until an advanced stage of disease. Therefore patients are often found to have inoperable disease. This fact is underlined by national registry findings. In 2015 the Dutch national cancer registry (IKNL) registered 1165 new cases of gastric cancer in the Netherlands, not including cardia malignancies. In the same year 428 patients underwent surgery for gastric cancer in the Netherlands according to the Dutch Upper GI Cancer Audit [2, 3]. Notably, there are differences in these resection rates even within Western Europe with a much lower rate (i.e., $21.6 \%$ for gastric cancer) in the U.K. [4].

Important improvements in the treatment of gastric cancer patients were not in the surgical field. Effects of chemotherapy and radiotherapy have been studied. Introduction of perioperative chemotherapy has shown to improve progressionfree and overall survival as shown by the results of the MAGIC trial in 2006 [5]. Patients from the MAGIC trial were treated with epirubicin, cisplatin and fluoruracil (ECF) regimen. In more recent studies, changes in chemotherapeutic agents seems to further improve results. Docetaxel based regimen FLOT (fluoruracil, leucovorin, oxaplatin and docetaxel) showed improved results over ECF regimen in terms of more frequent complete histopathological response and less adverse events [6]. The role of adjuvant radiotherapy in addition to chemotherapy is still not very clear. Meta-analysis of randomized controlled trials totaling 3347 patients from 15 trials did not show benefits of chemoradiotherapy over chemotherapy alone [7].

\section{High-risk surgery}

Gastric cancer surgery is considered high-risk surgery and is associated with significant morbidity and mortality. Reported 30-day mortality rates from national registrations vary in the U.S. and Europe from 3.5 to $6.9 \%[4,8]$. Major 
complications after gastrectomy for gastric cancer include: anastomotic leakage or stenosis, bleeding, abscess, surgical site infection and also pulmonary complications such as pneumonia. Reported complication rates vary from a relatively low rate (i.e., 17.4\%) reported in a Korean study to a high rate of $36 \%$ of patients having a complication after total gastrectomy in a United States nationwide database study $[8,9]$.

\section{Surgical risk assessment and the elderly patient}

In the elderly patient gastric cancer surgery carries more risks with an increase in complications and mortality [10,11]. This is likely due to a higher incidence of comorbidities and possibly reduced functional residual capacity. The fact that age is not sufficient to exclude patients from treatment is fairly widely accepted [1214].

In order to further classify the patient's general condition, ASA-physical status (American Society of Anaesthesiologists) was first introduced in the $1940 \mathrm{~s}$ in a publication entitled: 'Grading of patients for surgical procedures' [15]. It defines the six degrees of 'physical state' in order to create a common language for communicating about the preoperative condition of the patient. This has gained widespread acceptance as a scoring system for determining a patient's physical status and is widely used to assess risks from surgery. The high degree of interobserver variability is a problem for the ASA classification, i.e. different scores are given by different assessors to the same patient [16]. Moreover, it is also limited as a predictor for an adverse postoperative course; it performed moderately for prediction of postoperative mortality in a meta-analysis [17].

Scoring comorbidities by means of a scoring system such as the Charlson Comorbidity Index (CCI) is a method that can also determine risk of mortality [18]. The $\mathrm{CCl}$ has a more defined scoring system than the ASA classification and can be expected to have less interobserver variability. Octo- and nonogenarians who underwent gastric cancer surgery were found to have higher morbidity and mortality rates associated with higher $\mathrm{CCl}(\mathrm{CCl} \geq 5)$ [19]. However, a study which included 139 patients in Germany, found that age rather than increased $\mathrm{CCl}$ was an independent predictor for adverse postoperative events [20].

These date imply that age and comorbidities are not universally found to be predictors for adverse outcome. Also, it is important to realize that surgical risk assessment is complex and general physical status is only a component of overall assessment. 


\section{Chapter 1.}

\section{Geriatric frailty}

It is axiomatic to say that a patient's chronological age does not necessarily correspond with the biological age. There are a multitude of biological markers,

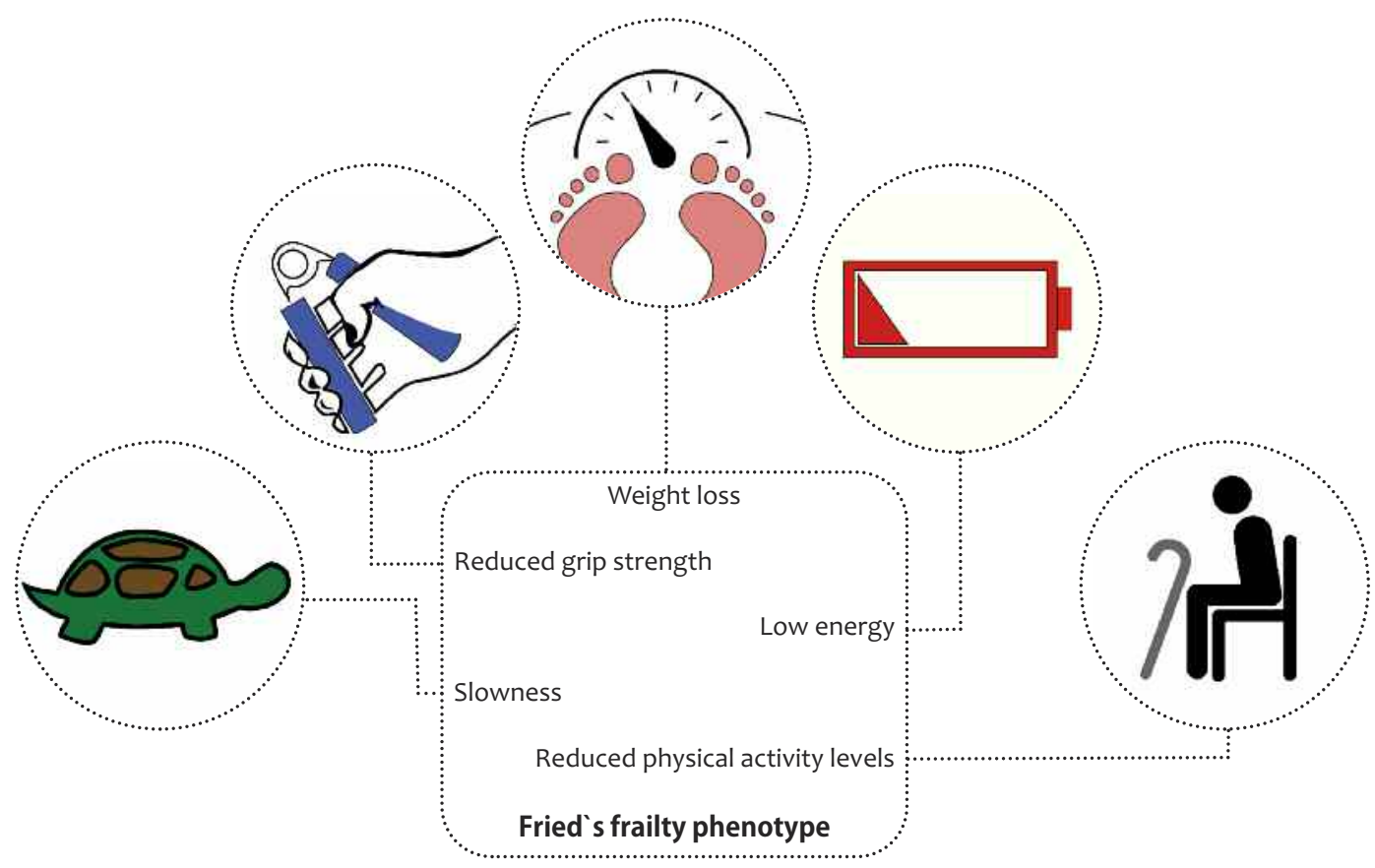

some more evident than others, that give an indication of a person's biological age. Geriatric frailty is a concept which can loosely be translated to biological age. It is defined as a state of increased vulnerability to stressors in older individuals, which leads to an increased risk of developing adverse health outcomes [21].

Geriatric frailty has been gaining increasing attention in recent years as a predictor of adverse outcome after surgery, because in Western countries gastric cancer is a disease predominantly in the elderly and in an ageing population worldwide [22, 23]. Therefore, geriatric frailty assessment is a very useful tool for preoperative risk assessment in gastric cancer patients.

The frailty phenotype proposed by Fried et al. describes presence of one or more of the following components: shrinking (i.e, unintentional weight loss), weakness (decreased grip strength), poor endurance and energy (self reported exhaustion), slowness (i.e., slow walking speed) and low physical activity level [24]. 
Assessment methods of geriatric frailty are not uniform between studies but the basic concept remains the same. All components of Fried's frailty phenotype can be measured or screened for in a variety of manners. By performing a comprehensive geriatric assessment (CGA) thorough assessment of parameters of frailty can be achieved. It is usually performed by trained professionals in an outpatient setting. It employs the use of clinical history taking, a variety of questionnaires and physical tests (e.g., grip strength measurement or timed getup-and-go test) to assess or screen for the presence of frailty components. For instance, weakness can be measured by measuring grip strength or by using questionnaire items that give an indication of low physical strength. This is true for most components of frailty. Performing a CGA is a time- and therefore resourceconsuming effort.

Questionnaires have been developed as a low-cost, low-effort, low-resource consuming method to assess or screen for presence of frailty in elderly individuals. Examples that have been used in surgical patients include the Hopkins Frailty score and Edmonton Frail Scale [22, 25]. For example, scores $>7$ on the Edmonton Frail Scale, were associated with increased complications after non-cardiac surgery [25]. Frailty was also associated with increased postoperative complications and lengthof-stay in patients who underwent various types of elective surgery [26].

Thus, age and physical status (i.e., ASA classification) do not provide adequate risk assessments especially in elderly patients with gastric cancer. Frailty may improve estimation of perioperative risks. Also, previous studies suggest that frailty questionnaires provide clinically applicable solutions for frailty assessment.

\section{Body composition and sarcopenia}

As mentioned earlier, developing tools to identify patients who are at an increased risk for adverse events is very important. Current surgical risk assessment is complex and prone to interobserver variability. Therefore tools that can provide a reliable measurement would be of great value.

Such a tool would preferably also give a good indication of the patient's physiological reserves. It could hypothetically better predict a person's tolerance of (surgical) stressors and therefore risk of adverse outcome after surgery. Analytic morphomics employs the use of medical imaging to measure specific biomarkers from patients. Taking advantage of the fact that most patients who undergo major surgery have had radiographic imaging performed preoperatively. An abdominal CT (computed tomography)-scan with intravenous contrast agent enhancement is standard care for all gastric cancer patients. Most often thoracic CT-scan imaging 


\section{Chapter 1.}

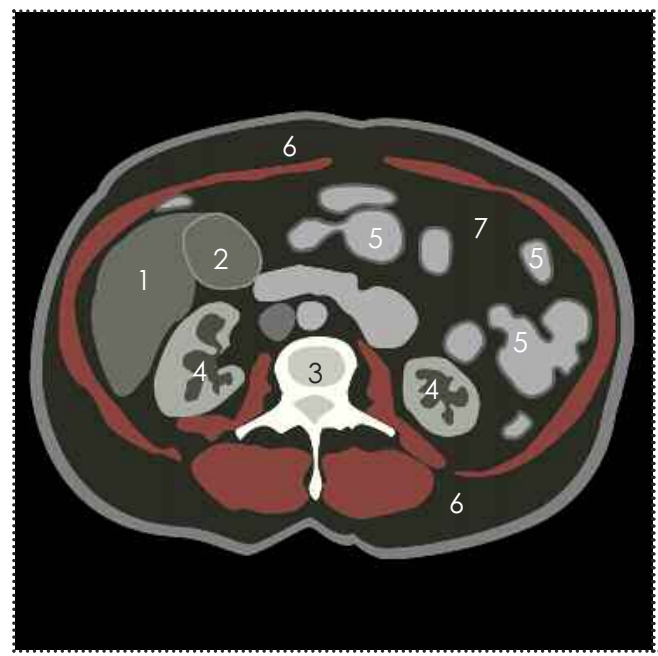

Schematic representation of transverse section at level of lumbar vertebra L3

With muscles highlighted in red, similar to what the semi-automated software puts out after setting tissue of interest threshold to 30 to +110 Hounsfield units.

Muscle highlighted in red.

1. Liver

2. Gallbladder

3. Lumbar vertebra $\mathrm{L} 3$

4. Kidneys

5. Intestines

6. Subcutaneous adipose tissue

7. Visceral or intra-abdominal adipose tissue

is performed at the same time. Measurement of fat area and muscle area on CTscan imaging can be performed relatively easily and with very low interobserver variability $[27,28]$.

Visceral obesity (i.e., high intraabdominal fat area) has been associated with prolonged operative time, more surgical site infections and overall more complications for instance in elective laparoscopic colorectal surgery [29]. In this study no differences in outcome were observed when patients were classified as obese based on body mass index (BMI). In another study patients with low visceral fat area had significantly worse oncological outcome, i.e., overall- and disease-free survival, after surgery for hepatocellular carcinoma [30].

Markers for skeletal muscle size have also been investigated for use as a predictor for adverse outcome after surgery. Sarcopenia, or loss of muscle mass and function, is an important area of investigation. Sarcopenia is a complex syndrome. The European Working Group on Sarcopenia in Older People (EWGSOP) states that low gait speed or low grip strength in addition to low muscle mass is required for diagnosing sarcopenia in older individuals [31]. However, sarcopenia and loss of muscle mass, although strictly speaking not the same, are often used interchangeably in literature [32-36].

Studies have shown an association between low skeletal muscle mass, which is closely related to sarcopenia, and worsened short-term as well as long-term outcomes after surgery for gastrointestinal malignancies [35, 37, 38]. 


\section{A brief history of laparoscopic gastric cancer surgery}

Reducing the impact of the surgical intervention in elderly and more frail patients may help improve outcomes of gastric cancer surgery. One of the ways of achieving this might be the implementation of laparoscopic gastric cancer surgery. In 1901 Georg Kelling (1866 - 1945), a German physician in Dresden, performed the first laparoscopic intervention in a dog by using a cystoscope [39]. In a 1910 publication titled "The Possibilities for Performing Cystoscopy in Examinations of Serous Cavities" Hans Christian Jacobaeus published his first experiences in laparoscopic surgery in humans. Initially used for diagnostic purposes, the first non-diagnostic publications started to appear in the 1930 [40]. Increasing interest by general surgeons came after the first acknowledged laparoscopic cholecystectomy by using four trocars in 1987 by the French gynecologist Mouret [41]. There were others before him such as Lukichev in 1983 and Muhe in 1985, but their techniques did not receive as much attention [41].

The first laparoscopic cholecystectomy and subsequent acceptance of this new technique was made possible by rapid advances in development of the video computer chip and therefore projection and magnification of images on television screens [40].

As experience with laparoscopic surgery grew, Kitano et al. described the first laparoscopic assisted distal gastrectomy for gastric cancer in 1994 [42]. They described a technique that was, at that time, still difficult due to lack of appropriate laparoscopic instruments and techniques. During the following years, especially in Japan and Korea, laparoscopic surgery gained more and more acceptance for treating early gastric cancer. Later, with growing experience and improvements in equipment, lymph node dissection and thereby treatment of more advanced stage gastric cancer became possible and more commonplace [43-45]. Yearly numbers of minimally invasive procedures for gastric cancer in Japan grew from just under 1000 procedures in the year 2000 to $4500+$ procedures in 2007 [46].

The goal of laparoscopic surgery is to reduce the surgical trauma to the patient and thereby reduce the overall impact of the procedure on the patient. This can result in reduction of intraoperative blood loss, less pain and use of pain medication, fewer complications and reduced length of stay. This also holds true for laparoscopic gastric cancer surgery. An issue with laparoscopic surgery related to the oncological safety and adequacy. Currently there is not a large body of evidence but studies until now suggest that similar oncological outcomes at five years can be achieved by laparoscopic surgery [47-49]. 
Health care costs and business intelligence

As mentioned above, invention of new techniques and finding clinical applications as well as expanding knowledge and using new techniques is a long and laborious process. It can take years and sometimes decades before new techniques gain widespread acceptance and use.

Nowadays governmental organizations and health insurance companies have a major influence on the regulation of costs in healthcare due to the economic circumstances. Health care providers therefore have to prove implementation of new techniques is cost-effective, both for hospital organizations as well as society as a whole. Data on health care costs related to laparoscopic surgery for gastric cancer have been lacking.

Business intelligence is a term used to describe a set of efforts (strategies, processes, applications, data and technology) directed towards gathering and analyzing data of business information [50]. This can be carried out in different ways. Business intelligence can be used to analyze different aspects of a business process in order to identify weaknesses or potential for improvement. For example, data from the hospital's fully digitized patient information system that also registers operating room process times (i.e., time of entry into the theatre, time of incision and closure and total operating room occupancy) can be analyzed to study efficiency.

Quality of life

Survival after gastrectomy for gastric cancer is increasing in part due to better surgical techniques and also improvement of perioperative chemotherapy [5, 51]. Because of this, quality of life after treatment for gastric cancer is becoming increasingly important.

Gastric cancer patients who have undergone major surgery can have a plethora of symptoms, which may be due to the change in bowel continuity and absence of the reservoir function of the stomach or due to (neo)adjuvant chemotherapy. Such symptoms include loss of appetite, early satiety, reflux, dysphagia or change of stools. Specific to chemotherapy-related symptoms are hand-foot syndrome (related to capecitabin) and organ toxicity (e.g., ototoxicity of cisplatin). Some of these are temporary and reversible whilst others are permanent. All these can potentially have a profound impact on a gastric cancer patient's Health-Related Quality of Life (HRQoL) [52].

HRQoL assesses multiple dimensions of a person's well being. This includes physical, medical, psychological and social parameters secondary to a disease and 
its treatment. HRQoL is becoming one of the more important outcome measurement in cancer treatment. Assessment of the impact of treatment on quality of life helps health care professionals to focus and improve specific aspects of treatment strategies. Importantly, on the other hand, a better understanding of HRQoL can help informing patients about short and long-term risks and benefits of treatment. 


\section{Chapter 1.}

\section{Aims and outline of the thesis}

The first aim of this thesis was to provide a structured review of current literature concerning improvements in gastric cancer surgical care. Part one of this thesis will provide an overview of literature on advances in the preoperative-, intraoperative and postoperative stage as well as regional organization of gastric cancer surgery.

This thesis aimed to investigate factors that can preoperatively be assessed and possibly be used as predictors for adverse outcome after surgery. Part two of this thesis provides two studies which deal with this. In the first study geriatric frailty and nutritional status are evaluated. In the second study, body composition measurements such as sarcopenia are assessed for their use as predictors of adverse postoperative outcome.

Introduction of new techniques always results in a comparison between the traditional approach and the new. The aim of part three of this thesis was to investigate the impact of introduction of the laparoscopic technique for gastric cancer and mainly focuses on its cost and organizational aspects.

Part four, the final part of this thesis, provides an insight into the impact of gastric cancer surgery on the Quality of Life of patients. 


\section{References}

1. Torre LA, Siegel RL, Ward EM, and Jemal A, Global Cancer Incidence and Mortality Rates and Trends-An Update. Cancer Epidemiol Biomarkers Prev, 2016. 25(1): p. 16-27.

2. Integral Cancer Center of the Netherlands (IKNL IKN. Gastric cancer incidence report. 201710 April 2017]; Available from: http://www.cijfersoverkanker.nl/.

3. Eddes E TR, Wouters M. Dutch Institute for Clinical Auditing, Year Report 2015 (DICA Jaarrapportage 2015). 2015; Available from: https://www.dica.nl/jaarrapportage-2015.

4. Dikken JL, van Sandick JW, Allum WH, Johansson J, Jensen LS, Putter H, Coupland VH, Wouters MW, Lemmens VE, van de Velde CJ, van der Geest LG, Larsson HJ, Cats A, and Verheij M, Differences in outcomes of oesophageal and gastric cancer surgery across Europe. Br J Surg, 2013. 100(1): p. 83-94. 5. Cunningham D, Allum WH, Stenning SP, Thompson JN, Van de Velde CJ, Nicolson M, Scarffe JH, Lofts FJ, Falk SJ, Iveson TJ, Smith DB, Langley RE, Verma M, Weeden S, Chua YJ, and Participants MT, Perioperative chemotherapy versus surgery alone for resectable gastroesophageal cancer. N Engl J Med, 2006. 355(1): p. 11-20.

6. Al-Batran SE, Hofheinz RD, Pauligk C, Kopp HG, Haag GM, Luley KB, Meiler J, Homann N, Lorenzen S, Schmalenberg H, Probst S, Koenigsmann M, Egger M, Prasnikar N, Caca K, Trojan J, Martens UM, Block A, Fischbach W, Mahlberg R, Clemens M, Illerhaus G, Zirlik K, Behringer DM, Schmiegel W, Pohl M, Heike M, Ronellenfitsch U, Schuler M, Bechstein WO, Konigsrainer A, Gaiser T, Schirmacher P, Hozaeel W, Reichart A, Goetze TO, Sievert M, Jager E, Monig S, and Tannapfel A, Histopathological regression after neoadjuvant docetaxel, oxaliplatin, fluorouracil, and leucovorin versus epirubicin, cisplatin, and fluorouracil or capecitabine in patients with resectable gastric or gastro-oesophageal junction adenocarcinoma (FLOT4-AIO): results from the phase 2 part of a multicentre, open-label, randomised phase 2/3 trial. Lancet Oncol, 2016.17(12): p. 1697-1708.

7. Wang MJ, Li C, Sun Y, Shen FJ, and Wang CB, Prognostic effect of adjuvant chemoradiotherapy for patients with gastric cancer: an updated evidence of randomized controlled trials. Oncotarget, 2017. 8(61): p. $102880-102887$.

8. Bartlett EK, Roses RE, Kelz RR, Drebin JA, Fraker DL, and Karakousis GC, Morbidity and mortality after total gastrectomy for gastric malignancy using the American College of Surgeons National Surgical Quality Improvement Program database. Surgery, 2014. 156(2): p. 298-304.

9. Park DJ, Lee HJ, Kim HH, Yang HK, Lee KU, and Choe KJ, Predictors of operative morbidity and mortality in gastric cancer surgery. Br J Surg, 2005. 92(9): p. 1099-102.

10. Takeshita H, Ichikawa D, Komatsu S, Kubota T, Okamoto K, Shiozaki A, Fujiwara H, and Otsuji E, Surgical outcomes of gastrectomy for elderly patients with gastric cancer. World J Surg, 2013. 37(12): p. $2891-8$.

11. Fujiwara Y, Tsujie M, Hara J, Kato H, Kitani K, Isono S, Takeyama H, Yukawa M, Inoue M, and Kanaizumi $\mathrm{H}$, Comparison of gastric cancer surgery between patients aged $>80$ years and $<79$ years: complications and multivariate analysis of prognostic factors. Hepatogastroenterology, 2014. 61(134): p. $1785-93$.

12. Saif MW, Makrilia N, Zalonis A, Merikas M, and Syrigos K, Gastric cancer in the elderly: an overview. Eur J Surg Oncol, 2010. 36(8): p. 709-17.

13. Bi YM, Chen XZ, Jing CK, Zhou RB, Gao YF, Yang LB, Chen XL, Yang K, Zhang B, Chen ZX, Chen JP, Zhou ZG, and Hu JK, Safety and survival benefit of surgical management for elderly gastric cancer patients. Hepatogastroenterology, 2014. 61(134): p. 1801-5.

14. Leo S, Accettura C, Gnoni A, Licchetta A, Giampaglia M, Mauro A, Saracino V, and Carr BI, Systemic treatment of gastrointestinal cancer in elderly patients. J Gastrointest Cancer, 2013. 44(1): p. $22-32$.

15. Saklad M, Grading of patients for surgical procedures. Anesthesiology, 1941. 2(May): p. 281-4.

16. Fitz-Henry J, The ASA classification and peri-operative risk. Ann R Coll Surg Engl, 2011. 93(3):

p. $185-7$. 
17. Koo CY, Hyder JA, Wanderer JP, Eikermann M, and Ramachandran SK, A meta-analysis of the predictive accuracy of postoperative mortality using the American Society of Anesthesiologists' physical status classification system. World J Surg, 2015. 39(1): p. 88-103.

18. Charlson ME, Pompei P, Ales KL, and MacKenzie CR, A new method of classifying prognostic comorbidity in longitudinal studies: development and validation. J Chronic Dis, 1987. 40(5): p. 373-83. 19. Hsu JT, Liu MS, Wang F, Chang CJ, Hwang TL, Jan YY, and Yeh TS, Standard radical gastrectomy in octogenarians and nonagenarians with gastric cancer: are short-term surgical results and long-term survival substantial? J Gastrointest Surg, 2012. 16(4): p. 728-37.

20. Lubke T, Monig SP, Schneider PM, Holscher AH, and Bollschweiler E, [Does Charlson-comorbidity index correlate with short-term outcome in patients with gastric cancer?]. Zentralbl Chir, 2003. 128(11): p. 970-6.

21. Fried LP, Hadley EC, Walston JD, Newman AB, Guralnik JM, Studenski S, Harris TB, Ershler WB, and Ferrucci L, From bedside to bench: research agenda for frailty. Sci Aging Knowledge Environ, 2005. 2005(31): p. pe24.

22. Robinson TN, Eiseman B, Wallace JI, Church SD, McFann KK, Pfister SM, Sharp TJ, and Moss M, Redefining geriatric preoperative assessment using frailty, disability and co-morbidity. Ann Surg, 2009. 250(3): p. 449-55.

23. Oresanya LB, Lyons WL, and Finlayson E, Preoperative assessment of the older patient: a narrative review. JAMA, 2014. 311(20): p. 2110-20.

24. Fried LP, Tangen CM, Walston J, Newman AB, Hirsch C, Gottdiener J, Seeman T, Tracy R, Kop WJ, Burke G, McBurnie MA, and Cardiovascular Health Study Collaborative Research G, Frailty in older adults: evidence for a phenotype. J Gerontol A Biol Sci Med Sci, 2001. 56(3): p. M146-56.

25. Dasgupta M, Rolfson DB, Stolee P, Borrie MJ, and Speechley M, Frailty is associated with postoperative complications in older adults with medical problems. Arch Gerontol Geriatr, 2009. 48(1): p. $78-83$.

26. Makary MA, Segev DL, Pronovost PJ, Syin D, Bandeen-Roche K, Patel P, Takenaga R, Devgan L, Holzmueller CG, Tian J, and Fried LP, Frailty as a predictor of surgical outcomes in older patients. J Am Coll Surg, 2010. 210(6): p. 901-8.

27. Mitsiopoulos N, Baumgartner RN, Heymsfield SB, Lyons W, Gallagher D, and Ross R, Cadaver validation of skeletal muscle measurement by magnetic resonance imaging and computerized tomography. J Appl Physiol (1985), 1998. 85(1): p. 115-22.

28. Reisinger KW, van Vugt JL, Tegels JJ, Snijders C, Hulsewe KW, Hoofwijk AG, Stoot JH, Von Meyenfeldt MF, Beets GL, Derikx JP, and Poeze M, Functional compromise reflected by sarcopenia, frailty, and nutritional depletion predicts adverse postoperative outcome after colorectal cancer surgery. Ann Surg, 2015. 261(2): p. 345-52.

29. Tsujinaka S, Konishi F, Kawamura YJ, Saito M, Tajima N, Tanaka O, and Lefor AT, Visceral obesity predicts surgical outcomes after laparoscopic colectomy for sigmoid colon cancer. Dis Colon Rectum, 2008. 51(12): p. 1757-65; discussion 1765-7.

30. Itoh S, Shirabe K, Matsumoto Y, Yoshiya S, Muto J, Harimoto N, Yamashita Y, Ikegami T, Yoshizumi $\mathrm{T}$, Nishie A, and Maehara $\mathrm{Y}$, Effect of body composition on outcomes after hepatic resection for hepatocellular carcinoma. Ann Surg Oncol, 2014. 21(9): p. 3063-8.

31. Cruz-Jentoft AJ, Baeyens JP, Bauer JM, Boirie Y, Cederholm T, Landi F, Martin FC, Michel JP, Rolland Y, Schneider SM, Topinkova E, Vandewoude M, Zamboni M, and European Working Group on Sarcopenia in Older P, Sarcopenia: European consensus on definition and diagnosis: Report of the European Working Group on Sarcopenia in Older People. Age Ageing, 2010. 39(4): p. 412-23.

32. Dello SA, Lodewick TM, van Dam RM, Reisinger KW, van den Broek MA, von Meyenfeldt MF, Bemelmans $\mathrm{MH}$, Olde Damink SW, and Dejong $\mathrm{CH}$, Sarcopenia negatively affects preoperative tota functional liver volume in patients undergoing liver resection. HPB (Oxford), 2013. 15(3): p. 165-9.

33. Harimoto N, Shirabe K, Yamashita YI, Ikegami T, Yoshizumi T, Soejima Y, Ikeda T, Maehara Y, Nishie A, and Yamanaka T, Sarcopenia as a predictor of prognosis in patients following hepatectomy for hepatocellular carcinoma. Br J Surg, 2013. 100(11): p. 1523-30. 
34. Lieffers JR, Bathe OF, Fassbender K, Winget M, and Baracos VE, Sarcopenia is associated with postoperative infection and delayed recovery from colorectal cancer resection surgery. Br J Cancer, 2012. 107(6): p. 931-6.

35. Peng PD, van Vledder MG, Tsai S, de Jong MC, Makary M, Ng J, Edil BH, Wolfgang CL, Schulick RD, Choti MA, Kamel I, and Pawlik TM, Sarcopenia negatively impacts short-term outcomes in patients undergoing hepatic resection for colorectal liver metastasis. HPB (Oxford), 2011. 13(7): p. 439-46.

36. van Vledder MG, Levolger S, Ayez N, Verhoef C, Tran TC, and ljzermans JN, Body composition and outcome in patients undergoing resection of colorectal liver metastases. Br J Surg, 2012. 99(4): p. 5507.

37. Peng P, Hyder O, Firoozmand A, Kneuertz P, Schulick RD, Huang D, Makary M, Hirose K, Edil B, Choti MA, Herman J, Cameron JL, Wolfgang CL, and Pawlik TM, Impact of sarcopenia on outcomes following resection of pancreatic adenocarcinoma. J Gastrointest Surg, 2012. 16(8): p. 1478-86.

38. Tan BH, Birdsell LA, Martin L, Baracos VE, and Fearon KC, Sarcopenia in an overweight or obese patient is an adverse prognostic factor in pancreatic cancer. Clin Cancer Res, 2009. 15(22): p. 6973-9.

39. Hatzinger M, Kwon ST, Langbein S, Kamp S, Hacker A, and Alken P, Hans Christian Jacobaeus: Inventor of human laparoscopy and thoracoscopy. J Endourol, 2006. 20(11): p. 848-50.

40. Spaner SJ and Warnock GL, A brief history of endoscopy, laparoscopy, and laparoscopic surgery. J Laparoendosc Adv Surg Tech A, 1997. 7(6): p. 369-73.

41. Vecchio R, MacFayden BV, and Palazzo F, History of laparoscopic surgery. Panminerva Med, 2000. 42(1): p. 87-90.

42. Kitano S, Iso Y, Moriyama M, and Sugimachi K, Laparoscopy-assisted Billroth I gastrectomy. Surg Laparosc Endosc, 1994. 4(2): p. 146-8.

43. Kawamura H, Homma S, Yokota R, Yokota K, Watarai H, Hagiwara M, Sato M, Noguchi K, Ueki S, and Kondo $\mathrm{Y}$, Inspection of safety and accuracy of D2 lymph node dissection in laparoscopy-assisted distal gastrectomy. World J Surg, 2008. 32(11): p. 2366-70.

44. Sakuramoto S, Kikuchi S, Futawatari N, Katada N, Moriya H, Hirai K, Yamashita K, and Watanabe M, Laparoscopy-assisted pancreas- and spleen-preserving total gastrectomy for gastric cancer as compared with open total gastrectomy. Surg Endosc, 2009. 23(11): p. 2416-23.

45. Shinohara T, Kanaya S, Taniguchi K, Fujita T, Yanaga K, and Uyama I, Laparoscopic total gastrectomy with D2 lymph node dissection for gastric cancer. Arch Surg, 2009. 144(12): p. 1138-42.

46. Koeda K, Nishizuka S, and Wakabayashi G, Minimally invasive surgery for gastric cancer: the future standard of care. World J Surg, 2011. 35(7): p. 1469-77.

47. Huscher CG, Mingoli A, Sgarzini G, Sansonetti A, Di Paola M, Recher A, and Ponzano C, Laparoscopic versus open subtotal gastrectomy for distal gastric cancer: five-year results of a randomized prospective trial. Ann Surg, 2005. 241(2): p. 232-7.

48. Lee MS, Lee JH, Park do J, Lee HJ, Kim HH, and Yang HK, Comparison of short- and long-term outcomes of laparoscopic-assisted total gastrectomy and open total gastrectomy in gastric cancer patients. Surg Endosc, 2013. 27(7): p. 2598-605.

49. Siani LM, Ferranti F, De Carlo A, and Quintiliani A, Completely laparoscopic versus open total gastrectomy in stage I-III/C gastric cancer: safety, efficacy and five-year oncologic outcome. Minerva Chir, 2012. 67(4): p. 319-26.

50. Dedic N and Stanier C, Measuring the Success of Changes to Existing Business Intelligence Solutions to Improve Business Intelligence Reporting. Lecture Notes in Business Information Processing. Springer International Publishing, 2016. 268: p. 225-236.

51. Hartgrink $\mathrm{HH}$, van de Velde CJ, Putter H, Bonenkamp JJ, Klein Kranenbarg E, Songun I, Welvaart K, van Krieken JH, Meijer S, Plukker JT, van Elk PJ, Obertop H, Gouma DJ, van Lanschot JJ, Taat CW, de Graaf PW, von Meyenfeldt MF, Tilanus H, and Sasako M, Extended lymph node dissection for gastric cancer: who may benefit? Final results of the randomized Dutch gastric cancer group trial. J Clin Oncol, 2004. 22(11): p. 2069-77.

52. Blazeby JM, Conroy T, Bottomley A, Vickery C, Arraras J, Sezer O, Moore J, Koller M, Turhal NS, Stuart R, Van Cutsem E, D'Haese S, Coens C, European Organisation for R, Treatment of Cancer G, and Quality of Life G, Clinical and psychometric validation of a questionnaire module, the EORTC QLQ-STO 22, to assess quality of life in patients with gastric cancer. Eur J Cancer, 2004. 40(15): p. 2260-8. 


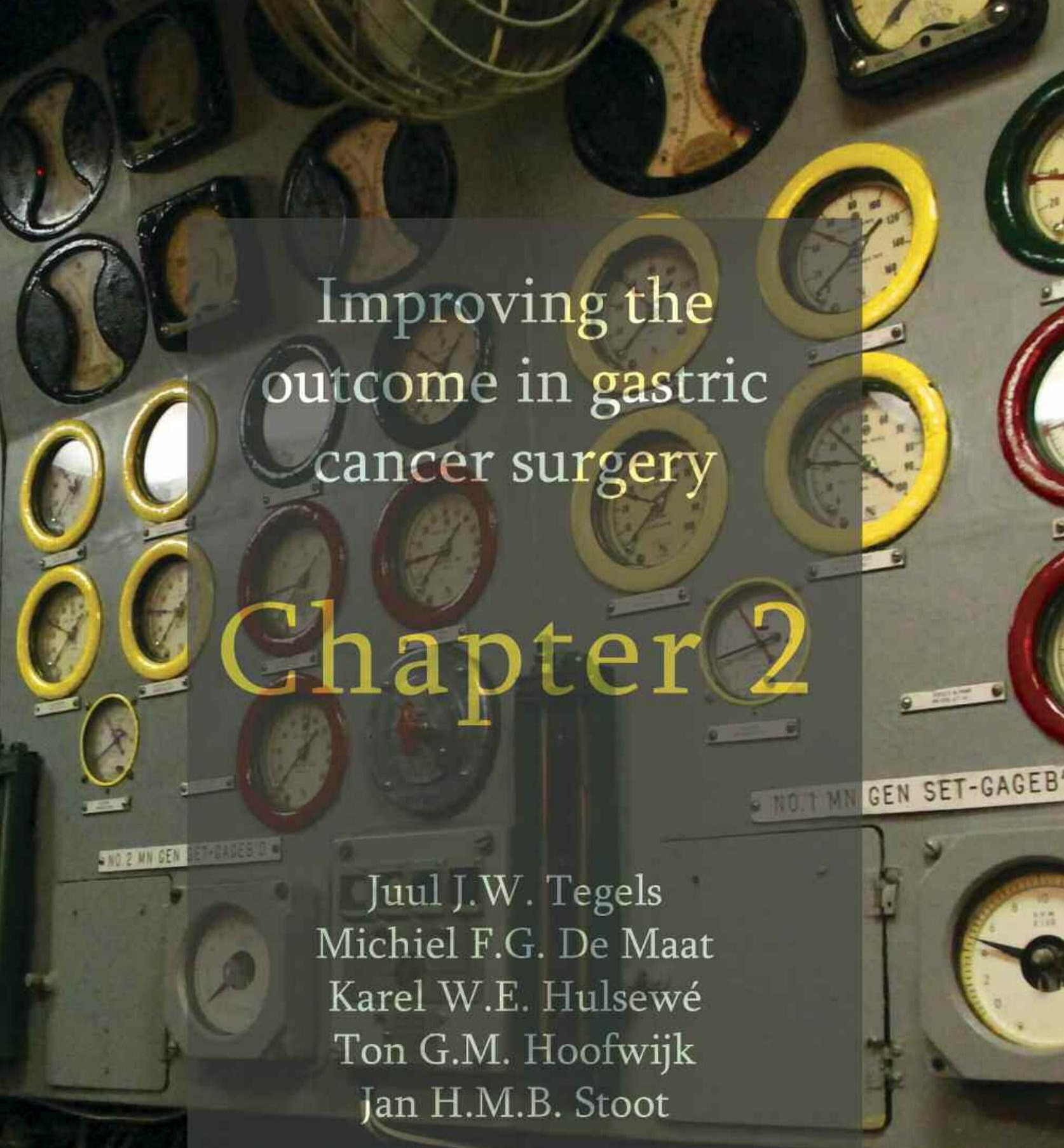

Michiel F.G. De Maat

Karel W.E. Hulsewé

Ton G.M. Hoofwijk

Jan H.M.B. Stoot

World Journal of Gastroenterology, October 2014

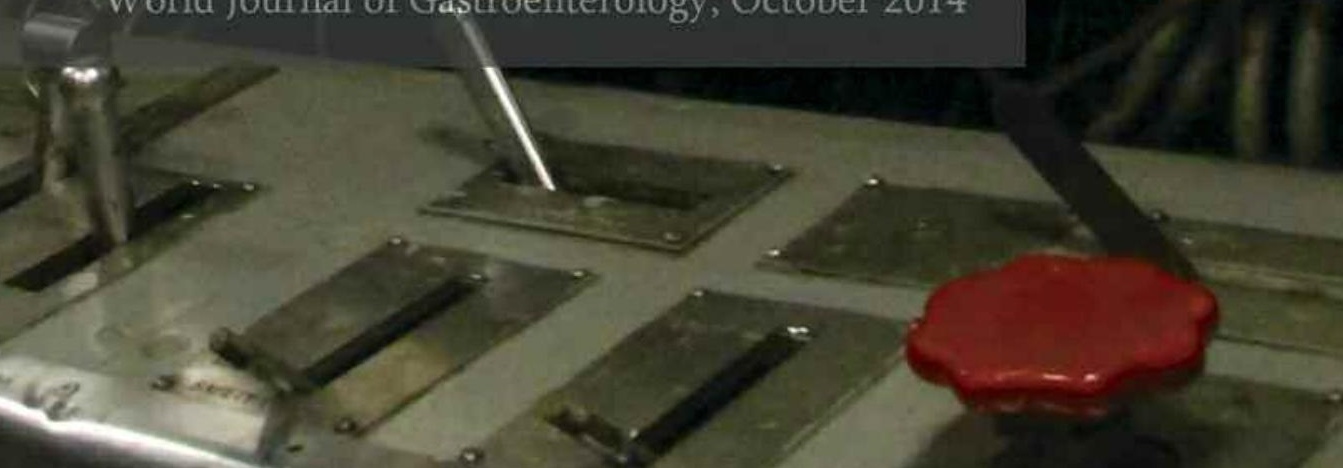




\section{Abstract}

Gastric cancer remains a significant health problem worldwide and surgery is currently the only potentially curative treatment option. Gastric cancer surgery is generally considered to be high risk surgery and five year survival rates are poor, therefore a continuous strive to improve outcomes for these patients is warranted. Fortunately, in the last decades several potential advances have been introduced that intervene at various stages of the treatment process. This review provides an overview of methods implemented in the pre-, intra- and postoperative stage of gastric cancer surgery to improve outcome. Better preoperative risk assessment using comorbidity index (e.g. , Charlson comorbidity index), assessment of nutritional status (e.g. , short nutritional assessment questionnaire, nutritional risk screening - 2002) and frailty assessment (Groningen frailty indicator, Edmonton frail scale, Hopkins frailty) was introduced. Also preoperative optimization of patients using prehabilitation has future potential. Implementation of fast-track or enhanced recovery after surgery programs is showing promising results, although future studies have to determine what the exact optimal strategy is. Introduction of laparoscopic surgery has shown improvement of results as well as optimization of lymph node dissection. Hyperthermic intraperitoneal chemotherapy has not shown to be beneficial in peritoneal metastatic disease thus far. Advances in postoperative care include optimal timing of oral diet, which has been shown to reduce hospital stay. In general, hospital volume, i.e. , centralization, and clinical audits might further improve the outcome in gastric cancer surgery. In conclusion, progress has been made in improving the surgical treatment of gastric cancer. However, gastric cancer treatment is high risk surgery and many areas for future research remain. 


\section{Introduction}

Gastric cancer constitutes a major health problem worldwide and is one of the leading causes of cancer-related deaths. In the United States gastric cancer compromises only $2 \%$ (25.500 cases) of all new cancer cases yearly. In Korea it is the leading form of cancer constituting $20.8 \%$ of malignant neoplasms. The number of deaths due to gastric cancer has decreased from 774,000 in 1990 to 755,000 in 2010 worldwide. It remains however, the second leading cause of cancer death after lung cancer [1]. Prognosis of gastric cancer is relatively poor with an overall five-year survival rate for gastric cancer in the U.S. between 1999 and 2005 of 27\% [2]. For localized disease 5 -year survival rate was $63 \%$, but only $23 \%$ of all gastric cancer cases were diagnosed at this stage [2]. In 2008 gastric cancer was responsible for a disability-adjusted life-year (DALY) rate of 241 per 100,000 for males and 146 per 100,000 in females worldwide, which is $9.8 \%$ and $6.3 \%$ of total cancer related DALY-rates respectively [3].

Surgery is the mainstay of treatment for gastric malignancy. In European and other Western countries gastric cancer surgery is regarded to be high risk surgery and there are major differences in outcome between countries [4]. Therefore, knowledge to improve the outcome of gastric cancer treatment is of great importance. As with all operations perioperative planning of this type of surgery is crucial for the clinical outcome of treatment, not only in terms of morbidity but also in functional recovery and hospital stay. Many efforts have been made to improve outcome after surgery for these patients in pre-, intra- and postoperative stage of treatment. Not only surgical efforts have been implemented, medical oncology has also contributed a great deal with neoadjuvant and adjuvant chemotherapeutic regimens for example. However, these advances are beyond the scope of this review.

This paper will provide a structured review of current literature that deals with advances in surgical care for gastric cancer patients in the preoperative-, intraoperative- and postoperative stage. Literature will be discussed in this order. Lastly, advances in organization of surgical care will be discussed. 


\section{Advances in preoperative care}

Surgical morbidity in gastric cancer surgery is reported to be as high as 39\% [5]. Therefore much effort should be made in preventing morbidity and mortality. Needles to say, the preferential moment to assess the risk of morbidity and mortality is during preoperative work-up. Gastric cancer patients in Western countries constitute a group that is especially frail to surgical treatment due to the condition in which patients usually present at time of diagnosis. An example is the reported rate of malnutrition as high as $85 \%$ [6]. The on average poor physical state and advanced age as well as disease stage contributes to poorer outcomes in Western countries as compared to Eastern countries such as Japan and Korea where nationwide screening programs exist to diagnose gastric cancer at an early stage [7].

Preventing morbidity is becoming especially important since multidisciplinary treatment schedules are becoming the standard in gastric cancer. Deterioration of general condition or delay because of required rehabilitation time due to serious adverse events (e.g. abdominal sepsis due to anastomotic leakage requiring longterm ICU treatment) may disqualify a patients for his/her treatment.

\section{Surgical risk assessment}

Surgical risk assessment can be complex. Several risk scores have been introduced. A globally used risk-score is the ASA-Physical status and was first introduced in 1941 [8]. To the best knowledge of the authors, ASA physical status as a risk factor has not been extensively investigated in gastric cancer surgery. ASA-physical status is only a component of the overall risk assessment. Moreover, it might also be subject to interpretation by the assessor. Different ASA classifications may be ascribed by different assessors depending on which factors are taken into account [8]. The ASA classification is also a quite non-specific instrument. Moreover, it is just a momentary status, without any clues to improve its figure in the future. By definition each cancer patient is having systemic disease and only therefore already ASA 2-classified. Practical applicability of this classification remains a challenge not only in daily practice but also in clinical research. Therefore new classifications have been developed.

The Charlson Comorbidity Index ( $\mathrm{Cl})$ was developed as a method for classifying comorbid conditions that determine risks of mortality [9]. CCl was later identified and validated in a surgical setting for prediction of mortality risk in patients undergoing complex gastrointestinal surgery [10]. It was shown in octo- and nonagenarians who underwent radical gastrectomies that these elderly patients had higher morbidity and mortality rates, and this was associated with higher $\mathrm{CCl}$ 25) [11]. Cancer specific survival was comparable to younger patients [11]. In another cross-sectional study the only independent factor predicting mortality was 
the presence of comborbidity and not age [12]. In contrast, a German study which included 139 gastric cancer patients did not find a significant correlation between $\mathrm{CCl}$ and the occurrence of morbidity and mortality postoperatively [13]. In multivariate analysis age was found to be an independent factor for postoperative events.

Several patient factors associated with an impaired outcome after gastric cancer surgery have been reported over the years. In a series of 118 laparoscopic total gastrectomies, male gender was independently associated with postoperative morbidity [14]. Overweight patients (i.e. BMI>25 kg/m2) are at an increased risk of complications; this was shown in a large prospective series of 1,853 patients [15]. This showed increased complication rate (47.9\%vs. $35.8 \%, \mathrm{P}<0.001)$. Obese patients especially had more anastomotic leakages ( $11.8 \%$ vs. $5.4 \%$ ) and wound infections ( $8.9 \%$ vs. $4.7 \%$ ). Several other studies have also shown the association between higher BMI and increased postoperative morbidity [16-18]. Although no valid explanation for this finding is reported; it is suggested that in open and laparoscopic surgery, obesity is associated with more technical difficulties [19].

A history of upper abdominal surgery is not a contraindication for laparoscopic gastrectomy. In a series of 22 cases with previous upper abdominal surgery (PUAS) no differences were found for operative time, blood loss or conversion to open surgery when compared to patients without a history of PUAS [20]. In a larger series of 50 patients with a history of laparotomy similar results were obtained for laparoscopic assisted gastrectomies [21]. Also, when compared to open surgery in patients with PUAS laparoscopic gastrectomy was performed with comparable postoperative outcome [20].

The literature fairly uniformly states that age should not be factored in clinical decision making. Rather comorbid conditions and general condition are far more important factors predicting adverse outcomes. It remains challenging to adequately assess a patient's general condition and decide what factors exclude a patients from surgical treatment. Therefore, we discuss some of the features that are crucial to take into account during preoperative work-up.

\section{Nutritional status}

Gastric cancer patients are at a high risk for malnutrition and between 30 and $38 \%$ of patients are reported to have $>10 \%$ weight loss in the past six months [22]. A imbalance between energy expenditure and nutritional supplementation is the fundamental physiologic derangement leading to cancer-induced weight loss. Tumor related causes of malnutrition include early satiety and obstruction, but also tumor induced metabolic alterations [6]. Additionally, malnutrition is associated with increased morbidity and mortality after gastric cancer surgery [6]. It is highly important to thoroughly screen patients for malnutrition as interventions can be done to preoperatively improve nutritional status and subsequently surgical outcome. Both malnourishment and weight loss are associated with poor clinical 
outcome after surgery [23].

\section{Questionnaires}

An easy and non-invasive tool to estimate the patient's physical and/or mental condition preoperatively is the use of questionnaires. Several questionnaires have been developed to identify patients at risk for malnutrition. The Short Nutritional Assessment Questionnaire (SNAQ) and Malnutrition Universal Screening Tool (MUST) scores are commonly used nutritional screening tools in surgical patients (see Table 1) [24, 25]. These questionnaires accurately screen for malnutrition and are obligatory in some Western countries as a part of governmental health care quality programs [26, 27]. Although it is easy to apply, evidence for the value of nutritional screening tools to predict postoperative outcome in gastric cancer surgery is scarce. It has been shown that screening for nutritional risk in gastric cancer surgery patients using NRS 2002 is helpful. Increased scores are associated with more complications and increased length-of-stay [28]. The authors group recently published a study in which SNAQ was used to evaluate risks of adverse postoperative events after gastric cancer surgery. A SNAQ $\geq 1$ was associated with increased severe complications ( $17.7 \%$ vs. $35.7 \%, \mathrm{P}=0.02$ ) and in-hospital mortality (OR5.1, 95\% $\mathrm{Cl} 1.01$ to 23.8, $\mathrm{P}=0.04)$ [29].
Table 1. Malnutrition Universal Screening Tool (MUST) and Short Nutritional Assessment Questionnaire (SNAQ), screening tools for detecting malnutrition

\section{MUST} Points

$>20$

$18.5-20$

$<18.5$

Step 2. Unintentional weight loss past 3-6 months

$<5 \%$

$5-10 \%$

$>10 \%$

Step 3. Acute disease effect

If patient is acutely ill and there has been or is

likely to be no nutritional intake for $>5$ days

Risk of malnutrition

$0=$ Low risk

$1=$ Medium risk

2 or more=High risk

\section{SNAQ}

Did you lose weight unintentionally?

More than $6 \mathrm{~kg}$ in past 6 months

More than $3 \mathrm{~kg}$ in past 3 months

No

Did you experience a decreased appetite over the last month? Yes

No

Did you use supplemental drinks or tube feeding over the last month?

Yes

No

Risk of malnutrition

1=no intervention

2=moderately malnourished

3=severely malnourished 
The detection of nutritional depletion is important, especially with neo-adjuvant therapies potentially further compromising the nutritional and metabolic status [30]. Questionnaires are subjective methods to assess nutritional status and therefore methods to objectively measure a patient's condition might improve outcomes.

\section{Sarcopenia}

Sarcopenia, or the decrease of muscle tissue, is a part of the cachexia syndrome [6]. Presence of sarcopenia has been shown to affect short-term postoperative outcome with increased morbidity and mortality rates in patients undergoing liver resection for colorectal liver metastases [31]. It also predicts adverse long-term outcome in liver and pancreas surgery for malignancy $[32,33]$. The method for measuring sarcopenia in these studies was to calculate the total muscle or psoas muscle cross-sectional area using a specialized software package (e.g. OsiriX5.5.2, open-source software) on Computed Tomography (CT) imaging on a set level (e.g. at the level of spinous process of lumbar vertebra L3). This could also be a useful method in gastric cancer patients as they all have preoperative staging CT-imaging of the abdomen. However, as far as the authors are aware no literature on this subject exists to date. Other objective parameters such as lowered preoperative serum albumin levels have been identified as risk factors for postoperative complications after surgery for gastrointestinal carcinomas [34, 35]. However, the latter risk factors remain under debate as some authors dispute the role of malnutrition and lowered serum albumin levels as risk factors for impaired outcome after gastric cancer surgery [36].

For the future it is important to establish objective screening tools to detect malnutrition in surgical patients as these are related to perioperative outcomes. More importantly, studies need to be done to establish whether correction of nutritional status results in improved outcome.

Frailty

In Western countries gastric cancer is a disease of the elderly, and therefore geriatric aspects have an important role in these patients. Frailty is defined as a state of increased vulnerability towards stressors in older individuals, leading to increased risk of developing adverse health outcomes. Geriatric frailty is considered by Fried et al. to be a clinical syndrome in which three of the following five aspects are present. These are: unintentional weight loss (10 lbs in the past year), self-reported exhaustion, weakness (grip strength), slow walking speed, and low physical activity [37]. Methods for assessing frailty are numerous. They range from a comprehensive geriatric assessment (CGA), which often employs the use of multiple questionnaires and short physical tests (e.g. 4-meter walk test, grip 
strength measurement) to using specific frailty questionnaires (e.g. Edmonton Frail Scale).

Frailty assessment is an emerging method to aid surgical risk assessment and it is rapidly gaining evidence based support $[38,39]$. It has been shown that scores on the Edmonton Frail Scale (EFS) >7, i.e. increased frailty, were associated with increased complications after non-cardiac surgery (OR 5.02, 95\% Cl 1.55-16.25) [38]. The relation between frailty and adverse postoperative outcomes has also been shown in patients undergoing cardiac surgery [40] and patients undergoing various types of elective surgery [41]. Some use tools such as EFS or Hopkins Frailty Score that include various tests with regards to cognition, ADL function and more (including laboratory tests such as serum albumin) $[38,39]$. Recently published results from a large prospective study with patients who underwent general, oncologic and urologic procedures confirmed these findings in a larger patient population ( $n=189$ ) [42]. They showed that 'intermediately frail' or 'frail' as judged by the Hopkins Frailty score was an independent predictor for complications. Another example of frailty assessment questionnaire is the Groningen Frailty Indicator [43]. This questionnaire was used in a retrospective study to evaluate frailty assessment as a predictor for adverse outcome after gastric cancer surgery. In this recent study, incorporating 180 patients, increased GFI was significantly associated with postoperative morbidity and in-hospital mortality [29].

\section{Prehabilitation}

A novel strategy for improving outcomes after surgery is by preoperatively improving the functional, nutritional, physical and neurophysiological state of patients also called prehabilitation [44]. This type of intervention might prove to be especially beneficial in elderly patients because they are often compromised in these aspects. Most available literature on prehabilitation concerns joint replacement surgery. A pilot study has been published that evaluates multimodality prehabilitation interventions in colorectal surgical patients [45]. This study uses a trimodal approach of preoperative exercise, nutritional intervention (dietary behavior counseling and proteins supplementation) and anxiety reduction training (also aimed at increasing compliance of exercise and nutritional intervention). Multimodal approaches have yielded promising preliminary results such as better walking capacity in the weeks after surgery and higher physical activity levels after surgery compared to controls $[45,46]$. Because in Western society gastric cancer is predominantly a disease of the elderly, prehabilitation may provide a promising effort for improving outcomes in these patients in the future [47]. 


\section{Staging laparoscopy and wash cytology}

Preoperative staging laparoscopy improves detection of peritoneal metastases not otherwise detected by preoperative ultrasonography or CT imaging [48]. It can therefore prevent an unnecessary explorative laparotomy or change management in up to $60 \%$ of cases $[49,50]$. An expert panel concluded that a staging laparoscopy should be performed for reasons mentioned above, exceptions being early gastric cancer or known metastatic disease [51].

Also, during staging laparoscopy peritoneal wash cytology can be obtained to detect intraperitoneal free cancer cells (IFCC). This has been shown to be a predictor for early recurrence after curative intent surgery [52]. It is even a negative prognostic factor in overt peritoneal metastases in patients with suspected serosal invasion with median survival times of 14.0 and 10.0 months in patients without and with positive cytology respectively [53].

In patients with overt peritoneal metastases HIPEC together with cytoreductive surgery has been considered as additional treatment. A recent review concluded that HIPEC was not beneficial for these patients [54].

\section{ERAS and Fast-track programs}

Enhanced recovery after surgery (ERAS) programs have been developed and implemented with great success in colorectal surgery [55]. All recommendations by the ERAS society for colonic surgery (see also: http://www.erassociety.org/ index.php/eras-care-system/eras-protocol) can potentially be implemented in gastric cancer patients, i.e. early removal of urinary catheter, prevention of postoperative ileus, postoperative analgesia, and early mobilization and resumption of normal diet [56]. Important to note is that ERAS protocols not only include recommendations on postoperative care, but also preoperative measures (e.g. counseling) and intra-operative measures (e.g. avoidance of salt and water overload and use of short acting anesthetic agents). In recent years efforts have been made to develop, implement and evaluate the effect of similar programs in gastric cancer surgery. Studies on the timing of oral intake after gastrectomy for gastric cancer are sparse. Small studies that exist have evaluated early oral feeding as safe and feasible [57]. This study started liquid intake on day 1-2 and soft diet on postoperative day 3. Other comparative studies showed significantly shorter hospital stay (e.g. 5.7 vs. 9.2 days) and earlier return of bowel function [58-60]. Although the strategies for early oral feeding were different, ranging from oral diet on day one to liquid diet on day two followed by soft diet from day three until discharge, their findings were that it is safe and potentially leads to shorter hospital-stay.

A randomized comparison between fast-track surgery and conventional care in gastric cancer patients ( $n=45$ and $n=47$ respectively) showed less stress response in the fast-track surgery group [61]. This was measured by serum TNF-alfa, CRP 
and interleukin-6 levels. Also, fast-track patients had a shorter hospital stay and higher quality of life with no increase in complications. Yamada et al. compared ERAS $(n=91)$ with conventional care $(n=100)$ after gastrectomy and found that ERAS was associated with less postoperative pain and analgesics use [62]. There was no difference in complication rates between ERAS and conventional care. They did not find a significant difference in mean length-of-stay.

The implementation of a fast-track or ERAS program was also investigated as an addition to laparoscopic procedures [63-65]. A consecutive series of 32 patients showed that it was safe and had similar postoperative results [63]. In addition, a randomized clinical trial in gastric cancer patients including 22 fast-track and 22 conventional care patients showed a shorter length of stay for fast-track patients ( 5 vs. 8 days, $P<0.001$ ) but no difference was noted for postoperative pain [64]. Chen Hu et al. found that the laparoscopic assisted procedure with the addition of a fast-track approach resulted in shortest length-of-stay [65].

\section{Advances in intraoperative care}

One of the most significant and fundamental developments in gastrointestinal surgery in the last decades has been the introduction of the laparoscopic technique. Large incisions are avoided and surgical trauma is minimized.

\section{Laparoscopic surgery}

Introduced in Asia in the early nineties, a laparoscopic approach was first implemented for the treatment of early gastric cancer (EGC) [66]. Early reports comparing open and laparoscopic surgery for EGC showed several advantages of the laparoscopic approach over conventional open surgery. These included less intra-operative blood loss, less postoperative pain and shorter length-of-stay. Also serum markers indicating postoperative stress were lower, i.e. lower C-reactive protein level on day 7, leukocyte count and interleukin-6 levels [67]. There were no significant differences in operation time, number of harvested lymph nodes and postoperative complications $[67,68]$. A meta-analysis evaluating randomized controlled trials and high quality non-randomized controlled trials on laparoscopic versus open approach for distal gastrectomy for cancer showed that major complications and mortality rates were similar between procedures and concluded that the laparoscopic approach is safe [69]. However, the majority of patients studied had EGC and therefore comparison to a Western population case mix is hard. The results further showed additional benefits of fewer overall and minor complications, shorter length-of-stay (Weighted Mean Difference -3.6 days) and less blood loss [69]. Also, a longer operation time and lower number of harvested 


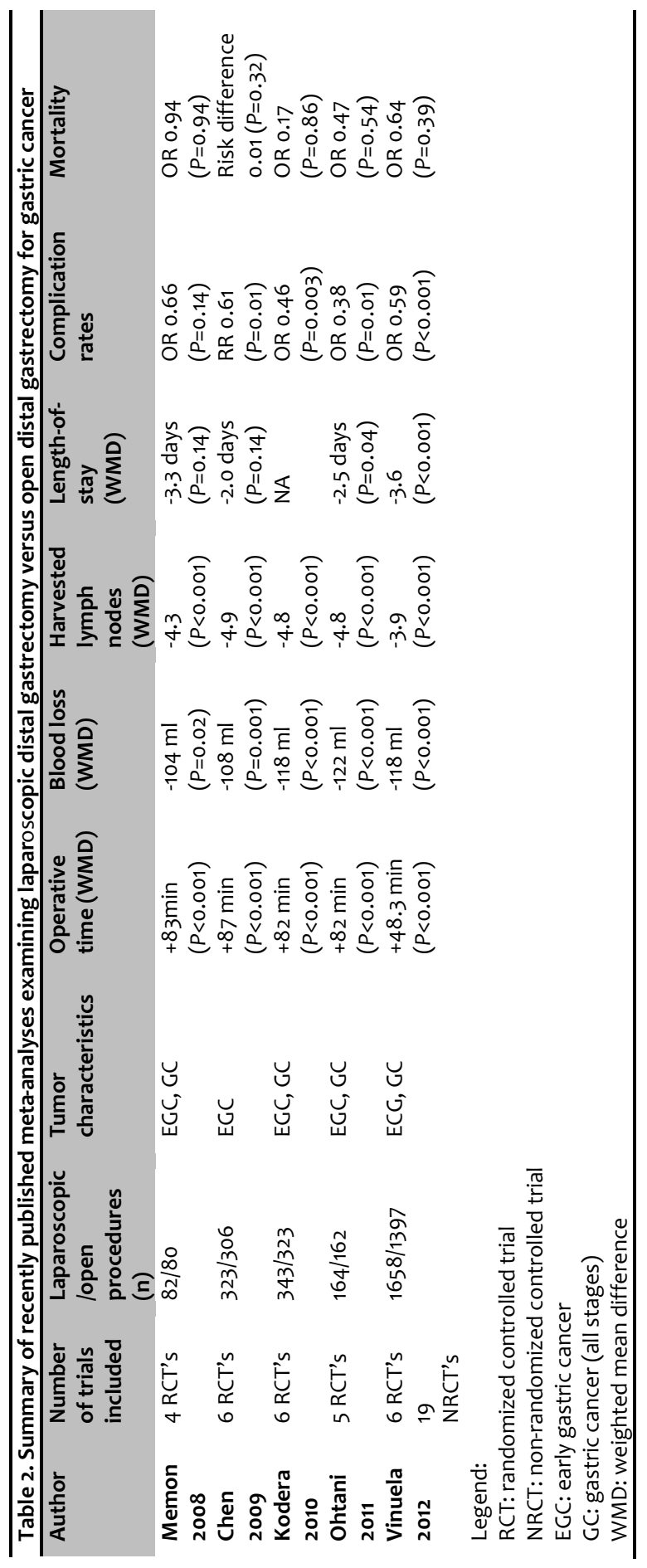


lymph nodes was reported for laparoscopic gastrectomy. Several other reviews and meta-analyses have been published on this subject since (see Table 2) [69-73]. The general conclusion of these studies is that the laparoscopic approach offers improved recovery after surgery at no compromise of morbidity and mortality. The laparoscopic approach for performing a total gastrectomy for gastric cancer is technically more demanding and has therefore not gained as much widespread acceptance as the laparoscopic distal gastrectomy. A systematic review and metaanalysis by Chen et al. showed similar differences between laparoscopic assisted total gastrectomy and total distal gastrectomy, i.e. Ionger operative time, shorter hospital stay, a decrease in medical complications and no difference in operative mortality [74]. It included nine studies comprising 1,221 patients (436 laparoscopic procedures and 758 open procedures), but none of the studies were RCT's. All but one study included both EGC and advanced stage disease patients. Nevertheless, the authors concluded that laparoscopic approach for total gastrectomy can be performed safely and with improved outcome in experienced surgical centers [74]. As mentioned, most reported studies report on laparoscopic procedures for EGC. The laparoscopic approach for advanced stage disease has also been shown to be associated with shorter length-of-stay and less blood loss with comparable morbidity and mortality rates [75-77]. Also similar oncological outcomes are reported for laparoscopic surgery in advanced stage disease [78]. A systematic review and meta-analysis on distal gastrectomy for advanced gastric cancer concluded that further prospective controlled studies are needed for a comprehensive comparison.

A critical issue with the laparoscopic approach is oncological adequacy. The evidence for this is still sparse although a few studies report similar oncological outcomes for laparoscopic procedures at five years $[75,76,79]$.

\section{Advances in intraoperative care: surgical strategies and techniques}

\section{Lymph node dissection}

Differences in treatment outcome between Asian and Western countries remain striking. The debate continues whether this is due to a more extensive approach of lymph node dissection advocated by the Japanese Gastric Cancer Association. D2 lymphadenectomy has been shown to increase survival in Chinese patients [80]. Results from randomized trials performed in the Netherlands and United Kingdom showed an increased morbidity and mortality rate in the D2 group and no survival benefit $[81,82]$. Fifteen-year follow-up results of the Dutch trial showed that D2 resection was associated with lower regional recurrence (22\% in D1 resection and $12 \%$ in D2 resection) and gastric-cancer-related death [83]. They advocate a spleen 
preserving D2 procedure as a safer alternative. Later studies showed however that D2 resections can be performed safely in the West. They showed low overall morbidity and mortality rates (3.0\% after D1 and 2.2\% after D2 gastrectomy, $\mathrm{P}=0.722$ ) [84]. The additional value of D3 dissection (dissection of hepatoduodenal ligament, superior mesenteric vein and retro-pancreatic area) is disputed. A prospective trial in Taiwan showed a slight 5-year survival benefit for D3 resections (59.5\% compared to $53.6 \%$ in $\mathrm{D} 1$ gastrectomy patients, $\mathrm{P}=0.041$ ) [80]. Para-aortic nodal dissection was shown to be performed safely in addition to D2 dissection but failed to show a 5 -year benefit $[85,86]$.

Another strategy for attempting to improve oncological outcome of gastric cancer surgery was to perform a bursectomy in addition to resection and lymphadenectomy for advanced stage gastric cancer. Several studies did not show a benefit in the bursectomy group [87, 88]. However, proponents of this technique argue that it may improve survival and should not be discarded as a futile technique [89]. A phase III trial that will also evaluate the effectiveness of this procedure is currently ongoing in Japan (see: http://www.jcog.jp/en/trials/index.html).

\section{Reconstruction technique}

Roux-en-Y is the accepted standard technique for reconstructing bowel continuity after total gastrectomy. Billroth I and II reconstruction after distal gastrectomy have been the standard for a long time but are associated with increased rates of reflux symptoms and esophagitis [90]. Roux-en-Y reconstruction as an alternative after distal gastrectomy has been thoroughly investigated. Studies have shown beneficial outcomes in terms of less reflux symptoms and less gastric remnant gastritis [91, 92]. These findings persist in long-term follow-up [93]. However patients did not differ in terms of quality of life [94]. Morbidity and mortality were similar between the Billroth I and Roux-en-Y technique, but the latter was associated with longer length-of-stay and discontinuance of food intake [95].

\section{Intra-operative feeding-jejunostomy placement}

Routine intra-operative placement of a feeding jejunostomy can potentially decrease malnutrition and improve tolerance of adjuvant chemotherapy [96]. A study with data from a prospectively maintained database including 132 patients showed no advantage of jejunostomy placement and increased complications associated with jejunostomy placement [97]. In a series of 73 patients who received jejunostomy placement, it was shown that 21 patients had jejunostomy specific complications (11 minor and 10 major) [98]. Therefore, routine jejunostomy placement is not recommended and should be reserved for selected patients. 


\section{Advances in postoperative care: detection and treatment of anastomotic leakage}

Anastomotic failure or leakage is an important complication of gastric surgery with potentially detrimental consequences. Risk factors for anastomotic leakage have been identified in several studies. These include: older age ( $>65$ years), longer operating time, intra-operative errors, increased blood loss and co-morbidities [99101].

When leakage or associated intra-abdominal abscess is suspected clinically by positive peritoneal signs, fever and/or wound infection, further investigation using computed tomography should be prompted. If detected and leakage is minor it can be successfully managed with percutaneous drainage [102,103]. Some authors advocate the use of conservative management techniques for treating anastomotic leakage such as placement of a naso-jejunal tube combined with percutaneous drainage of an abscess [104]. In this study this approach was associated with lower mortality rates compared to operative intervention. Therefore, reoperation is only required when conservative treatment is ineffective. When reoperation is carried out the anastomosis can be evaluated reconstruction can be carried out [105].

The endoscopic approach also offers a chance to assess the anastomosis site and endoscopic treatment options for leakage are available. Recent literature describes endoscopic approaches for the management of anastomotic leakage and different techniques can be applied [106]. The authors concluded that defects smaller than $2 \mathrm{~cm}$ in size could be successfully managed using endoscopy. Techniques include use of fibrosealant or Histoacryl and also stent insertion. Multiple studies report use of removable covered metal stents to treat anastomotic leaks with relatively good results [107, 108]. The main advantage of this approach is that it enables evaluation of the anastomosis without the need for invasive surgery. However, this technique requires a well trained and well equipped endoscopy department.

\section{Advances in organization of care: centralization and audits}

In Western countries the incidence of gastric cancer is relatively low. Annual hospital volume can therefore be low in institutions in non-centralized regions. Centralization offers a chance to increase volumes in selected centers. Increased hospital volume leads to better treatment results in gastric cancer surgery [109]. More recent studies support this idea and show that increased volumes are associated with lower short-term mortality and improved survival [110, 111]. Other literature suggests that hospital volume is not a determinant for disease-free survival or overall survival in gastric cancer surgery survivors (i.e. perioperative 
mortality excluded) [112]. Although the optimal number of procedures is not clearly defined in literature expert panel based recommendations state that an annual volume of more than 15 for an institution and more than 6 for the individual surgeon are appropriate [51]. They also state that the necessity of these volumes is undetermined.

In several countries, clinical auditing has been initiated in various fields of surgery. It is considered an important tool for quality assessment and the identification of factors needing improvement. Furthermore, clinical audits provide a unique dataset for research as well. For gastric cancer surgery, a nationwide audit has been initiated in the Netherlands, the Dutch Upper GI Cancer Audit (DUCA) (see also: http://duca.clinicalaudit.nl/). The DUCA has become a performance index for gastric cancer surgeons as it was also adopted as a quality indicator for the health care inspectorate. It is expected that postoperative mortality and anastomotic leakage rates will decrease but few reports have been published in the Netherlands so far. From 2011 to 2012 30-day mortality decreased from 8.8\% to 6.7\% (see: http:// www.clinicalaudit.nl/ jaarrapportage/ \#dica_rapportages_duca). Whether these improvements are directly related to the introduction of the audit has to be determined. At least, it can be stated that the DUCA has effectuated increased awareness of and insight in aspects of improvement.

Clinical audits have revealed several interesting findings with respect to postoperative complications. Hospitals with higher mortality rates had only slightly higher incidences of postoperative complications. However, in high volume centers these patients with a serious complication had a lesser chance of dying than in high-mortality centers. This phenomenon is addressed as failure to rescue and was not only described for gastrectomy but also for other gastro-intestinal operations [113]. Data from the American College of Surgeons National Surgical Quality Improvement Program showed that although complication incidences did not vary between hospitals, mortality rates significantly varied, indicating that timely recognition and treatment of complications deserves greater attention [114]. Future research should aim at identifying and improving the fundamental aspects causing failure to rescue. 


\section{Conclusion}

Surgical risk assessment is complex and difficult. In preoperative assessment of gastric cancer patients age should not be a criterion on which treatment decisions are made. Rather, presence of comorbidities, nutritional status and geriatric frailty should be assessed and taken into account. Future studies should further determine the role geriatric frailty and nutritional status assessment has in the preoperative evaluation of gastric cancer surgery patients, especially in Western counties, as these patients are more often at an advanced age.

Improving postoperative recovery by using fast-track and ERAS protocols has yielded improved results. The timing of oral intake is still at debate, but early oral feeding (postoperative day 1-3) seems to be feasible and safe. Further studies have to verify this and investigate its effect on morbidity, length-of-stay and quality of life/patient satisfaction. Also optimal fast-track/ERAS programs have to be developed to further improve outcome and quality of care for these patients. Introduction of laparoscopic surgery has improved short-term postoperative outcome for gastric cancer patients. Oncological safety remains an area of debate, but available literature suggest that oncological safety is not compromised.

In conclusion, although advances have been made in pre-, intra- and postoperative stage of gastric cancer surgery to improve the outcome of these patients, there still remain many areas for improvement and future research. 


\section{References}

1. Lozano R, Naghavi M, Foreman K, Lim S, Shibuya K, Aboyans V, Abraham J, Adair T, Aggarwal R, Ahn SY, Alvarado M, Anderson HR, Anderson LM, Andrews KG, Atkinson C, Baddour LM, Barker-Collo S, Bartels DH, Bell ML, Benjamin EJ, Bennett D, Bhalla K, Bikbov B, Bin Abdulhak A, Birbeck G, Blyth F, Bolliger I, Boufous S, Bucello C, Burch M, Burney P, Carapetis J, Chen H, Chou D, Chugh SS, Coffeng LE, Colan SD, Colquhoun S, Colson KE, Condon J, Connor MD, Cooper LT, Corriere M, Cortinovis M, de Vaccaro KC, Couser W, Cowie BC, Criqui MH, Cross M, Dabhadkar KC, Dahodwala N, De Leo D, Degenhardt L, Delossantos A, Denenberg J, Des Jarlais DC, Dharmaratne SD, Dorsey ER, Driscoll T, Duber H, Ebel B, Erwin PJ, Espindola P, Ezzati M, Feigin V, Flaxman AD, Forouzanfar MH, Fowkes FG, Franklin R, Fransen M, Freeman MK, Gabriel SE, Gakidou E, Gaspari F, Gillum RF, Gonzalez-Medina D, Halasa YA, Haring D, Harrison JE, Havmoeller R, Hay RJ, Hoen B, Hotez PJ, Hoy D, Jacobsen KH, James SL, Jasrasaria R, Jayaraman S, Johns N, Karthikeyan G, Kassebaum N, Keren A, Khoo JP, Knowlton LM, Kobusingye O, Koranteng A, Krishnamurthi R, Lipnick M, Lipshultz SE, Ohno SL, Mabweijano J, MacIntyre MF, Mallinger L, March L, Marks GB, Marks R, Matsumori A, Matzopoulos R, Mayosi BM, McAnulty JH, McDermott MM, McGrath J, Mensah GA, Merriman TR, Michaud C, Miller M, Miller TR, Mock C, Mocumbi AO, Mokdad AA, Moran A, Mulholland K, Nair MN, Naldi L, Narayan KM, Nasseri K, Norman P, O'Donnell M, Omer SB, Ortblad K, Osborne R, Ozgediz D, Pahari B, Pandian JD, Rivero AP, Padilla RP, Perez-Ruiz F, Perico N, Phillips D, Pierce K, Pope CA, 3rd, Porrini E, Pourmalek F, Raju M, Ranganathan D, Rehm JT, Rein DB, Remuzzi G, Rivara FP, Roberts T, De Leon FR, Rosenfeld LC, Rushton L, Sacco RL, Salomon JA, Sampson U, Sanman E, Schwebel DC, Segui-Gomez M, Shepard DS, Singh D, Singleton J, Sliwa K, Smith E, Steer A, Taylor JA, Thomas B, Tleyjeh IM, Towbin JA, Truelsen T, Undurraga EA, Venketasubramanian N, Vijayakumar L, Vos T, Wagner GR, Wang M, Wang W, Watt K, Weinstock MA, Weintraub R, Wilkinson JD, Woolf AD, Wulf S, Yeh PH, Yip P, Zabetian A, Zheng ZJ, Lopez AD, Murray CJ, AIMazroa MA and Memish ZA, Global and regional mortality from 235 causes of death for 20 age groups in 1990 and 2010: a systematic analysis for the Global Burden of Disease Study 2010. Lancet, 2012. 380(9859): p. 2095-128.

2. Jemal A, Siegel R, Xu J, and Ward E, Cancer statistics, 2010. CA Cancer J Clin, 2010. 60(5): p. 277-300. 3. Soerjomataram I, Lortet-Tieulent J, Parkin DM, Ferlay J, Mathers C, Forman D, and Bray F, Global burden of cancer in 2008: a systematic analysis of disability-adjusted life-years in 12 world regions. Lancet, 2012. 380(9856): p. 1840-50.

4. Dikken JL, van Sandick JW, Allum WH, Johansson J, Jensen LS, Putter H, Coupland VH, Wouters MW, Lemmens VE, van de Velde CJ, van der Geest LG, Larsson HJ, Cats A, and Verheij M, Differences in outcomes of oesophageal and gastric cancer surgery across Europe. Br J Surg, 2013. 100(1): p. 83-94. 5. Bosing NM, Goretzki PE, and Roher HD, Gastric cancer: which patients benefit from systematic lymphadenectomy? Eur J Surg Oncol, 2000. 26(5): p. 498-505.

6. Mariette C, De Botton ML, and Piessen G, Surgery in esophageal and gastric cancer patients: what is the role for nutrition support in your daily practice? Ann Surg Oncol, 2012. 19(7): p. 2128-34.

7. Bickenbach K and Strong VE, Comparisons of Gastric Cancer Treatments: East vs. West. J Gastric Cancer, 2012.12(2): p. 55-62.

8. Fitz-Henry J, The ASA classification and peri-operative risk. Ann R Coll Surg Engl, 2011. 93(3): p. 1857.

9. Charlson ME, Pompei P, Ales KL, and MacKenzie CR, A new method of classifying prognostic comorbidity in longitudinal studies: development and validation. J Chronic Dis, 1987. 40(5): p. 373-83. 10. Grendar J, Shaheen AA, Myers RP, Parker R, Vollmer CM, Jr., Ball CG, Quan ML, Kaplan GG, AlManasra T, and Dixon E, Predicting in-hospital mortality in patients undergoing complex gastrointestinal surgery: determining the optimal risk adjustment method. Arch Surg, 2012. 147(2): p. 126-35.

11. Hsu JT, Liu MS, Wang F, Chang CJ, Hwang TL, Jan YY, and Yeh TS, Standard radical gastrectomy in octogenarians and nonagenarians with gastric cancer: are short-term surgical results and long-term survival substantial? J Gastrointest Surg, 2012. 16(4): p. 728-37. 
12. Pisanu A, Montisci A, Piu S, and Uccheddu A, Curative surgery for gastric cancer in the elderly: treatment decisions, surgical morbidity, mortality, prognosis and quality of life. Tumori, 2007. 93(5): $\mathrm{p}$. 478-84.

13. Lubke T, Monig SP, Schneider PM, Holscher AH, and Bollschweiler E, [Does Charlson-comorbidity index correlate with short-term outcome in patients with gastric cancer?]. Zentralbl Chir, 2003. 128(11): p. 970-6.

14. Jeong O, Ryu SY, Zhao XF, Jung MR, Kim KY, and Park YK, Short-term surgical outcomes and operative risks of laparoscopic total gastrectomy (LTG) for gastric carcinoma: experience at a largevolume center. Surg Endosc, 2012. 26(12): p. 3418-25.

15. Bickenbach KA, Denton B, Gonen M, Brennan MF, Coit DG, and Strong VE, Impact of obesity on perioperative complications and long-term survival of patients with gastric cancer. Ann Surg Oncol, 2013. 20(3): p. 780-7.

16. Kunisaki C, Makino H, Takagawa R, Sato K, Kawamata M, Kanazawa A, Yamamoto N, Nagano Y, Fujii $\mathrm{S}$, Ono HA, Akiyama H, and Shimada H, Predictive factors for surgical complications of laparoscopyassisted distal gastrectomy for gastric cancer. Surg Endosc, 2009. 23(9): p. 2085-93.

17. Oh SJ, Hyung WJ, Li C, Song J, Rha SY, Chung HC, Choi SH, and Noh SH, Effect of being overweight on postoperative morbidity and long-term surgical outcomes in proximal gastric carcinoma. J Gastroenterol Hepatol, 2009. 24(3): p. 475-9.

18. Kulig J, Sierzega M, Kolodziejczyk P, Dadan J, Drews M, Fraczek M, Jeziorski A, Krawczyk M, Starzynska T, and Wallner G, Implications of overweight in gastric cancer: A multicenter study in a Western patient population. Eur J Surg Oncol, 2010. 36(10): p. 969-76.

19. Noshiro H, Shimizu S, Nagai E, Ohuchida K, and Tanaka M, Laparoscopy-assisted distal gastrectomy for early gastric cancer: is it beneficial for patients of heavier weight? Ann Surg, 2003. 238(5): p. 680-5. 20. Tsunoda S, Okabe H, Obama K, Tanaka E, Akagami M, Kinjo Y, and Sakai Y, Laparoscopic gastrectomy for patients with a history of upper abdominal surgery: results of a matched-pair analysis. Surg Today, 2013.

21. Nunobe S, Hiki N, Fukunaga T, Tokunaga M, Ohyama S, Seto Y, and Yamaguchi T, Previous laparotomy is not a contraindication to laparoscopy-assisted gastrectomy for early gastric cancer. World J Surg, 2008. 32(7): p. 1466-72.

22. Dewys WD, Begg C, Lavin PT, Band PR, Bennett JM, Bertino JR, Cohen MH, Douglass HO, Jr., Engstrom PF, Ezdinli EZ, Horton J, Johnson GJ, Moertel CG, Oken MM, Perlia C, Rosenbaum C, Silverstein MN, Skeel RT, Sponzo RW, and Tormey DC, Prognostic effect of weight loss prior to chemotherapy in cancer patients. Eastern Cooperative Oncology Group. Am J Med, 1980. 69(4): p. 491-7.

23. Correia MI and Waitzberg DL, The impact of malnutrition on morbidity, mortality, length of hospital stay and costs evaluated through a multivariate model analysis. Clin Nutr, 2003. 22(3): p. 235-9.

24. Lomivorotov VV, Efremov SM, Boboshko VA, Nikolaev DA, Vedernikov PE, Deryagin MN, Lomivorotov VN, and Karaskov AM, Prognostic value of nutritional screening tools for patients scheduled for cardiac surgery. Interact Cardiovasc Thorac Surg, 2013. 16(5): p. 612-8.

25. Tu MY, Chien TW, and Chou MT, Using a nutritional screening tool to evaluate the nutritional status of patients with colorectal cancer. Nutr Cancer, 2012. 64(2): p. 323-30.

26. Kruizenga HM, Seidell JC, de Vet HC, Wierdsma NJ, and van Bokhorst-de van der Schueren MA, Development and validation of a hospital screening tool for malnutrition: the short nutritional assessment questionnaire (SNAQ). Clin Nutr, 2005. 24(1): p. 75-82.

27. van Venrooij LM, van Leeuwen PA, Hopmans W, Borgmeijer-Hoelen MM, de Vos R, and De Mol BA, Accuracy of quick and easy undernutrition screening tools--Short Nutritional Assessment Questionnaire, Malnutrition Universal Screening Tool, and modified Malnutrition Universal Screening Tool--in patients undergoing cardiac surgery. J Am Diet Assoc, 2011. 111(12): p. 1924-30.

28. Guo W, Ou G, Li X, Huang J, Liu J, and Wei H, Screening of the nutritional risk of patients with gastric carcinoma before operation by NRS 2002 and its relationship with postoperative results. J Gastroenterol Hepatol, 2010. 25(4): p. 800-3.

29. Tegels JJ, De Maat MF, Hulsewe KW, Hoofwijk AG, and Stoot JH, Value of Geriatric Frailty and Nutritional Status Assessment in Predicting Postoperative Mortality in Gastric Cancer Surgery. Journal of Gastrointestinal Surgery, 2014. In press. 
30. Awad S, Tan BH, Cui H, Bhalla A, Fearon KC, Parsons SL, Catton JA, and Lobo DN, Marked changes in body composition following neoadjuvant chemotherapy for oesophagogastric cancer. Clin Nutr, 2012. 31(1): p. 74-7.

31. Peng PD, van Vledder MG, Tsai S, de Jong MC, Makary M, Ng J, Edil BH, Wolfgang CL, Schulick RD, Choti MA, Kamel I, and Pawlik TM, Sarcopenia negatively impacts short-term outcomes in patients undergoing hepatic resection for colorectal liver metastasis. HPB (Oxford), 2011. 13(7): p. 439-46.

32. Peng P, Hyder O, Firoozmand A, Kneuertz P, Schulick RD, Huang D, Makary M, Hirose K, Edil B, Choti MA, Herman J, Cameron JL, Wolfgang CL, and Pawlik TM, Impact of sarcopenia on outcomes following resection of pancreatic adenocarcinoma. J Gastrointest Surg, 2012. 16(8): p. 1478-86.

33. van Vledder MG, Levolger S, Ayez N, Verhoef C, Tran TC, and ljzermans JN, Body composition and outcome in patients undergoing resection of colorectal liver metastases. Br J Surg, 2012. 99(4): p. 5507.

34. Marrelli D, Roviello F, De Stefano A, Vuolo G, Brandi C, Lottini M, and Pinto E, Surgical treatment of gastrointestinal carcinomas in octogenarians: risk factors for complications and long-term outcome. Eur J Surg Oncol, 2000. 26(4): p. 371-6.

35. Bozzetti F, Gianotti L, Braga M, Di Carlo V, and Mariani L, Postoperative complications in gastrointestinal cancer patients: the joint role of the nutritional status and the nutritional support. Clin Nutr, 2007. 26(6): p. 698-709.

36. Pacelli F, Bossola M, Rosa F, Tortorelli AP, Papa V, and Doglietto GB, Is malnutrition still a risk factor of postoperative complications in gastric cancer surgery? Clin Nutr, 2008. 27(3): p. 398-407.

37. Fried LP, Tangen CM, Walston J, Newman AB, Hirsch C, Gottdiener J, Seeman T, Tracy R, Kop WJ, Burke G, McBurnie MA, and Cardiovascular Health Study Collaborative Research G, Frailty in older adults: evidence for a phenotype. J Gerontol A Biol Sci Med Sci, 2001. 56(3): p. M146-56.

38. Dasgupta M, Rolfson DB, Stolee P, Borrie MJ, and Speechley M, Frailty is associated with postoperative complications in older adults with medical problems. Arch Gerontol Geriatr, 2009. 48(1): p. $78-83$.

39. Robinson TN, Eiseman B, Wallace JI, Church SD, McFann KK, Pfister SM, Sharp TJ, and Moss M, Redefining geriatric preoperative assessment using frailty, disability and co-morbidity. Ann Surg, 2009. 250(3): p. 449-55.

40. Lee DH, Buth KJ, Martin BJ, Yip AM, and Hirsch GM, Frail patients are at increased risk for mortality and prolonged institutional care after cardiac surgery. Circulation, 2010. 121(8): p. 973-8.

41. Makary MA, Segev DL, Pronovost PJ, Syin D, Bandeen-Roche K, Patel P, Takenaga R, Devgan L, Holzmueller CG, Tian J, and Fried LP, Frailty as a predictor of surgical outcomes in older patients. J Am Coll Surg, 2010. 210(6): p. 901-8.

42. Revenig LM, Canter DJ, Taylor MD, Tai C, Sweeney JF, Sarmiento JM, Kooby DA, Maithel SK, Master VA, and Ogan K, Too frail for surgery? Initial results of a large multidisciplinary prospective study examining preoperative variables predictive of poor surgical outcomes. J Am Coll Surg, 2013. 217(4): p. 665-670 e1.

43. Schuurmans H, Steverink N, Lindenberg S, Frieswijk N, and Slaets JP, Old or frail: what tells us more? J Gerontol A Biol Sci Med Sci, 2004. 59(9): p. M962-5.

44. Carli F and Zavorsky GS, Optimizing functional exercise capacity in the elderly surgical population. Curr Opin Clin Nutr Metab Care, 2005. 8(1): p. 23-32.

45. Li C, Carli F, Lee L, Charlebois P, Stein B, Liberman AS, Kaneva P, Augustin B, Wongyingsinn M, Gamsa A, Kim do J, Vassiliou MC, and Feldman LS, Impact of a trimodal prehabilitation program on functional recovery after colorectal cancer surgery: a pilot study. Surg Endosc, 2013. 27(4): p. 1072-82.

46. Mayo NE, Feldman L, Scott S, Zavorsky G, Kim do J, Charlebois P, Stein B, and Carli F, Impact of preoperative change in physical function on postoperative recovery: argument supporting prehabilitation for colorectal surgery. Surgery, 2011. 150(3): p. 505-14.

47. Silver JK and Baima J, Cancer prehabilitation: an opportunity to decrease treatment-related morbidity, increase cancer treatment options, and improve physical and psychological health outcomes. Am J Phys Med Rehabil, 2013. 92(8): p. 715-27. 
48. Gretschel S, Siegel R, Estevez-Schwarz L, Hunerbein M, Schneider U, and Schlag PM, Surgical strategies for gastric cancer with synchronous peritoneal carcinomatosis. Br J Surg, 2006. 93(12): p. 1530-5.

49. Mahadevan D, Sudirman A, Kandasami P, and Ramesh G, Laparoscopic staging in gastric cancer: An essential step in its management. J Minim Access Surg, 2010. 6(4): p. 111-3.

50. Leake PA, Cardoso R, Seevaratnam R, Lourenco L, Helyer L, Mahar A, Law C, and Coburn NG, A systematic review of the accuracy and indications for diagnostic laparoscopy prior to curative-intent resection of gastric cancer. Gastric Cancer, 2012. 15 Suppl 1: p. S38-47.

51. Coburn N, Seevaratnam R, Paszat L, Helyer L, Law C, Swallow C, Cardosa R, Mahar A, Lourenco LG, Dixon M, Bekaii-Saab T, Chau I, Church N, Coit D, Crane CH, Earle C, Mansfield P, Marcon N, Miner T, Noh SH, Porter G, Posner MC, Prachand V, Sano T, van de Velde C, Wong S, and McLeod R, Optimal Management of Gastric Cancer: Results From an International RAND/UCLA Expert Panel. Ann Surg, 2014. 259(1): p. 102-8.

52. Bentrem D, Wilton A, Mazumdar M, Brennan M, and Coit D, The value of peritoneal cytology as a preoperative predictor in patients with gastric carcinoma undergoing a curative resection. Ann Surg Oncol, 2005. 12(5): p. 347-53.

53. Lee SD, Ryu KW, Eom BW, Lee JH, Kook MC, and Kim YW, Prognostic significance of peritoneal washing cytology in patients with gastric cancer. Br J Surg, 2012. 99(3): p. 397-403.

54. Roviello F, Caruso S, Neri A, and Marrelli D, Treatment and prevention of peritoneal carcinomatosis from gastric cancer by cytoreductive surgery and hyperthermic intraperitoneal chemotherapy: Overview and rationale. Eur J Surg Oncol, 2013. 39(12): p. 1309-16.

55. Gillissen F, Hoff C, Maessen JM, Winkens B, Teeuwen JH, von Meyenfeldt MF, and Dejong $\mathrm{CH}$, Structured synchronous implementation of an enhanced recovery program in elective colonic surgery in 33 hospitals in The Netherlands. World J Surg, 2013. 37(5): p. 1082-93.

56. Gustafsson UO, Scott MJ, Schwenk W, Demartines N, Roulin D, Francis N, McNaught CE, MacFie J, Liberman AS, Soop M, Hill A, Kennedy RH, Lobo DN, Fearon K, Ljungqvist O, and Enhanced Recovery After Surgery S, Guidelines for perioperative care in elective colonic surgery: Enhanced Recovery After Surgery (ERAS(R)) Society recommendations. Clin Nutr, 2012. 31(6): p. 783-800.

57. Jo DH, Jeong O, Sun JW, Jeong MR, Ryu SY, and Park YK, Feasibility study of early oral intake after gastrectomy for gastric carcinoma. J Gastric Cancer, 2011. 11(2): p. 101-8.

58. Hur H, Si Y, Kang WK, Kim W, and Jeon HM, Effects of early oral feeding on surgical outcomes and recovery after curative surgery for gastric cancer: pilot study results. World J Surg, 2009. 33(7): p. 1454 8.

59. Suehiro T, Matsumata T, Shikada Y, and Sugimachi K, Accelerated rehabilitation with early postoperative oral feeding following gastrectomy. Hepatogastroenterology, 2004. 51(60): p. 1852-5. 60. Hur H, Kim SG, Shim JH, Song KY, Kim W, Park CH, and Jeon HM, Effect of early oral feeding after gastric cancer surgery: a result of randomized clinical trial. Surgery, 2011. 149(4): p. 561-8.

61. Wang D, Kong Y, Zhong B, Zhou X, and Zhou Y, Fast-track surgery improves postoperative recovery in patients with gastric cancer: a randomized comparison with conventional postoperative care. $J$ Gastrointest Surg, 2010. 14(4): p. 620-7.

62. Yamada T, Hayashi T, Cho H, Yoshikawa T, Taniguchi H, Fukushima R, and Tsuburaya A, Usefulness of enhanced recovery after surgery protocol as compared with conventional perioperative care in gastric surgery. Gastric Cancer, 2012. 15(1): p. 34-41.

63. Grantcharov TP and Kehlet H, Laparoscopic gastric surgery in an enhanced recovery programme. Br J Surg, 2010. 97(10): p. 1547-51.

64. Kim JW, Kim WS, Cheong JH, Hyung WJ, Choi SH, and Noh SH, Safety and efficacy of fast-track surgery in laparoscopic distal gastrectomy for gastric cancer: a randomized clinical trial. World J Surg, 2012. 36(12): p. 2879-87.

65. Chen Hu J, Xin Jiang L, Cai L, Tao Zheng H, Yuan Hu S, Bing Chen H, Chang Wu G, Fei Zhang Y, and Chuan Lv Z, Preliminary experience of fast-track surgery combined with laparoscopy-assisted radical distal gastrectomy for gastric cancer. J Gastrointest Surg, 2012. 16(10): p. 1830-9.

66. Kitano S, Iso Y, Moriyama M, and Sugimachi K, Laparoscopy-assisted Billroth I gastrectomy. Surg Laparosc Endosc, 1994. 4(2): p. 146-8. 
67. Adachi Y, Shiraishi N, Shiromizu A, Bandoh T, Aramaki M, and Kitano S, Laparoscopy-assisted Billroth I gastrectomy compared with conventional open gastrectomy. Arch Surg, 2000. 135(7): p. 806-10.

68. Kitano S, Shiraishi N, Kakisako K, Yasuda K, Inomata M, and Adachi Y, Laparoscopy-assisted BillrothI gastrectomy (LADG) for cancer: our 10 years' experience. Surg Laparosc Endosc Percutan Tech, 2002. 12(3): p. 204-7.

69. Vinuela EF, Gonen M, Brennan MF, Coit DG, and Strong VE, Laparoscopic versus open distal gastrectomy for gastric cancer: a meta-analysis of randomized controlled trials and high-quality nonrandomized studies. Ann Surg, 2012. 255(3): p. 446-56.

70. Chen XZ, Hu JK, Yang K, Wang L, and Lu QC, Short-term evaluation of laparoscopy-assisted distal gastrectomy for predictive early gastric cancer: a meta-analysis of randomized controlled trials. Surg Laparosc Endosc Percutan Tech, 2009. 19(4): p. 277-84.

71. Kodera Y, Fujiwara M, Ohashi N, Nakayama G, Koike M, Morita S, and Nakao A, Laparoscopic surgery for gastric cancer: a collective review with meta-analysis of randomized trials. J Am Coll Surg, 2010. 211(5): p. 677-86.

72. Memon MA, Khan S, Yunus RM, Barr R, and Memon B, Meta-analysis of laparoscopic and open distal gastrectomy for gastric carcinoma. Surg Endosc, 2008. 22(8): p. 1781-9.

73. Ohtani H, Tamamori Y, Noguchi K, Azuma T, Fujimoto S, Oba H, Aoki T, Minami M, and Hirakawa K, Meta-analysis of laparoscopy-assisted and open distal gastrectomy for gastric cancer. J Surg Res, 2011. 171(2): p. 479-85.

74. Chen K, Xu XW, Zhang RC, Pan Y, Wu D, and Mou YP, Systematic review and meta-analysis of laparoscopy-assisted and open total gastrectomy for gastric cancer. World J Gastroenterol, 2013. 19(32): p. 5365-76.

75. Huscher CG, Mingoli A, Sgarzini G, Sansonetti A, Di Paola M, Recher A, and Ponzano C, Laparoscopic versus open subtotal gastrectomy for distal gastric cancer: five-year results of a randomized prospective trial. Ann Surg, 2005. 241(2): p. 232-7.

76. Siani LM, Ferranti F, De Carlo A, and Quintiliani A, Completely laparoscopic versus open total gastrectomy in stage I-III/C gastric cancer: safety, efficacy and five-year oncologic outcome. Minerva Chir, 2012. 67(4): p. 319-26.

77. Dulucq JL, Wintringer P, Stabilini C, Solinas L, Perissat J, and Mahajna A, Laparoscopic and open gastric resections for malignant lesions: a prospective comparative study. Surg Endosc, 2005. 19(7): p. 933-8.

78. Park do J, Han SU, Hyung WJ, Kim MC, Kim W, Ryu SY, Ryu SW, Song KY, Lee HJ, Cho GS, and Kim $\mathrm{HH}$, Long-term outcomes after laparoscopy-assisted gastrectomy for advanced gastric cancer: a largescale multicenter retrospective study. Surg Endosc, 2012. 26(6): p. 1548-53.

79. Lee MS, Lee JH, Park do J, Lee HJ, Kim HH, and Yang HK, Comparison of short- and long-term outcomes of laparoscopic-assisted total gastrectomy and open total gastrectomy in gastric cancer patients. Surg Endosc, 2013. 27(7): p. 2598-605.

80. Wu CW, Hsiung CA, Lo SS, Hsieh MC, Chen JH, Li AF, Lui WY, and Whang-Peng J, Nodal dissection for patients with gastric cancer: a randomised controlled trial. Lancet Oncol, 2006. 7(4): p. 309-15.

81. Bonenkamp JJ, Songun I, Hermans J, Sasako M, Welvaart K, Plukker JT, van Elk P, Obertop H, Gouma DJ, Taat CW, and et al., Randomised comparison of morbidity after D1 and D2 dissection for gastric cancer in 996 Dutch patients. Lancet, 1995. 345(8952): p. 745-8.

82. Cuschieri A, Fayers P, Fielding J, Craven J, Bancewicz J, Joypaul V, and Cook P, Postoperative morbidity and mortality after D1 and D2 resections for gastric cancer: preliminary results of the MRC randomised controlled surgical trial. The Surgical Cooperative Group. Lancet, 1996. 347(9007): p. 9959.

83. Songun I, Putter H, Kranenbarg EM, Sasako M, and van de Velde CJ, Surgical treatment of gastric cancer: 15-year follow-up results of the randomised nationwide Dutch D1D2 trial. Lancet Oncol, 2010. 11(5): p. 439-49.

84. Degiuli M, Sasako M, Ponti A, and Italian Gastric Cancer Study G, Morbidity and mortality in the Italian Gastric Cancer Study Group randomized clinical trial of D1 versus D2 resection for gastric cancer. Br J Surg, 2010. 97(5): p. 643-9. 
85. Sano T, Sasako M, Yamamoto S, Nashimoto A, Kurita A, Hiratsuka M, Tsujinaka T, Kinoshita T, Arai K, Yamamura Y, and Okajima K, Gastric cancer surgery: morbidity and mortality results from a prospective randomized controlled trial comparing D2 and extended para-aortic lymphadenectomyJapan Clinical Oncology Group study 9501. J Clin Oncol, 2004. 22(14): p. 2767-73.

86. Sasako M, Sano T, Yamamoto S, Kurokawa Y, Nashimoto A, Kurita A, Hiratsuka M, Tsujinaka T, Kinoshita T, Arai K, Yamamura Y, Okajima K, and Japan Clinical Oncology G, D2 lymphadenectomy alone or with para-aortic nodal dissection for gastric cancer. N Engl J Med, 2008. 359(5): p. 453-62.

87. Kochi M, Fujii M, Kanamori N, Kaiga T, Mihara Y, Funada T, Tamegai H, Takayama Y, Yoshida N, and Takayama T, D2 Gastrectomy With Versus Without Bursectomy for Gastric Cancer. Am J Clin Oncol, 2012. 88. Eom BW, Joo J, Kim YW, Bae JM, Park KB, Lee JH, Ryu KW, and Kook MC, Role of bursectomy for advanced gastric cancer: Result of a case-control study from a large volume hospital. Eur J Surg Oncol, 2013.

89. Fujita J, Kurokawa Y, Sugimoto T, Miyashiro I, lijima S, Kimura Y, Takiguchi S, Fujiwara Y, Mori M, and Doki Y, Survival benefit of bursectomy in patients with resectable gastric cancer: interim analysis results of a randomized controlled trial. Gastric Cancer, 2012. 15(1): p. 42-8.

90. Nomura E, Lee SW, Bouras G, Tokuhara T, Hayashi M, Hiramatsu M, Okuda J, and Tanigawa N, Functional outcomes according to the size of the gastric remnant and type of reconstruction following laparoscopic distal gastrectomy for gastric cancer. Gastric Cancer, 2011. 14(3): p. 279-84.

91. Kojima K, Yamada H, Inokuchi M, Kawano T, and Sugihara K, A comparison of Roux-en-Y and BillrothI reconstruction after laparoscopy-assisted distal gastrectomy. Ann Surg, 2008. 247(6): p. 962-7.

92. Ishikawa M, Kitayama J, Kaizaki S, Nakayama H, Ishigami H, Fujii S, Suzuki H, Inoue T, Sako A, Asakage $\mathrm{M}$, Yamashita H, Hatono K, and Nagawa H, Prospective randomized trial comparing Billroth I and Rouxen-Y procedures after distal gastrectomy for gastric carcinoma. World J Surg, 2005. 29(11): p. 1415-20; discussion 1421.

93. Inokuchi M, Kojima K, Yamada H, Kato K, Hayashi M, Motoyama K, and Sugihara K, Long-term outcomes of Roux-en-Y and Billroth-I reconstruction after laparoscopic distal gastrectomy. Gastric Cancer, 2013. 16(1): p. 67-73.

94. Takiguchi S, Yamamoto K, Hirao M, Imamura H, Fujita J, Yano M, Kobayashi K, Kimura Y, Kurokawa Y, Mori M, Doki Y, and Osaka University Clinical Research Group for Gastroenterological S, A comparison of postoperative quality of life and dysfunction after Billroth I and Roux-en-Y reconstruction following distal gastrectomy for gastric cancer: results from a multi-institutional RCT. Gastric Cancer, 2012. 15(2): p. 198-205.

95. Imamura H, Takiguchi S, Yamamoto K, Hirao M, Fujita J, Miyashiro I, Kurokawa Y, Fujiwara Y, Mori $\mathrm{M}$, and Doki $\mathrm{Y}$, Morbidity and mortality results from a prospective randomized controlled trial comparing Billroth I and Roux-en-Y reconstructive procedures after distal gastrectomy for gastric cancer. World J Surg, 2012. 36(3): p. 632-7.

96. Wu Q, Yu JC, Kang WM, and Ma ZQ, Short-term effects of supplementary feeding with enteral nutrition via jejunostomy catheter on post-gastrectomy gastric cancer patients. Chin Med J (Engl), 2011. 124(20): p. 3297-301.

97. Patel SH, Kooby DA, Staley CA, 3rd, and Maithel SK, An assessment of feeding jejunostomy tube placement at the time of resection for gastric adenocarcinoma. J Surg Oncol, 2013. 107(7): p. 728-34. 98. Llaguna OH, Kim HJ, Deal AM, Calvo BF, Stitzenberg KB, and Meyers MO, Utilization and morbidity associated with placement of a feeding jejunostomy at the time of gastroesophageal resection. J Gastrointest Surg, 2011. 15(10): p. 1663-9.

99. Deguchi Y, Fukagawa T, Morita S, Ohashi M, Saka M, and Katai H, Identification of risk factors for esophagojejunal anastomotic leakage after gastric surgery. World J Surg, 2012. 36(7): p. 1617-22.

100. Migita K, Takayama T, Matsumoto S, Wakatsuki K, Enomoto K, Tanaka T, Ito M, and Nakajima Y, Risk factors for esophagojejunal anastomotic leakage after elective gastrectomy for gastric cancer. J Gastrointest Surg, 2012.16(9): p. 1659-65.

101. Tsou CC, Lo SS, Fang WL, Wu CW, Chen JH, Hsieh MC, and Shen KH, Risk factors and management of anastomotic leakage after radical gastrectomy for gastric cancer. Hepatogastroenterology, 2011. 58(105): p. 218-23. 
102. Schurawitzki H, Karnel F, Stiglbauer R, Schimmerl S, and Salomonowitz E, CT-guided percutaneous drainage and fluid aspiration in intensive care patients. Acta Radiol, 1992. 33(2): p. 131-6.

103. Lambiase RE, Deyoe L, Cronan JJ, and Dorfman GS, Percutaneous drainage of 335 consecutive abscesses: results of primary drainage with 1-year follow-up. Radiology, 1992. 184(1): p. 167-79.

104. Lang H, Piso P, Stukenborg C, Raab R, and Jahne J, Management and results of proximal anastomotic leaks in a series of 1114 total gastrectomies for gastric carcinoma. Eur J Surg Oncol, 2000. 26(2): p. 168-71.

105. Etoh T, Inomata M, Shiraishi N, and Kitano S, Revisional surgery after gastrectomy for gastric cancer: review of the literature. Surg Laparosc Endosc Percutan Tech, 2010. 20(5): p. 332-7.

106. Kim YJ, Shin SK, Lee HJ, Chung HS, Lee YC, Park JC, Hyung WJ, Noh SH, Kim CB, and Lee SK, Endoscopic management of anastomotic leakage after gastrectomy for gastric cancer: how efficacious is it? Scand J Gastroenterol, 2013. 48(1): p. 111-8.

107. Roy-Choudhury SH, Nicholson AA, Wedgwood KR, Mannion RA, Sedman PC, Royston CM, and Breen DJ, Symptomatic malignant gastroesophageal anastomotic leak: management with covered metallic esophageal stents. AJR Am J Roentgenol, 2001. 176(1): p. 161-5.

108. Kwak HS, Lee JM, Jin GY, Han YM, and Yang DH, Treatment of gastrojejunal anastomotic leak with a covered metallic stent. Hepatogastroenterology, 2003. 50(49): p. 62-4.

109. Meyer $\mathrm{HJ}$, The influence of case load and the extent of resection on the quality of treatment outcome in gastric cancer. Eur J Surg Oncol, 2005. 31(6): p. 595-604.

110. Coupland VH, Lagergren J, Luchtenborg M, Jack RH, Allum W, Holmberg L, Hanna GB, Pearce N, and Moller $\mathrm{H}$, Hospital volume, proportion resected and mortality from oesophageal and gastric cancer: a population-based study in England, 2004-2008. Gut, 2013. 62(7): p. 961-6.

111. Anderson O, Ni Z, Moller H, Coupland VH, Davies EA, Allum WH, and Hanna GB, Hospital volume and survival in oesophagectomy and gastrectomy for cancer. Eur J Cancer, 2011. 47(16): p. 2408-14. 112. Enzinger PC, Benedetti JK, Meyerhardt JA, McCoy S, Hundahl SA, Macdonald JS, and Fuchs CS, Impact of hospital volume on recurrence and survival after surgery for gastric cancer. Ann Surg, 2007. 245(3): p. 426-34.

113. Ghaferi AA, Birkmeyer JD, and Dimick JB, Hospital volume and failure to rescue with high-risk surgery. Med Care, 2011. 49(12): p. 1076-81.

114. Ghaferi AA, Birkmeyer JD, and Dimick JB, Variation in hospital mortality associated with inpatient surgery. N Engl J Med, 2009. 361(14): p. 1368-75. 


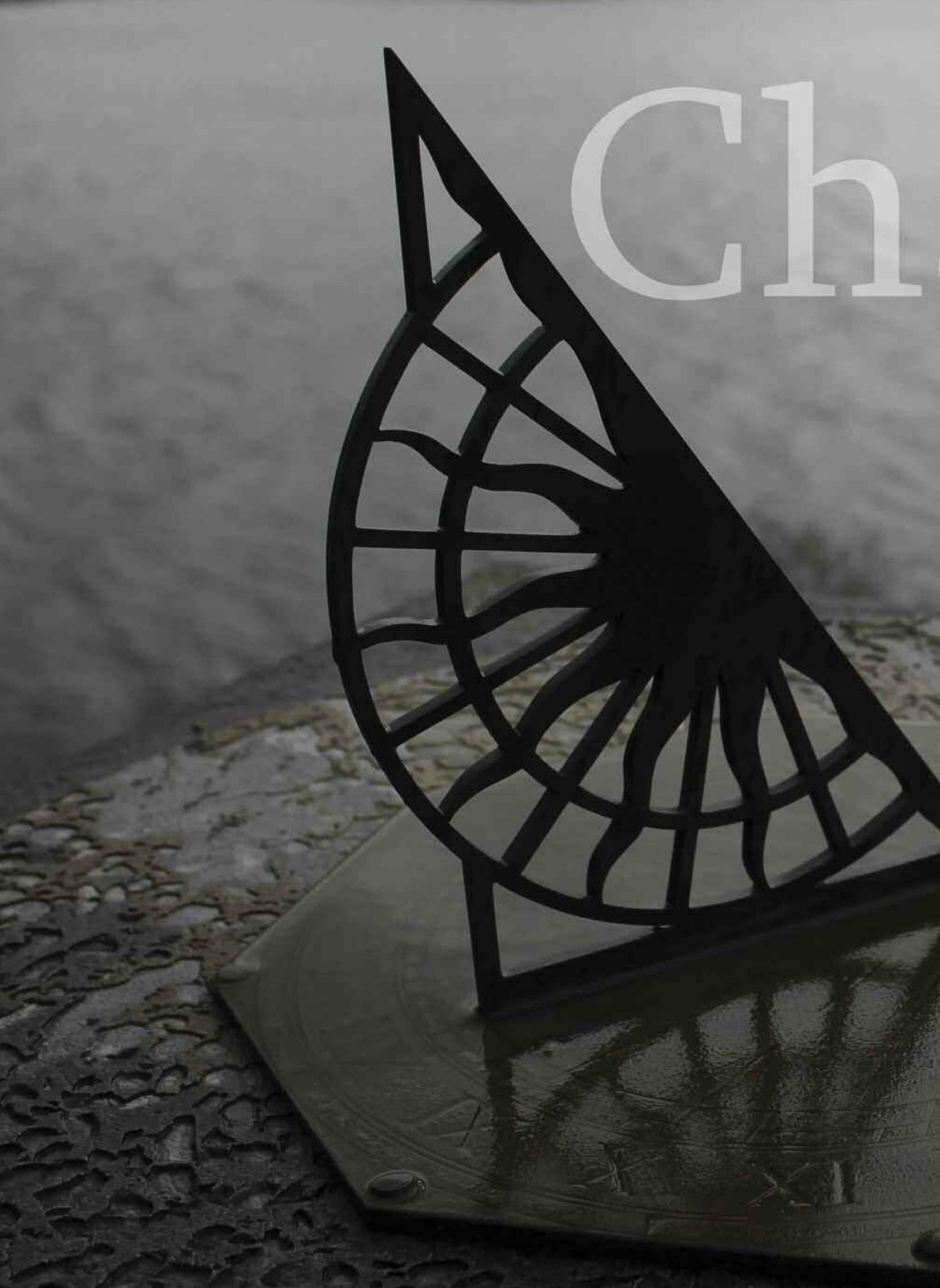




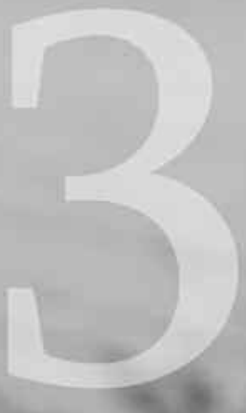

Value of geriatric frailty and nutritional status assessment in predicting postoperative mortality in gastric cancer surgery

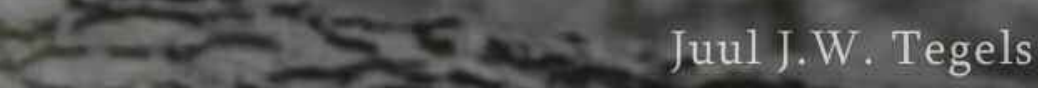

S. -1 .

Karel W. E. Hulsewé

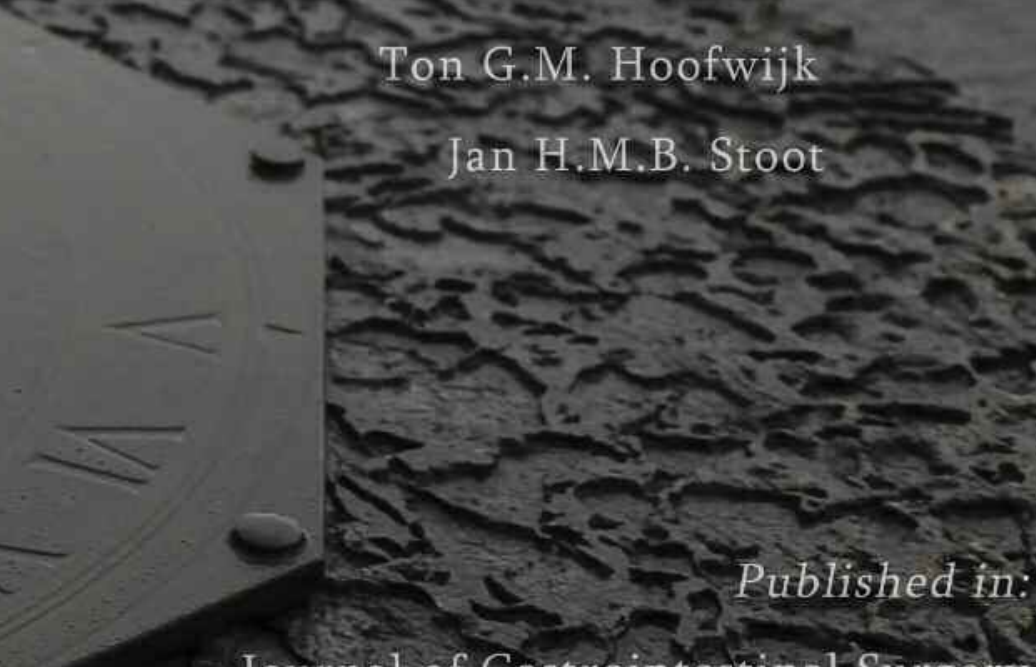

Journal of Gastrointestinal Surgery

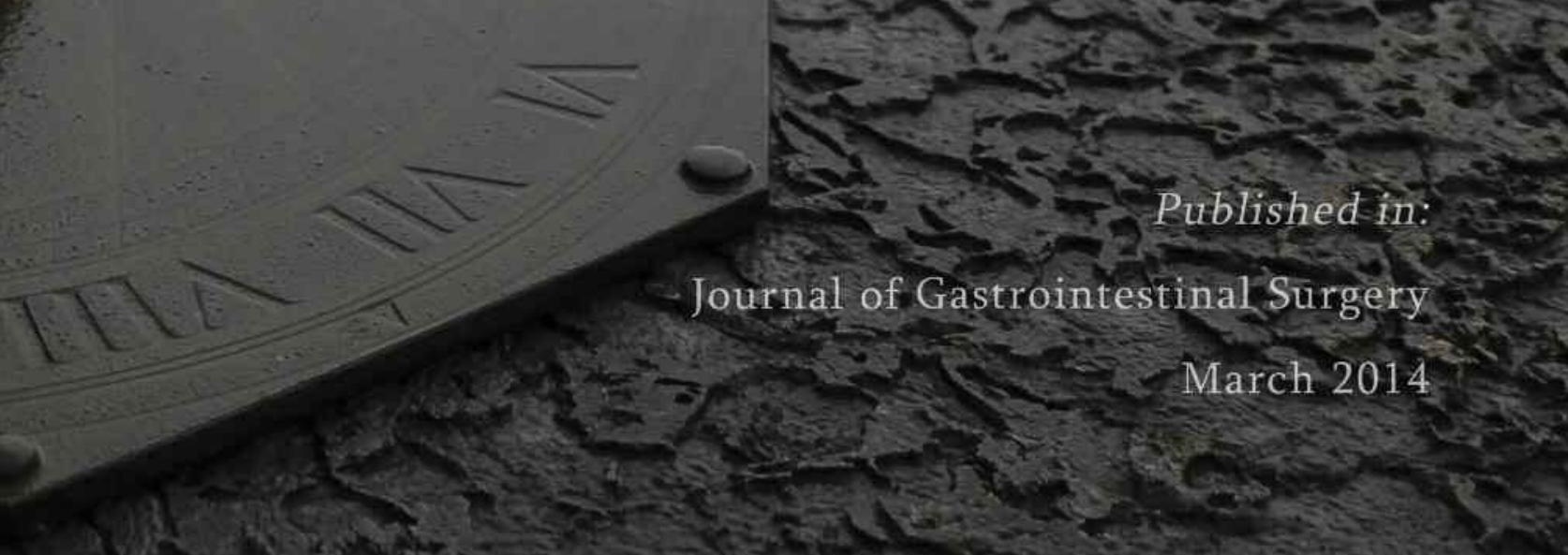




\section{Chapter 3.}

\section{Abstract}

\section{Objectives}

This study seeks to evaluate assessment of geriatric frailty and nutritional status in predicting postoperative mortality in gastric cancer surgery.

\section{Methods}

Preoperatively, patients operated for gastric adenocarcinoma underwent assessment of Groningen Frailty Indicator (GFI) and Short Nutritional Assessment Questionnaire (SNAQ). We studied retrospectively whether these scores were associated with in-hospital mortality.

\section{Results}

From 2005 to September 2012180 patients underwent surgery with an overall mortality of $8.3 \%$. Patients with a GFI $\geq 3(n=30,24 \%)$ had a mortality rate of $23.3 \%$ versus $5.2 \%$ in the lower GFI group (OR $4.0,95 \% \mathrm{Cl} 1.1$ to $14.1, \mathrm{P}=0.03$ ). For patients who underwent surgery with curative intent $(n=125)$, this was $27.3 \%$ for patients with $\mathrm{GFI} \geq 3(\mathrm{n}=22,18 \%)$ versus $5.7 \%$ with $\mathrm{GFI}<3$ (OR 4.6, 95\% $\mathrm{Cl} 1.0$ to $20.9, \mathrm{P}=0.05$ ). SNAQ $\geq 1(n=98,61 \%)$ was associated with a mortality rate of $13.3 \%$ versus $3.2 \%$ in patients with $\mathrm{SNAQ}=0$ (OR 5.1, 95\% Cl 1.1 to $23.8, \mathrm{P}=0.04$ ). Given odds ratios are corrected in multivariate analysis for age, neoadjuvant chemotherapy, type of surgery, tumor stage and ASA classification.

\section{Conclusions}

This study shows a significant relationship between gastric cancer surgical mortality and geriatric frailty as well as nutritional status using a simple questionnaire. This may have implications in preoperative decision making in selecting patients who optimally benefit from surgery. 


\section{Introduction}

Although the incidence has been declining in the past decennia, gastric carcinoma remains responsible for a significant part of cancer related mortality worldwide, with an estimated 738,000 deaths (9.7\% of total) in 2008 [1]. Mainstay of gastric carcinoma treatment is surgical resection and this is the only treatment that can offer cure or long-term survival [2]. Gastric cancer surgery is associated with relatively high rates of reported postoperative morbidity and mortality ranging between $29-33 \%$ and 4-16\%, respectively, in several studies [3-5]. Age, comorbidity and disease stage are known factors that influence postoperative outcome of surgery [6]. Characteristics of the treating hospital, i.e. case volume and individual surgeon expertise, have also been shown to be factors that affect short-term postoperative as well as long-term outcomes [6-12].

Although it seems a platitude to say that a patient's chronological age may not correspond to a patient's biological age, doctors are inclined to use this number to make treatment decisions. Recent studies have shown that geriatric frailty might be a better predictor than age for predicting postoperative outcome in the elderly $[13,14]$. However, no literature is available that has evaluated the relationship between frailty and postoperative outcome in gastric cancer surgery. The Groningen Frailty Indicator (GFI) is a short, 15-item questionnaire filled out by nursing staff at hospital admission that was selected by our geriatrics department's physicians to evaluate frailty in elderly patients. The GFI has been associated with delirium risk in vascular surgery patients and with worse outcome after chemotherapy for breast cancer and colorectal cancer [15-17].

Nutritional status is another important aspect in patients with upper gastrointestinal tract malignancies as their intake is often compromised by mechanical obstruction. In the Netherlands all patients admitted to a hospital are routinely screened for malnutrition using tools such as the Short Nutritional Assessment Questionnaire (SNAQ) [18]. In the case of an aberrant SNAQ score intervention by a dietitian follows. Several studies have shown the value of nutritional evaluation by SNAQ in surgical patients however not specifically for gastric cancer surgery [19, 20].

The aim of our study was to investigate if preoperative assessment of geriatric frailty using the Groningen Frailty Indicator (GFI) and nutritional status using SNAQ could be a helpful tool in the preoperative risk assessment of gastric cancer patients $[18,21]$. 


\section{Methods}

\section{Study population}

All patients with histologically proven gastric adenocarcinoma who underwent surgical treatment in our hospital between January 2005 and September 2012 were identified. Clinical outcome results of patients treated from 1994 to 2005 have been published in the past [22]. The Orbis Medical Center is a community teaching hospital that was assigned as the regional referral center for surgical treatment of gastric malignancies in 2009.

\section{Predictor and outcome variables}

The primary outcome for this study was in-hospital mortality. Secondary outcome measurements were: serious adverse events (i.e. complications at Clavien-Dindo grade $\geq 3$ a), length of stay and 6-month mortality. All necessary data were obtained retrospectively through the hospital's fully digitalized patient information system. Nature of preoperative comorbidities was registered and severity classified according to the ASA classification [23]. Complications were classified using the Clavien-Dindo classification of surgical complications [24, 25]. By consulting the municipal administration database using the patients' Social Security Number we collected data on 6-month survival.

\section{Frailty and nutritional status}

Frailty was assessed using the Groningen Frailty Indicator (GFI) [21] and nutritional status was obtained using the Short Nutritional Assessment Questionnaire (SNAQ) [20]. Questionnaire items are provided in Table 1 and 2. Both GFI and SNAQ assessments were performed preoperatively at admission by nursing staff as part of the standard intake and entered into the digital nursing charts. GFI encompasses aspects of mobility, self perceived physical fitness, problems due to impaired vision and/or hearing, nourishment (i.e. weight loss), morbidity (i.e. multipharmacy), cognition and psychosocial aspects (see also Table 1). The GFI questionnaire consists of 15 items that are scored o or 1 point. SNAQ consists of three items regarding unintentional weight loss, loss of appetite and use of nutritional supplements (see Table 2) [18, 20]. Only cases with all items completed were used in analysis.

\section{Statistical analysis}

Statistical analysis was performed using SPSS 20 (IBM Corp. Armonk, NY). Independent samples t-test was used to perform analyses on continuous variables and Fisher's Exact test, to assess categorical data. Patients who died in-hospital 
postoperatively were excluded in length of stay analysis. Binary logistic backward regression was used to perform multivariate analysis. Factors that were used for multivariate analysis were: GFI score, SNAQ score, patient age, ASA classification, neoadjuvant chemotherapy, disease stage and type of surgery. Statistical significance was stated as $\mathrm{P}<0.05$. Means and standard deviation will be reported as mean $\pm \mathrm{SD}$.

\begin{tabular}{|c|c|c|c|c|}
\hline Question & $\begin{array}{l}\text { Percentage } \\
\text { scoring 1 point } \\
\text { Patients with } \\
\text { complete GFI } \\
(n=127)\end{array}$ & $\begin{array}{l}\text { Percentage s } \\
\text { point in: } \\
\text { In-hospital } \\
\text { mortality } \\
\text { group }(n=12)\end{array}$ & $\begin{array}{l}\text { oring } 1 \\
\text { Alive } \\
\text { patients } \\
(n=115)\end{array}$ & $P$-value \\
\hline \multicolumn{5}{|l|}{$\begin{array}{l}\text { Are you able to perform this task } \\
\text { without help }\end{array}$} \\
\hline 1. Shopping (no=1point) & $21.3 \%$ & $58.3 \%$ & $17.4 \%$ & 0.004 \\
\hline $\begin{array}{l}\text { 2. Walking around the house } \\
\text { (no=1point) }\end{array}$ & $7.1 \%$ & $16.7 \%$ & $6.1 \%$ & 0.20 \\
\hline 3. Dress and undress (no=1point) & $7.1 \%$ & $0 \%$ & $7.8 \%$ & 0.60 \\
\hline \multicolumn{5}{|l|}{ Physical Fitness } \\
\hline $\begin{array}{l}\text { 5. Mark your physical fitness (o to } \\
\text { 10) } \\
\text { (o-6=1 point, } 7-10=0 \text { points) } \\
\text { Vision and hearing }\end{array}$ & $51.2 \%$ & $50.0 \%$ & $51.3 \%$ & 1.00 \\
\hline $\begin{array}{l}\text { 6. Problems due to poor vision } \\
\text { (yes=1 point) }\end{array}$ & $4.7 \%$ & $33.3 \%$ & $1.7 \%$ & 0.001 \\
\hline $\begin{array}{l}\text { 7. Problems due to hard hearing } \\
\text { (yes=1 point) } \\
\text { Nourishment }\end{array}$ & $9.4 \%$ & $25.0 \%$ & $7.8 \%$ & 0.09 \\
\hline $\begin{array}{l}\text { 8. Unintended weight loss past six } \\
\text { months? (yes=1 point) } \\
\text { Morbidity }\end{array}$ & $37.8 \%$ & $66.7 \%$ & $34.8 \%$ & 0.06 \\
\hline $\begin{array}{l}\text { 9. Use of }=4 \text { prescription } \\
\text { medications (yes=1 point) } \\
\text { Cognition }\end{array}$ & $49.6 \%$ & $58.3 \%$ & $48.7 \%$ & 0.56 \\
\hline $\begin{array}{l}\text { 10. Memory complaints or dementia } \\
\text { (yes=1 point) }\end{array}$ & $11.0 \%$ & $25.0 \%$ & $9.6 \%$ & 0.13 \\
\hline \multicolumn{5}{|l|}{ Psychosocial } \\
\hline $\begin{array}{l}\text { 11. Experience emptiness (yes }=1 \\
\text { point) }\end{array}$ & $8.7 \%$ & $25.0 \%$ & $7.0 \%$ & 0.07 \\
\hline $\begin{array}{l}\text { 12. Miss people around you (yes }=1 \\
\text { point) }\end{array}$ & $10.2 \%$ & $16.7 \%$ & $9.6 \%$ & 0.35 \\
\hline 13. Feel abandoned (yes=1 point) & $2.4 \%$ & $0 \%$ & $2.6 \%$ & 1.00 \\
\hline $\begin{array}{l}\text { 14. Feel sad or downhearted (yes }=1 \\
\text { point) }\end{array}$ & $13.4 \%$ & $16.7 \%$ & $13.0 \%$ & 0.66 \\
\hline $\begin{array}{l}\text { 15. Feel nervous or anxious (yes }=1 \\
\text { point) }\end{array}$ & $18.1 \%$ & $16.7 \%$ & $18.3 \%$ & 1.00 \\
\hline
\end{tabular}




\section{Results}

\section{Baseline characteristics}

A total of 180 patients underwent surgery for histologically proven gastric carcinoma in the study period of which 125 were operated with curative intent (for characteristics see Table 3). In total 147 (81.7\%) patients underwent surgical resection. Seventy-six patients $(42.2 \%)$ received neoadjuvant chemotherapy. Forty of those patients (52.6\%) were enrolled in the national multicenter CRITICS trial [26]. Overall in-hospital mortality was $8.3 \%(n=15)$ for the entire study population. Table 4 lists the parameters that showed to be significantly different between deceased and non-deceased patients.

For patients with a complete GFI assessment in-hospital mortality was $9.4 \%$ (12 out of 127 ) versus $5.7 \%$ in remaining patients $(P=0.56)$. There was also no significant difference in ASA classification, disease stage and neoadjuvant chemotherapy between patients who did and did not have a complete GFI. Mean age differed significantly of patients with and without $(\mathrm{n}=53,29.4 \%)$ a complete $\mathrm{GFI}(72.2$, range 37 to 83 , and 63.8 , range 40 to 88 , respectively, $\mathrm{P}<0.001)$. In patients under 70 years of age $(n=75) 48 \%$ had a complete GFI compared to $86.7 \%$ in patients over 70 years.

\begin{tabular}{lllc}
\hline \multicolumn{3}{l}{ Table 2. Short Nutritional Assessment Questionnaire and scoring results } \\
\hline Question & $\begin{array}{l}\text { Percentage } \\
\text { answered } \\
(\mathbf{n}=160)\end{array}$ & $\begin{array}{l}\text { Percentage in in- } \\
\text { hospital mortality } \\
(\mathbf{n}=\mathbf{1 5}) \text { vs. alive } \\
\text { patients (n=145) }\end{array}$ & P-value \\
& & $33.3 \% / 53.1 \%$ & 0.18 \\
Did you lose weight unintentionally? & $51.2 \%$ & $20.0 \% / 15.2 \%$ & 0.71 \\
- No (o points) & $15.6 \%$ & $46.7 \% / 31.7 \%$ & 0.26 \\
- More than 3kg in the last month (2 points) & & \\
- More than 6kg in the last 6 months (3 & $33.1 \%$ & $60.0 \% / 40.0 \% *$ & 0.17 \\
points) & & $60.0 \% / 34.5 \% *$ & 0.09 \\
Did you, in the last month: & $41.9 \%^{*}$ & & \\
- Experience a decreased appetite? & & & \\
- Use supplemental drinks or tube feeding? & $36.9 \%^{*}$ & & \\
\hline * Percentage that answered yes (1 point) & &
\end{tabular}

GFI and SNAQ score analysis

Tables 1 and 2 show the GFI and SNAQ scoring results as well as the differences between deceased and non-deceased patients. These results demonstrate that the inability to do independent shopping as well as reporting vision impairment related significantly to surgical mortality. In SNAQ score assessment none of the questions were answered significantly different between deceased and nondeceased patients. In addition, no statistical difference was found in responses on 


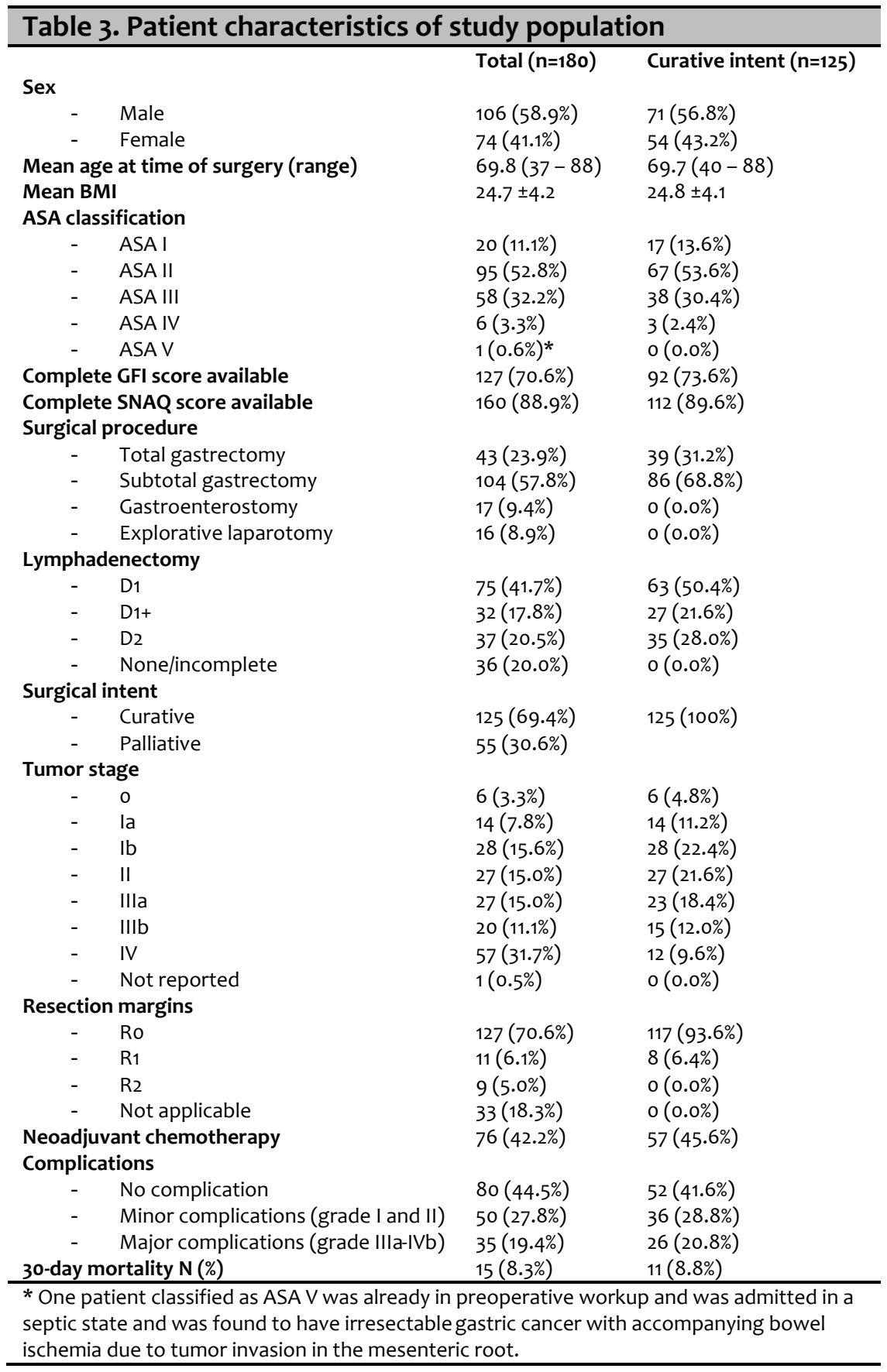




\begin{tabular}{|c|c|c|c|}
\hline \multicolumn{4}{|c|}{$\begin{array}{l}\text { Table 4. Significantly differing patient characteristics between } \\
\text { patients who were alive and who were deceased at } 30 \text {-day } \\
\text { postoperatively }\end{array}$} \\
\hline & $\begin{array}{l}\text { In-hospital } \\
\text { mortality }\end{array}$ & $\begin{array}{l}\text { Alive } \\
\text { postoperatively }\end{array}$ & P-value \\
\hline Total population $(n=180)$ & $\mathrm{n}=15(8.3 \%)$ & $\mathrm{n}=165(91.7 \%)$ & \\
\hline \multicolumn{4}{|l|}{ ASA classification } \\
\hline - ASA I and II & $5(33 \%)$ & $110(67 \%)$ & 0.02 \\
\hline - $\quad$ ASA III to V & $10(67 \%)$ & $55(33 \%)$ & \\
\hline Mean GFI $(n=127)^{*}$ & $4.0 \pm 1.8(n=12)$ & $2.2 \pm 1.9(n=115)$ & 0.002 \\
\hline Neoadjuvant chemotherapy & $2(13 \%)$ & $74(44.8 \%)$ & 0.03 \\
\hline Curative intent surgery $(n=125)$ & $\mathrm{n}=11(8.8 \%)$ & $\mathrm{n}=114$ (91.2\%) & \\
\hline \multicolumn{4}{|l|}{ ASA classification } \\
\hline - ASA I and II & $4(36 \%)$ & $80(70 \%)$ & 0.04 \\
\hline - $\quad$ ASA III to V & $7(64 \%)$ & $34(30 \%)$ & \\
\hline Mean GFI $(n=92)$ & $4.1 \pm 1.9$ & $2.1 \pm 1.8$ & 0.01 \\
\hline Neoadjuvant chemotherapy & $1(9 \%)$ & $56(49 \%)$ & 0.01 \\
\hline
\end{tabular}

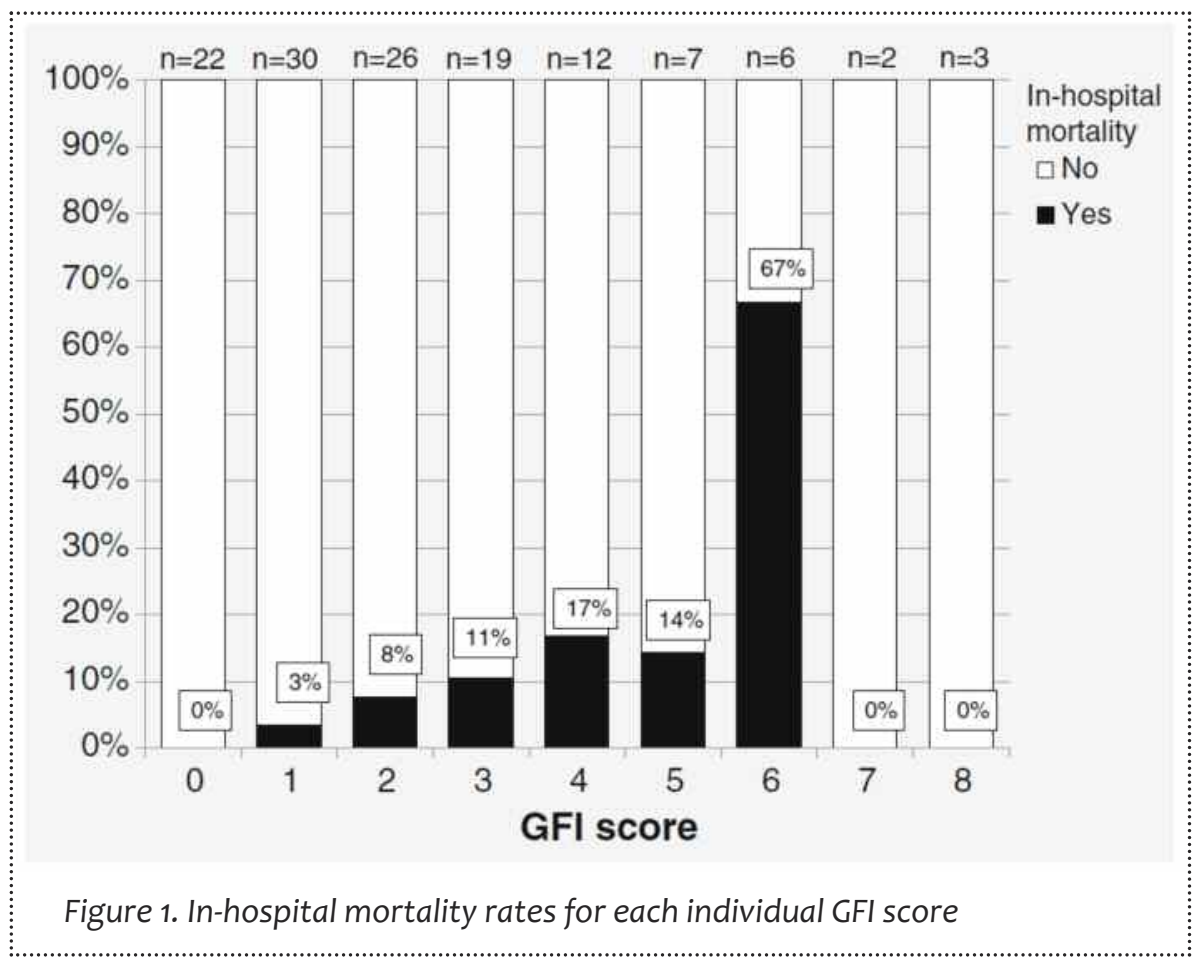




\begin{tabular}{|c|c|c|c|}
\hline \multicolumn{4}{|c|}{$\begin{array}{l}\text { Table 5. Multivariate regression analysis of GFI=3 AND } \\
\text { SNAQ =1 for predicting in-hospital mortality }\end{array}$} \\
\hline Predictor variable & OR & $95 \% \mathrm{Cl}$ & $P$-value \\
\hline $\begin{array}{l}\text { Neoadjuvant } \\
\text { chemotherapy }\end{array}$ & 0.97 & 0.14 to 6.51 & 0.97 \\
\hline ASA (I-II vs. III-V) & 1.23 & 0.32 to 4.84 & 0.65 \\
\hline Resection vs. no resection & 0.35 & 0.04 to 3.20 & 0.35 \\
\hline Stage I-II vs. stage IIIa-IV & 0.47 & 0.11 to 2.05 & 0.32 \\
\hline Age & 1.11 & 1.00 to 1.24 & 0.06 \\
\hline GFI=3 & 3.964 & 1.12 to 14.09 & 0.03 \\
\hline $\mathrm{SNAQ}=1$ & 5.071 & 1.08 to 23.81 & 0.04 \\
\hline $\mathrm{GFI}=3^{*}$ & 4.635 & 1.03 to 20.94 & 0.05 \\
\hline $\mathrm{SNAQ}=1^{*}$ & 4.685 & 0.82 to 26.64 & 0.08 \\
\hline
\end{tabular}

* Analysis restricted to patients operated with curative intent $(\mathrm{n}=125)$

SNAQ between patients who received neoadjuvant chemotherapy and those who did not. In patients who received neoadjuvant treatment ( $n=76,46.3 \%) 44.6 \%$ had no points on their SNAQ versus $33.7 \%$ in patients who did $(n=86,53.7 \%)$, Pvalue $=0.19$.

\section{Univariate analysis}

Mean GFI score for the 12 patients who died postoperatively was $4.0 \pm 1.8$ versus $2.2 \pm 1.9$ for patients who survived $(P=0.002)$. Mortality accumulated with increasing GFI scores and this non-parametric relationship was significant (see Figure 1, $\mathrm{P}=0.004$ ). Optimal discriminative power of the GFI score was reached when a cutoff was chosen at $\mathrm{GFI} \geq 3$ which resulted in a mortality rate in the lower scoring group ( $n=97$ ) of $5.2 \%$ versus $23.3 \%$ in the higher scoring group $(n=30)$ at $P=0.007$. For patients with a complete SNAQ score $(n=160)$ in-hospital mortality was the same as for the patients with a complete GFI i.e. 9.4\%. For SNAQ, optimal discriminative power was achieved at SNAQ $\geq 1$. At $S N A Q \geq 1$ the lower score group $(n=62,38.7 \%)$ had a mortality rate of $3.2 \%$ versus $13.3 \%$ in the higher group $(n=98$, $61.3 \%)$ at $\mathrm{P}=0.05$.

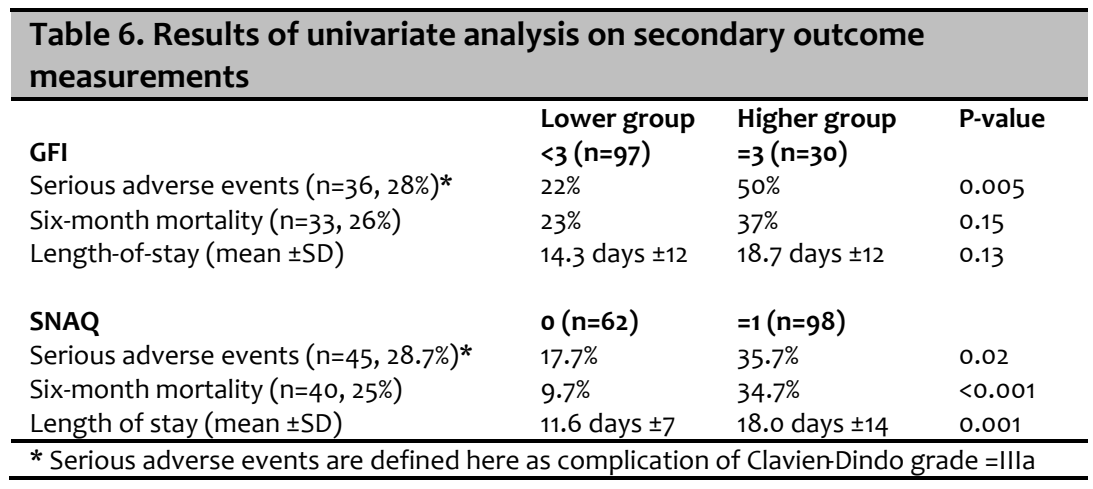




\section{Chapter 3.}

\section{Multivariate analysis}

Multivariate analysis showed a statistically significant association between increasing GFI and in-hospital mortality, OR 1.352 (95\% Cl 1.009 to $1.813, P=0.04$ ) independent of age, ASA-classification, neoadjuvant chemotherapy, type of surgery and tumor stage. Further, GFI $\geq 3$ was statistically significant at OR 3.96 (95\% $\mathrm{Cl} 1.12$ to $14.09, \mathrm{P}=0.03$ ) for predicting in-hospital mortality (Table 5) using binary logistic regression which was also corrected for the parameters as listed above. Age was no predictor of mortality, OR 1.11 ( $95 \% \mathrm{Cl} 1.00$ to 1.24, $\mathrm{P}=0.06)$. We performed separate analyses to evaluate

the predictive value in patients who underwent surgery with curative intent $(n=125)$. This yields similar results in multivariate analysis as presented in Table 5 with OR 4.64 for in-hospital mortality at $\mathrm{GFI} \geq 3$ ( $95 \% \mathrm{Cl} 1.03$ to 20.94, P-value 0.05). A SNAQ $\geq 1$ score was independently associated with in-hospital mortality in multivariate analysis at $\mathrm{OR} 5.1$ ( $95 \% \mathrm{Cl} 1.01$ to $23.8, \mathrm{P}=0.04$ ).

\section{Secondary outcome parameters}

To further assess the predictive qualities of GFI an SNAQ, we also explored the relationship with serious adverse events, length-of-stay and 6-month mortality. Table 6 shows that GFI $\geq 3$ was associated with increased risk of serious adverse events (Clavien-Dindo grade $\geq 3$ a) at $21.6 \%$ in the lower group versus $50 \%$ in the higher group (see also Table 6). This was independent of age, type of surgery, tumor stage, ASA classification and neoadjuvant chemotherapy in multivariate analysis (OR $3.6295 \% \mathrm{Cl} 1.53$ to $8.58, \mathrm{P}=0.04$ ). $\mathrm{GFl} \geq 3$ was not associated with either increased six-month mortality or increased length-of-stay (see Table 6). Contrary to GFI, SNAQ $\geq 1$ is not only significantly associated with in-hospital mortality and serious adverse events but also with six-month mortality and increased length of stay (see Table 6). 


\section{Discussion}

Identifying patients with an elevated risk for postoperative mortality is important in gastric cancer surgery because it can influence preoperative decision making. This retrospective study is the first to show geriatric frailty assessment by GFI as well as nutritional status assessment by SNAQ to predict increased risk of inhospital mortality and complications in patients who undergo surgery for gastric cancer. As multivariate analysis shows, GFI and SNAQ score may have better predictive power to identify patients at risk compared to classical parameters such as age and ASA classification. GFI and SNAQ also were significantly related to complication-rate and six month mortality, underlining their importance in gastric cancer clinical outcome. These data suggest that frailty may be an important parameter in elderly oncological patients who need to undergo major surgical interventions. It also stresses the importance of nutrition in surgery of the upper GI tract and subsequently the need to correct malnutrition pre- and postoperatively.

The first limitation of this study was that this was a retrospective study by design which resulted in incomplete GFI and SNAQ questionnaires. Also the rate of completion of the GFI questionnaire was lower in patients under 70 years of age. The nursing staff was more likely to skip geriatric frailty assessment at admission in younger patients. Further, the number of primary outcome events $(n=15)$ limits statistical analysis which permits logistic regression correction for only one other variable. We did perform the analysis with only two variables entered into logistic regression analysis and this did not affect the results. A further weakness may be that we set cutoffs for GFI and SNAQ score at an optimal discriminative power. This should be confirmed in a larger, independent patient group. Importantly, GFI as a continuous variable showed a significant relationship with the primary outcome events in multivariate analyses. Also, GFI and SNAQ score have never been used to predict surgical outcomes previously.

In recent years frailty has been shown to predict outcomes in surgical patients [13, 14, 27, 28]. Dasgupta et al. used the Edmonton Frail Scale and showed a relationship between frailty and increased risk of complications and increased length of hospitalization [13]. Later Robinson et al. performed a study on elderly patients who underwent major elective surgery that required standard ICU admission postoperatively [14]. They were able to show the predictive value of geriatric assessment makers for frailty (e.g. age, cognitive function, poor nutritional status, falls, depressed mood and anemia) in predicting 6-month postoperative mortality [14]. Other authors showed that frailty is also a predictor for postoperative mortality, surgical complications, increased length of stay and increased six-month healthcare costs [27-29]. The methods for assessing frailty were diverse in these studies and included: questionnaires, history taking, blood tests (e.g. hemoglobin 
and albumin measurements), grip strength measurement and timed get-up-andgo tests.

Due to the retrospective study design GFI was the only recorded available parameter to assess frailty in our patient population. GFI encompasses multiple aspects of frailty contrary to questionnaires/tests that only address single aspects such as diminished ADL functioning or comorbidities (e.g. Lawton IADL, Charlson Comorbidity Index). Compared to other tools such as PRISMA-7, which is also a short questionnaire, GFI is more comprehensive, i.e. encompasses more aspects of frailty. In a recent study GFI was evaluated along with Fried's frailty and PRISMA7 of which the latter showed to be more robust in identifying frail older adults [30]. There are no established instruments to evaluate frailty in specific surgical patient populations. Maybe better, more specific instruments exist compared to GFI however our results show that frailty assessment by GFI is of clinical value. The data suggest that frailty aspects form an important element of preoperative risk assessment in gastric cancer patients.

Another important advantage of GFI and SNAQ questionnaires over other assessment tools (i.e. Edmonton Frail Scale, Short Physical Performance Battery Tests) is that these require no further invasive or physical tests.

SNAQ was evaluated for preoperative detection of malnutrition in 979 surgical patients undergoing various procedures and showed acceptable diagnostic accuracy [20]. Further, SNAQ is associated with prolonged length-of-stay in cardiac surgery patients [19]. As mentioned, SNAQ is used nationwide in the Netherlands to screen hospitalized patients for malnutrition and was recorded in our study's patient's chart and available for our retrospective study.

In conclusion, our study demonstrates that geriatric frailty and nutritional status assessment using a simple questionnaire, i.e. GFI and SNAQ, may be useful tools to improve preoperative assessment and may aid clinical decision making in the future. The better predictive value of frailty over age confirms that age is a nonsensitive and non-specific measure for use in clinical decision making. It indicates the need for a more individual approach in preoperative risk assessment. 


\section{References}

1. Jemal A, Bray F, Center MM, Ferlay J, Ward E, and Forman D, Global cancer statistics. CA Cancer J Clin, 2011. 61(2): p. 69-90.

2. Hartgrink HH, van de Velde CJ, Putter H, Bonenkamp JJ, Klein Kranenbarg E, Songun I, Welvaart K, van Krieken JH, Meijer S, Plukker JT, van Elk PJ, Obertop H, Gouma DJ, van Lanschot JJ, Taat CW, de Graaf PW, von Meyenfeldt MF, Tilanus H, and Sasako M, Extended lymph node dissection for gastric cancer: who may benefit? Final results of the randomized Dutch gastric cancer group trial. J Clin Oncol, 2004. 22(11): p. 2069-77.

3. Saif MW, Makrilia N, Zalonis A, Merikas M, and Syrigos K, Gastric cancer in the elderly: an overview. Eur J Surg Oncol, 2010. 36(8): p. 709-17.

4. Hara H, Isozaki H, Nomura E, Fujii K, Sako S, and Tanigawa N, Evaluation of treatment strategies for gastric cancer in the elderly according to the number of abnormal parameters on preoperative examination. Surg Today, 1999. 29(9): p. 837-41.

5. Lepage C, Sant M, Verdecchia A, Forman D, Esteve J, Faivre J, and group Ew, Operative mortality after gastric cancer resection and long-term survival differences across Europe. Br J Surg, 2010. 97(2): p. 235-9.

6. Nelson H, Predictors of surgical outcomes. J Gastroenterol Hepatol, 2002. 17 Suppl: p. S167-71.

7. de Wilde RF, Besselink MG, van der Tweel I, de Hingh IH, van Eijck CH, Dejong CH, Porte RJ, Gouma DJ, Busch OR, and Molenaar IQ, Impact of nationwide centralization of pancreaticoduodenectomy on hospital mortality. Br J Surg, 2012. 99(3): p. 404-10.

8. Birkmeyer NJ, Goodney PP, Stukel TA, Hillner BE, and Birkmeyer JD, Do cancer centers designated by the National Cancer Institute have better surgical outcomes? Cancer, 2005. 103(3): p. 435-41.

9. van de Poll-Franse LV, Lemmens VE, Roukema JA, Coebergh JW, and Nieuwenhuijzen GA, Impact of concentration of oesophageal and gastric cardia cancer surgery on long-term population-based survival. Br J Surg, 2011. 98(7): p. 956-63.

10. Meyer HJ, The influence of case load and the extent of resection on the quality of treatment outcome in gastric cancer. Eur J Surg Oncol, 2005. 31(6): p. 595-604.

11. Lemmens VE, Bosscha K, van der Schelling G, Brenninkmeijer S, Coebergh JW, and de Hingh IH, Improving outcome for patients with pancreatic cancer through centralization. Br J Surg, 2011. 98(10): p. $1455-62$.

12. Wouters MW, Karim-Kos HE, le Cessie S, Wijnhoven BP, Stassen LP, Steup WH, Tilanus HW, and Tollenaar RA, Centralization of esophageal cancer surgery: does it improve clinical outcome? Ann Surg Oncol, 2009. 16(7): p. 1789-98.

13. Dasgupta M, Rolfson DB, Stolee P, Borrie MJ, and Speechley M, Frailty is associated with postoperative complications in older adults with medical problems. Arch Gerontol Geriatr, 2009. 48(1): p. $78-83$.

14. Robinson TN, Eiseman B, Wallace JI, Church SD, McFann KK, Pfister SM, Sharp TJ, and Moss M, Redefining geriatric preoperative assessment using frailty, disability and co-morbidity. Ann Surg, 2009. 250(3): p. 449-55.

15. Pol RA, van Leeuwen BL, Visser L, Izaks GJ, van den Dungen JJ, Tielliu IF, and Zeebregts CJ, Standardised frailty indicator as predictor for postoperative delirium after vascular surgery: a prospective cohort study. Eur J Vasc Endovasc Surg, 2011. 42(6): p. 824-30.

16. Aaldriks AA, Giltay EJ, le Cessie S, van der Geest LG, Portielje JE, Tanis BC, Nortier JW, and Maartense $\mathrm{E}$, Prognostic value of geriatric assessment in older patients with advanced breast cancer receiving chemotherapy. Breast, 2013.

17. Aaldriks AA, van der Geest LGM, Giltay EJ, le Cessie S, Portielje JEA, Tanis BC, Nortier JWR, and Maartense E, Frailty and malnutrition predictive of mortality risk in older patients with advanced colorectal cancer receiving chemotherapy. Journal of Geriatric Oncology, 2013. 4(3): p. 218-226. 
18. Kruizenga HM, Seidell JC, de Vet HC, Wierdsma NJ, and van Bokhorst-de van der Schueren MA, Development and validation of a hospital screening tool for malnutrition: the short nutritional assessment questionnaire (SNAQ). Clin Nutr, 2005. 24(1): p. 75-82.

19. Lomivorotov VV, Efremov SM, Boboshko VA, Nikolaev DA, Vedernikov PE, Deryagin MN, Lomivorotov VN, and Karaskov AM, Prognostic value of nutritional screening tools for patients scheduled for cardiac surgery. Interact Cardiovasc Thorac Surg, 2013. 16(5): p. 612-8.

20. Neelemaat F, Kruizenga HM, de Vet HC, Seidell JC, Butterman M, and van Bokhorst-de van der Schueren MA, Screening malnutrition in hospital outpatients. Can the SNAQ malnutrition screening tool also be applied to this population? Clin Nutr, 2008. 27(3): p. 439-46.

21. Schuurmans H, Steverink N, Lindenberg S, Frieswijk N, and Slaets JP, Old or frail: what tells us more? J Gerontol A Biol Sci Med Sci, 2004. 59(9): p. M962-5.

22. Heemskerk VH, Lentze F, Hulsewe KW, and Hoofwijk TG, Gastric carcinoma: review of the results of treatment in a community teaching hospital. World J Surg Oncol, 2007. 5: p. 81.

23. Wolters U, Wolf T, Stutzer H, and Schroder T, ASA classification and perioperative variables as predictors of postoperative outcome. Br J Anaesth, 1996. 77(2): p. 217-22.

24. Clavien PA, Barkun J, de Oliveira ML, Vauthey JN, Dindo D, Schulick RD, de Santibanes E, Pekolj J, Slankamenac K, Bassi C, Graf R, Vonlanthen R, Padbury R, Cameron JL, and Makuuchi M, The ClavienDindo classification of surgical complications: five-year experience. Ann Surg, 2009. 250(2): p. $187-96$. 25. Dindo D, Demartines N, and Clavien PA, Classification of surgical complications: a new proposal with evaluation in a cohort of 6336 patients and results of a survey. Ann Surg, 2004. 240(2): p. 205-13.

26. Dikken JL, van Sandick JW, Maurits Swellengrebel HA, Lind PA, Putter H, Jansen EP, Boot H, van Grieken NC, van de Velde CJ, Verheij M, and Cats A, Neo-adjuvant chemotherapy followed by surgery and chemotherapy or by surgery and chemoradiotherapy for patients with resectable gastric cancer (CRITICS). BMC Cancer, 2011. 11: p. 329.

27. Makary MA, Segev DL, Pronovost PJ, Syin D, Bandeen-Roche K, Patel P, Takenaga R, Devgan L, Holzmueller CG, Tian J, and Fried LP, Frailty as a predictor of surgical outcomes in older patients. J Am Coll Surg, 2010. 210(6): p. 901-8.

28. Saxton A and Velanovich $\mathrm{V}$, Preoperative frailty and quality of life as predictors of postoperative complications. Ann Surg, 2011. 253(6): p. 1223-9.

29. Robinson TN, Wu DS, Stiegmann GV, and Moss M, Frailty predicts increased hospital and six-month healthcare cost following colorectal surgery in older adults. Am J Surg, 2011. 202(5): p. 511-4.

30. Hoogendijk EO, van der Horst HE, Deeg DJ, Frijters DH, Prins BA, Jansen AP, Nijpels G, and van Hout $\mathrm{HP}$, The identification of frail older adults in primary care: comparing the accuracy of five simple instruments. Age Ageing, 2013. 42(2): p. 262-5. 


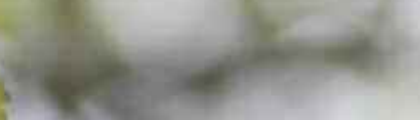

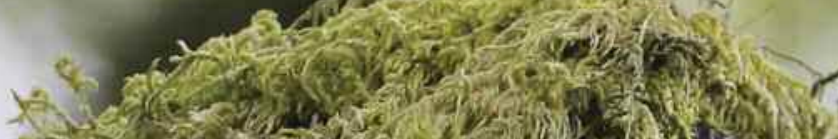

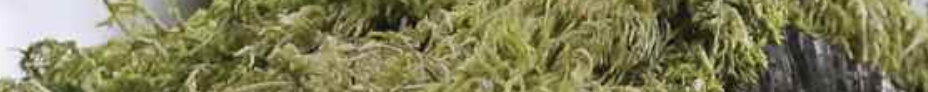
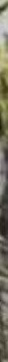

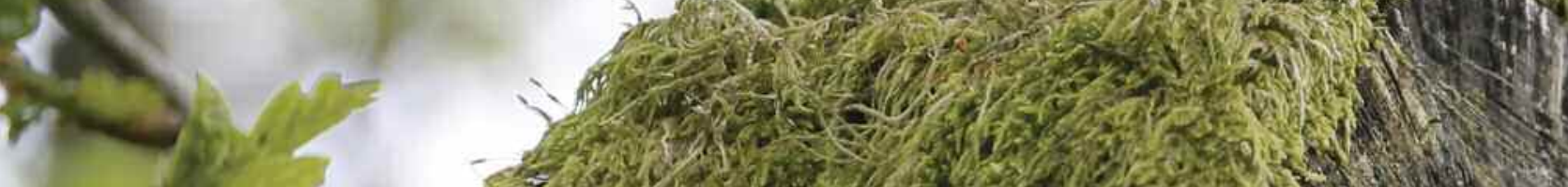
L

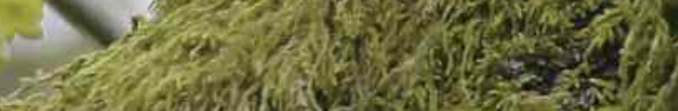

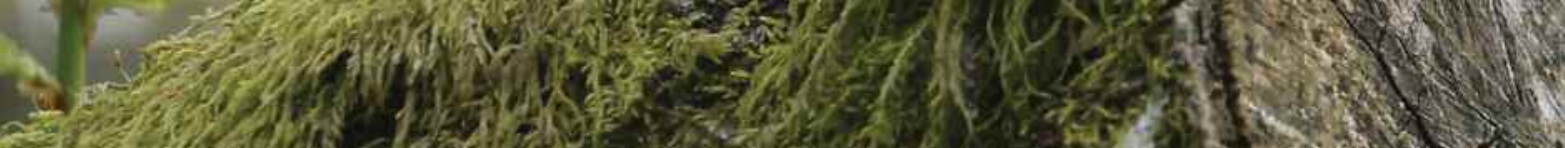

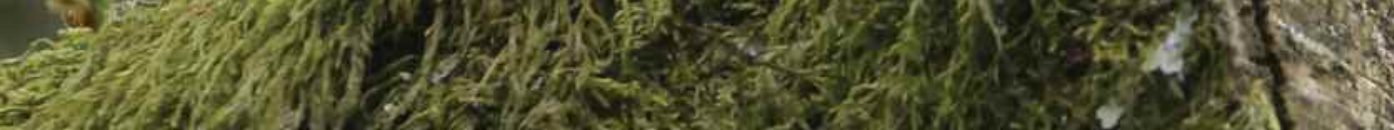

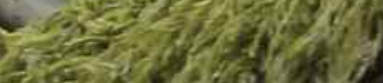

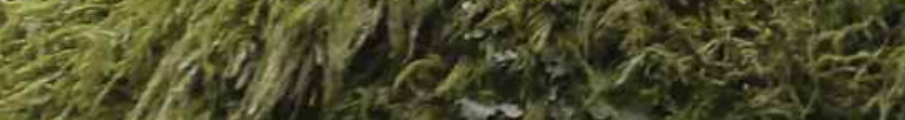

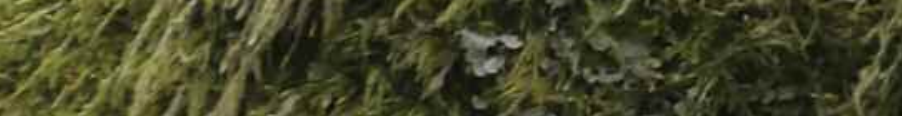

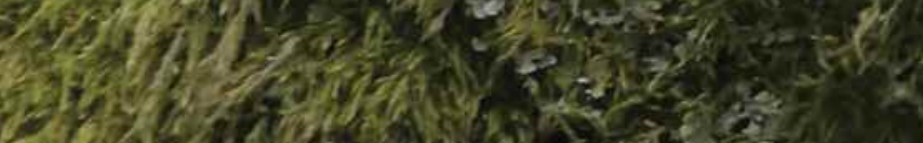

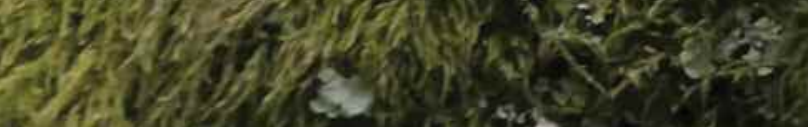

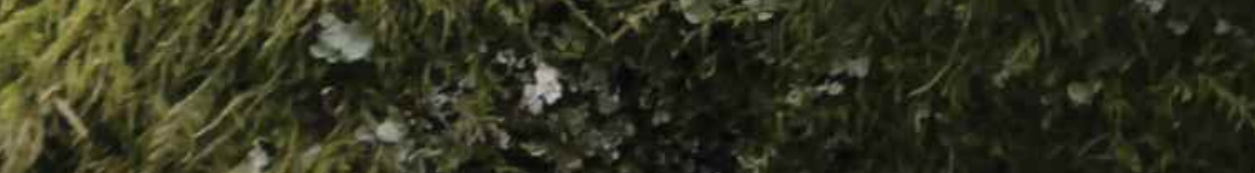

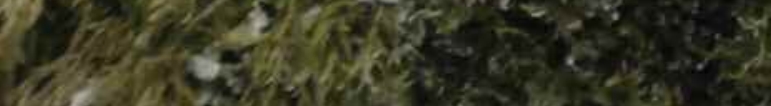

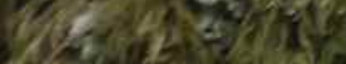

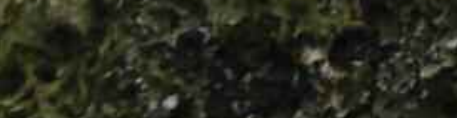

$$
\begin{aligned}
& \text { 48 }
\end{aligned}
$$

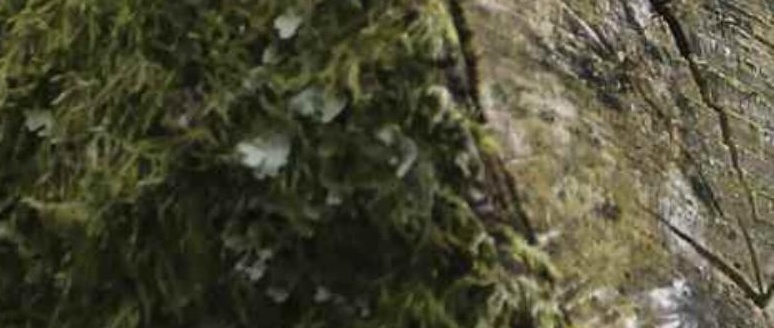

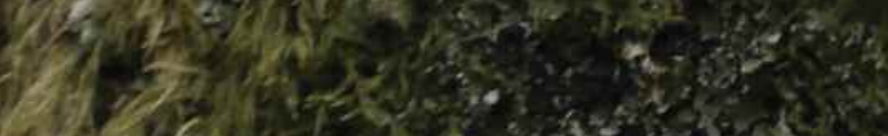

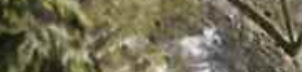

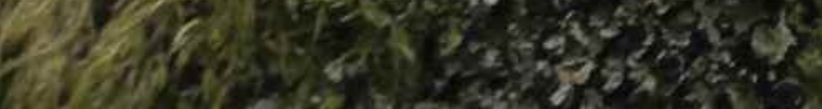


Sarcopenia is highly prevalent in patients undergoing surgery for gastric cancer but not associated with worse outcomes

\title{
Chapter 4
}

\author{
Juul J.W. Tegels \\ Jeroen L.A. van Vugt \\ Kostan W. Reisinger \\ Karel W.E. Hulsewé \\ Ton G.M. Hoofwijk \\ Joep P.M. Derikx \\ Jan H.M.B. Stoot
}

\footnotetext{
Published in

Journal of Surgical Oncology
}

August 2015 


\section{Abstract}

\section{Objectives}

Aim of this study was to assess the prevalence of sarcopenia and body composition (i.e., subcutaneous and visceral fat) in gastric cancer surgical patients and its association with adverse postoperative outcome.

\section{Methods}

Preoperative CT-scans were obtained from all patients who underwent surgery for gastric adenocarcinoma between January 2005 and September 2012. Total muscle and adipose tissue cross-sectional area were measured at the level of the third lumbar vertebra (L3) transverse processes. Sarcopenia was defined according to gender and Body Mass Index (BMI) specific cutoff points. Primary outcome was in-hospital mortality. Secondary outcomes were severe postoperative complications (i.e. Clavien-Dindo classification $\geq 3$ a complications) and six-month mortality.

\section{Results}

In 152 out of a total of 180 (84.4\%) patients a CT-scan was available for analysis. In total, $86(57.7 \%)$ of the patients were classified as sarcopenic. Sarcopenia was no predictor for in-hospital mortality $(p=0.52)$, severe complications $(p=1.00)$ or sixmonth mortality $(p=0.69)$. Intraabdominal and subcutaneous adipose tissue measurements were not associated with in-hospital mortality, severe complications or six-month mortality.

\section{Conclusions}

In this population of gastric cancer surgical patients the prevalence of sarcopenia was $57.7 \%$, which is high compared to other abdominal surgical oncology populations. However, sarcopenia was not associated with postoperative morbidity or mortality. 


\section{Introduction}

The incidence of cancer is rising, as well as the average age of the patients. Data from the Dutch Upper GI Cancer Audit (DUCA) show that 35\% and 29\% of the patients undergoing surgery for gastric cancer in the Netherlands in 2013 were over 75 and 80 years of age respectively (http://www.clinicalaudit.nl/ jaarrapportage/2013/). Gastric cancer surgery is associated with relatively high postoperative morbidity and mortality. Elderly patients are at an increased risk for impaired postoperative recovery [1]. Therefore, developing tools to identify patients with an increased operative risk is of great importance. Ideally, such a tool represents the patient's physiological reserves, which hypothetically should better predict postoperative outcome than traditional risk factors (e.g., age, ASA classification, comorbidities).

Biological age rather than chronological age and so-called analytic morphomics increasingly gained interest in the last years [2,3]. A main determinant of biological age is frailty, a state of increased vulnerability towards stressors in older individuals, leading to an increased risk of developing adverse health outcomes [4]. As shown recently, frailty is an independent predictor of mortality after gastric cancer surgery [5].

Recent studies postulated an association between low skeletal muscle mass, which is closely related to sarcopenia syndrome, and both short and long term outcomes in patients undergoing surgery for gastrointestinal malignancies [6-8]. Moreover, the amount of visceral fat has been identified as a predictor for postoperative course after colorectal surgery [9]. The relationship between body composition and postoperative outcome in gastric cancer populations has not yet been investigated.

Therefore, the aim of the present study was to assess sarcopenia and body composition in gastric cancer surgical patients and to investigate its association with adverse postoperative outcome. 


\section{Methods}

\section{Patients}

All patients who underwent surgery for gastric adenocarcinoma in Orbis Medical Centre (tertiary referral centre for gastric cancer surgery since 2009) from January 2005 to September 2012 were included this study. Patient characteristics (e.g. age, sex and BMI), tumour characteristics (e.g., type and stage), surgical parameters (e.g., estimated blood loss and resection margins) and preoperative treatment (e.g., neoadjuvant chemotherapy) were retrospectively collected from the electronic health record system [10]. Preoperative comorbidities were classified according to the American Society of Anesthesiologists (ASA) classification [11].

\section{Imaging studies}

Patients underwent contrast-enhanced abdominal computed tomography (CT) as part of routine preoperative work-up. Although all perioperative CT-studies (i.e., closest to time of surgery) were collected only preoperative CT-studies were used in the primary analysis. For patients who had been referred from other centres attempts were made to obtain these imaging studies. For patients who received neoadjuvant chemotherapy CT-imaging before and after neoadjuvant treatment were obtained if possible.

\section{Assessment of skeletal muscle- and adipose tissue surface}

Imaging studies were analyzed using OsiriX5.5.2 open-source software. Measurements of the surface area were performed on transverse slides at the caudal level of third lumbar vertebra (L3) where both transverse processes were visible. Two consecutive slides were analyzed and averaged. Measurements were executed in a semi-automated fashion by setting the tissue of interest threshold at -30 to +110 Hounsfield Units (HU) for skeletal muscle and -190 to $-30 \mathrm{HU}$ for adipose tissue [12]. Automatically generated tissue of interest outlines were corrected manually when needed. Total cross-sectional area was calculated automatically and presented in square centimetres. Two medically trained investigators (JJWT, JLAVV) independently carried out the image analysis and were blinded for each other's measurements as well as patient outcome. In cases of disagreement a third investigator (KWR) repeated the measurements. Crosssectional muscle area measurements were corrected for patient height resulting in $\mathrm{L} 3$ muscle index $(\mathrm{cm} 2 / \mathrm{m} 2)$.

Sarcopenia was defined based on internationally accepted BMI and sexe specific cutoff values: $43 \mathrm{~cm} 2 / \mathrm{m}_{2}$ for males with $B M I<25.0 \mathrm{~cm} 2 / \mathrm{m}_{2}$ and $53 \mathrm{~cm} 2 / \mathrm{m}_{2}$ for males with $\mathrm{BMI} \geq 25.0$, in females threshold for sarcopenia was $41 \mathrm{~cm} 2 / \mathrm{m} 2$ [13]. The 
European Working Group on Sarcopenia in Older People (EWGSOP) requires low gait speed or low grip strength in addition to low muscle mass for finding sarcopenia in older individuals [14]. Strictly speaking low muscle mass will be measured rather than sarcopenia, but henceforth we shall call this sarcopenia since similar studies have used the same technique and nomenclature [6, 15-18]. The cutoff value for visceral fat area was set at $163.8 \mathrm{~cm} 2$ for males and $80.1 \mathrm{~cm} 2$ for females [19]. For subcutaneous fat no internationally accepted cutoff values have been defined yet.

\section{Outcome variables}

The primary outcome measure was in-hospital mortality. Data regarding length of hospital stay as well as the nature and severity of complications were also collected. Severity of the complications was classified according to the ClavienDindo classification and severe postoperative complications were defined as Clavien-Dindo $\geq 3 a[20,21]$. Six-month mortality was identified by accessing the municipal administration database using the patients' Social Security number six months after surgery.

\section{Statistical analysis}

Frequencies are presented as absolute numbers and percentages. Continuous data are presented as mean with standard deviation ( \pm SD). Normality of data was tested using the Kolmogorov-Smirnov test. Differences between groups were analyzed using the Pearson Chi-square test for dichotomous variables and Student $\mathrm{t}$-test or Mann-Whitney $\mathrm{U}$ test for continuous variables, depending on normality. Two-tailed $p$-values $<0.05$ were considered statistically significant. Statistical analyses were performed using SPSS Statistics 20 (IBM Corp., Chicago, IL,USA). 


\begin{tabular}{|c|c|c|c|}
\hline & & Total $(n=180)$ & $\begin{array}{l}\text { Preoperative } \\
\text { Computed } \\
\text { Tomography available } \\
(\mathrm{n}=152,84.4 \%)^{*}\end{array}$ \\
\hline \multicolumn{4}{|r|}{ - } \\
\hline- & Male & $106(58.9 \%)$ & $87(57.2 \%)$ \\
\hline - & Female & $74(41.1 \%)$ & $65(42.8 \%)$ \\
\hline Mean a & at time of surgery (range) & $69.8(37-88)$ & $69.6(37-88)$ \\
\hline Mean $\mathrm{E}$ & & $24.7 \pm 4.2$ & $24.5 \pm 4.1$ \\
\hline \multicolumn{4}{|c|}{ ASA classification } \\
\hline- & ASA I & $20(11.1 \%)$ & $18(11.8 \%)$ \\
\hline - & ASA II & $95(52.8 \%)$ & $80(52.6 \%)$ \\
\hline- & ASA III & $58(32.2 \%)$ & $50(32.9 \%)$ \\
\hline - & ASA IV & $6(3.3 \%)$ & $4(2.6 \%)$ \\
\hline - & ASA V & $1(0.6 \%)^{* *}$ & $0(0.0 \%)^{* *}$ \\
\hline \multicolumn{4}{|c|}{ Surgical procedure } \\
\hline- & Total gastrectomy & $43(23.9 \%)$ & $40(26.3 \%)$ \\
\hline- & Subtotal gastrectomy & $104(57.8 \%)$ & $84(55 \cdot 3 \%)$ \\
\hline - & Gastroenterostomy & $17(9.4 \%)$ & $15(9.9 \%)$ \\
\hline & Explorative laparotomy & $16(8.9 \%)$ & $13(8.6 \%)$ \\
\hline \multicolumn{4}{|c|}{ Lymphadenectomy } \\
\hline- & D1 & $75(41.7 \%)$ & $59(38.8 \%)$ \\
\hline- & D1+ & $32(17.8 \%)$ & $30(19.7 \%)$ \\
\hline - & D2 & $37(20.5 \%)$ & $34(22.4 \%)$ \\
\hline- & None/incomplete & $36(20.0 \%)$ & $29(19.1 \%)$ \\
\hline \multicolumn{4}{|c|}{ Surgical intent } \\
\hline- & Curative & $125(69.4 \%)$ & $106(69.7 \%)$ \\
\hline & Palliative & $55(30.6 \%)$ & $46(30.3 \%)$ \\
\hline \multicolumn{4}{|c|}{ Tumour stage } \\
\hline- & 0 & $6(3.3 \%)$ & $4(2.6 \%)$ \\
\hline - & la & $14(7.8 \%)$ & $11(7.2 \%)$ \\
\hline - & lb & $28(15.6 \%)$ & $24(15.8 \%)$ \\
\hline - & II & $27(15.0 \%)$ & $25(16.4 \%)$ \\
\hline- & IIla & $27(15.0 \%)$ & $21(13.8 \%)$ \\
\hline - & IIIb & $20(11.1 \%)$ & $19(12.5 \%)$ \\
\hline - & IV & $57(31.7 \%)$ & $47(30.9 \%)$ \\
\hline- & Not reported & $1(0.5 \%)$ & $1(0.7 \%)$ \\
\hline \multicolumn{4}{|c|}{ Resection margins } \\
\hline- & Ro & $127(70.6 \%)$ & $109(71.7 \%)$ \\
\hline - & R1 & $11(6.1 \%)$ & $9(5.9 \%)$ \\
\hline- & R2 & $9(5.0 \%)$ & $10(6.6 \%)$ \\
\hline & Not applicable & $33(18.3 \%)$ & $24(15.8 \%)$ \\
\hline \multirow{2}{*}{\multicolumn{4}{|c|}{ Complications }} \\
\hline & & & \\
\hline- & No complication & $80(44.5 \%)$ & $64(42.1 \%)$ \\
\hline- & Minor complications (grade I and II) & $50(27.8 \%)$ & $47(30.9 \%)$ \\
\hline - & Major complications (grade IIIa-IVb) & $35(19.4 \%)$ & $30(19.7 \%)$ \\
\hline \multicolumn{4}{|c|}{$\begin{array}{l}\text { In-hospital mortality N }(\%) \\
* * \text { One patient classified as ASA V was already in preoperative workup and was admitted in a } \\
\text { septic state and was found to have irresectable gastric cancer with accompanying bowel } \\
\text { ischemia due to tumour invasion in the mesenteric root. }\end{array}$} \\
\hline
\end{tabular}




\section{Results}

\section{Baseline characteristics}

A total of 180 patients underwent surgery in the studied timeframe. Overall inhospital mortality was $8.3 \%(n=15)$; all of these patients died within 30 days postoperatively (i.e., 30-day mortality). A preoperative CT-scan was available in 152 (84.4\%) patients; their characteristics are presented in Table 1. No significant differences were found in baseline characteristics between patients with and without preoperative CT-scan. A total of 106 (69.7\%) patients underwent surgery with curative intent. A total of 76 patients (42.2\%) received neoadjuvant chemotherapy of whom 40 patients (52.6\%) were enrolled in the multicentre CRITCS trial [22].

Characteristics of the preoperative CT-scans are represented in Table 2. The mean time between CT-imaging and surgery was $40( \pm 26)$ days before surgery. In 43 $(56.6 \%)$ of the patients who received neoadjuvant treatment a second (i.e., pretreatment) CT-study was available. A decrease of $\mathrm{L} 3$ muscle index was seen in 29 $(67.4 \%)$ of these patients (mean decrease $-4.8 \mathrm{~cm} 2 / \mathrm{m}_{2} \pm 3.0$ range -11 to $0.55 \mathrm{~cm} 2 / \mathrm{mz})$. The remaining $14(32.6 \%)$ patients had an mean increase of 2.5 $\mathrm{cm} 2 / \mathrm{m} 2 \pm 2.7$ range 0.0 to $7.75 \mathrm{~cm} 2 / \mathrm{m} 2$.

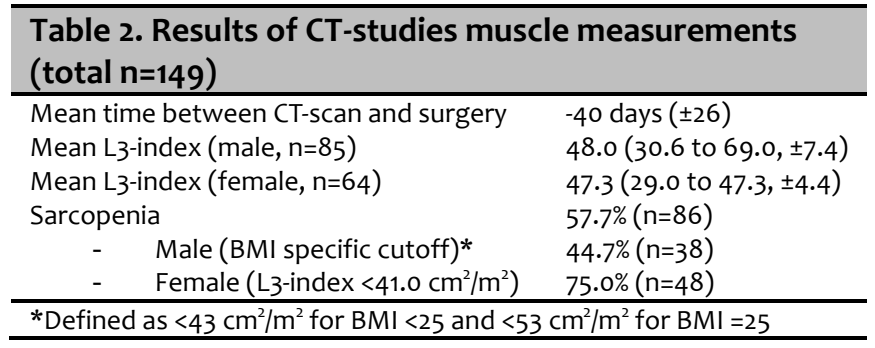

Skeletal muscle mass and postoperative morbidity and mortality

Sarcopenia was present in $57.7 \%(n=86)$ of patients $44.7 \%$ in men and $75.0 \%$ in women. Patients with advanced stage of disease (i.e., stage Illa or greater, $n=86$ ), $54.7 \%$ were sarcopenic versus $61.9 \%$ in early stage disease (i.e. stage I or II, $n=63$ ). Out of 152 patients with an available preoperative CT-scan no height was recorded in three patients. Therefore $L 3$ muscle index could not be calculated for these patients.

Overall in-hospital mortality in patients with an available preoperative CT-scan was $7.2 \%(n=11)$. Six of these patients died due to sepsis and (multi-)organ failure as a result of an abdominal complication (e.g., intra-abdominal abscess, anastomotic leakage). Four patients died as a result of cardiopulmonary complications (e.g., 


\begin{tabular}{llll}
\hline \multicolumn{4}{c}{ Table 3. Analysis of sarcopenia and outcome measurements (total $\mathbf{n = 1 4 9 )}$} \\
\hline & Sarcopenic & Non-sarcopenic & $\begin{array}{l}\text { - } \\
\text { value } \\
\end{array}$ \\
& $(\mathrm{n}=86)$ & $(\mathrm{n}=63)$ & 0.519 \\
In-hospital mortality $(6.7 \%, \mathrm{n}=10)$ & $8.1 \%(\mathrm{n}=7)$ & $4.8 \%(\mathrm{n}=3)$ & 1.000 \\
Serious adverse events $(27.8 \%, \mathrm{n}=44) *$ & $26.7 \%(\mathrm{n}=23)$ & $27.0 \%(\mathrm{n}=17)$ & 0.509 \\
Length-of-stay $(15$ days \pm 12$)$ & 16 days \pm 14 & 15 days \pm 9 & 0.688 \\
Six-month mortality $(21.5 \%, \mathrm{n}=34)$ & $22.1 \%(\mathrm{n}=19)$ & $19.0 \%(\mathrm{n}=12)$ & \\
\hline * Defined as Clavien-Dindo grade $=3 a$ & & & \\
\hline
\end{tabular}

respiratory insufficiency or congestive heart failure). In one patients the cause of death remained unknown.

No statistically significant difference was found for in-hospital mortality between patients with and without sarcopenia $(8.1 \%(n=7)$ and $4.8 \%(n=3)$ respectively, $\mathrm{p}=0.519)$. In-hospital mortality and the secondary outcome parameters are shown in Table 3. No significant differences in serious adverse events (i.e. Clavien-Dindo classification $\geq 3$ a), length of hospital stay and six-month mortality were shown in patients with sarcopenia and non-sarcopenic patients (see Table 3). Moreover, no differences were found for infectious complications (31.4\% vs. 36.5\%, $\mathrm{p}=0.599$ ) or minor complications (i.e., Clavien-Dindo grade 1 or 2 at $33.7 \%$ vs. $28.6 \%, p=0.772$ ). When analyses were restricted to patients who underwent resection $(n=129)$ similar results were found in non-sarcopenic and sarcopenic patients with regards to in-hospital mortality ( $5.3 \%$ vs. $9.7 \%, p=0.511)$, serious

adverse events ( $31.6 \%$ vs. $26.4 \%, p=0.560)$, six-month mortality $(12.3 \%$ vs. $16.7 \%$, $\mathrm{p}=0.619$ ) and hospital stay (16.9 vs. 15.6 days, $\mathrm{p}=0.571$ ).

Various separate analyses, restricted to men or women, for abovementioned outcomes and sarcopenia did not yield any different results. Also, similar result were obtained when analyses were restricted to patients who underwent resection with curative intent $(n=104)$ or restricted to palliative intent $(n=45)$.

In patients who received neoadjuvant chemotherapy, no differences were found for mean change in L3-index with regard to in-hospital mortality, serious adverse events and six-month mortality.

\begin{tabular}{|c|c|c|c|}
\hline \multicolumn{4}{|c|}{$\begin{array}{l}\text { Table 4. Analysis of subcutaneous fat area (SFA) in } \mathrm{cm}^{2} \text { and outcome } \\
\text { (total } \mathrm{n}=152 \text { ) }\end{array}$} \\
\hline In-hospital mortality & Mean SFA & SD (range) & $\begin{array}{l}\boldsymbol{p} \text {-value } \\
0.080\end{array}$ \\
\hline - $\quad$ Alive $(\mathrm{n}=141)$ & 148 & \pm 77 (o to 435$)$ & \\
\hline - $\quad$ Deceased $(n=11)$ & 106 & $\pm 47(10$ to 184$)$ & \\
\hline Serious adverse events* & & & 0.376 \\
\hline - $\quad$ Clavien-Dindo grade $=2(n=111)$ & 146 & \pm 73 (o to 435$)$ & \\
\hline - Clavien-Dindo grade $=3 a(n=41)$ & 135 & \pm 83 (o to 340$)$ & \\
\hline Six-month mortality & & & 0.001 \\
\hline - $\quad$ Alive $(\mathrm{n}=119)$ & 155 & \pm 74 ( 15 to 435$)$ & \\
\hline Deceased $(n=33)$ & 108 & $\pm 70(0$ to 261$)$ & \\
\hline
\end{tabular}


Adipose tissue surface area and postoperative morbidity and mortality

Mean intraabdominal adipose tissue surface area was not significantly different between patients who deceased in-hospital or within six months postoperatively compared to patients who survived $(p=0.483$ and $p=0.409$ respectively). No statistically significant differences were found between patients who had a high visceral fat area and those who did not with respect to in-hospital mortality, serious adverse events or six-month mortality $(p=0.577, p=0.861$ and $p=0.575$ respectively). With regard to six-month mortality, the mean subcutaneous fat area was significantly different between patients who were alive and deceased, $155.5( \pm 74.3)$ $\mathrm{cm} 2$ and $108.0( \pm 70.0) \mathrm{cm} 2$ respectively $(\mathrm{p}=0.001)$, see Table 4 . No significant difference in mean subcutaneous fat was found for in-hospital mortality or serious adverse events (Table 4). In multivariable analysis using binary logistic regression when patient age, ASA-classification and tumour stage were also included, tumour stage was independently associated with six-month mortality (OR 5.9, 95\% Cl 2.1 to $16.2, p=0.001$ ) but not subcutaneous fat area (OR $0.99,95 \% \mathrm{Cl} 0.99$ to 1.00 ). 


\section{Discussion}

This study showed a high prevalence of sarcopenia $57.7 \%$ (44.7\% in men and $75.0 \%$ in women) in gastric cancer patients undergoing surgery. There is a clear difference between the prevalence of sarcopenia in this study (i.e. $57.7 \%$ ) and previously published studies (16 to $47.7 \%$ ) $[6,7,16-18,23,24]$. However, no association between sarcopenia and in-hospital mortality, serious adverse events, length of hospital stay or six-month mortality was found in this study.

Results from this study are in contrast with previously published studies on sarcopenia in other distinct surgical oncologic populations. For example, sarcopenia was associated with both short term (i.e. complications and perioperative mortality) and long term outcome (i.e., survival) after surgery for colorectal liver metastases $[6,18]$. However, not all published studies unequivocally show this association between sarcopenia and outcome. For example, one study showed a significant increase in major complications in women after radical cystectomy for bladder cancer but not in men [24]. Importantly, a recent study in patients undergoing surgery for colorectal liver metastases also did not show an association between sarcopenia and complications, disease free survival or overall survival [25].

Sarcopenia is a complex syndrome with multiple mechanisms contributing to its development [26]. Several factors that contribute to the development of sarcopenia are likely to be found in gastric cancer patients. Malnutrition might be one of the most important contributors. Gastric cancer patients are at high risk for malnutrition, which is reported as high as $85 \%$ [27]. This might be due to dysphagia, nausea or mechanical obstruction. Adequate protein intake is also essential for maintaining muscle mass and inadequate intake of protein is another important cause of sarcopenia [26]. A decline in nutritional intake plays a prominent role in development of sarcopenia in elderly individuals [28]. In conjunction with malnutrition, and subsequent decreased protein intake, the risk for sarcopenia in gastric cancer patients is probably high. Data from this study support this hypothesis. Decreased activity is also another important cause of sarcopenia. It remains to be investigated whether tumour related factors also contribute to the development of sarcopenia in gastric cancer patients. Higher age, low albumin levels and weight loss, which are all factors that are related to sarcopenia, have been identified as risk factors for increased morbidity and mortality after gastrectomy for gastric cancer [29-31]. The combination of decreased activity, declined nutritional and protein intake, and higher age probably result in a high rate of sarcopenia in gastric cancer patients.

The explanation for the difference in the effect of sarcopenia on postoperative outcome in gastric cancer patients compared to other gastrointestinal malignancies has to be elucidated. One might postulate that the majority of gastric 
cancer patients have such a high degree of malnutrition and energy depletion that the presence of sarcopenia does not have a measurable effect in this population. An alternative preoperative assessment might be a multiscale evaluation of geriatric frailty and nutritional status, for example assessed with the Groningen Frailty Indicator (GFI) questionnaire and Short Nutritional Assessment Questionnaire (SNAQ), an easy and low cost method. This has been shown to predict adverse outcome after gastric cancer surgery in a recent study [5]. It was previously shown that the combination of preoperative skeletal muscle mass assessment with the SNAQ and GFI predicted adverse outcome after colorectal cancer surgery [23]. Loss of skeletal muscle mass, rather than muscle mass, has been found to be of prognostic value in oesophageal cancer patients and might better predict for adverse outcome after surgery [32].

Adipose tissue measurements showed that patients with six-month mortality had a significantly lower amount of subcutaneous adipose tissue. This might also be an indicator of lower physiological reserves and therefore put these patients at an increased risk for an adverse outcome. Previous studies have investigated the relationship between adipose tissue surface area and outcome. In one study low visceral fat area was associated with worse oncological outcome after resection for hepatocellular carcinoma [33]. Furthermore, the amount of perirenal fat has been identified as a marker for intraabdominal fat and was associated with postoperative complications in elective colorectal surgery [34]. In conjunction with results from this study another study in gastric cancer surgery patients also did not show differences in outcome in association with visceral adipose tissue [35]. Although this is the first study investigating skeletal muscle mass in gastric cancer patients, it is limited by its retrospective design. Not all CT imaging studies were available for analysis in all patients, since the study was conducted in a tertiary referral centre. Despite efforts to retrospectively obtain missing CT studies data was available in $152(84.4 \%)$ cases. However, these patients were not statistically different from the total population. Also, the sample of patients who had two CTscans prior to and after neoadjuvant chemotherapy was too limited to perform adequate statistical analysis.

In conclusion, this single centre study is the first to show that sarcopenia is highly prevalent in patients undergoing surgery for gastric cancer. In contrast to previous studies among various gastrointestinal cancer populations sarcopenia was not associated with worse outcome after surgery. Visceral adiposity was also not associated with worse outcome. Future studies are needed to determine the usefulness of preoperative body composition measurements in gastric cancer patients. 
Chapter 4.

\section{Acknowledgments}

We thank Surgical Oncological Network Limburg (SONL) for their regional collaboration in centralization of gastric cancer surgical care. 


\section{References}

1. Takeshita H, Ichikawa D, Komatsu S, Kubota T, Okamoto K, Shiozaki A, Fujiwara H, and Otsuji E, Surgical outcomes of gastrectomy for elderly patients with gastric cancer. World J Surg, 2013. 37(12): p. 2891-8.

2. Leo S, Accettura C, Gnoni A, Licchetta A, Giampaglia M, Mauro A, Saracino V, and Carr BI, Systemic treatment of gastrointestinal cancer in elderly patients. J Gastrointest Cancer, 2013. 44(1): p. $22-32$.

3. Englesbe MJ, Lee JS, He K, Fan L, Schaubel DE, Sheetz KH, Harbaugh CM, Holcombe SA, Campbell DA, Jr., Sonnenday CJ, and Wang SC, Analytic morphomics, core muscle size, and surgical outcomes. Ann Surg, 2012. 256(2): p. 255-61.

4. Fried LP, Hadley EC, Walston JD, Newman AB, Guralnik JM, Studenski S, Harris TB, Ershler WB, and Ferrucci L, From bedside to bench: research agenda for frailty. Sci Aging Knowledge Environ, 2005. 2005(31): p. pe24.

5. Tegels JJ, de Maat MF, Hulsewe KW, Hoofwijk AG, and Stoot JH, Value of geriatric frailty and nutritional status assessment in predicting postoperative mortality in gastric cancer surgery. J Gastrointest Surg, 2014. 18(3): p. 439-45; discussion 445-6.

6. Peng PD, van Vledder MG, Tsai S, de Jong MC, Makary M, Ng J, Edil BH, Wolfgang CL, Schulick RD, Choti MA, Kamel I, and Pawlik TM, Sarcopenia negatively impacts short-term outcomes in patients undergoing hepatic resection for colorectal liver metastasis. HPB (Oxford), 2011. 13(7): p. 439-46.

7. Peng P, Hyder O, Firoozmand A, Kneuertz P, Schulick RD, Huang D, Makary M, Hirose K, Edil B, Choti MA, Herman J, Cameron JL, Wolfgang CL, and Pawlik TM, Impact of sarcopenia on outcomes following resection of pancreatic adenocarcinoma. J Gastrointest Surg, 2012.16(8): p. 1478-86.

8. Tan BH, Birdsell LA, Martin L, Baracos VE, and Fearon KC, Sarcopenia in an overweight or obese patient is an adverse prognostic factor in pancreatic cancer. Clin Cancer Res, 2009. 15(22): p. 6973-9.

9. Tsujinaka S, Konishi F, Kawamura YJ, Saito M, Tajima N, Tanaka O, and Lefor AT, Visceral obesity predicts surgical outcomes after laparoscopic colectomy for sigmoid colon cancer. Dis Colon Rectum, 2008. 51(12): p. 1757-65; discussion 1765-7.

10. Derikx JP, Erdkamp FL, and Hoofwijk AG, [The electronic health record: computerised provider order entry and the electronic instruction document as new functionalities]. Ned Tijdschr Geneeskd, 2013. 157(34): p. A5695.

11. Wolters U, Wolf T, Stutzer H, and Schroder T, ASA classification and perioperative variables as predictors of postoperative outcome. Br J Anaesth, 1996. 77(2): p. 217-22.

12. Mitsiopoulos N, Baumgartner RN, Heymsfield SB, Lyons W, Gallagher D, and Ross R, Cadaver validation of skeletal muscle measurement by magnetic resonance imaging and computerized tomography. J Appl Physiol (1985), 1998. 85(1): p. 115-22.

13. Martin L, Birdsell L, Macdonald N, Reiman T, Clandinin MT, McCargar L, Murphy R, Ghosh S, Sawyer $\mathrm{MB}$, and Baracos VE, Cancer cachexia in the age of obesity: skeletal muscle depletion is a powerful prognostic factor, independent of body mass index. J Clin Oncol, 2013. 31(12): p. 1539-47.

14. Cruz-Jentoft AJ, Baeyens JP, Bauer JM, Boirie Y, Cederholm T, Landi F, Martin FC, Michel JP, Rolland Y, Schneider SM, Topinkova E, Vandewoude M, Zamboni M, and European Working Group on Sarcopenia in Older P, Sarcopenia: European consensus on definition and diagnosis: Report of the European Working Group on Sarcopenia in Older People. Age Ageing, 2010. 39(4): p. 412-23.

15. Dello SA, Lodewick TM, van Dam RM, Reisinger KW, van den Broek MA, von Meyenfeldt MF, Bemelmans $\mathrm{MH}$, Olde Damink SW, and Dejong $\mathrm{CH}$, Sarcopenia negatively affects preoperative total functional liver volume in patients undergoing liver resection. HPB (Oxford), 2013. 15(3): p. 165-9.

16. Harimoto N, Shirabe K, Yamashita Yl, Ikegami T, Yoshizumi T, Soejima Y, Ikeda T, Maehara Y, Nishie A, and Yamanaka T, Sarcopenia as a predictor of prognosis in patients following hepatectomy for hepatocellular carcinoma. Br J Surg, 2013. 100(11): p. 1523-30.

17. Lieffers JR, Bathe OF, Fassbender K, Winget M, and Baracos VE, Sarcopenia is associated with postoperative infection and delayed recovery from colorectal cancer resection surgery. Br J Cancer, 2012.107(6): p. 931-6. 
18. van Vledder MG, Levolger S, Ayez N, Verhoef C, Tran TC, and ljzermans JN, Body composition and outcome in patients undergoing resection of colorectal liver metastases. Br J Surg, 2012. 99(4): p. 5507.

19. Doyle SL, Bennett AM, Donohoe CL, Mongan AM, Howard JM, Lithander FE, Pidgeon GP, Reynolds JV, and Lysaght J, Establishing computed tomography-defined visceral fat area thresholds for use in obesity-related cancer research. Nutr Res, 2013. 33(3): p. 171-9.

20. Clavien PA, Barkun J, de Oliveira ML, Vauthey JN, Dindo D, Schulick RD, de Santibanes E, Pekolj J, Slankamenac K, Bassi C, Graf R, Vonlanthen R, Padbury R, Cameron JL, and Makuuchi M, The ClavienDindo classification of surgical complications: five-year experience. Ann Surg, 2009. 250(2): p. 187-96. 21. Dindo D, Demartines N, and Clavien PA, Classification of surgical complications: a new proposal with evaluation in a cohort of 6336 patients and results of a survey. Ann Surg, 2004. 240(2): p. 205-13.

22. Dikken JL, van Sandick JW, Maurits Swellengrebel HA, Lind PA, Putter H, Jansen EP, Boot H, van Grieken NC, van de Velde CJ, Verheij M, and Cats A, Neo-adjuvant chemotherapy followed by surgery and chemotherapy or by surgery and chemoradiotherapy for patients with resectable gastric cancer (CRITICS). BMC Cancer, 2011. 11: p. 329.

23. Reisinger KW, van Vugt JL, Tegels JJ, Snijders C, Hulsewe KW, Hoofwijk AG, Stoot JH, Von Meyenfeldt MF, Beets GL, Derikx JP, and Poeze M, Functional compromise reflected by sarcopenia, frailty, and nutritional depletion predicts adverse postoperative outcome after colorectal cancer surgery. Ann Surg, 2015. 261(2): p. 345-52.

24. Smith AB, Deal AM, Yu H, Boyd B, Matthews J, Wallen EM, Pruthi RS, Woods ME, Muss H, and Nielsen ME, Sarcopenia as a predictor of complications and survival following radical cystectomy. J Urol, 2014. 191(6): p. 1714-20.

25. Lodewick TM, van Nijnatten TJ, van Dam RM, van Mierlo K, Dello SA, Neumann UP, Olde Damink SW, and Dejong $\mathrm{CH}$, Are sarcopenia, obesity and sarcopenic obesity predictive of outcome in patients with colorectal liver metastases? HPB (Oxford), 2014.

26. Morley JE, Sarcopenia in the elderly. Fam Pract, 2012. 29 Suppl 1: p. i44-i48.

27. Mariette C, De Botton ML, and Piessen G, Surgery in esophageal and gastric cancer patients: what is the role for nutrition support in your daily practice? Ann Surg Oncol, 2012. 19(7): p. 2128-34.

28. Morley JE, Argiles JM, Evans WJ, Bhasin S, Cella D, Deutz NE, Doehner W, Fearon KC, Ferrucci L, Hellerstein MK, Kalantar-Zadeh K, Lochs H, MacDonald N, Mulligan K, Muscaritoli M, Ponikowski P, Posthauer ME, Rossi Fanelli F, Schambelan M, Schols AM, Schuster MW, Anker SD, Society for Sarcopenia C, and Wasting D, Nutritional recommendations for the management of sarcopenia. J Am Med Dir Assoc, 2010. 11(6): p. 391-6.

29. Bartlett EK, Roses RE, Kelz RR, Drebin JA, Fraker DL, and Karakousis GC, Morbidity and mortality after total gastrectomy for gastric malignancy using the American College of Surgeons National Surgical Quality Improvement Program database. Surgery, 2014. 156(2): p. 298-304.

30. Kurita N, Miyata H, Gotoh M, Shimada M, Imura S, Kimura W, Tomita N, Baba H, Kitagawa Y, Sugihara K, and Mori M, Risk Model for Distal Gastrectomy When Treating Gastric Cancer on the Basis of Data From 33,917 Japanese Patients Collected Using a Nationwide Web-based Data Entry System. Ann Surg, 2015.

31. Sauvanet A, Mariette C, Thomas P, Lozac'h P, Segol P, Tiret E, Delpero JR, Collet D, Leborgne J, Pradere B, Bourgeon A, and Triboulet JP, Mortality and morbidity after resection for adenocarcinoma of the gastroesophageal junction: predictive factors. J Am Coll Surg, 2005. 201(2): p. $253-62$.

32. Reisinger KW, Bosmans JW, Uittenbogaart M, Alsoumali A, Poeze M, Sosef MN, and Derikx JP, Loss of Skeletal Muscle Mass During Neoadjuvant Chemoradiotherapy Predicts Postoperative Mortality in Esophageal Cancer Surgery. Ann Surg Oncol, 2015.

33. Itoh S, Shirabe K, Matsumoto Y, Yoshiya S, Muto J, Harimoto N, Yamashita Y, Ikegami T, Yoshizumi $T$, Nishie A, and Maehara $Y$, Effect of body composition on outcomes after hepatic resection for hepatocellular carcinoma. Ann Surg Oncol, 2014. 21(9): p. 3063-8.

34. Jung M, Volonte F, Buchs NC, Gayet-Ageron A, Pugin F, Gervaz P, Ris F, and Morel P, Perirenal fat surface area as a risk factor for morbidity after elective colorectal surgery. Dis Colon Rectum, 2014. 57(2): p. 201-9. 
35. Kim JH, Chin HM, Hwang SS, and Jun KH, Impact of intra-abdominal fat on surgical outcome and overall survival of patients with gastric cancer. Int J Surg, 2014. 12(4): p. 346-52. 


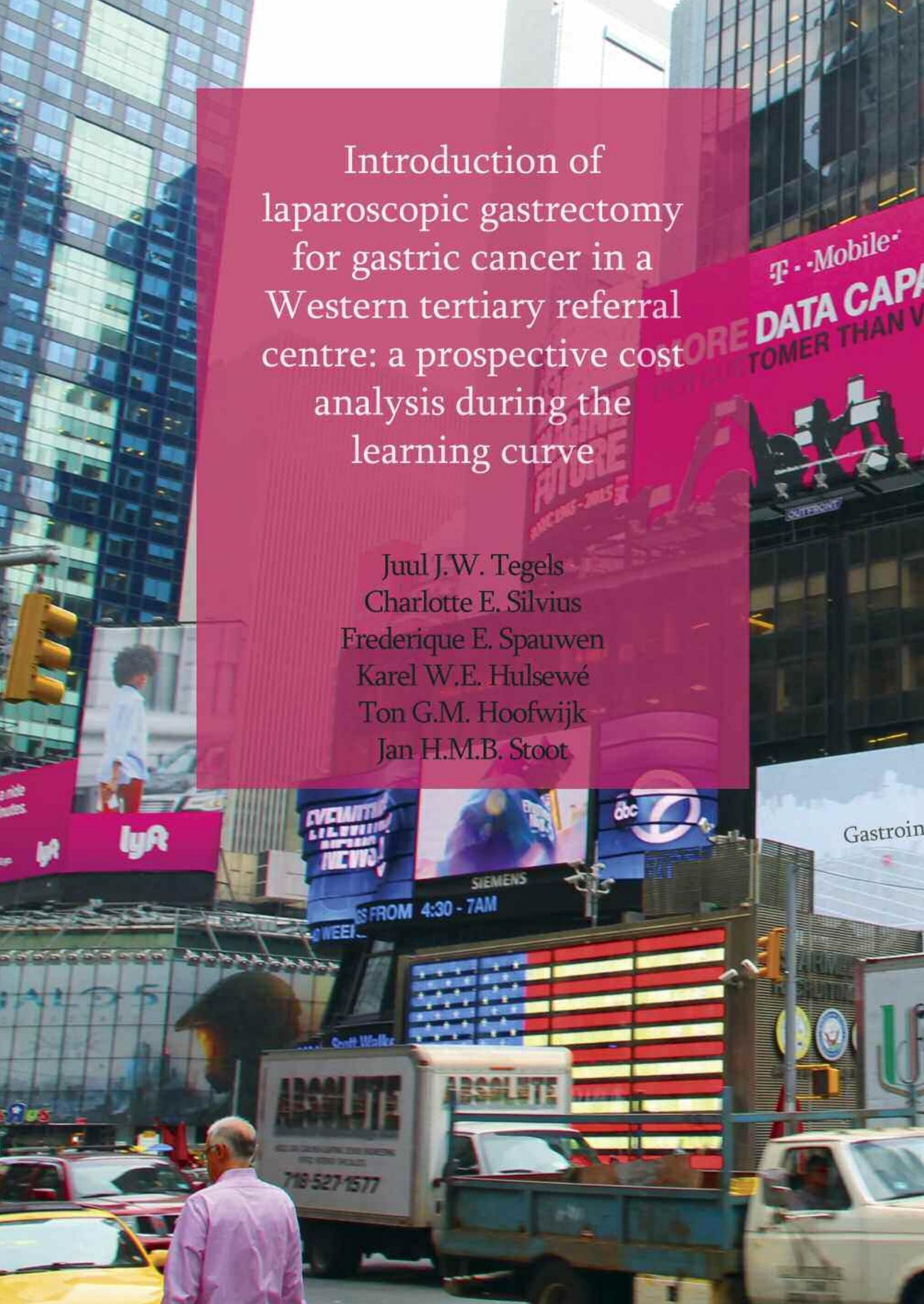




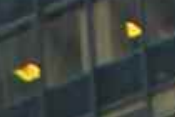




\section{Abstract}

Aim

Financial aspects of new techniques remain important due to expanding health care costs. Therefore, a cost analysis was performed during the introduction of laparoscopic gastrectomy for gastric cancer.

\section{Methods}

All patients who underwent surgery for gastric cancer with curative intent in 2013 and 2014 were prospectively included. Primary outcomes were costs regarding surgery and hospital stay.

\section{Results}

Laparoscopic gastrectomy was used in 52 patients (mean age 68 years [ \pm 9 , range 50 to 87 ] years) and open gastrectomy was used in 25 patients (mean age 70 years [ \pm 10 , range 46 to 85$]$ ). Mean costs (in euro's) of surgical instrumentation were significantly higher for laparoscopic surgery: mean $2270( \pm 670)$ vs. $1181( \pm 680)$ in the open approach $(P<0.001)$. Costs of theatre use were higher in the laparoscopic group: mean $3818( \pm 865)$ vs. $2545( \pm 1268)$ in the open surgery $(P<0.001)$. Total costs of hospitalization (i.e., costs of surgery and admission) were not different between laparoscopic and open surgery, $8187( \pm 4864)$ and $6152( \pm 2680)$ respectively $(P=0.729)$. Mean length of hospital stay was $9( \pm 12)$ days in the laparoscopic group versus $14( \pm 14)$ days in the open group $(P=0.044)$.

\section{Conclusions}

The introduction of laparoscopic gastrectomy for gastric cancer coincided with higher costs for theatre use and surgical instrumentation compared to the open technique. Total costs were not significantly different due to shorter length of stay and less ICU admissions and shorter ICU stay in the laparoscopic group. 


\section{Introduction}

In patients with gastric cancer, surgical resection is the only treatment that can offer cure or increase long-term survival [1]. Laparoscopic surgery for gastric cancer has gained popularity despite initial concerns regarding safety and oncological adequacy [2]. Studies conducted in Korea and Japan reported that laparoscopic gastrectomy (LG) is comparable to open gastrectomy with regard to surgical and oncological outcomes [2-4]. A meta-analysis by Memon et al. showed that laparoscopic procedures are associated with less blood loss but longer operation time [4]. Many studies have reported outcomes of laparoscopic surgery for Early Gastric Cancer (EGC), but several authors have shown that a laparoscopic approach can also be used in cases of advanced gastric cancer [5-7]. This makes it a potentially important strategy in Europe where the vast majority of patients present at stage II or higher as opposed to Asian countries where EGC is far more common [8].

In the current economic climate, governmental organizations and health insurance companies have a major influence on the regulation of costs in healthcare. Moreover, surgeons often have to prove that new techniques are cost-effective for hospital organizations. To the best of our knowledge, no cost-analysis studies have yet been performed concerning the introduction of the laparoscopic procedure for gastric resections [2]. The aim of this study was to evaluate the costs of the introduction of a laparoscopic surgery program for gastric cancer in a Western community training hospital and tertiary referral centre for gastric cancer surgery. 


\section{Methods}

\section{Patients}

Introduction of laparoscopic gastrectomy was started in January 2013. All consecutive patients with gastric adenocarcinoma eligible for curative surgery from January 2013 to December 2014 were included. Whether the patient would undergo laparoscopic or open surgery depended on the surgeon's experience in laparoscopic gastric surgery and surgeon preferences. Patients who underwent multivisceral resections were not included in this study. All data were collected in a prospective database. If non-equal groups were obtained, a consecutive number of patients who underwent open gastrectomy with curative intent would be retrospectively included to create two groups of equal size. All data, including intraoperatively used materials (e.g., electrosurgical devices, staplers, suture materials and reusable instruments) were all available through the hospitals fully digitized patient information system, also for retrospectively included patients. This observational study collected data concerning direct hospital-related costs and complication rates and admission length. The Charlson Comorbidity Index $(\mathrm{CCl})$ was used to classify comorbidities in patients [9]. Patients received care as usual. Approval for this study was obtained from the medical ethics committee.

\section{Preoperative stage}

Preoperatively all patients underwent gastroesophageal endoscopy and biopsies were taken to confirm the diagnosis. Further preoperative staging was done with Computed Tomography (CT) of the abdomen and chest. Magnetic Resonance Imaging (MRI) and/or Positron Emission Tomography (PET)/CT imaging was selectively performed when liver lesions were visible on CT-imaging. Multidisciplinary consensus regarding the treatment was obtained in all cases. Neoadjuvant chemotherapy was administered whenever patient condition and comorbidities would allow.

\section{Outcome measurement}

Primary outcomes included costs regarding surgery and hospital stay. Costs were obtained from the Financial Controllers of the involved departments. Data (e.g. duration of operation, use of disposables) were collected prospectively. For patients who were retrospectively included all data were available through the electronic patient record system. This system also recorded which disposable and reusable operating theatre materials were used during surgery. Costs of ward stay were 180 euros per day, intensive care unit (ICU) admission was 665 euros per day. Costs of operating theatre use were hourly rates for surgery and anesthesiology 
combined at 800 euros per hour. Sterilization costs of reusable instruments were also accounted for and varied for different types of surgical sets that were used. All used instruments, disposable and reusable, were noted during the procedure by one of the operating room nurses on a prepared list that was provided to prospectively collect data. Costs of the disposable instruments for the laparoscopic and open surgery are shown in table $1 \mathrm{a}$ and table $1 \mathrm{~b}$. Postoperatively all patients were admitted to the recovery ward before they were transferred to the general ward. For laparoscopic and open gastrectomy, costs of both disposable and reusable instruments, operating theatre use, ICU stay and hospital stay were calculated separately.

Secondary outcomes were estimated blood loss, duration of operation, length of ICU stay, length of hospital stay, anastomotic leakage rate and complications. Complications were graded according to Clavien-Dindo classification: grade $3 a$ (i.e., complication requiring reintervention) or greater was considered a major complication [10]. Tumour stage was classified in line with the American Joint Committee on Cancer TNM 5th edition.

\begin{tabular}{ll}
\hline Table 1a. Costs of disposable instruments for laparoscopic surgery \\
\hline Item & Price \\
\hline Ligasure Impact 5mm, Medtronic, Ireland* & $€ 448.22$ \\
Ligasure Impact 10mm, Medtronic, Ireland* & $€ 376.00$ \\
Autosuture endobag, endocatch, Medtronic, Ireland* & $€ 63.56$ \\
Autosuture EndoGIA 12mm, Medtronic, Ireland* & $€ 203.00$ \\
Reload EndoGIA purple 45, Medtronic, Ireland* & $€ 173.00$ \\
Reload EndoGIA purple 60, Medtronic, Ireland* & $€ 176.00$ \\
Reload EndoGIA Gold 45, Medtronic, Ireland* & $€ 181.00$ \\
Endopaddle 12mm, Medtronic, Ireland* & $€ 81.84$ \\
Alexis small/medium, applied medical & $€ 31.00$ \\
Endoshear 5mm, Medtronic, Ireland* & $€ 73.50$ \\
EEA XL, Medtronic, Ireland* & $€ 439.62$ \\
EEA Orvil, Medtronic, Ireland* & $€ 94.20$ \\
Bladeless trocar 5mm, Medtronic, Ireland* & $€ 48.88$ \\
Bladeless trocar 5-12mm, Medtronic, Ireland* & $€ 48.88$ \\
Blunt trocar 5-12mm, Medtronic, Ireland* & $€ 47.81$ \\
Pyramidal bladed trocar 10-15mm, Medtronic, Ireland* & $€ 80.43$ \\
Hem-o-lok L filling, Weck USA & $€ 23.00$ \\
Hem-o-lok XL filling, Weck USA & $€ 23.00$ \\
\hline * Formerly Covidien USA & \\
\hline
\end{tabular}




\begin{tabular}{ll}
\hline \multicolumn{2}{l}{ Table 1b. Costs of disposable instruments for open surgery } \\
\hline Item & Price \\
\hline Ligasure Impact, Medtronic, Ireland* & $€ 343.80$ \\
Purssting stapler, Medtronic, Ireland* & $€ 57.34$ \\
TA Green 30, Medtronic, Ireland* & $€ 106.30$ \\
Reload TA Green 30, Medtronic, Ireland* & $€ 60.50$ \\
TA Green 60, Medtronic, Ireland* & $€ 110.09$ \\
Reload TA Green 60, Medtronic, Ireland* & $€ 65.00$ \\
GIA Blue 60, Medtronic, Ireland* & $€ 119.68$ \\
Reload GIA Blue 60, Medtronic, Ireland* & $€ 75.51$ \\
GIA Blue 80, Medtronic, Ireland* & $€ 147.48$ \\
Reload GIA Blue 80, Medtronic, Ireland* & $€ 81.74$ \\
GIA Green 80, Medtronic, Ireland* & $€ 148.96$ \\
Reload GIA Green 80, Medtronic, Ireland* & $€ 81.74$ \\
CEEA 21, Medtronic, Ireland* & $€ 408.97$ \\
CEEA 25, Medtronic, Ireland* & $€ 384.48$ \\
CEEA 28, Medtronic, Ireland* & $€ 388.33$ \\
CEEA 25 XL, Medtronic, Ireland* & $€ 439.62$ \\
\hline * Formerly Covidien USA & \\
\hline
\end{tabular}

Surgical technique and postoperative care

Open surgery was performed by three surgeons prior to introduction of laparoscopic surgery for gastric cancer. All three had extensive experience in open surgery for gastric cancer.

Laparoscopic procedures were performed by two of the abovementioned three surgeons. Both surgeons also had extensive prior expertise in laparoscopic surgery for other gastrointestinal malignancies, mainly colorectal surgery and gastric GIST tumours. Prior to introducing laparoscopic surgery for gastric cancer, specific expertise and proficiency was obtained by the laparoscopic surgeons by taking expert courses in the Netherlands and Singapore.

Surgical resections for gastric malignancy were defined as either distal or total gastrectomies. The type of resection performed depended on the localization and depth of invasion of the tumour. In both open and laparoscopic surgery, a standard D2 or D1+ lymph node dissection (dissection of group 1 and number $8 \mathrm{a}$ and 9 lymph nodes) was performed in accordance with Dutch guidelines. Continuity of the gastrointestinal tract in subtotal gastrectomies was restored either by a Billroth-II or a Roux-en-Y reconstruction. In the case of a total gastrectomy a Roux-en-Y reconstruction was always performed. Patients were not routinely admitted to the ICU postoperatively. Intensive care unit admission was always for complication management (e.g., sepsis, pulmonary complications).

Postoperative care of both open and laparoscopic patients included several aspects of a multimodal perioperative ERAS (Enhanced Recovery After Surgery) program for gastrointestinal cancer [11]. These include early enteral feeding (i.e., 
resumption of liquids on postoperative day one) and early mobilization. Follow-up of the patients after discharge was performed periodically. Follow-up consisted of physical examination, blood tests, and CT-imaging if indicated. 


\section{Statistical analysis}

Data were analyzed using SPSS 20 (IBM Corp. Armonk, NY). Continuous variables were expressed as mean with standard deviation $( \pm S D)$ or mean (range) if appropriate. Chi-squared ( $\left.\chi_{2}\right)$ tests were used to compare the difference in frequencies of categorical variables. To compare the means of two independent samples, t-tests and non-parametric tests were used. The threshold for statistical significance was set at a P-value of $<0.05$.

\begin{tabular}{|c|c|c|c|}
\hline & $\begin{array}{l}\text { Open gastrectomy } \\
(\mathrm{n}=25,32 \%)\end{array}$ & $\begin{array}{l}\text { Laparoscopic gastrectomy } \\
(n=52,68 \%)\end{array}$ & P-value \\
\hline Age & $70.0( \pm 10,46$ to 85$)$ & $68( \pm 9,50$ to 87$)$ & 0.470 \\
\hline Sex (male/female) & $17 / 8$ & $32 / 20$ & 0.623 \\
\hline $\mathrm{BMI}^{\mathrm{a}}$ & $25( \pm 4,18$ to 36$)$ & $25( \pm 5,15$ to 38$)$ & 0.824 \\
\hline $\mathrm{CCl}^{\mathrm{b}}:$ & & & 0.158 \\
\hline$-0-2$ & $16(64 \%)$ & $27(52 \%)$ & \\
\hline$-3-4$ & $7(28 \%)$ & $11(21 \%)$ & \\
\hline$>4$ & $2(8 \%)$ & $14(27 \%)$ & \\
\hline Tumour stage & & & 0.681 \\
\hline-0 & $0(0.0 \%)$ & $2(4 \%)$ & \\
\hline$-1 a$ & $4(16 \%)$ & $11(21 \%)$ & \\
\hline$-1 b$ & $6(24 \%)$ & $15(29 \%)$ & \\
\hline-2 & $5(20 \%)$ & $4(8 \%)$ & \\
\hline$-3 a$ & $4(16 \%)$ & $10(19 \%)$ & \\
\hline$-3 b$ & $3(12 \%)$ & $4(8 \%)$ & \\
\hline-4 & $3(12 \%)$ & $6(11 \%)$ & \\
\hline Subtotal gastrectomy & $16(64 \%)$ & $38(73 \%)$ & 0.436 \\
\hline Total gastrectomy & $9(36 \%)$ & $14(27 \%)$ & \\
\hline $\begin{array}{l}\text { Neoadjuvant } \\
\text { chemotherapy }\end{array}$ & $11(44 \%)$ & $36(69 \%)$ & 0.046 \\
\hline $\begin{array}{l}\text { Legend: } \\
\text { a. BMI: Body mass inde } \\
\text { b. CCI: Charlson Comor } \\
\text { c. In accordance with T }\end{array}$ & $\begin{array}{l}\mathrm{g} / \mathrm{cm} 2 \\
\text { Index } \\
\text { th edition }\end{array}$ & & \\
\hline
\end{tabular}




\section{Results}

\section{Baseline characteristics}

A total of 77 patients underwent gastrectomy with curative intent from January 2013 to December 2014. The laparoscopic approach was used in 52 (68\%) patients. The open approach was used in 25 (32\%) patients. There were no statistically significant differences in sex, age, $\mathrm{CCl}$ (i.e., comorbidities) or tumour stage. Patients undergoing laparoscopic gastrectomy had significantly more frequently received neoadjuvant chemotherapy ( $69 \%$ vs. $44 \%, \mathrm{P}=0.046$ ) (table 2 ).

A consecutive series of 30 patients who underwent open surgery were included retrospectively. These patients underwent surgery between May 2012 and January 2013. These patients did not differ from patients who underwent open surgery in the prospective series with regards to the baseline characteristics mentioned in the prospective group.

\begin{tabular}{|c|c|c|c|}
\hline \multicolumn{4}{|c|}{$\begin{array}{l}\text { Table 3. Primary outcome, costs of surgery, hospital admission and Intensive } \\
\text { Care Unit (ICU) stay }\end{array}$} \\
\hline Costs (in euros) & $\begin{array}{l}\text { Open gastrectomy } \\
(\mathrm{n}=25,32.5 \%)\end{array}$ & $\begin{array}{l}\text { Laparoscopic gastrectomy } \\
(\mathrm{n}=52,67.5 \%)\end{array}$ & $P$-value \\
\hline Surgical instrumentation & $1,181( \pm 680)$ & $2,270( \pm 670)$ & $<0.001$ \\
\hline Operating theatre use & $2,545( \pm 1,268)$ & $3,819( \pm 865)$ & $<0.001$ \\
\hline Ward stay & $2,218( \pm 1,810)$ & $1,381( \pm 1,298)$ & 0.023 \\
\hline ICU stay ${ }^{a}$ & $1,729( \pm 6,499)$ & $716( \pm 3,299)$ & 0.366 \\
\hline Admission & $3,947( \pm 6,719)$ & $2,097( \pm 4,419)$ & 0.153 \\
\hline Total costs & $7,673( \pm 8,064)$ & $8,187( \pm 4,864)$ & 0.729 \\
\hline \multicolumn{4}{|c|}{ Table 4 . Secondary outcome parameters } \\
\hline & $\begin{array}{l}\text { Open gastrectomy } \\
(n=25,32.5 \%)\end{array}$ & $\begin{array}{l}\text { Laparoscopic gastrectomy } \\
(\mathrm{n}=52,67.5 \%)\end{array}$ & $P$-value \\
\hline Intraoperative blood loss (ml) & $\begin{array}{l}592( \pm 529,100 \text { to } \\
2500)\end{array}$ & $267( \pm 316,20 \text { to } 2000)^{*}$ & 0.002 \\
\hline OR time $(\min )$ & $\begin{array}{l}191( \pm 95, \text { range } 95 \text { to } \\
554)\end{array}$ & $286( \pm 65$, range 207 to 597$)$ & $<0.001$ \\
\hline Lymph node yield ( $n$ ) & $25( \pm 10,7$ to 51$)$ & $26( \pm 8,10$ to 47$)$ & 0.651 \\
\hline Any complication & $15(60 \%)$ & $16(31 \%)$ & 0.025 \\
\hline Grade Clavien-Dindo $=3 a$ & $7(28 \%)$ & $6(12 \%)$ & 0.104 \\
\hline Anastomotic leakage & $3(12 \%)$ & $2(4 \%)$ & 0.322 \\
\hline Mean length of stay (days) & $15( \pm 14,5$ to 59$)$ & $9( \pm 12,2$ to 84$)$ & 0.044 \\
\hline Mean ICU stay (days) & $3( \pm 10,0$ to 49$)$ & $1( \pm 5,0$ to 35$)$ & 0.366 \\
\hline Readmission & $4(16 \%)$ & $6(12 \%)$ & 0.720 \\
\hline
\end{tabular}




\section{Chapter 5.}

\section{Primary outcome}

The costs (in euro's) of surgical instrumentation were significantly higher for laparoscopic surgery compared to open gastrectomy, 2,270 ( \pm 670$)$ and 1,181 $( \pm 680)$ respectively, $\mathrm{P}<0.001$ (table 3 ). Also, the costs of theatre use were significantly higher in the laparoscopic group compared to open gastrectomy, 3,819 ( \pm 865$)$ and $2,545( \pm 1268)$ respectively, $P<0.001$. Costs of general ward stay were significantly lower in the laparoscopic group compared to open gastrectomy, 1,381 $( \pm 1298)$ and $2,218( \pm 1810)$ respectively, $\mathrm{P}=0.023$.

ICU stay and total admission costs (i.e., ward stay and ICU stay combined) were not significantly different. The total costs of admission and surgery did not significantly differ between open and laparoscopic gastrectomy, 7,672 $( \pm 8,064)$ and $8,187( \pm 4,863)$ respectively, $\mathrm{P}=0.729$.

When a retrospective consecutive series of open gastrectomies was included to obtain equal sized groups (i.e., 55 open versus 52 laparoscopic gastrectomies), total admission costs were significantly lower in the laparoscopy group, 2,097 $( \pm 4,420)$ versus $4,611( \pm 7,991), P=0.048$. Costs difference of total hospitalisation (i.e, operating theatre and ward stay) between open and laparoscpic gastrectomy was not smaller at $8,187( \pm 4,868)$ for laparoscopic patients versus $7,915( \pm 8,653)$ for patients who underwent open surgery, $\mathrm{P}=0.843$.

\section{Secondary outcomes}

Comparison between the two techniques showed that total theatre time utilized was $191 \mathrm{~min} \pm 95$ for the open procedure and $286 \mathrm{~min} \pm 65$ for the laparoscopic gastric resection $(\mathrm{P}<0.001)$ (table 4$)$. Results for secondary outcome parameters are listed in table 4. Mean intraoperative blood loss was significantly less in the laparoscopic gastrectomy group $(267 \mathrm{ml}$ vs. $592 \mathrm{ml}, \mathrm{P}=0.002)$. In three cases, the laparoscopic approach was converted to an open procedure. In one case this was due to a splenic rupture, which was caused during laparoscopic surgery. In the other two patients the reason of conversion to an open procedure was a limited view of suspected ingrowth of tumour in the pancreas.

Laparoscopic gastrectomy was associated with a lower rate of overall complications and major complications, 16 (31\%) vs. 15 (60\%), P=0.025 and 6 (12\%) vs. 7 (28\%), $\mathrm{P}=0.104$ respectively. Anastomotic leakage rates were higher in patients undergoing open gastrectomy than laparoscopic gastrectomy 2 (12\%) and 2(4\%) respectively, $\mathrm{P}=0.322$. The differences in major complications and anastomotic leakage rates were not statistically significant in the prospective series. Also, patients who underwent laparoscopic resection had a shorter length of hospital stay and ICU stay (see table 4).

When comparing equal sized groups (i.e., 55 open and 52 laparoscopic gastrectomies), significantly more major complications occur in the open surgery group, 17 (31\%), compared to the laparoscopic group, 6 (12\%), P=0.019. Also, the 
anastomotic leakage rate was significantly higher in the open surgery group at 10 (18.2\%) compared to $2(4 \%)$ in the laparoscopic group, $P=0.029$.

In the prospective series two patients died after surgery; one (4\%) after open gastrectomy and one (2\%) after laparoscopic gastrectomy. In the total series (i.e., including the restrospective series of open gastrectomies) four patients $(7.3 \%)$ died after open gastrectomy, three died after septicemia from anastomotic leakage with one patient who also had a concurrent pancreatic leakage. One patient died of a severe aspiration pneumonia. One patient (1.9\%) died after a laparoscopic gastrectomy from intestinal ischemia of the right and transverse colon.

Both techniques had a similar lymph node yield: mean $29( \pm 10)$ and $26( \pm 8.5)$ for open and laparoscopic gastrectomy respectively $(P=0.103)$. There were three cases of microscopically irradical resection: one in the open group and two in laparoscopic gastrectomy group $(\mathrm{P}=0.614)$.

Analysis of equal sized groups (i.e., 55 open versus 52 laparoscopic gastrectomies) resulted in similar results for the abovementioned secondary outcome parameters. 


\section{Discussion}

The aim of this study was to evaluate the costs of laparoscopic surgery for gastric cancer during the introduction of this new technique in a tertiary referral centre. The results show a significant increase in costs of surgery associated with the laparoscopic procedure. These costs are mainly due to increased use of (non)disposable instrumentation and theatre time. The secondary outcomes suggest that laparoscopic gastrectomy is safe. This is represented by less blood loss, and less (major) post-operative complications in laparoscopic surgery. With regards to oncological safety the number of harvested lymph nodes and microscopically irradical resections were equal in laparoscopic and open surgery. Only two patients died in this study, one following open and one following laparoscopic gastrectomy. This study was conducted at the time when the laparoscopic approach was introduced in our tertiary referral hospital for gastric cancer. The complexity of the laparoscopic approach is one of the reasons for a more time-consuming procedure. As surgeons gain experience, operative time is expected to decrease and theatre costs (at an hourly rate) will decline. Moreover, knowledge of the postoperative care on the clinical wards and safety of earlier discharge (ERAS) for patients who underwent laparoscopic as well as open surgery may help reduce hospital stay. This study shows positive results with regards to financial aspects of laparoscopic surgery even during the introduction and learning curve phase of its introduction.

Even though the duration of operation is expected to decline, the longer operative time compared to open surgery will probably remain. This has been shown in larger meta-analyses with weighted mean differences ranging from +48 to +82 min of longer operative time for laparoscopy [12-14].

These meta-analyses also show several other advantages of laparoscopic surgery compared to open surgery such as significantly shorter hospital stay (2.5 to 3.6 days) and significantly lower complication rates $[13,14]$. These differences can be expected to be associated with lower costs. Moreover, laparoscopic gastrectomy has been shown to be associated with improved quality of life [15]. Studies in liver surgery, pancreatectomy and wedge resections for gastrointestinal tumours, have shown that laparoscopic surgery has the same advantages discussed above compared to open surgery (e.g. shorter hospital stay, less intraoperative blood loss, decreased medical complications and no differences in operative mortality) [16-18]. For pancreatic and wedge resections this was performed at the cost of a longer operative time and a more expensive procedure due to costly surgical instruments $[16,17]$. In these studies increased costs associated with the procedure and instrumentation are offset by a reduction in other costs (e.g., shorter hospital stay). This possibly makes laparoscopy a viable and cost effective option. 
Another potential cost benefit of laparoscopic surgery could be found in long term complications of open abdominal surgery. Incidence of incisional hernia can be expected to be much lower in laparoscopic surgery compared to patients who underwent midline laparotomy. Therefore costs of treating incisional hernia might be lower in laparoscopic compared to open surgery for gastric cancer.

Multimodal fast-track programs such as ERAS (Enhanced Recovery After Surgery) could further decrease hospital stay and complication rates and therefore costs. A fast-track program in laparoscopic gastrectomy for gastric cancer has been shown to be associated with decreased hospital stay and costs [19].

One of the main limitations of this study is its non-randomized design. Therefore a selection bias cannot be excluded. Also the non-equal sized groups is a consequence of this fact. By partially retrospectively studying prospectively maintained digital registration data of used materials an effort could be made to compare equal sized groups. Most data and all costs-related data regarding laparoscopic procedures however were collected prospectively. Despite this, statistically significant differences were shown for the primary and secondary outcomes. No definitive conclusions can be drawn with regard to aspects such as postoperative complications and long term oncological safety. However, secondary outcomes show differences in favor of laparoscopic surgery. These are in line with other studies and show a shorter length-of hospital stay and fewer complications. Another limitation is that only patients who underwent surgery with curative intent for gastric adenocarcinoma were included. No conclusions can be drawn with regard to costs of palliative resections.

In conclusion, during the introduction of a laparoscopic gastrectomy programme for gastric cancer costs for theatre use and surgical instrumentation were higher compared to the open technique but overall costs were similar due to reduced length of stay and lower complications rates (and therefore lower ICU admission rates and costs). Similar results regarding surgical safety, feasibility and postoperative complications between laparoscopic and open gastrectomy were found. Larger prospective studies will be needed to determine cost effectiveness of laparoscopic surgery for gastric cancer.

\section{Acknowledgements}

We thank the Surgical Oncological Network Limburg for the regional implementation of centralization of gastric cancer surgery in our region. 


\section{References}

1. Hartgrink HH, van de Velde CJ, Putter H, Bonenkamp JJ, Klein Kranenbarg E, Songun I, Welvaart K, van Krieken JH, Meijer S, Plukker JT, van Elk PJ, Obertop H, Gouma DJ, van Lanschot JJ, Taat CW, de Graaf PW, von Meyenfeldt MF, Tilanus H, and Sasako M, Extended lymph node dissection for gastric cancer: who may benefit? Final results of the randomized Dutch gastric cancer group trial. J Clin Oncol, 2004. 22(11): p. 2069-77.

2. Shehzad K, Mohiuddin K, Nizami S, Sharma H, Khan IM, Memon B, and Memon MA, Current status of minimal access surgery for gastric cancer. Surg Oncol, 2007. 16(2): p. 85-98.

3. Kim MC, Kim W, Kim HH, Ryu SW, Ryu SY, Song KY, Lee HJ, Cho GS, Han SU, Hyung WJ, and Korean Laparoscopic Gastrointestinal Surgery Study G, Risk factors associated with complication following laparoscopy-assisted gastrectomy for gastric cancer: a large-scale korean multicenter study. Ann Surg Oncol, 2008. 15(10): p. 2692-700.

4. Memon MA, Khan S, Yunus RM, Barr R, and Memon B, Meta-analysis of laparoscopic and open distal gastrectomy for gastric carcinoma. Surg Endosc, 2008. 22(8): p. 1781-9.

5. Azagra JS, Goergen M, De Simone P, and Ibanez-Aguirre J, Minimally invasive surgery for gastric cancer. Surg Endosc, 1999. 13(4): p. 351-7.

6. Lee $\mathrm{J}$ and Kim W, Clinical experience of 528 laparoscopic gastrectomies on gastric cancer in a single institution. Surgery, 2013. 153(5): p. 611-8.

7. Lin JX, Huang CM, Zheng CH, Li P, Xie JW, Wang JB, and Lu J, Laparoscopy-assisted gastrectomy with D2 lymph node dissection for advanced gastric cancer without serosa invasion: a matched cohort study from South China. World J Surg Oncol, 2013.11(1): p. 4.

8. Dikken JL, van Sandick JW, Allum WH, Johansson J, Jensen LS, Putter H, Coupland VH, Wouters MW, Lemmens VE, van de Velde CJ, van der Geest LG, Larsson HJ, Cats A, and Verheij M, Differences in outcomes of oesophageal and gastric cancer surgery across Europe. Br J Surg, 2013. 100(1): p. 83-94.

9. Charlson ME, Pompei P, Ales KL, and MacKenzie CR, A new method of classifying prognostic comorbidity in longitudinal studies: development and validation. J Chronic Dis, 1987. 40(5): p. $373-83$. 10. Dindo D, Demartines N, and Clavien PA, Classification of surgical complications: a new proposal with evaluation in a cohort of 6336 patients and results of a survey. Ann Surg, 2004. 240(2): p. 205-13.

11. Mortensen K, Nilsson M, Slim K, Schafer M, Mariette C, Braga M, Carli F, Demartines N, Griffin SM, Lassen K, and Enhanced Recovery After Surgery G, Consensus guidelines for enhanced recovery after gastrectomy: Enhanced Recovery After Surgery (ERAS(R)) Society recommendations. Br J Surg, 2014. 101(10): p. 1209-29.

12. Kodera Y, Fujiwara M, Ohashi N, Nakayama G, Koike M, Morita S, and Nakao A, Laparoscopic surgery for gastric cancer: a collective review with meta-analysis of randomized trials. J Am Coll Surg, 2010. 211(5): p. 677-86.

13. Ohtani H, Tamamori Y, Noguchi K, Azuma T, Fujimoto S, Oba H, Aoki T, Minami M, and Hirakawa K, Meta-analysis of laparoscopy-assisted and open distal gastrectomy for gastric cancer. J Surg Res, 2011. 171(2): p. 479-85.

14. Vinuela EF, Gonen M, Brennan MF, Coit DG, and Strong VE, Laparoscopic versus open distal gastrectomy for gastric cancer: a meta-analysis of randomized controlled trials and high-quality nonrandomized studies. Ann Surg, 2012. 255(3): p. 446-56.

15. Kim YW, Baik YH, Yun YH, Nam BH, Kim DH, Choi IJ, and Bae JM, Improved quality of life outcomes after laparoscopy-assisted distal gastrectomy for early gastric cancer: results of a prospective randomized clinical trial. Ann Surg, 2008. 248(5): p. 721-7.

16. de'Angelis N, Brunetti F, Felli E, Mehdaoui D, Memeo R, Carra MC, Zuddas V, and Azoulay D, Laparoscopic versus open gastric wedge resection for primary gastrointestinal tumors: clinical outcomes and health care costs analysis. Surg Laparosc Endosc Percutan Tech, 2015. 25(2): p. $143-6$.

17. Rutz DR, Squires MH, Maithel SK, Sarmiento JM, Etra JW, Perez SD, Knechtle W, Cardona K, Russell MC, Staley CA, 3rd, Sweeney JF, and Kooby DA, Cost comparison analysis of open versus laparoscopic distal pancreatectomy. HPB (Oxford), 2014. 16(10): p. 907-14. 
18. Stoot JH, van Dam RM, Coelen RJ, Winkens B, Olde Damink SW, Bemelmans MH, and Dejong $\mathrm{CH}$, The introduction of a laparoscopic liver surgery programme: a cost analysis of initial experience in a university hospital. Scand J Surg, 2012. 101(1): p. 32-7.

19. Chen ZX, Liu AH, and Cen Y, Fast-track program vs traditional care in surgery for gastric cancer. World J Gastroenterol, 2014. 20(2): p. 578-83. 
Hylke J.F. Brenkman Juul J.W. Tegels Jelle J.P. Ruurda

Micha D.P. Luyer Ewout A. Kouwenhoven

Werner A. Draaisma

Donald L. van der Peet

Bas P.L. Wijnhoven Jan H.M.B. Stoot

Richard van Hillegersberg

\section{Published in:}

Gastric Cancer May 2018

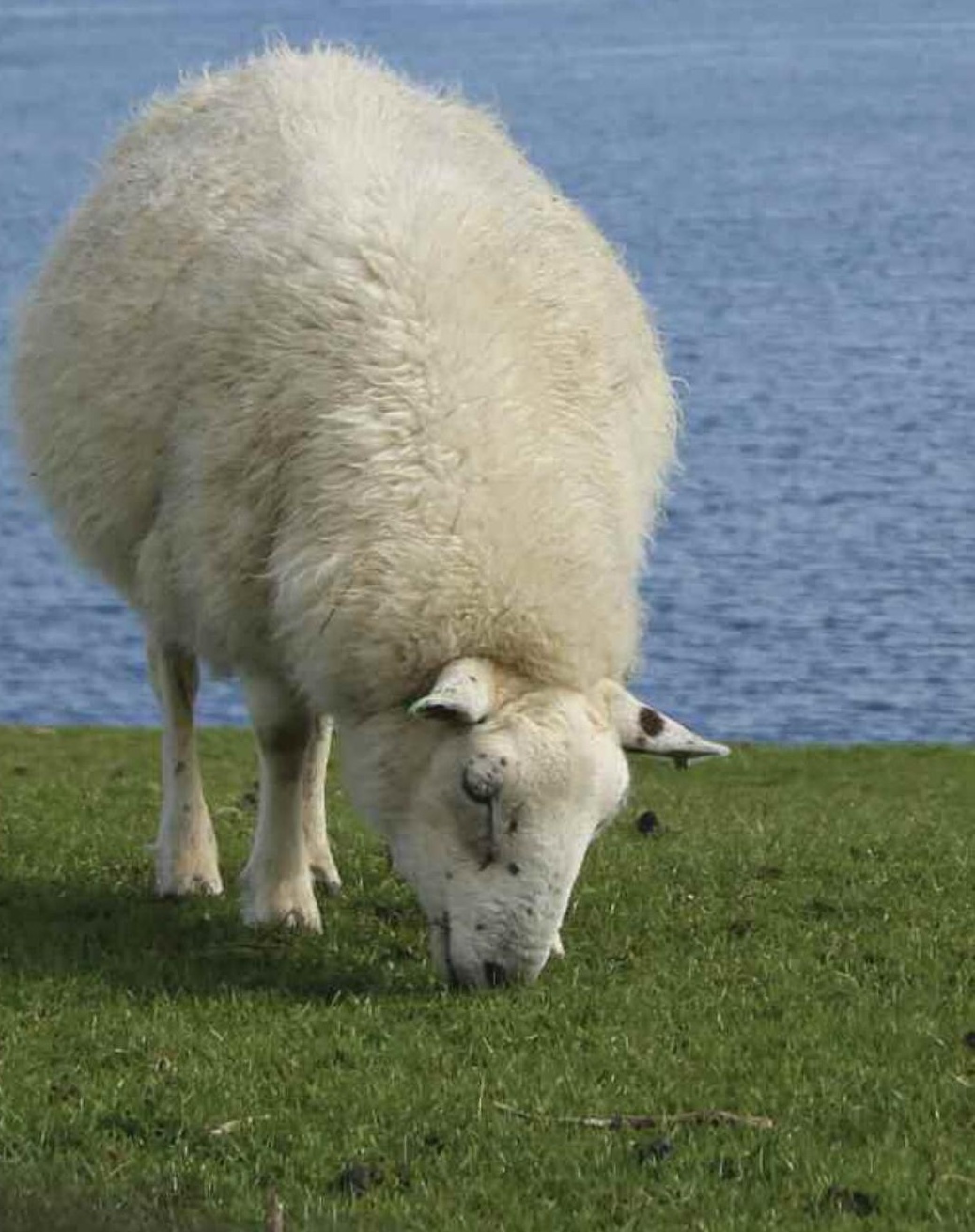




\section{Factors Influencing \\ Health-Related Quality of Life after Gastrectomy for Cancer}

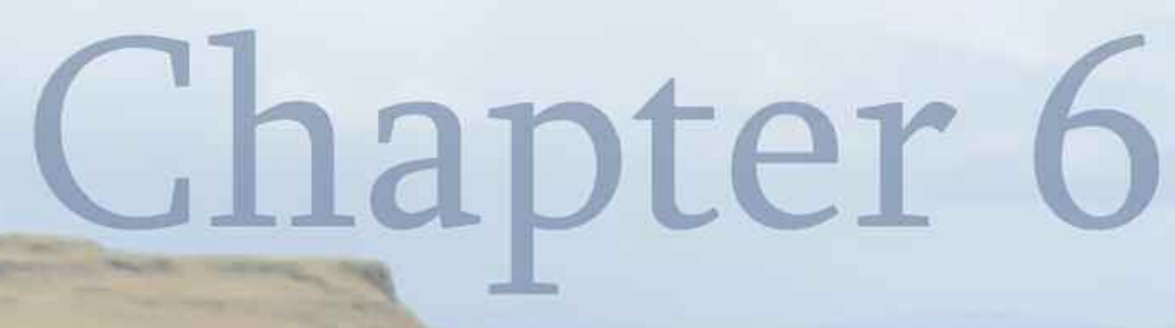

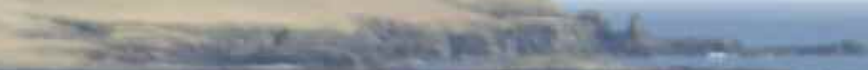

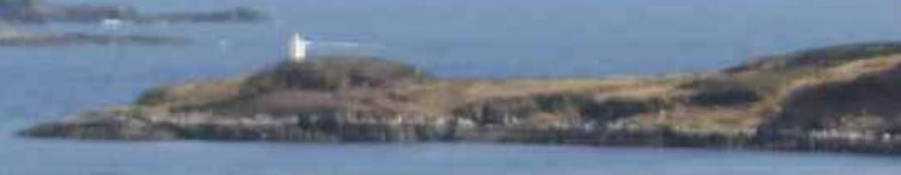

3.2.

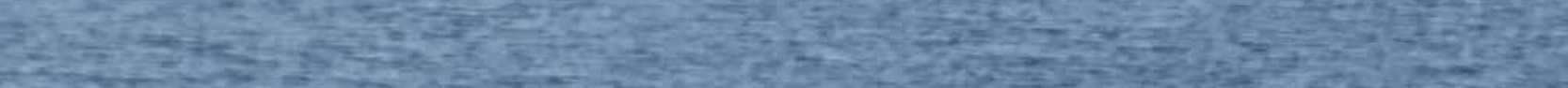

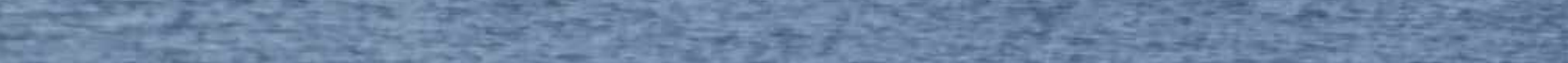

I 3. 6.

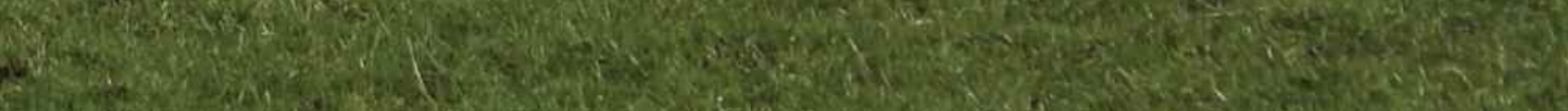

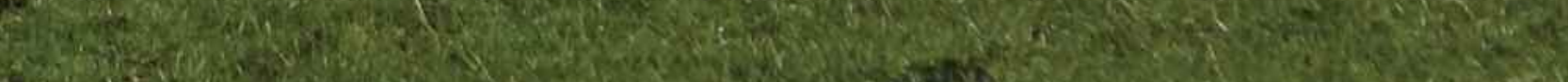

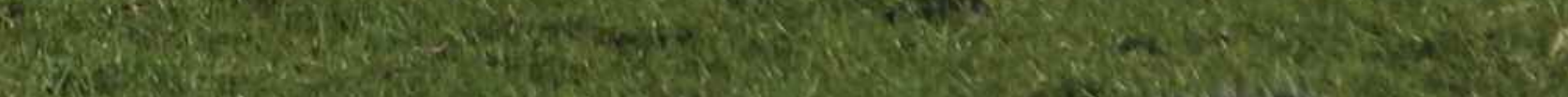




\section{Abstract}

Aim

Insight in health-related quality of life (HRQoL) may improve clinical decisionmaking and inform patients about the long-term effects of gastrectomy. This study aimed to evaluate HRQoL and identify factors associated with HRQoL after gastrectomy.

\section{Methods}

This cross-sectional study used prospective databases from 7 Dutch centers and included patients who underwent gastrectomy for cancer between 2001-2015. Between July 2015 and November 2016, European Organization for Research and Treatment of Cancer HRQOL questionnaires QLQ-C30 and QLQ-STO22 were sent to all patients that were alive without recurrence. The QLQ-C30 scores were compared to a Dutch reference population using one-sample t-test. Spearman's rank was used to correlate time after surgery to $\mathrm{HRQ}$ oL, and multivariable linear regression was performed to identify factors associated with HRQoL.

\section{Results}

A total of $222 / 274$ (81.0\%) patients completed the questionnaires. Median followup was 29 months (range $3-171$ ) and $86.9 \%$ of patients had a follow-up $>1$ year. The majority of patients had undergone neoadjuvant treatment (64.4\%) and total gastrectomy (52.7\%). Minimally invasive gastrectomy (MIG) was performed in 50\% of the patients. Compared to the general population, gastrectomy patients scored significantly worse on most functional and symptom scales $(\mathrm{p}<0.001)$, and slightly worse on global HRQoL (78 vs. 74, $\mathrm{p}=0.012$ ). Time after surgery did not correlate with global HRQoL (Spearman's $\rho=0.06, p=0.384$ ). Partial gastrectomy, neoadjuvant treatment, and MIG were associated with better HRQOL $(p<0.050)$.

\section{Conclusion}

After gastrectomy, patients encounter functional impairments and symptoms, but experience only a slightly impaired global HRQoL. Partial gastrectomy, the ability to receive neoadjuvant treatment, and MIG are associated with HRQoL benefits. 


\section{Introduction}

Gastric cancer is the fifth most common type of cancer worldwide [1], and surgical resection is the cornerstone of treatment with curative intent. As survival after gastrectomy for cancer has improved since the introduction of a more extensive lymphadenectomy and perioperative chemotherapy [2, 3], the quality of life following treatment has become increasingly important. Various complaints that are associated with the treatment, such as a loss of appetite, early satiety, reflux, dysphagia, nausea and change of stools, may have a profound impact on patients' Health-Related Quality of Life (HRQoL) [4].

$\mathrm{HRQ}$ oL is multidimensional, comprising physical, medical, psychological and social parameters secondary to a disease and its treatment, and is considered as one of the most important outcome measurements in cancer treatment nowadays. Evaluating HRQoL helps health professionals to focus on certain aspects to improve current treatment strategies. Moreover, understanding $\mathrm{HRQ}$ oL in patients after surgery for gastric cancer is useful for informing patients about the (longterm) risks and benefits of an intervention.

High-quality studies evaluating HRQoL after gastrectomy for cancer in Western countries are scarce. In addition, it is unknown if HRQoL of patients after gastrectomy differs from HRQoL in the general population. The aim of this multicenter cross-sectional study was therefore to evaluate HRQoL in patients who underwent gastrectomy for cancer in relation to the general population and to identify factors influencing HRQoL. 


\section{Methods}

\section{Study design}

This cross-sectional multicenter cohort study included data from 7 referral centers for gastric cancer surgery in the Netherlands. All data were extracted from prospectively collected institutional databases. Institutional Review Board approval was obtained and informed consent requirement was waived for this study.

\section{Patient population}

This study included patients who underwent gastrectomy for gastric adenocarcinoma between 2001-2015. Only patients who were alive and free of disease were approached for participation. According to national guidelines, patients received either perioperative treatment and gastrectomy or gastrectomy alone. Staging was performed in accordance with the 7th American Joint Committee on Cancer TNM staging system [5, 6]. Information on patient, treatment, and histopathological characteristics were collected from the prospective institutional databases. Follow-up was updated retrospectively.

Quality of Life

Cross-sectional HRQoL was measured by means of the European Organisation for Research and Treatment of Cancer (EORTC) questionnaires. The EORTC-QLQ-C30 was developed to assess the HRQoL of patients with cancer in general [7], the EORTC-QLQ-STO22 was developed to assess the HRQoL of patients with gastric cancer specifically [4]. The EORTC-QLQ-C3O and EORTC-QLQ-STO22 consist of 30 and 22 questions respectively, scored on a 4-point or 7-point Likert scale, which are translated to a global QoL scale, functional scales (physical, role, emotional, cognitive, social, and body image) and symptom scales (fatigue, nausea and vomiting, pain, dyspnea, insomnia, appetite loss, constipation, diarrhoea, financial difficulties, dysphagia, reflux, eating restrictions, anxiety, dry mouth, taste, and hair loss). Higher scores in global HRQoL and functional scales indicate better HRQoL, whereas higher scores in the symptom scales indicate more severe symptoms. Patients were contacted to complete the questionnaires by mail, and received one reminder by telephone in case of no response.

\section{Statistical analyses}

Variables were presented as numbers with percentages (ordinal variables), mean with standard deviation (parametric continues variables), or median with range (non-parametric continues variables). HRQoL data obtained by the questionnaires 
were scored according to the manual [8], and presented as values between 0-100. The patients' HRQOL scores of the EORTC-QLQ-C30 were compared to a general Dutch reference population by using data from a previous study, consisting of 1,731 individuals ( 925 men and 796 women) with a mean age of 52.9 years [9], and performing one sample t-tests. No such reference population exists for the EORTCSTO-22. Based on previous studies, a difference in $\mathrm{HRQOL}>10$ points was considered clinically relevant [10]. A Spearman's rank correlation coefficient $(\rho)$ was calculated to measure the dependence of different HRQoL scores to time since surgery, and is presented as a value between 0.0-1.0. A positive or negative correlation coefficient was considered very strong if $\rho>0.8$, strong if $\rho=0.6-0.8$, moderate if $\rho=0.4-0.6$, weak if $\rho=0.2-0.4$, and very weak if $\rho<0.2$. Moreover, the Kruskal-Wallis test was used to compare HRQoL between the years of surgery. Last, multivariable linear regression analysis with stepwise backward elimination of the least significant variables was performed to evaluate the association between HRQoL scales and patient-, surgical and histopathological variables. These variables were chosen based on their possible association with HRQOL as demonstrated by previous studies [11-15], and included gender, age, neoadjuvant treatment, subtotal vs. total gastrectomy, minimally invasive vs. open gastrectomy, ASA score, major complications (defined as complications requiring a reintervention or intensive care admission.), tumor stage and length of follow-up. Results of the multivariable linear regression were demonstrated as linear regression coefficients with $95 \%$ confidence intervals ( $95 \% \mathrm{Cls}$ ). A p-value $<0.05$ was considered statistically significant. All statistical analyses were performed using IBM SPSS version 21 for Windows.

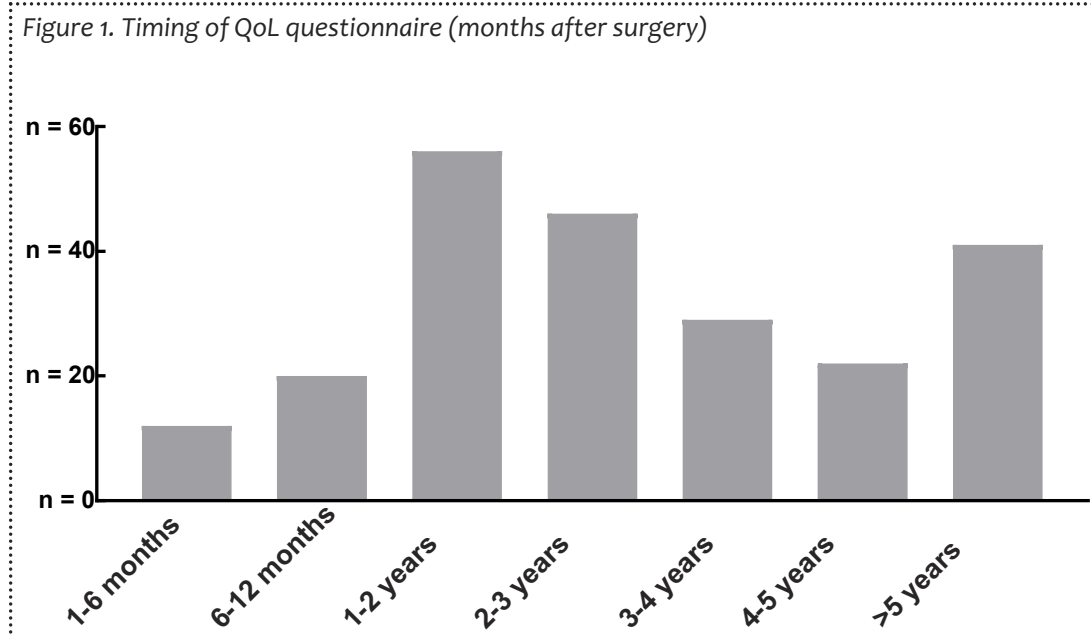




\begin{tabular}{|c|c|c|c|}
\hline \multirow[t]{2}{*}{ Results } & \multicolumn{3}{|c|}{$\begin{array}{l}\text { Table 1. Baseline characteristics of } 222 \text { patients who } \\
\text { underwent gastrectomy for cancer }\end{array}$} \\
\hline & & $n=22$ & \\
\hline \multirow{2}{*}{ Patients } & Age (years) [mean $( \pm S D)]$ & 67.7 & \pm 10.6 \\
\hline & BMI $(\mathrm{kg} / \mathrm{m} 2)[$ mean $( \pm \mathrm{SD})]$ & 25.5 & \pm 4.4 \\
\hline \multirow{14}{*}{$\begin{array}{l}\text { A total of } 683 \text { patients who } \\
\text { underwent gastrectomy for gastric } \\
\text { adenocarcinoma were identified } \\
\text { from the combined database. Some } \\
409 \text { patients were excluded due to } \\
\text { death or recurrent disease. The } \\
\text { remaining } 274 \text { patients were invited } \\
\text { to participate in the study and were } \\
\text { sent HRQoL questionnaires. The } \\
\text { questionnaires were completed by } \\
222 \text { of } 274(81.0 \%) \text { patients. }\end{array}$} & Gender & & \\
\hline & Male & 141 & $(63.5)$ \\
\hline & Female & 81 & (36.5) \\
\hline & Malignancy history & & \\
\hline & No & 157 & $(86.3)$ \\
\hline & Yes & 25 & $(14.7)$ \\
\hline & Unknown & 40 & \\
\hline & Comorbidity & 169 & $(76.1)$ \\
\hline & Pulmonary & 37 & $\begin{array}{l}(49.5) \\
(16.7)\end{array}$ \\
\hline & Diabetes Mellitus & 37 & $(16.7)$ \\
\hline & ASA & & \\
\hline & 1 & 33 & (14.9) \\
\hline & II & 141 & $(63.5)$ \\
\hline & III & 46 & $(20.7)$ \\
\hline Baseline & IV & 2 & $(0.9)$ \\
\hline \multirow{10}{*}{$\begin{array}{l}\text { The median follow-up at completing } \\
\text { the questionnaires was } 29 \text { months } \\
\text { (range } 3-171) ; 193(86.9 \%) \text { of the } \\
\text { respondents had a follow-up of }>1 \\
\text { year, whereas } 40(18.0 \%) \text { had a } \\
\text { follow-up of }>5 \text { years (figure } 1) \text {. } \\
\text { Patient-, surgical-, and } \\
\text { histopathological characteristics of } \\
\text { the patients are shown in table } 1 .\end{array}$} & Neoadjuvant treatment & 143 & $(64.4)$ \\
\hline & Adjuvant treatment & 67 & (30.2) \\
\hline & Year of surgery & & \\
\hline & & 3 & (11.4) \\
\hline & 200 & 10 & (4.5) \\
\hline & & 66 & $(29.7)$ \\
\hline & 2013 & 143 & $(64.4)$ \\
\hline & Surgical type & & \\
\hline & Partial gastrectomy & 105 & $(47 \cdot 3)$ \\
\hline & $\begin{array}{l}\text { Total gastrectomy } \\
\text { Surgical approach }\end{array}$ & 117 & $(52.7)$ \\
\hline \multirow{2}{*}{$\begin{array}{l}\text { Some } 143(64.4 \%) \text { patients had } \\
\text { undergone neoadjuvant treatment, }\end{array}$} & Open & 111 & $(50.0)$ \\
\hline & Laparoscopic & 111 & $(50.0)$ \\
\hline \multirow{6}{*}{$\begin{array}{l}117 \text { patients (52.7\%) a total } \\
\text { gastrectomy, and } 111 \text { patients } \\
(50.0 \% \text { a minimally invasive } \\
\text { gastrectomy (MIG). Of the patients } \\
\text { receiving perioperative treatment, }\end{array}$} & Complications & 89 & $(40.1)$ \\
\hline & Major & 42 & (18.9) \\
\hline & Anastomotic leakage & 16 & $(7.2)$ \\
\hline & Pulmonary & 24 & $(10.8)$ \\
\hline & Hospital stay (median, range) & 9 & $(3-124)$ \\
\hline & Radicality & & \\
\hline \multirow{9}{*}{$\begin{array}{l}\text { the vast majority received } \\
\text { perioperative chemotherapy } \\
\text { according to a regimen similar to } \\
\text { epirubicin, cisplatin, and } \\
\text { capecitabinz. Radiotherapy was not } \\
\text { routinely performed, except for } \\
\text { some patients who received }\end{array}$} & Ro & 214 & $(96.4)$ \\
\hline & $\mathrm{R}+$ & 5 & $(2.3)$ \\
\hline & Missing & 3 & $(1.4)$ \\
\hline & pTNM-stage & & \\
\hline & 0 & 15 & $(6.8)$ \\
\hline & I & 88 & (39.6) \\
\hline & II & 78 & $(35.1)$ \\
\hline & III & 40 & $(18.0)$ \\
\hline & IV & 1 & $(0.5)$ \\
\hline
\end{tabular}


adjuvant chemoradiation as part of the CRITICS trial [16]. The majority of patients $(n=119,53.6 \%)$ had an advanced tumor stage ( $\geq 11)$. Major postoperative complications were seen in $42(18.9 \%)$ patients. Median hospital stay was 9 days (range 3-124), and 24 (10.8\%) patients were readmitted within 30 days after discharge.

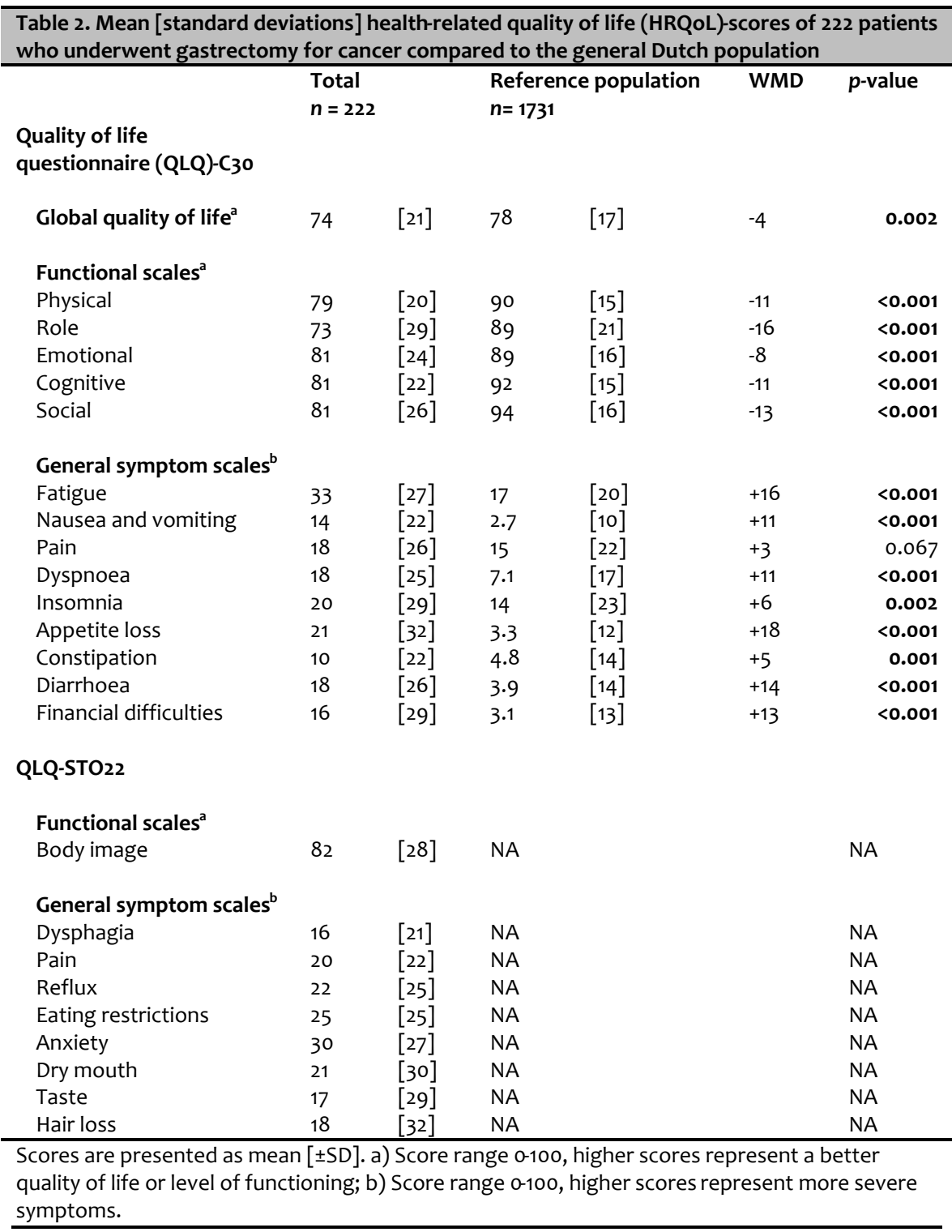


Table 3. Spearman's rank correlation coefficients between quality of life and length of followup since surgery

\section{Spearman's rank coefficient (rho)}

Total cohort

$\mathrm{FU}<1$ year $(n=29)$

FU $>1$ year $(n=193)$

Quality of life questionnaire

$(n=222)$

(QLQ)-C30

\begin{tabular}{|c|c|c|c|}
\hline Global quality of life ${ }^{a}$ & +0.06 & -0.01 & +0.11 \\
\hline \multicolumn{4}{|l|}{ Functional scales $^{\mathrm{a}}$} \\
\hline Physical & -0.08 & -0.11 & -0.03 \\
\hline Role & -0.02 & -0.17 & +0.06 \\
\hline Emotional & +0.07 & -0.11 & +0.14 \\
\hline Cognitive & +0.08 & +0.10 & +0.20 \\
\hline Social & +0.03 & -0.03 & +0.07 \\
\hline \multicolumn{4}{|c|}{ General symptom scales ${ }^{\mathrm{b}}$} \\
\hline Fatigue & +0.08 & +0.29 & -0.01 \\
\hline Nausea and vomiting & +0.07 & -0.14 & +0.06 \\
\hline Pain & +0.06 & +0.03 & -0.01 \\
\hline Dyspnoea & +0.03 & +0.17 & -0.03 \\
\hline Insomnia & +0.04 & -0.11 & -0.05 \\
\hline Appetite loss & -0.02 & -0.25 & -0.05 \\
\hline Constipation & -0.07 & -0.17 & -0.08 \\
\hline Diarrhoea & +0.07 & -0.06 & +0.09 \\
\hline Financial difficulties & -0.02 & -0.14 & -0.06 \\
\hline \multicolumn{4}{|l|}{ QLQ-STO22 } \\
\hline \multicolumn{4}{|l|}{ Functional scales $^{\mathrm{a}}$} \\
\hline Body image & +0.03 & +0.25 & +0.02 \\
\hline \multicolumn{4}{|c|}{ General symptom scales ${ }^{\mathrm{b}}$} \\
\hline Dysphagia & -0.03 & -0.32 & -0.03 \\
\hline Pain & -0.02 & -0.16 & -0.09 \\
\hline Reflux & +0.13 & +0.01 & +0.13 \\
\hline Eating restrictions & -0.11 & -0.11 & -0.07 \\
\hline Anxiety & -0.11 & -0.03 & -0.13 \\
\hline Dry mouth & +0.02 & -0.03 & +0.03 \\
\hline Taste & -0.13 & +0.05 & -0.13 \\
\hline Hair loss & -0.05 & -0.46 & -0.03 \\
\hline
\end{tabular}

HRQOL vs. reference population

The mean HRQoL score and standard deviation of the study population and the reference population are shown in table 2 [9]. Patients who underwent gastrectomy for cancer had statistically significantly lower scores than the reference population for all functional scales $(p<0.001)$ and most general symptom scales $(p<0.002)$, expect for pain symptoms $(p=0.067)$ (table 2$)$. This difference 
was clinically relevant for most scales (physical, role, cognitive, and social functioning, fatigue, nausea and vomiting, dyspnoea, appetite loss, diarrhea, and financial difficulties). On global HRQoL, patients scored significantly worse compared to the reference population, although this difference was clinically irrelevant (weighted mean difference $=4, p=0.002$ ). The distribution of global HRQoL scores is demonstrated in figure $2: 78 \%$ of patients scored a global HRQoL $>60$, compared to $83 \%$ in the reference population ( $p=0.027)$.

In a subgroup analysis of males or females compared to a reference population of comparable age (60-69 years), similar results as demonstrated in table 2 were found (supplementary file 1 and 2). In addition, subgroup analyses of patients with a follow-up of $\geq 12$ months did not influence the results either (supplementary file 3).

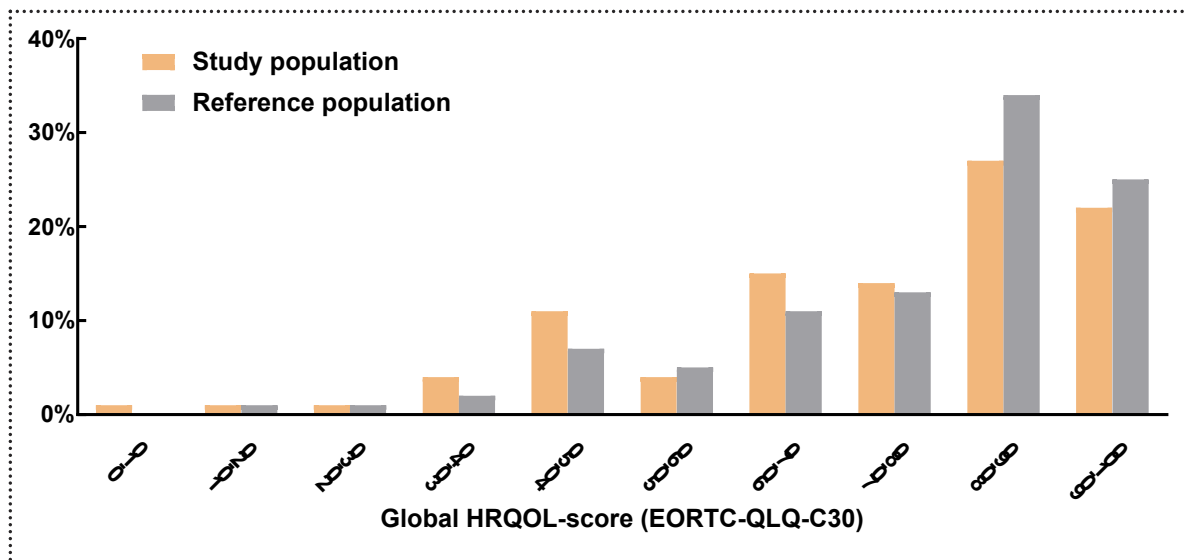

Figure 2. Distribution of global HRQOL-scores (EORTC-QLQ-C30) of 222 patients who underwent gastrectomy for cancer compared to the general Dutch population

HRQoL and time since surgery

Spearman's rank correlation coefficients between HRQoL and time after surgery were calculated, and demonstrated weak correlations, ranging from -0.13 to +0.13 (table 3). In patients with a follow-up <1 year, a larger variation of correlations was present, ranging from -0.46 to +0.29 . Moreover, there was no difference in $\mathrm{HRQOL}$ between the years of surgery $(p=0.523)$.

\section{Predictive factors for HRQoL}

Global HRQoL was significantly higher in patients who underwent partial gastrectomy $(+6.595 \% \mathrm{Cl}[0.8 ; 12, \mathrm{p}=0.026])$ and neoadjuvant treatment $(+8.295 \%$ $\mathrm{Cl}[1.8 ; 15], \mathrm{p}=0.012)$. Moreover, both partial gastrectomy and neoadjuvant treatment were associated with better HRQoL scores in other symptom and 

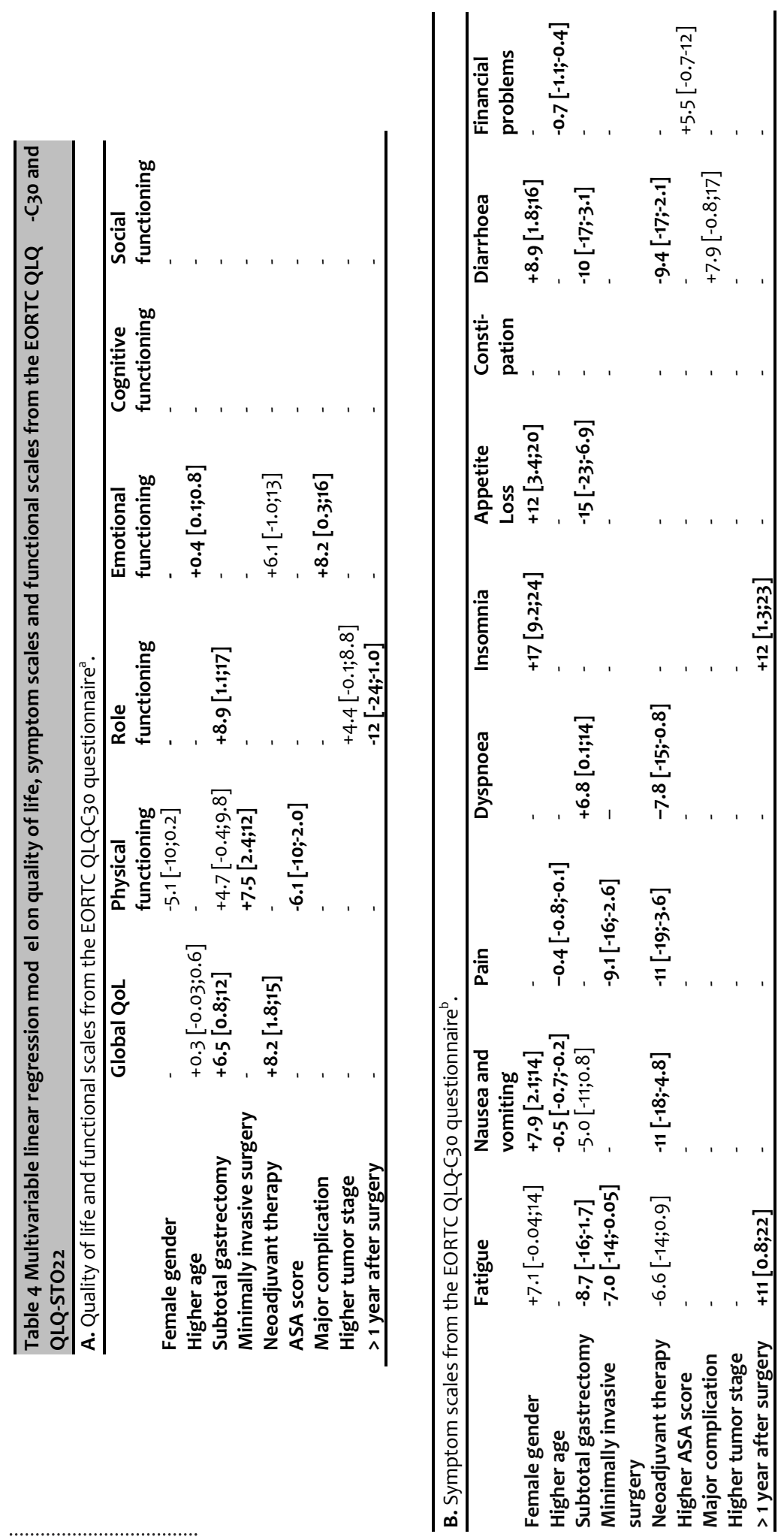


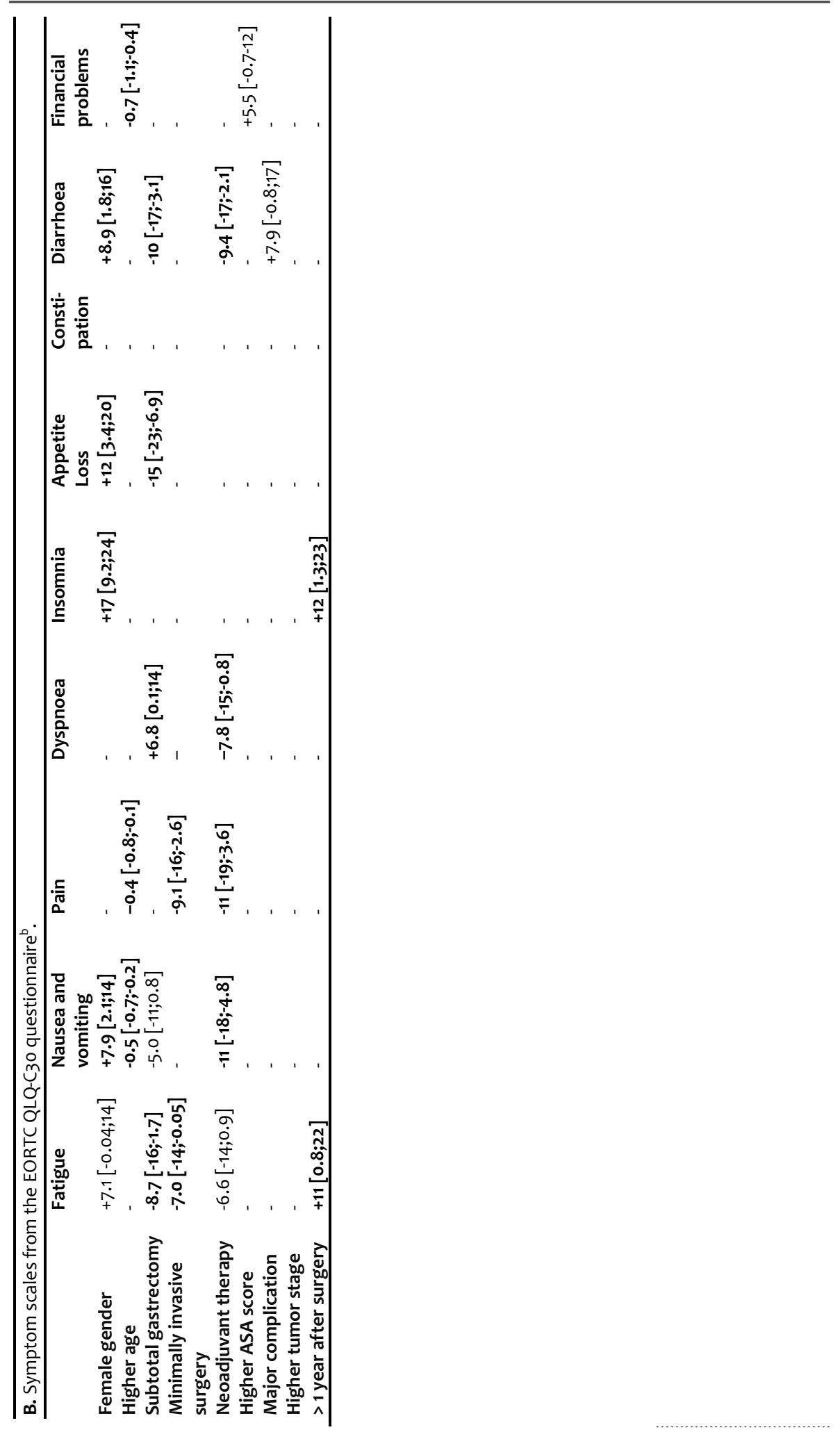


functioning scales (table 4). Minimally invasive surgery resulted in significantly better HRQoL scores on physical functioning $(+7.5$ [2.4;12], $p=0.004)$, fatigue $(-7.0$ $[-14 ;-0.05] p=0.048)$, pain $(-9.1[-16 ;-2.6], p=0.007)$, and dry mouth $(-9.5[-17 ;-1.8]$, $p=0.015$ ). Furthermore, female gender and a high ASA-score were predictive factors for impaired HRQoL in some scales. 


\section{Discussion}

This cross-sectional multicenter study demonstrates that patients who underwent gastrectomy experienced functional complaints and symptoms, whereas global HRQoL was only slightly lower compared to the Dutch reference population. No strong correlations between time after surgery and HRQoL scores was found, indicating that $\mathrm{HRQOL}$ remains stable after surgery. Most importantly, partial gastrectomy and the ability to receive neoadjuvant treatment were associated with higher global HRQoL, whereas minimally invasive surgery was associated with better functional and symptom scores.

This study included consecutively treated patients in 7 centers in the Netherlands, a population which consists of elderly patients, with multiple comorbidities and advanced tumor stages, who frequently underwent perioperative chemotherapy and minimally invasive surgery. The results of this study are therefore relevant, as they may represent the average population undergoing gastrectomy for cancer in the West. Unfortunately, to date, most studies on HRQoL after gastrectomy lacked data on patient characteristics [12], were performed in the Asian population [1315], or made a selection of patients by age [14], minimally invasive procedures [14, 15], comorbidities [14, 15], tumor stage [13] or perioperative chemotherapy [11]. The present study is the first study to include all disease-free patients who underwent gastrectomy for cancer, and to compare the results to a general Western reference population.

Patient experience significant functional impairment and symptoms after gastrectomy. However, this study demonstrates that the absolute difference in global HRQoL is clinically irrelevant. These findings correspond with previous studies on HRQoL after other types of cancer surgery, such as esophagectomy [17] and breast cancer surgery [18], and demonstrate that patients can achieve a high life satisfaction after surviving cancer, regardless of the presence of symptoms or functional impairment. This might be explained by a phenomenon called reconceptualization, which is well known in HRQoL assessments [19]. Reconceptualization implies that certain circumstances, such as surviving cancer, can alter the internal reference points of an individual's well-being, which are critical for an evaluation of HRQoL. As a result, objective impairments in different areas of life can be measured, but the overall HRQoL is based on other factors and can therefore be comparable to before the circumstance, or as in this study, to the general population. For example, a recent study even found a higher global HRQoL in patients who underwent partial gastrectomy for early gastric cancer compared to a general reference population, even though they experienced more symptoms [14]. 
The superiority of minimally invasive gastrectomy over open gastrectomy in HRQoL was previously demonstrated by an Asian randomized controlled trial as well [13]. Comparable benefits were found on physical functioning, and symptoms such as fatigue and dry mouth. However, benefits in global HRQoL, as demonstrated by the Asian study, could not be confirmed by the present study. This difference could be explained by the fact that the present study evaluated a population with longer follow-up than the Asian study (median of 29 vs. 3 months). As minimally invasive surgery was introduced to reduce surgical trauma and fasten recovery, one might expect $\mathrm{HRQ}$ oL benefits of minimally invasive surgery mainly on the short-term. Nevertheless, the present study was also able to detect HRQoL benefits of minimally invasive surgery in a population with long-term follow-up. Minimally invasive gastrectomy may have additional advantages over open gastrectomy, such as reduced morbidity and shorter hospital stay [20], and it is used more frequently over the years [21]. On the other hand, minimally invasive gastrectomy is known to have a significant learning curve [22, 23], and results from randomized controlled trials should be awaited before broad implementation can be performed [24-26].

Other factors possibly influencing HRQoL that were evaluated in this study were the extent of gastrectomy, neoadjuvant treatment, gender and time since surgery. Partial gastrectomy is a less extensive procedure, in which a functional part of the stomach is preserved, and requires a less extensive lymphadenectomy [27], which probably contributed to a higher HRQoL compared to total gastrectomy on several domains. This finding is in line with previous studies $[15,28]$. Unfortunately, partial gastrectomy can only be performed in selected cases in which oncologic safety can be guaranteed by a safe margin around the tumor [27]. An interesting finding is the higher HRQoL in patients who were able to receive neoadjuvant treatment, which was chemotherapy in almost all patients, compared to patients who did not receive neoadjuvant treatment. Although chemotherapy has been shown to increase HRQoL in the palliative setting in comparison to best supportive care [29], to our knowledge there is no comparative data on HRQoL in the perioperative, curative setting. The only evidence available demonstrates that physical fitness of patients decreases during neoadjuvant treatment [30]. The present study suggests that if patients are fit enough to receive neoadjuvant treatment, they are likely to have HRQoL benefits on the long term. The lower HRQoL after gastrectomy found in females is consistent with previous studies and the general reference population $[9,17]$. Time since surgery was not associated, nor correlated with HRQoL. This may be explained by the fact that the present study consisted mostly of patients with long-term follow-up, and therefore could not focus on patients with a shortterm follow-up. Previous studies have demonstrated that time since surgery is 
mainly associated with $\mathrm{HRQ}$ oL in the early recovery period [11], whereas it remains relatively stable after the first year since surgery [31].

There are some limitations of this study that need to be addressed. First, compared to the reference population, the study population consisted of older patients, and a higher proportion of males. In order to reduce the risk of confounding by gender, we performed subgroup analyses of males and females. Second, patients with undiagnosed recurrent disease might have been included in this study. As recurrent disease is an important negative predictor of HRQoL [11], this could have decreased the HRQoL measured in the study population. Third, despite correcting for confounding factors, selection bias cannot be fully excluded. These previous two limitations might also explain the higher HRQoL in patients who were able to receive neoadjuvant treatment, as these patients are generally more fit and at a lower risk for recurrence compared to patients not receiving neoadjuvant treatment [2]. Another form of selection-bias influencing the results of this study is that mainly long-term survivors were included. Patients with recurrence or patients who have died were excluded, which may be patients with worse HRQoL after gastrectomy. This may have led to an overestimation of the quality of life of patients after gastrectomy in this study. Lastly, due to the cross-sectional design of this study, repeated measurements of HRQoL over time could not be analyzed.

In conclusion, although surviving patients experience significant symptoms and functional problems after gastrectomy, the global HRQoL is more or less comparable to the general population. Partial gastrectomy, the ability to receive neoadjuvant treatment and minimally invasive surgery are associated with HRQoL benefits, and should therefore be preferred if oncological safety is not compromised. The results of this study may help health care professionals during clinical decision-making and the preoperative process of informed consent.

\section{Acknowledgements}

The authors thank Peter van Rossum for his assistance in the statistical analyses, and Nicole van der Wielen, Judith Schots, Rob Tolboom and Ilse Masselink for their help in obtaining the HRQoL data.

\section{Conflict of Interest Statement}

The authors have nothing to disclose. All authors are participants of the LOGICAtrial consortium, a trial comparing open versus laparoscopic gastrectomy funded by a ZonMw Health Care Efficiency Grant (ID: 237002502) 


\section{References}

1. Ferlay J, Soerjomataram I, Dikshit R, Eser S, Mathers C, Rebelo M, Parkin DM, Forman D, and Bray F, Cancer incidence and mortality worldwide: sources, methods and major patterns in GLOBOCAN 2012. Int J Cancer, 2015. 136(5): p. E359-86.

2. Cunningham D, Allum WH, Stenning SP, Thompson JN, Van de Velde CJ, Nicolson M, Scarffe JH, Lofts FJ, Falk SJ, Iveson TJ, Smith DB, Langley RE, Verma M, Weeden S, Chua YJ, and Participants MT, Perioperative chemotherapy versus surgery alone for resectable gastroesophageal cancer. $\mathrm{N}$ Engl J Med, 2006. 355(1): p. 11-20.

3. Hartgrink HH, van de Velde CJ, Putter H, Bonenkamp JJ, Klein Kranenbarg E, Songun I, Welvaart K, van Krieken JH, Meijer S, Plukker JT, van Elk PJ, Obertop H, Gouma DJ, van Lanschot JJ, Taat CW, de Graaf PW, von Meyenfeldt MF, Tilanus H, and Sasako M, Extended lymph node dissection for gastric cancer: who may benefit? Final results of the randomized Dutch gastric cancer group trial. J Clin Oncol, 2004. 22(11): p. 2069-77.

4. Blazeby JM, Conroy T, Bottomley A, Vickery C, Arraras J, Sezer O, Moore J, Koller M, Turhal NS, Stuart R, Van Cutsem E, D'Haese S, Coens C, European Organisation for R, Treatment of Cancer G, and Quality of Life G, Clinical and psychometric validation of a questionnaire module, the EORTC QLQ-STO 22, to assess quality of life in patients with gastric cancer. Eur J Cancer, 2004. 40(15): p. 2260-8.

5. Edge SB and Compton CC, The American Joint Committee on Cancer: the 7th edition of the AJCC cancer staging manual and the future of TNM. Ann Surg Oncol, 2010. 17(6): p. 1471-4.

6. Washington K, 7th edition of the AJCC cancer staging manual: stomach. Ann Surg Oncol, 2010. 17(12): p. 3077-9.

7. Aaronson NK, Ahmedzai S, Bergman B, Bullinger M, Cull A, Duez NJ, Filiberti A, Flechtner H, Fleishman SB, de Haes JC, and et al., The European Organization for Research and Treatment of Cancer QLQ-C30: a quality-of-life instrument for use in international clinical trials in oncology. J Natl Cancer Inst, 1993. 85(5): p. 365-76.

8. Fayers P, Aaronson N, Bjordal K, Groenvold M, Curran D, and Bottomley A, The EORTC QLQ-C30 scoring manual. 3rd Edition ed. 2001: Brussels: European Organisation for Research and Treatment of Cancer.

9. van de Poll-Franse LV, Mols F, Gundy CM, Creutzberg CL, Nout RA, Verdonck-de Leeuw IM, Taphoorn MJ, and Aaronson NK, Normative data for the EORTC QLQ-C30 and EORTC-sexuality items in the general Dutch population. Eur J Cancer, 2011. 47(5): p. 667-75.

10. Osoba D, Rodrigues G, Myles J, Zee B, and Pater J, Interpreting the significance of changes in healthrelated quality-of-life scores. J Clin Oncol, 1998. 16(1): p. 139-44.

11. Avery K, Hughes R, McNair A, Alderson D, Barham P, and Blazeby J, Health-related quality of life and survival in the 2 years after surgery for gastric cancer. Eur J Surg Oncol, 2010. 36(2): p. 148-54.

12. Karanicolas PJ, Graham D, Gonen M, Strong VE, Brennan MF, and Coit DG, Quality of life after gastrectomy for adenocarcinoma: a prospective cohort study. Ann Surg, 2013. 257(6): p. 1039-1046.

13. Kim YW, Baik YH, Yun YH, Nam BH, Kim DH, Choi IJ, and Bae JM, Improved quality of life outcomes after laparoscopy-assisted distal gastrectomy for early gastric cancer: results of a prospective randomized clinical trial. Ann Surg, 2008. 248(5): p. 721-7.

14. Lee SS, Chung HY, Kwon O, and Yu W, Long-term Shifting Patterns in Quality of Life After Distal Subtotal Gastrectomy: Preoperative- and Healthy-based Interpretations. Ann Surg, 2015. 261(6): p. 11317.

15. Lee SS, Chung HY, Kwon OK, and Yu W, Long-term Quality of Life After Distal Subtotal and Total Gastrectomy: Symptom- and Behavior-oriented Consequences. Ann Surg, 2016. 263(4): p. 738-44.

16. Dikken JL, van Sandick JW, Maurits Swellengrebel HA, Lind PA, Putter H, Jansen EP, Boot H, van Grieken NC, van de Velde CJ, Verheij M, and Cats A, Neo-adjuvant chemotherapy followed by surgery and chemotherapy or by surgery and chemoradiotherapy for patients with resectable gastric cancer (CRITICS). BMC Cancer, 2011. 11: p. 329. 
17. Akkerman RD, Haverkamp L, van Rossum PS, van Hillegersberg R, and Ruurda JP, Long-term quality of life after oesophagectomy with gastric conduit interposition for cancer. Eur J Cancer, 2015. 51(12): p. $1538-45$.

18. Arndt V, Merx H, Sturmer T, Stegmaier C, Ziegler H, and Brenner H, Age-specific detriments to quality of life among breast cancer patients one year after diagnosis. Eur J Cancer, 2004. 40(5): p. 673-80.

19. Blome $C$ and Augustin M, Measuring change in quality of life: bias in prospective and retrospective evaluation. Value Health, 2015. 18(1): p. 110-5.

20. Kim W, Kim HH, Han SU, Kim MC, Hyung WJ, Ryu SW, Cho GS, Kim CY, Yang HK, Park DJ, Song KY, Lee SI, Ryu SY, Lee JH, Lee HJ, and Korean Laparo-endoscopic Gastrointestinal Surgery Study G, Decreased Morbidity of Laparoscopic Distal Gastrectomy Compared With Open Distal Gastrectomy for Stage I Gastric Cancer: Short-term Outcomes From a Multicenter Randomized Controlled Trial (KLASS01). Ann Surg, 2016. 263(1): p. 28-35.

21. Busweiler LA, Wijnhoven BP, van Berge Henegouwen MI, Henneman D, van Grieken NC, Wouters MW, van Hillegersberg R, van Sandick JW, and Dutch Upper Gastrointestinal Cancer Audit G, Early outcomes from the Dutch Upper Gastrointestinal Cancer Audit. Br J Surg, 2016. 103(13): p. 1855-1863. 22. Jung DH, Son SY, Park YS, Shin DJ, Ahn HS, Ahn SH, Park DJ, and Kim HH, The learning curve associated with laparoscopic total gastrectomy. Gastric Cancer, 2016. 19(1): p. 264-72.

23. Zhang $X$ and Tanigawa N, Learning curve of laparoscopic surgery for gastric cancer, a laparoscopic distal gastrectomy-based analysis. Surg Endosc, 2009. 23(6): p. 1259-64.

24. Haverkamp L, Brenkman HJ, Seesing MF, Gisbertz SS, van Berge Henegouwen MI, Luyer MD, Nieuwenhuijzen GA, Wijnhoven BP, van Lanschot JJ, de Steur WO, Hartgrink HH, Stoot JH, Hulsewe KW, Spillenaar Bilgen EJ, Rutter JE, Kouwenhoven EA, van Det MJ, van der Peet DL, Daams F, Draaisma WA, Broeders IA, van Stel HF, Lacle MM, Ruurda JP, van Hillegersberg R, and group Ls, Laparoscopic versus open gastrectomy for gastric cancer, a multicenter prospectively randomized controlled trial (LOGICA-trial). BMC Cancer, 2015. 15: p. 556.

25. Hur H, Lee HY, Lee HJ, Kim MC, Hyung WJ, Park YK, Kim W, and Han SU, Efficacy of laparoscopic subtotal gastrectomy with D2 lymphadenectomy for locally advanced gastric cancer: the protocol of the KLASS-02 multicenter randomized controlled clinical trial. BMC Cancer, 2015. 15: p. 355.

26. Straatman J, Cuesta MA, and van der Peet DL, Optimal Management of Gastric Cancer: Laparoscopic Versus Open Gastrectomy. Ann Surg, 2015. 262(6): p. e97.

27. Japanese Gastric Cancer A, Japanese gastric cancer treatment guidelines 2010 (ver. 3). Gastric Cancer, 2011. 14(2): p. 113-23.

28. Diaz De Liano A, Oteiza Martinez F, Ciga MA, Aizcorbe M, Cobo F, and Trujillo R, Impact of surgical procedure for gastric cancer on quality of life. Br J Surg, 2003. 90(1): p. 91-4.

29. Wagner AD, Unverzagt S, Grothe W, Kleber G, Grothey A, Haerting J, and Fleig WE, Chemotherapy for advanced gastric cancer. Cochrane Database Syst Rev, 2010(3): p. CDo04064.

30. Jack S, West MA, Raw D, Marwood S, Ambler G, Cope TM, Shrotri M, Sturgess RP, Calverley PM, Ottensmeier $\mathrm{CH}$, and Grocott MP, The effect of neoadjuvant chemotherapy on physical fitness and survival in patients undergoing oesophagogastric cancer surgery. Eur J Surg Oncol, 2014. 40(10): p. 1313 20.

31. Yu W, Park KB, Chung HY, Kwon OK, and Lee SS, Chronological Changes of Quality of Life in LongTerm Survivors after Gastrectomy for Gastric Cancer. Cancer Res Treat, 2016. 48(3): p. 1030-6. 

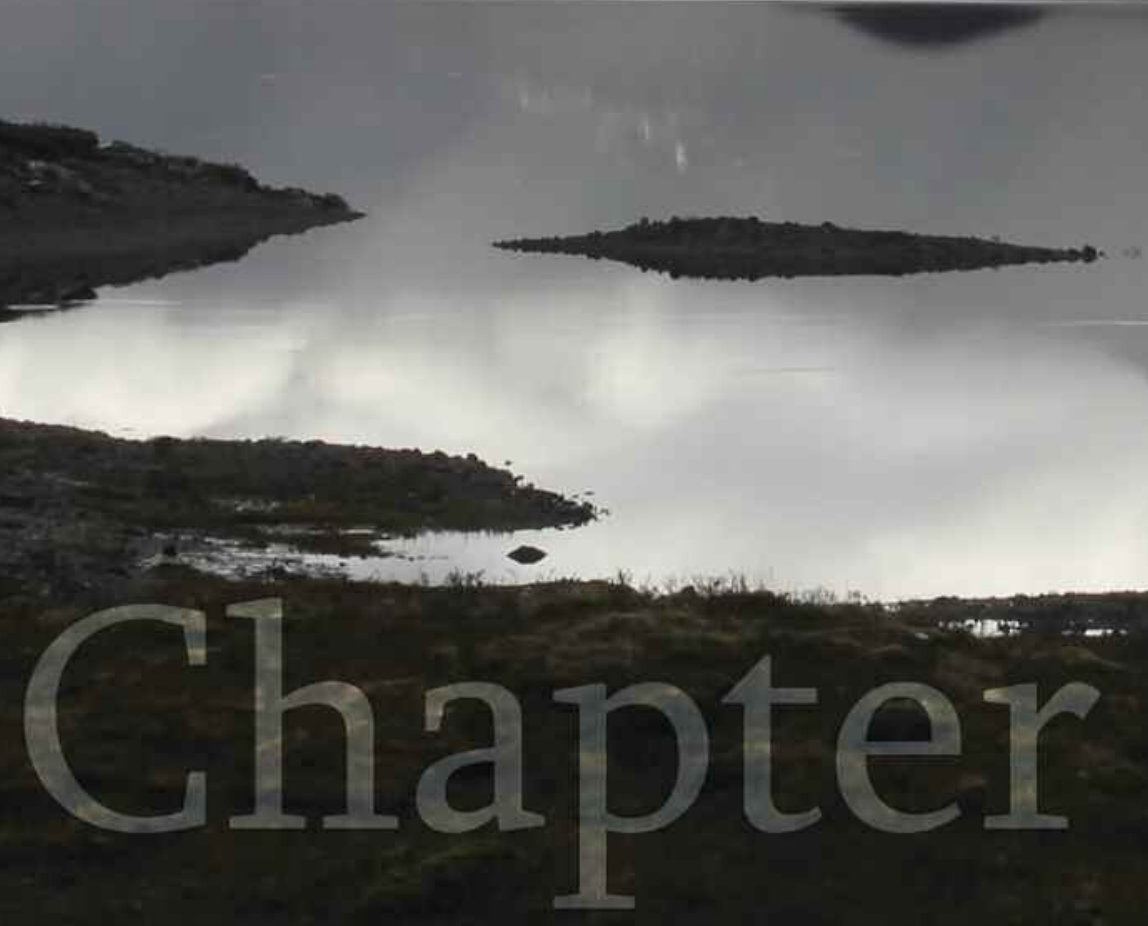


\section{General discussion and summary}

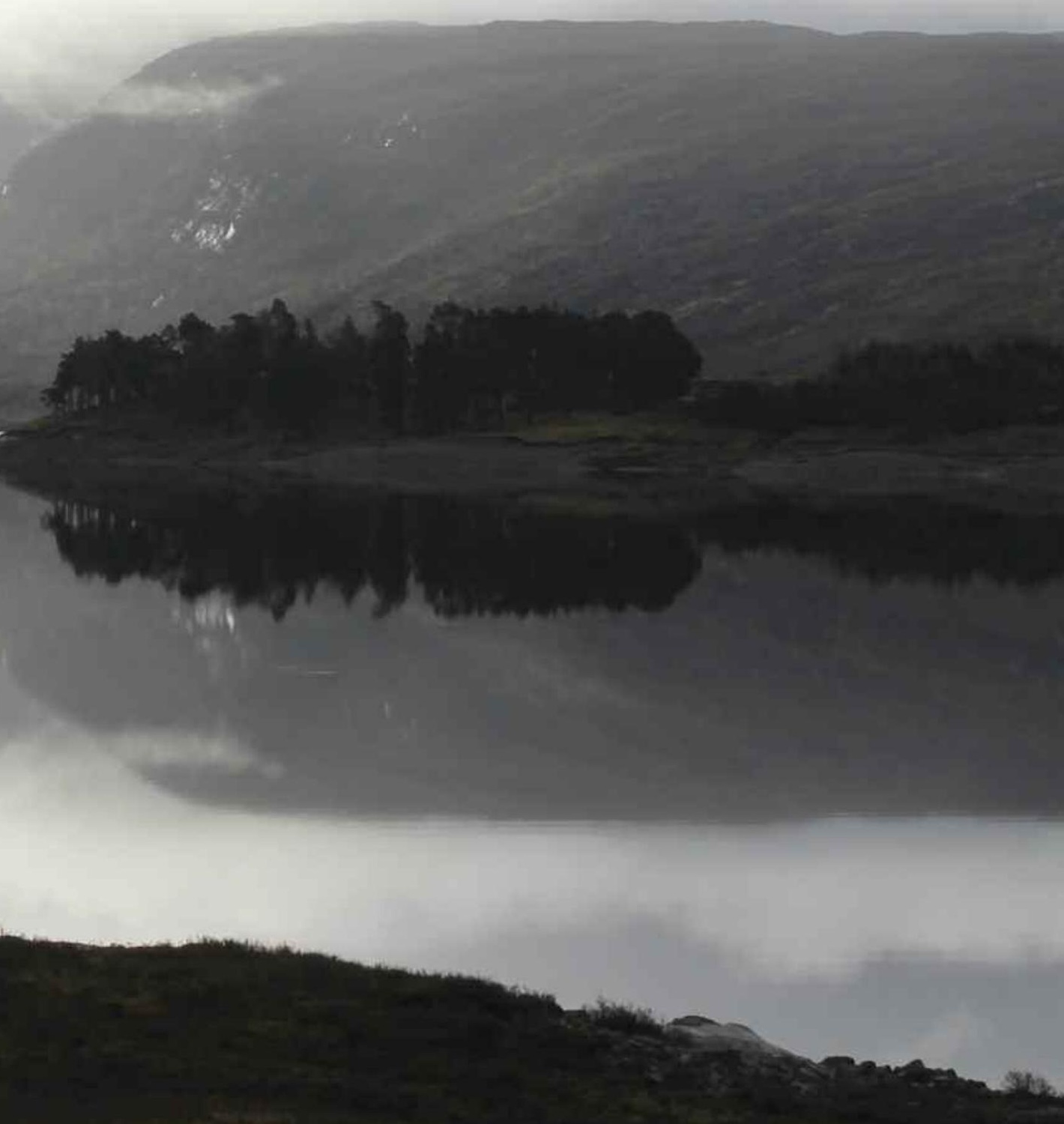


The first aim of this thesis was to provide an overview of literature on advances in the preoperative-, intra-operative and postoperative stage as well as regional organization of gastric cancer surgery. This is described in part one of this thesis and will be summarized below.

Next, part two of this thesis aimed to assess factors in preoperative assessment that could possibly be used to predict adverse outcomes after surgery. Geriatric frailty, nutritional status and body composition measurements such as sarcopenia were assessed for their use as predictors of adverse postoperative outcome. Interesting and promising characteristics for these predictors were found. These were for example in case of sarcopenia contradictory to some other known studies and maybe counterintuitive at first glance. In this chapter all these predictive factors will be discussed.

Part three deals with the third aim of this thesis which was to explore the financial impact of introducing a new surgical technique for gastric cancer: laparoscopic surgery. This section will provide a summary and discussion of the results which may also not be what might be expected.

Lastly, part four, was aimed to explore the impact on Quality of Life of patients after gastric cancer surgery among gastric cancer survivors. In this last part of the thesis more interesting results were found. In the final part of this chapter these will be summarized and discussed. 


\section{Advances in gastric cancer treatment}

Physicians continuously strive to improve care for their patients. For gastric cancer treatment many improvements have been made in recent years. In part one of this thesis an assessment of a number of improvements in surgical care for gastric cancer is provided. Some other important steps forward in gastric cancer treatment are outside the scope of this thesis and are hence not addressed. The most important of these are perhaps the results of perioperative chemotherapy for gastric cancer patients in improving survival.

\section{Preoperative care}

\section{Risk assessment}

Planning for every surgery starts with a risk-benefit assessment. This means optimizing surgical care and preoperative informed consent starts with adequate surgical risk assessment. Risk assessment in general is complex, especially in high risk surgery. Risk assessment in gastric cancer surgery is especially important because morbidity after gastric cancer surgery is relatively high with reported complication rates up to $39 \%$ [1].

Over the years classification systems such as ASA-physical status and Charlson Comorbidity Index $(\mathrm{CCl})$ have helped physicians in clinical decision making, each with their own merits and difficulties [2,3]. For example, octo- and nonagenarians who underwent radical gastrectomies had higher morbidity and mortality rates associated with higher $\mathrm{CCl} \geq 5$ [4]. Table 1 shows examples of other potential risk factors in gastric cancer surgery such as BMI and previous abdominal surgery.

Age in itself should not be a deciding factor on which treatment decisions are made. Comorbid conditions and general condition are far more important factors predicting for adverse outcomes and should therefore be considered in clinical decision making. However, it remains challenging to adequately assess a patient's

\begin{tabular}{llll}
\hline \multicolumn{2}{l}{ Table 1. Preoperative factors as predictors for impaired outcome } & & \\
\hline Factor & Effect & Results & P-value \\
Obesity $(\mathrm{BMI}>25 \mathrm{~kg} / \mathrm{mz})[5]$ & Increased overall complications & $47.9 \mathrm{vs.} \mathrm{35.8 \%}$ & $<0.001$ \\
& Increased anastomotic leakage & $11.8 \mathrm{vs.} \mathrm{5.4 \%}$ & 0.002 \\
& Increased SSI & 8.9 vs. $4.7 \%$ & 0.02 \\
History of PUAS/laparotomy [6] [7] & Similar morbidity & 13.6 vs. 10.6\% & 0.70 \\
\hline BMI: Body Mass Index, PUAS: previous upper abdominal surgery, SSI: surgical site infection.
\end{tabular}


general condition and decide what factors exclude a patient from surgical treatment. Therefore, these other dimensions of patient condition and function that should be considered are discussed.

\section{Dimensions of patient condition and functioning as risk factors}

One of the topics that are further explored in this thesis in chapter three are geriatric frailty and nutritional status. In Western countries gastric cancer is a disease of the elderly, and therefore geriatric aspects have an important role in these patients. Geriatric frailty is defined as a state of increased vulnerability towards stressors in older individuals, leading to increased risk of developing adverse health outcomes. Geriatric frailty is considered by Fried et al. to be a clinical syndrome in which three of the following five aspects are present. Unintentional weight loss (10 lbs in the past year), self-reported exhaustion, weakness (grip strength), slow walking speed, and low physical activity [8]. Geriatric frailty has been identified as a risk factor for impaired outcome after surgery and assessment of frailty is an emerging method to aid surgical risk assessment and which is rapidly gaining evidence based support [9-12].

Gastric cancer patients are at a high risk for malnutrition with 30 to $38 \%$ of patients having $>10 \%$ weight loss in the past six months [13]. Importantly, malnutrition is associated with increased morbidity and mortality after gastric cancer surgery [14]. The detection of nutritional depletion is important, especially with neo-adjuvant therapies potentially further compromising the nutritional and metabolic status [15]. This means that screening for malnutrition makes sense to help identify patients who are at risk of adverse outcomes and to provide a point of intervention in an effort to improve outcome.

Sarcopenia, or the decrease of muscle mass and function, is a part of the cachexia syndrome [14]. Sarcopenia has been shown to affect short- and long-term postoperative outcome in patients undergoing liver and pancreatic surgery for malignancy [16-18]. Assessment of sarcopenia can therefore perhaps help to identify patients who are at risk for adverse outcome. Sarcopenia as a body composition measurement is further explored for gastric cancer patients in this thesis in chapter four.

\section{Staging laparoscopy and wash cytology}

Detection of peritoneal metastases is improved by staging laparoscopy for disease which is not otherwise detected by preoperative imaging [19]. Patient management is changed in up to $60 \%$ of cases and can thereby also prevent an unnecessary explorative laparotomy [20, 21]. For the aforementioned reasons an expert panel concluded that a staging laparoscopy should be performed with exceptions being early gastric cancer or known metastatic disease [22]. Additionally, staging laparoscopy offers the ability to obtain peritoneal wash 
cytology. This can help detect intraperitoneal free cancer cells (IFCC). IFCC's are a predictor of early recurrence after curative intent surgery and its assessment might in the future change management [23].

\section{Advances in intraoperative care: laparoscopic surgery}

As for other types of procedures laparoscopic surgery is advocated to have a multitude of benefits for patients. In gastric cancer it has been shown to be associated with less intra-operative blood loss, fewer overall and minor complications, less postoperative pain and shorter length-of-stay [24]. Also serum markers indicating postoperative stress were lower, i.e. lower C-reactive protein level on day 7, leukocyte count and interleukin-6 levels [25].

There are however downsides to the laparoscopic technique such as increase in operation time, number of harvested lymph nodes and postoperative complications [25, 26]. A meta-analysis evaluating randomized controlled trials and high quality non- randomized controlled trials on laparoscopic versus open approach for distal gastrectomy for cancer showed that major complications and mortality rates were similar between procedures and concluded that the laparoscopic approach is safe [24].

Importantly most of these data are derived from Asian countries which are mainly based on patients with early gastric cancer and therefore comparison to a Western population is difficult because these patients most often have advanced stage disease. The general conclusion of these studies is that the laparoscopic approach offers improved recovery after surgery at no compromise of morbidity and mortality.

A critical issue with laparoscopic surgery according to opponents of this approach is oncological adequacy and perhaps an increase in costs. The evidence for this is still sparse although a few studies report similar oncological outcomes for laparoscopic procedures at five years [27-29].

Therefore work needs to be done to provide evidence for the value of laparoscopic surgery in Western gastric cancer patients. Chapter five of this thesis provides a study that analyses the financial impact of the introduction of laparoscopic surgery for gastric cancer. Larger multi-center randomized controlled trials are needed to provide evidence based data on patient benefit (e.g. reduction in length of hospital stay).

\section{Advances in postoperative care}

ERAS and Fast-track programs

In colorectal surgery, Enhanced recovery after surgery (ERAS) programs have been developed and implemented with great success [30]. Importantly, ERAS protocol 
recommendations are not solely concerned with postoperative care. Additionally, they include preoperative items (e.g., counseling) and intra-operative recommendations (e.g., avoidance of salt and water overload and use of short acting anesthetic agents). Most recommendations by the ERAS society for colonic surgery can potentially be implemented, albeit in modified form, in gastric cancer patients. Examples include: early removal of urinary catheters, prevention of postoperative ileus, postoperative analgesia, and early mobilization and resumption of normal diet [31]. A multitude of studies have investigated fast-track aspects such as early oral feeding. This has resulted in the publication of a gastric cancer surgery specific ERAS protocol, but because of limited evidence for many aspects of ERAS it is largely a consensus guideline [32].

\section{Detection and treatment of anastomotic leakage}

One of the most grave complications of gastric cancer surgery is anastomotic failure or leakage. It can have detrimental consequences including septicemia, multi-organ failure, ICU admission and is potentially fatal. Risk factors for anastomotic leakage include: older age ( $>65$ years), longer operating time, intraoperative errors, increased blood loss and co-morbidities [33-35]. Therefore early detection and treatment are aimed to minimize deleterious consequences to the patient.

Clinical suspicion of anastomotic leakage or intraabdominal abscess requires further evaluation using CT-imaging augmented with oral and intravenous contrast. Fever, Systemic Inflammatory Response Syndrome (SIRS) and positive peritoneal signs can raise suspicion for anastomotic leakage.

Minor leaks can be managed by percutaneous drainage of abscesses and placement of a nasogastric or naso-jejunal tube [36-38]. Reoperation is required when conservative treatment is ineffective if the patient condition warrants surgical exploration. During surgery the anastomosis can be evaluated and reconstruction can be carried out if the anastomosis is in a poor condition [39]. Endoscopy enables evaluation of the anastomotic site without need for invasive surgery and endoscopic treatment options for leakage are available [40]. Smaller defects $(<2 \mathrm{~cm})$ can be successfully managed using endoscopy, e.g., fibrosealant or Histoacryl and removable covered metal stents to treat anastomotic leaks [41, 42]. This technique admittedly requires a well trained and well equipped endoscopy department.

\section{Advances in organization of care: centralization and audits}

In complex surgery and surgical care, such as gastric cancer surgery, increased hospital volume leads to better outcome (i.e., lower short term mortality and improved survival) [43-45]. Annual hospital volume can be low in Western 
countries because of the relatively low incidence of gastric cancer. Centralization of care can be implemented in an effort to increase hospital volume in selected centers, although until now the optimal or minimal number of procedures has not been clearly defined.

Clinical audit is regarded as an important tool to assess quality of care and to help identify factors that require improvement. They also provide unique, uniformly collected datasets for research. An example of results from the Dutch Upper GI Cancer Audit (DUCA) data is that a high lymph node yield ( $>25$ nodes) is associated with prolonged survival [46]. This study, including 3764 patients over an eight year time span, is something that would have been impossible in a Western single centre study.

Similarly interesting, the American College of Surgeons National Surgical Quality Improvement Program (ACS NSQIP) showed that complication rates did not vary much between hospitals, but their mortality rates did. This was largely attributed to the fact that the chance of death after major complications significantly varied. This concept is called failure to rescue. This indicates that timely recognition and treatment of complications deserves greater attention [47]. These findings underline the importance of clinical auditing.

\section{Predictors for adverse postoperative outcome}

In order to improve surgical risk assessment in gastric cancer patients, predictors for adverse outcome can help us identify high-risk patients. This can in turn improve clinical decision making by doctors and shared decision making between doctors and patients. Part two of this thesis deals with several of these.

\section{Geriatric frailty}

Our society is ageing and health care professionals are confronted with elderly patients on a daily basis. This is especially true for Western gastric cancer patients. It is almost axiomatic that a patient's chronological age is only a number and does not correspond to his biological age. However, it remains a challenge to determine or estimate a patient's biological age. Geriatric frailty by definition is a measure of a patient's increased vulnerability towards stressors (e.g., surgery) in older individuals, leading to increased risk of developing adverse health outcomes.

In chapter three a retrospective study is presented that shows that geriatric frailty assessment by using the Groningen Frailty Indicator (GFI) can be used to identify high risk patients. Patients with higher GFI scores (i.e., $\geq 3$ ) had significantly more in-hospital mortality and serious adverse events, i.e., mortality rate and serious adverse event rate. Furthermore, these findings were independent from other known factors such as ASA classification, age and disease stage.

These findings are in line with other studies and the emerging field of geriatric surgery. Earlier studies published showed that frailty is a good predictor for 
outcome in surgical patients, far better than age or comorbidities alone [9, 10, 12, 48].

One of the major challenges of geriatric frailty is that there is no universal way to measure it. Different methods have been used in other studies. For example, increased risk of complications and increased length of hospitalization was observed in patients with higher scores on the Edmonton Frail Scale [9].

In another study several markers for geriatric frailty were used (e.g. age, cognitive function, poor nutritional status, falls, depressed mood and anemia) and showed more 6-month postoperative mortality in patients undergoing major surgery [10]. These markers were assessed using tests such as Mini-Cog 6, laboratory measurement (i.e. hematocrit and serum albumin levels) and KATZ-score for independence of activities of daily living. In another study Fried's frailty was used with questionnaires, grip-strength measurement and timed five meter walk test. It showed that frail patients have increased complications, increased length of hospital stay and are more likely to be discharged to a assisted living facility [12]. So the methods for assessing frailty are diverse in these studies. They include: questionnaires, history taking, laboratory tests, grip strength measurement and timed get-up-and-go tests. These can be cumbersome and time consuming. This in turn often means that doctors or trained nursing staff have to be allocated for these tasks which is resource consuming.

Questionnaires offer a low-cost, low-resource consuming method for estimating the level of frailty in patients. For geriatric frailty multiple questionnaires exist with different performances [49]. The study in chapter three performed geriatric frailty assessment using only a questionnaire.

\section{Nutritional status}

The second item chapter three deals with is nutritional status. In this retrospective study nutritional status was estimated by using a short questionnaire. The Short Nutritional Assessment Questionnaire (SNAQ) is originally designed as a screening tool. Inadequate nutritional intake is a known risk factor for impaired outcome after surgery [14]. Additionally, the lack of adequate nutritional intake is often compromised in upper-gastrointestinal malignancies such as gastric cancer.

In chapter three it is shown that high scores on the SNAQ, i.e., patients at risk of malnutrition, is associated with impaired outcome. Patients with one or more points had a significantly increased mortality rate over patients who score zero. These patients also had an increased length of stay and a higher six-month mortality.

This shows that questionnaires that screen for malnutrition also might be able to identify high risk patients with regards to adverse postoperative outcome. It is unsure however if correction of nutritional imbalance completely reverses the deleterious effects of malnutrition. 


\section{Body composition measurements: sarcopenia}

In the search for indicators of patients' vulnerability to stressors, body composition measurements have been proposed. Low skeletal muscle mass and visceral obesity have been reported $[16,17,50]$. Sarcopenia is a syndrome characterized by low muscle mass and either decreased muscle strength or low physical performance [51]. In addition, sarcopenia can be present in obese patients which is called sarcopenic obesity [51]. The estimated prevalence of sarcopenia worldwide is approximately $10 \%$ in adults over 60 years of age [52].

Sarcopenia has been associated with negative effects on outcome after several types of surgery for cancer including liver, pancreatic and colorectal $[16,17,53]$. In chapter four a study is presented which investigated sarcopenia, or rather low muscle mass, as a predictor of adverse outcome.

The main conclusion from this chapter is that sarcopenia is highly prevalent in gastric cancer surgery patients. Of all patients nearly $60 \%$ were classified as sarcopenic. This was clearly higher compared to other studies that used a similar method for determining sarcopenia. These studies report a prevalence between $15 \%$ and $50 \%[16-18,53-56]$.

Contrary to other studies the study in chapter four did not find that sarcopenic patients were more at risk for short term morbidity and mortality. However, not all previously published studies show an unequivocal relationship between sarcopenia and adverse outcome. In one study a significant increase in major complications was seen in women after radical cystectomy for bladder cancer but not in men [56]. Another study also did not show an association between sarcopenia and complications, disease free survival or overall survival in patients undergoing surgery for colorectal liver metastases [57].

The high rate of sarcopenia found in gastric cancer patients is likely to be explained by a combination of factors that contribute to sarcopenia and are likely to be found in gastric cancer patients. Decreased activity, declined nutritional and protein intake, and higher age probably result in the high rate of sarcopenia seen in gastric cancer patients.

It remains to be clarified how the difference in the effect of sarcopenia on postoperative outcome between gastric cancer patients and other gastrointestinal malignancies can be explained. One might postulate that the majority of gastric cancer patients have such a high degree of malnutrition and energy depletion that the presence of sarcopenia does not have a measurable effect in this population. After the study in chapter four more studies have been published on this subject. All these studies are Asian studies and all report relatively low rates of sarcopenia [58-60].

In conclusion, chapter three and four show that frailty and nutritional status, assessed using questionnaires, provide a low-cost, low-resource consuming method for identifying high-risk patients. Also, sarcopenia is highly prevalent in 
patients undergoing surgery for gastric cancer. However, sarcopenia was not associated with worse outcome after surgery. These findings underline the importance of geriatric frailty and nutritional status assessment in the preoperative work-up of gastric cancer patients. It also offers information for better clinical decision making and improved shared decision making. Lastly it indicates that gastric cancer patients probably have undergone a long deterioration process even before they present themselves in the outpatient clinic or on the operating table.

\section{Potential clinical implications}

These studies show that frail patients and patients with compromised nutritional intake are at an increased risk of severe complications and mortality after surgery for gastric cancer. Importantly, questions can be raised as to how this information could and should be used.

Firstly, it can be used as an important piece of information in preoperative clinical decision-making and patients counseling. As gastric cancer is predominantly a disease of the elderly, survival might not be the ultimate goal in every patient and therefore should not always be the goal of treatment. Patients may regard optimal quality of life as their personal goal of treatment for instance. Each patient and their family should be able to make their own treatment decisions. This means that improved individualized risk assessment using frailty and nutritional status can provide patients with more information on which to base their choices in treatment.

Increased risks as assessed by frailty and nutritional status should not be used to exclude patients from surgical treatment. Rather, it should be used to inform patients of their potential increased risk and then they can decide for themselves whether they are willing to take those risks.

On the other hand improved risk identification can possibly help guide efforts to reverse or minimize risks by implementing interventions. An example is preoperative optimization of nutritional status by offering support of dietician and supplementary enteral of parenteral nutrition. There is no strong evidence that shows a complete reversal of the deleterious effects of malnutrition on postoperative risks by providing supplementary nutrition. It remains a challenge to use the results of risk assessment studies. Moreover, it may not always lead to interventions that can effectively mitigate those risks.

There are more difficulties to overcome when deciding on preoperative intervention. For instance, development of sarcopenia in a patient has been taking place over time. Trying to reverse its effects could be achieved by nutritional-and exercise therapy. However, it takes time to replenish nutrient deficiencies and build up new muscle mass. It should be considered that preoperative interventions, such as nutritional- and exercise therapy, may delay the time between diagnosis and surgery. Although no clear evidence exists that shows an adverse effect of treatment delay on survival [63-65]. Treatment delay can however have a clear 
negative impact on Quality of Life and emotional stress in cancer patients [66]. In some cases postponing definitive treatment is not even possible. For instance, patients with obstructive symptoms or bleeding from the tumor should be treated promptly. This means that increasing time to definitive treatment has to be balanced between expected positive impact of preoperative interventions and potential adverse effects.

To summarize, identifying frailty is a good way to improve clinical decision-making. Moreover, physician have more information to provide to patients and families for a well informed consent. Future studies need to focus on whether all risks that can be identified can be reversed. This might not be the case with frailty or sarcopenia. The time that some interventions take to have a positive impact provides an added challenge. Increased time to definitive treatment might not always be possible or desirable. Therefore, more clinical studies are needed to investigate whether these risks can be improved by for instance nutritional intervention and exercise. 


\section{Introduction of laparoscopic surgery for gastric cancer}

New procedures and techniques should first and foremost provide a health care improvement for the patient. This can be diverse, such as: less pain, faster recovery, shorter length of hospital stay, increased survival and so forth. However, with expanding health care costs new procedures and techniques are under increased scrutiny and will not only be judged on their merits with regards to patient care but also on their financial impact. Governmental organizations and health insurance companies have a major and increasing influence on the regulation of costs in healthcare.

Chapter five provides a prospective study that evaluates the costs of the introduction of a laparoscopic surgery program for gastric cancer in a Western community training hospital. This study takes into account hospital related costs. These were calculated as the sum of operating theatre costs and costs of length of hospital stay. Theatre costs were calculated by the time the operating room was occupied and its associated costs and the costs of instruments used (both disposable and reusable). Hospital stay costs were calculated separately for the general ward and the more expensive Intensive Care Unit (ICU) stay.

Results showed that for laparoscopic surgery the operation itself was more expensive due to longer operating theatre occupation time and more expensive surgical instruments compared to open procedures. However overall costs were similar due to shorter length of stay and less (and less lengthy) ICU stay in the laparoscopic group.

This study was performed during the introduction of the laparoscopic technique for gastrectomy for cancer. With more experience the duration of surgery is expected to decline. Nevertheless, a longer operating time is expected to remain for laparoscopic surgery as is seen in several meta-analyses $[24,67,68]$.

One of the main advantages of laparoscopic surgery for gastric cancer in previous studies is its positive effect on postoperative recovery and therefore hospital stay $[24,68]$. Despite more costs related to the surgical procedure itself, overall costs were similar due to decreased hospital stay and fewer complications. This reduction in complications is also seen in other studies [24,68].

It must be noted that the reported benefits of laparoscopic surgery are mostly based on data from patients with early gastric cancer and data mainly from Eastern populations. It is well known that major differences exist between treatment and outcome of Eastern and Western patients [69].

Therefore it cannot be extrapolated that improved outcome in Eastern patients will have the same effect size in Western patients. Large randomized controlled trials are currently being conducted in order to evaluate the effects of the laparoscopic approach for gastric cancer in Western patients. Moreover, costs and benefits of this approach should be evaluated as a cost-effectiveness analysis 
rather than just hospital related costs. However, data from chapter five may help persuade management in other hospitals to implement this new technique.

\section{Health Related Quality of Life after gastric cancer surgery}

Most research deals with improving outcomes such as complications, length of hospital stay, mortality and long-term survival. With improvements in these regards, insight in the effect of disease and its treatment on quality of life is becoming more and more important. Part four of this thesis deals with quality of life after gastric cancer surgery and factors that influence quality of life.

Gastric cancer surgery is associated with a number of complaints that can potentially have a major impact on quality of life, which include: loss of appetite, early satiety, reflux, dysphagia, nausea and change of stools [70]. This underlines the importance of evaluating the effect of gastric cancer treatment, especially surgical treatment, on Heal-Related Quality of Life (HRQoL). A better knowledge of HRQoL after gastric cancer surgery can provide useful information to physicians and patients on (long-term) risks and benefits of treatment.

HRQoL is an indication of a patient's wellbeing affected by disease and is rapidly becoming one of the more important outcome measurements in cancer treatment. Evaluation of $\mathrm{HRQOL}$ is multidimensional and encompasses physical, medical, psychological and social parameters secondary to a disease and its treatment.

The study presented in chapter six provides a cross-sectional multicentre study on HRQoL in patients who survived after gastrectomy for gastric cancer compared to a general Dutch reference population. Also factors that influenced HRQoL were analyzed. The most important findings were that compared to a general population, patients experience more functional complaints and more symptoms. However, global HRQoL of gastrectomy patients was only slightly lower. The difference was so low that it might even be interpreted as a clinically insignificant difference. The study has some inherent limitation due to its cross-sectional design and presence of confounding factors.

In this study correlation between time after surgery and HRQoL was not found and might indicate that HRQoL remains stable after surgery. The other important finding was that subtotal gastrectomy and the ability to receive neoadjuvant chemotherapy was associated with higher global HRQoL. Minimally invasive surgery was also associated with better functional and symptom scores.

Other studies to date have been mostly in Asian populations. As mentioned previously, there are important differences between Eastern and Western gastric cancer patients and their treatment [71-73]. One other Western study also found profound impact on HRQoL immediately after surgery and showed some improvement over the next six months [74]. In this prospective study only 86 out 
of 134 patients completed total follow-up. The study in chapter six included all known disease-free patients and did not exclude patients on any other grounds and therefore may better represent a typical Western gastric cancer surgical population.

Even though gastric cancer patients experience more symptoms, their overall HRQoL is similar to healthy control participants, which is something that is also seen in other studies. This has also been observed in patients who underwent esophagectomy and after breast cancer surgery $[75,76]$. This shows that despite having lived through cancer and its treatment patients can attain high life satisfaction despite having functional limitations or significant symptoms.

Reconceptualization can help explain this relatively high life satisfaction despite significant impairments. This entails that a person's internal reference point for well-being, which is important for the evaluation of HRQoL, is adjusted due to certain circumstances. This means that even though there are measurable impairments in different areas of life, overall $\mathrm{HRQOL}$ is determined by other factors and can because of that be comparable to the general population. An example of this from another study is that it is even possible to find higher global HRQoL in patients who underwent distal gastrectomy [72]. These patients, who underwent partial gastrectomy for cancer, also experienced more symptoms but had higher global HRQoL than a reference population [72].

In the study presented in chapter six benefits were found for minimally invasive surgery. This was also observed in an Asian randomized controlled trial comparing open and laparoscopy-assisted distal gastrectomy for gastric cancer [71]. Better results were reported with regards to physical functioning and certain symptoms (e.g., fatigue) [71]. Other factors that were associated with better HRQoL were partial gastrectomy and neadjuvant treatment. An important contributing factor may be the fact that partial gastrectomy is a less extensive surgical procedure, including less extensive lymphadenectomy. Hereby, a part of the stomach remains in the patient and has a residual function. This might explain why these patients perform better on several domains compared to total gastrectomy patients, which is also found in other studies [73, 77].

Neoadjuvant chemotherapy treatment was observed to be associated with better HRQoL. Most likely this is not directly related to chemotherapy itself. Evidence suggests that neoadjuvant treatment decreases physical fitness of patients [78]. Rather, the fact that these patient were physically fit enough to receive neoadjuvant treatment is probably the explanation why these patients perform better on HRQoL compared to patients who were not.

The main conclusion of chapter six is that gastric cancer surgery patients report more significant symptoms and impaired functioning after surgery. However, their global HRQoL is similar to a general reference population. These results may be helpful in clinical decision-making and can improve a patient's informed consent. 


\section{Future perspectives}

As outlined previously many advances have been made in the field of gastric cancer surgery on a preoperative, intraoperative, postoperative and organizational level. Nonetheless, more progress is to be made and a few options for this are outlined below.

More studies have to determine optimal evaluation methods for geriatric frailty, malnutrition, comorbidities and sarcopenia. Also their place in preoperative risk assessment of gastric cancer patients has to be further evaluated.

Frailty, sarcopenia and body composition measurements are relatively new in surgery. To further innovation, tools need to be developed that are optimized for surgical patients. Ideally they reliably identify high-risk patients, are fast and easy to administer, and offer points on which to intervene in order to improve outcome. A screening tool that can be administered without requiring a healthcare provider and gives automated results would be advantageous. This could take the shape of a digital questionnaire for instance. It might be an issue that gastric cancer patients are often elderly. However, there are several important reasons why digital tools can prove to be more advantageous over paper or orally administered questionnaires. Development of such tolls will take time and people, including elderly, are getting more used to digital media as time goes by. Secondly, digitally administered tests can include questions combined with functional measurements. An idea could be to build in a component that measures slowness (a frailty component) for instance, which would be relatively easy. A five-second maximum spacebar pressing test might be used analogous to a 5-meter walking test for instance. Also, cognitive tests can be more easily administered digitally, which would otherwise require a trained professional. Memory, attention and executive functions tests are hard to reliably test in the absence of a trained observer, but more easy when computer based tests are used.

Third, in a clinical setting time is a highly valuable commodity. So in questionnaires and clinical tests the time investment should be kept to a minimum. However, when patients take their tests at home this constraint no longer applies as strictly. Admittedly, overly long tests will be difficult to complete and can therefore produce unreliable results.

As stated earlier with respect to frailty and sarcopenia, more research is needed to minimize the risks for gastric cancer surgery. Prehabilitation, whereby a patients complete an exercise program to improve their cardiovascular, pulmonary and muscular condition prior to surgery. This is an area of research that might have great potential. Prehabilitation is a relatively new strategy used in medicine aimed to improve outcome for patients and could have promising potential for gastric cancer patients. It is a fact that after surgery patients lose general function in part due to loss of muscle mass. The goal is to improve physical fitness of patients prior 
to surgery so that the impact of surgery is counteracted and patients do not drop below the level of functioning prior to the start of the prehabilitation program. Gastric cancer patients would therefore have to be prepared for surgery by nutritional support and exercise therapy to optimize their nutritional and physical condition preoperatively. This may positively impact outcome by potentially improving the ability of patients to tolerate surgery and potential complications. Prehabilitation usually comprises physiotherapy and nutritional support, but can potentially be expanded to psychological support and counseling. Importantly, this should be a multidisciplinary effort. Specifically in gastric cancer patients a prehabilitation program may halt further deterioration before surgery. This, sometimes rapid, deterioration can be due to impaired nutritional intake.

One of the key elements but potential stumbling block for prehabilitation is timing. Ideally prehabilitation programs should have enough time to establish an effect and improve overall physical fitness, and this takes time. On the other hand, delay in treatment can have an unfavorable influence on long-term outcome. So for gastric cancer patients, and obviously other gastrointestinal malignancies, a balance will have to be achieved between the two.

Prehabilitation will have to prove its merits in gastric cancer patients. In Enhanced Recovery after Surgery (ERAS) programs the resulting improvement of a multimodal program proved to be greater than the sum of its parts. Research is needed to investigate whether this also is true for prehabilitation. If it is proved to be effective, prehabilitation can potentially have a large impact on the treatment program for gastric cancer patients. It will then also affect a multitude of stakeholders in the care for gastric cancer patients including physiotherapists, dieticians, psychologists, healthcare managers and health insurance providers. Concerning the minimally invasive approach in gastric cancer management, it is expected from the results of the current randomized controlled trials to determine the benefits of laparoscopic surgery for Western gastric cancer patients. These randomized controlled trials hopefully will provide results that may help determine whether broad implementation of this approach is to be advised to improve patients' outcome [30, 31, 79]. 


\section{References}

1. Bosing NM, Goretzki PE, and Roher HD, Gastric cancer: which patients benefit from systematic lymphadenectomy? Eur J Surg Oncol, 2000. 26(5): p. 498-505.

2. Fitz-Henry J, The ASA classification and peri-operative risk. Ann R Coll Surg Engl, 2011. 93(3): p. 185-7.

3. Charlson ME, Pompei $P$, Ales KL, and MacKenzie CR, A new method of classifying prognostic comorbidity in longitudinal studies: development and validation. J Chronic Dis, 1987. 40(5): p. 373-83. 4. Hsu JT, Liu MS, Wang F, Chang CJ, Hwang TL, Jan YY, and Yeh TS, Standard radical gastrectomy in octogenarians and nonagenarians with gastric cancer: are short-term surgical results and long-term survival substantial? J Gastrointest Surg, 2012. 16(4): p. 728-37.

5. Bickenbach KA, Denton B, Gonen M, Brennan MF, Coit DG, and Strong VE, Impact of obesity on perioperative complications and long-term survival of patients with gastric cancer. Ann Surg Oncol, 2013. 20(3): p. 780-7.

6. Tsunoda S, Okabe H, Obama K, Tanaka E, Akagami M, Kinjo Y, and Sakai Y, Laparoscopic gastrectomy for patients with a history of upper abdominal surgery: results of a matched-pair analysis. Surg Today, 2013.

7. Nunobe S, Hiki N, Fukunaga T, Tokunaga M, Ohyama S, Seto Y, and Yamaguchi T, Previous laparotomy is not a contraindication to laparoscopy-assisted gastrectomy for early gastric cancer. World J Surg, 2008. 32(7): p. 1466-72.

8. Fried LP, Tangen CM, Walston J, Newman AB, Hirsch C, Gottdiener J, Seeman T, Tracy R, Kop WJ, Burke G, McBurnie MA, and Cardiovascular Health Study Collaborative Research G, Frailty in older adults: evidence for a phenotype. J Gerontol A Biol Sci Med Sci, 2001. 56(3): p. M146-56.

9. Dasgupta M, Rolfson DB, Stolee P, Borrie MJ, and Speechley M, Frailty is associated with postoperative complications in older adults with medical problems. Arch Gerontol Geriatr, 2009. 48(1): p. $78-83$.

10. Robinson TN, Eiseman B, Wallace JI, Church SD, McFann KK, Pfister SM, Sharp TJ, and Moss M, Redefining geriatric preoperative assessment using frailty, disability and co-morbidity. Ann Surg, 2009. 250(3): p. 449-55.

11. Lee DH, Buth KJ, Martin BJ, Yip AM, and Hirsch GM, Frail patients are at increased risk for mortality and prolonged institutional care after cardiac surgery. Circulation, 2010. 121(8): p. 973-8.

12. Makary MA, Segev DL, Pronovost PJ, Syin D, Bandeen-Roche K, Patel P, Takenaga R, Devgan L, Holzmueller CG, Tian J, and Fried LP, Frailty as a predictor of surgical outcomes in older patients. J Am Coll Surg, 2010. 210(6): p. 901-8.

13. Dewys WD, Begg C, Lavin PT, Band PR, Bennett JM, Bertino JR, Cohen MH, Douglass HO, Jr., Engstrom PF, Ezdinli EZ, Horton J, Johnson GJ, Moertel CG, Oken MM, Perlia C, Rosenbaum C, Silverstein MN, Skeel RT, Sponzo RW, and Tormey DC, Prognostic effect of weight loss prior to chemotherapy in cancer patients. Eastern Cooperative Oncology Group. Am J Med, 1980. 69(4): p. 491-7.

14. Mariette C, De Botton ML, and Piessen G, Surgery in esophageal and gastric cancer patients: what is the role for nutrition support in your daily practice? Ann Surg Oncol, 2012. 19(7): p. 2128-34.

15. Awad S, Tan BH, Cui H, Bhalla A, Fearon KC, Parsons SL, Catton JA, and Lobo DN, Marked changes in body composition following neoadjuvant chemotherapy for oesophagogastric cancer. Clin Nutr, 2012. 31(1): p. 74-7.

16. Peng PD, van Vledder MG, Tsai S, de Jong MC, Makary M, Ng J, Edil BH, Wolfgang CL, Schulick RD, Choti MA, Kamel I, and Pawlik TM, Sarcopenia negatively impacts short-term outcomes in patients undergoing hepatic resection for colorectal liver metastasis. HPB (Oxford), 2011. 13(7): p. 439-46.

17. Peng P, Hyder O, Firoozmand A, Kneuertz P, Schulick RD, Huang D, Makary M, Hirose K, Edil B, Choti MA, Herman J, Cameron JL, Wolfgang CL, and Pawlik TM, Impact of sarcopenia on outcomes following resection of pancreatic adenocarcinoma. J Gastrointest Surg, 2012. 16(8): p. 1478-86.

18. van Vledder MG, Levolger S, Ayez N, Verhoef C, Tran TC, and Ijzermans JN, Body composition and outcome in patients undergoing resection of colorectal liver metastases. Br J Surg, 2012. 99(4):

p. 550-7. 
19. Gretschel S, Siegel R, Estevez-Schwarz L, Hunerbein M, Schneider U, and Schlag PM, Surgical strategies for gastric cancer with synchronous peritoneal carcinomatosis. Br J Surg, 2006. 93(12): p. 1530-5.

20. Mahadevan D, Sudirman A, Kandasami P, and Ramesh G, Laparoscopic staging in gastric cancer: An essential step in its management. J Minim Access Surg, 2010. 6(4): p. 111-3.

21. Leake PA, Cardoso R, Seevaratnam R, Lourenco L, Helyer L, Mahar A, Law C, and Coburn NG, A systematic review of the accuracy and indications for diagnostic laparoscopy prior to curative-intent resection of gastric cancer. Gastric Cancer, 2012. 15 Suppl 1: p. S38-47.

22. Coburn N, Seevaratnam R, Paszat L, Helyer L, Law C, Swallow C, Cardosa R, Mahar A, Lourenco LG, Dixon M, Bekaii-Saab T, Chau I, Church N, Coit D, Crane CH, Earle C, Mansfield P, Marcon N, Miner T, Noh SH, Porter G, Posner MC, Prachand V, Sano T, van de Velde C, Wong S, and McLeod R, Optimal Management of Gastric Cancer: Results From an International RAND/UCLA Expert Panel. Ann Surg, 2014. 259(1): p. 102-8.

23. Bentrem D, Wilton A, Mazumdar M, Brennan M, and Coit D, The value of peritoneal cytology as a preoperative predictor in patients with gastric carcinoma undergoing a curative resection. Ann Surg Oncol, 2005. 12(5): p. 347-53.

24. Vinuela EF, Gonen M, Brennan MF, Coit DG, and Strong VE, Laparoscopic versus open distal gastrectomy for gastric cancer: a meta-analysis of randomized controlled trials and high-quality nonrandomized studies. Ann Surg, 2012. 255(3): p. 446-56.

25. Adachi Y, Shiraishi N, Shiromizu A, Bandoh T, Aramaki M, and Kitano S, Laparoscopy-assisted Billroth I gastrectomy compared with conventional open gastrectomy. Arch Surg, 2000. 135(7): p. 806-10.

26. Kitano S, Shiraishi N, Kakisako K, Yasuda K, Inomata M, and Adachi Y, Laparoscopy-assisted BillrothI gastrectomy (LADG) for cancer: our 10 years' experience. Surg Laparosc Endosc Percutan Tech, 2002. 12(3): p. 204-7.

27. Huscher CG, Mingoli A, Sgarzini G, Sansonetti A, Di Paola M, Recher A, and Ponzano C, Laparoscopic versus open subtotal gastrectomy for distal gastric cancer: five-year results of a randomized prospective trial. Ann Surg, 2005. 241(2): p. 232-7.

28. Lee MS, Lee JH, Park do J, Lee HJ, Kim HH, and Yang HK, Comparison of short- and long-term outcomes of laparoscopic-assisted total gastrectomy and open total gastrectomy in gastric cancer patients. Surg Endosc, 2013. 27(7): p. 2598-605.

29. Siani LM, Ferranti F, De Carlo A, and Quintiliani A, Completely laparoscopic versus open tota gastrectomy in stage I-III/C gastric cancer: safety, efficacy and five-year oncologic outcome. Minerva Chir, 2012. 67(4): p. 319-26.

30. Haverkamp L, Brenkman HJ, Seesing MF, Gisbertz SS, van Berge Henegouwen MI, Luyer MD, Nieuwenhuijzen GA, Wijnhoven BP, van Lanschot JJ, de Steur WO, Hartgrink HH, Stoot JH, Hulsewe KW, Spillenaar Bilgen EJ, Rutter JE, Kouwenhoven EA, van Det MJ, van der Peet DL, Daams F, Draaisma WA, Broeders IA, van Stel HF, Lacle MM, Ruurda JP, van Hillegersberg R, and group Ls, Laparoscopic versus open gastrectomy for gastric cancer, a multicenter prospectively randomized controlled trial (LOGICA-trial). BMC Cancer, 2015. 15: p. 556.

31. Straatman J, Cuesta MA, and van der Peet DL, Optimal Management of Gastric Cancer: Laparoscopic Versus Open Gastrectomy. Ann Surg, 2015. 262(6): p. e97.

32. Gillissen F, Hoff C, Maessen JM, Winkens B, Teeuwen JH, von Meyenfeldt MF, and Dejong $\mathrm{CH}$, Structured synchronous implementation of an enhanced recovery program in elective colonic surgery in 33 hospitals in The Netherlands. World J Surg, 2013. 37(5): p. 1082-93.

33. Gustafsson UO, Scott MJ, Schwenk W, Demartines N, Roulin D, Francis N, McNaught CE, MacFie J, Liberman AS, Soop M, Hill A, Kennedy RH, Lobo DN, Fearon K, Ljungqvist O, and Enhanced Recovery After Surgery S, Guidelines for perioperative care in elective colonic surgery: Enhanced Recovery After Surgery (ERAS(R)) Society recommendations. Clin Nutr, 2012. 31(6): p. 783-800.

34. Mortensen K, Nilsson M, Slim K, Schafer M, Mariette C, Braga M, Carli F, Demartines N, Griffin SM, Lassen K, and Enhanced Recovery After Surgery G, Consensus guidelines for enhanced recovery after gastrectomy: Enhanced Recovery After Surgery (ERAS(R)) Society recommendations. Br J Surg, 2014. 101(10): p. 1209-29. 
35. Deguchi Y, Fukagawa T, Morita S, Ohashi M, Saka M, and Katai H, Identification of risk factors for esophagojejunal anastomotic leakage after gastric surgery. World J Surg, 2012. 36(7): p. 1617-22.

36. Migita K, Takayama T, Matsumoto S, Wakatsuki K, Enomoto K, Tanaka T, Ito M, and Nakajima Y, Risk factors for esophagojejunal anastomotic leakage after elective gastrectomy for gastric cancer. J Gastrointest Surg, 2012. 16(9): p. 1659-65.

37. Tsou CC, Lo SS, Fang WL, Wu CW, Chen JH, Hsieh MC, and Shen KH, Risk factors and management of anastomotic leakage after radical gastrectomy for gastric cancer. Hepatogastroenterology, 2011. 58(105): p. 218-23.

38. Schurawitzki H, Karnel F, Stiglbauer R, Schimmerl S, and Salomonowitz E, CT-guided percutaneous drainage and fluid aspiration in intensive care patients. Acta Radiol, 1992. 33(2): p. 131-6.

39. Lambiase RE, Deyoe L, Cronan JJ, and Dorfman GS, Percutaneous drainage of 335 consecutive abscesses: results of primary drainage with 1-year follow-up. Radiology, 1992. 184(1): p. 167-79.

40. Lang H, Piso P, Stukenborg C, Raab R, and Jahne J, Management and results of proximal anastomotic leaks in a series of 1114 total gastrectomies for gastric carcinoma. Eur J Surg Oncol, 2000. 26(2): p. 168-71.

41. Etoh T, Inomata M, Shiraishi N, and Kitano S, Revisional surgery after gastrectomy for gastric cancer: review of the literature. Surg Laparosc Endosc Percutan Tech, 2010. 20(5): p. 332-7.

42. Kim YJ, Shin SK, Lee HJ, Chung HS, Lee YC, Park JC, Hyung WJ, Noh SH, Kim CB, and Lee SK, Endoscopic management of anastomotic leakage after gastrectomy for gastric cancer: how efficacious is it? Scand J Gastroenterol, 2013. 48(1): p. 111-8.

43. Roy-Choudhury SH, Nicholson AA, Wedgwood KR, Mannion RA, Sedman PC, Royston CM, and Breen DJ, Symptomatic malignant gastroesophageal anastomotic leak: management with covered metallic esophageal stents. AJR Am J Roentgenol, 2001. 176(1): p. 161-5.

44. Kwak HS, Lee JM, Jin GY, Han YM, and Yang DH, Treatment of gastrojejunal anastomotic leak with a covered metallic stent. Hepatogastroenterology, 2003. 50(49): p. 62-4.

45. Meyer HJ, The influence of case load and the extent of resection on the quality of treatment outcome in gastric cancer. Eur J Surg Oncol, 2005. 31(6): p. 595-604.

46. Coupland VH, Lagergren J, Luchtenborg M, Jack RH, Allum W, Holmberg L, Hanna GB, Pearce N, and Moller $\mathrm{H}$, Hospital volume, proportion resected and mortality from oesophageal and gastric cancer: a population-based study in England, 2004-2008. Gut, 2013. 62(7): p. 961-6.

47. Anderson O, Ni Z, Moller H, Coupland VH, Davies EA, Allum WH, and Hanna GB, Hospital volume and survival in oesophagectomy and gastrectomy for cancer. Eur J Cancer, 2011. 47(16): p. 2408-14.

48. Brenkman HJF, Goense L, Brosens LA, Haj Mohammad N, Vleggaar FP, Ruurda JP, and van Hillegersberg R, A High Lymph Node Yield is Associated with Prolonged Survival in Elderly Patients Undergoing Curative Gastrectomy for Cancer: A Dutch Population-Based Cohort Study. Ann Surg Oncol, 2017. 24(8): p. 2213-2223.

49. Ghaferi AA, Birkmeyer JD, and Dimick JB, Variation in hospital mortality associated with inpatient surgery. N Engl J Med, 2009. 361(14): p. 1368-75.

50. Saxton A and Velanovich V, Preoperative frailty and quality of life as predictors of postoperative complications. Ann Surg, 2011. 253(6): p. 1223-9.

51. Hoogendijk EO, van der Horst HE, Deeg DJ, Frijters DH, Prins BA, Jansen AP, Nijpels G, and van Hout $\mathrm{HP}$, The identification of frail older adults in primary care: comparing the accuracy of five simple instruments. Age Ageing, 2013. 42(2): p. 262-5.

52. Tsujinaka S, Konishi F, Kawamura YJ, Saito M, Tajima N, Tanaka O, and Lefor AT, Visceral obesity predicts surgical outcomes after laparoscopic colectomy for sigmoid colon cancer. Dis Colon Rectum, 2008. 51(12): p. 1757-65; discussion 1765-7.

53. Cruz-Jentoft AJ, Baeyens JP, Bauer JM, Boirie Y, Cederholm T, Landi F, Martin FC, Michel JP, Rolland Y, Schneider SM, Topinkova E, Vandewoude M, Zamboni M, and European Working Group on Sarcopenia in Older P, Sarcopenia: European consensus on definition and diagnosis: Report of the European Working Group on Sarcopenia in Older People. Age Ageing, 2010. 39(4): p. 412-23.

54. Shafiee G, Keshtkar A, Soltani A, Ahadi Z, Larijani B, and Heshmat R, Prevalence of sarcopenia in the world: a systematic review and meta- analysis of general population studies. J Diabetes Metab Disord, 2017. 16: p. 21. 
55. Lieffers JR, Bathe OF, Fassbender K, Winget M, and Baracos VE, Sarcopenia is associated with postoperative infection and delayed recovery from colorectal cancer resection surgery. Br J Cancer, 2012. 107(6): p. 931-6.

56. Harimoto N, Shirabe K, Yamashita Yl, Ikegami T, Yoshizumi T, Soejima Y, Ikeda T, Maehara Y, Nishie A, and Yamanaka T, Sarcopenia as a predictor of prognosis in patients following hepatectomy for hepatocellular carcinoma. Br J Surg, 2013.100(11): p. 1523-30.

57. Reisinger KW, van Vugt JL, Tegels JJ, Snijders C, Hulsewe KW, Hoofwijk AG, Stoot JH, Von Meyenfeldt MF, Beets GL, Derikx JP, and Poeze M, Functional compromise reflected by sarcopenia, frailty, and nutritional depletion predicts adverse postoperative outcome after colorectal cancer surgery. Ann Surg, 2015. 261(2): p. 345-52.

58. Smith AB, Deal AM, Yu H, Boyd B, Matthews J, Wallen EM, Pruthi RS, Woods ME, Muss H, and Nielsen ME, Sarcopenia as a predictor of complications and survival following radical cystectomy. J Urol, 2014. 191(6): p. 1714-20.

59. Lodewick TM, van Nijnatten TJ, van Dam RM, van Mierlo K, Dello SA, Neumann UP, Olde Damink SW, and Dejong $\mathrm{CH}$, Are sarcopenia, obesity and sarcopenic obesity predictive of outcome in patients with colorectal liver metastases? HPB (Oxford), 2014.

60. Zheng ZF, Lu J, Zheng CH, Li P, Xie JW, Wang JB, Lin JX, Chen QY, Lin M, and Huang CM, A Novel Prognostic Scoring System Based on Preoperative Sarcopenia Predicts the Long-Term Outcome for Patients After Ro Resection for Gastric Cancer: Experiences of a High-Volume Center. Ann Surg Oncol, 2017. 24(7): p. 1795-1803.

61. Zhou CJ, Zhang FM, Zhang FY, Yu Z, Chen XL, Shen X, Zhuang CL, and Chen XX, Sarcopenia: a new predictor of postoperative complications for elderly gastric cancer patients who underwent radical gastrectomy. J Surg Res, 2017. 211: p. 137-146.

62. Huang DD, Zhou CJ, Wang SL, Mao ST, Zhou XY, Lou N, Zhang Z, Yu Z, Shen X, and Zhuang CL, Impact of different sarcopenia stages on the postoperative outcomes after radical gastrectomy for gastric cancer. Surgery, 2017.161(3): p. 680-693.

63. Brenkman HJF, Visser E, van Rossum PSN, Siesling S, van Hillegersberg R, and Ruurda JP, Association Between Waiting Time from Diagnosis to Treatment and Survival in Patients with Curable Gastric Cancer: A Population-Based Study in the Netherlands. Ann Surg Oncol, 2017. 24(7): p. 1761-1769.

64. Yun YH, Kim YA, Min YH, Park S, Won YJ, Kim DY, Choi IJ, Kim YW, Park SJ, Kim JH, Lee DH, Yoon SJ, Jeong SY, Noh DY, and Heo DS, The influence of hospital volume and surgical treatment delay on longterm survival after cancer surgery. Ann Oncol, 2012. 23(10): p. 2731-7.

65. Neal RD, Tharmanathan P, France B, Din NU, Cotton S, Fallon-Ferguson J, Hamilton W, Hendry A, Hendry M, Lewis R, Macleod U, Mitchell ED, Pickett M, Rai T, Shaw K, Stuart N, Torring ML, Wilkinson C, Williams B, Williams N, and Emery J, Is increased time to diagnosis and treatment in symptomatic cancer associated with poorer outcomes? Systematic review. Br J Cancer, 2015. 112 Suppl 1: p. S92-107. 66. Visser MR, van Lanschot JJ, van der Velden J, Kloek JJ, Gouma DJ, and Sprangers MA, Quality of life in newly diagnosed cancer patients waiting for surgery is seriously impaired. J Surg Oncol, 2006. 93(7): p. 571-7.

67. Kodera Y, Fujiwara M, Ohashi N, Nakayama G, Koike M, Morita S, and Nakao A, Laparoscopic surgery for gastric cancer: a collective review with meta-analysis of randomized trials. J Am Coll Surg, 2010. 211(5): p. 677-86.

68. Ohtani H, Tamamori Y, Noguchi K, Azuma T, Fujimoto S, Oba H, Aoki T, Minami M, and Hirakawa K, Meta-analysis of laparoscopy-assisted and open distal gastrectomy for gastric cancer. J Surg Res, 2011. 171(2): p. 479-85.

69. Bickenbach K and Strong VE, Comparisons of Gastric Cancer Treatments: East vs. West. J Gastric Cancer, 2012.12(2): p. 55-62.

70. Blazeby JM, Conroy T, Bottomley A, Vickery C, Arraras J, Sezer O, Moore J, Koller M, Turhal NS, Stuart R, Van Cutsem E, D'Haese S, Coens C, European Organisation for R, Treatment of Cancer G, and Quality of Life G, Clinical and psychometric validation of a questionnaire module, the EORTC QLQ-STO 22, to assess quality of life in patients with gastric cancer. Eur J Cancer, 2004. 40(15): p. 2260-8. 
71. Kim YW, Baik YH, Yun YH, Nam BH, Kim DH, Choi IJ, and Bae JM, Improved quality of life outcomes after laparoscopy-assisted distal gastrectomy for early gastric cancer: results of a prospective randomized clinical trial. Ann Surg, 2008. 248(5): p. 721-7.

72. Lee SS, Chung HY, Kwon O, and Yu W, Long-term Shifting Patterns in Quality of Life After Distal Subtotal Gastrectomy: Preoperative- and Healthy-based Interpretations. Ann Surg, 2015. 261(6): p. 11317.

73. Lee SS, Chung HY, Kwon OK, and Yu W, Long-term Quality of Life After Distal Subtotal and Total Gastrectomy: Symptom- and Behavior-oriented Consequences. Ann Surg, 2016. 263(4): p. 738-44.

74. Karanicolas PJ, Graham D, Gonen M, Strong VE, Brennan MF, and Coit DG, Quality of life after gastrectomy for adenocarcinoma: a prospective cohort study. Ann Surg, 2013. 257(6): p. 1039-1046.

75. Akkerman RD, Haverkamp L, van Rossum PS, van Hillegersberg R, and Ruurda JP, Long-term quality of life after oesophagectomy with gastric conduit interposition for cancer. Eur J Cancer, 2015. 51(12): p. $1538-45$.

76. Arndt V, Merx H, Sturmer T, Stegmaier C, Ziegler H, and Brenner H, Age-specific detriments to quality of life among breast cancer patients one year after diagnosis. Eur J Cancer, 2004. 40(5): p. 673-80.

77. Diaz De Liano A, Oteiza Martinez F, Ciga MA, Aizcorbe M, Cobo F, and Trujillo R, Impact of surgical procedure for gastric cancer on quality of life. Br J Surg, 2003. 90(1): p. 91-4.

78. Jack S, West MA, Raw D, Marwood S, Ambler G, Cope TM, Shrotri M, Sturgess RP, Calverley PM, Ottensmeier $\mathrm{CH}$, and Grocott MP, The effect of neoadjuvant chemotherapy on physical fitness and survival in patients undergoing oesophagogastric cancer surgery. Eur J Surg Oncol, 2014. 40(10): p. 131320.

79. Hur H, Lee HY, Lee HJ, Kim MC, Hyung WJ, Park YK, Kim W, and Han SU, Efficacy of laparoscopic subtotal gastrectomy with D2 lymphadenectomy for locally advanced gastric cancer: the protocol of the KLASS-02 multicenter randomized controlled clinical trial. BMC Cancer, 2015. 15: p. 355. 


\section{Nederlandse}

samenvatting

Valórisation addendum

Dankwoord

List of pulalications

Cuniculum nitas 


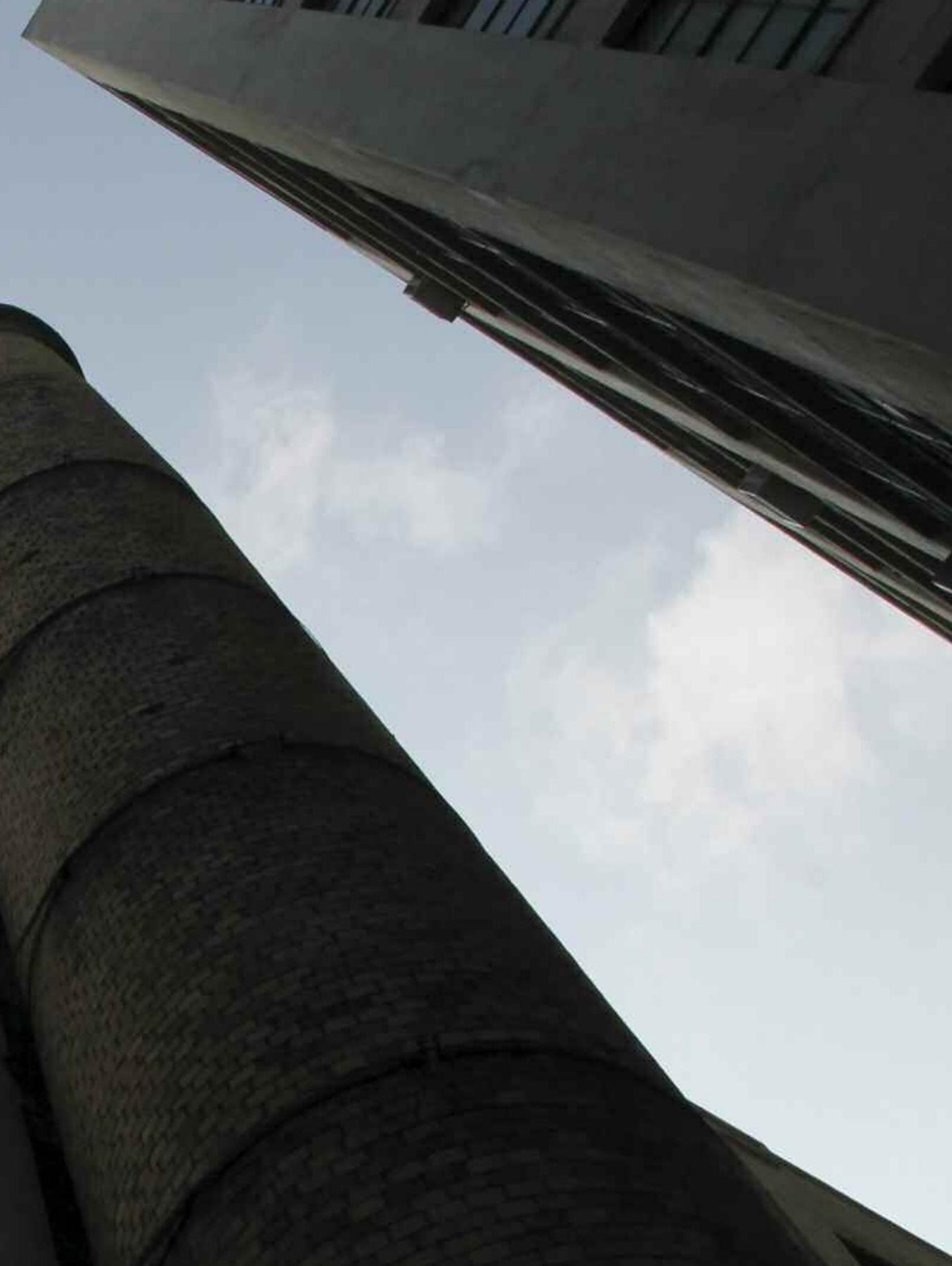




\title{
Nederlandse samenvatting
}

\author{
Introductie
}

De introductie zal u van basisinformatie van maagkanker voorzien evenals de concepten die in dit boek aan de orde komen introduceren.

Maagkanker is een van de meest voorkomende oorzaken voor kankergerelateerde sterfte wereldwijd. In 2012 waren er wereldwijd naar schatting 951.600 nieuwe gevallen en 723.100 overlijdens ten gevolge van maagkanker [1]. Tussen Westerse en Oosterse landen bestaan er wereldwijd grote verschillen. De incidentie van maagkanker is het hoogst in Japan en Korea met respectievelijk een incidentie van $66,7 / 100.000$ en 64,6/100.000. Dit is een groot verschil met de veel lagere incidentie in Nederland (9,3/100.000), het Verenigd Koninkrijk (8,9/100.000) en de Verenigde Staten $(5,3 / 100.000)[1]$.

\section{Maagkankerchirurgie}

Chirurgie is de enige behandeling die genezing of langdurige overleving kan bieden voor maagkankerpatiënten. In Westerse landen wordt maagkanker helaas pas vaak in een laat stadium gediagnosticeerd. Hierdoor is chirurgie bij veel patiënten geen optie meer. In 2015 werden in de Nederlandse landelijke kankerregistratie 1165 nieuwe gevallen van maagkanker geregistreerd. In datzelfde jaar ondergingen 428 patiënten een operatie vanwege maagkanker volgens de data van de Dutch Upper GI Cancer Audit (DUCA) [2, 3].

Maagkankerchirurgie wordt gezien als hoogrisico chirurgie, omdat het gepaard gaat met significante morbiditeit (complicaties) en mortaliteit (overlijden). Morbiditeit wordt veroorzaakt door zowel de operatie als door complicaties die kunnen optreden. In de V.S. en Europa variëren de gerapporteerde 30-dagen sterftecijfers van zo'n 3,5\% tot 6,9\% [4, 5]. Ernstige complicaties die kunnen optreden na maagresectie zijn: naadlekkage, naadstenose (vernauwing), bloeding, intra-abdominaal abces, wondproblemen (o.a. infectie) en pulmonale complicaties (met name pneumonie oftewel longontsteking). De mate waarin ernstige complicaties optreden verschilt ook met Oosterse landen. Van een relatief laag percentage van $17,4 \%$ in een Koreaanse studie en $36 \%$ na totale maagresectie in een landelijke studie in de Verenigde Staten $[4,6]$. 


\section{Voedingsstatus}

Door de aard en de locatie van de tumor is er een aanzienlijk risico op ondervoeding bij maagkankerpatiënten. Zo hebben 30 tot $38 \%$ van maagkankerpatiënten $>10 \%$ gewichtsverlies in de laatste zes maanden voor diagnose [7]. Ondervoeding is belangrijk omdat het een negatief effect heeft op morbiditeit en mortaliteit na maagkankerchirurgie [8]. Neoadjuvante chemotherapie, chemotherapie gegeven voor de operatie, kan de metabole- en voedingsstatus van patiënten potentieel nog verder verslechteren [9]. Daarom is screenen, detecteren en behandelen van ondervoeding bij maagkankerpatiënten van belang.

\section{Geriatrische frailty}

Geriatrische frailty, oftewel mate van kwetsbaarheid bij ouderen, is een relatief nieuw concept binnen de chirurgie. Het wordt gedefinieerd als een toestand van verhoogde kwetsbaarheid voor stressoren (invloeden van buitenaf) in oudere individuen die leidt tot een verhoogd risico op ongunstige gezondheidsconsequenties. Het is een klinisch syndroom dat door Fried et al. gekenmerkt wordt door de aanwezigheid van drie van de volgende vijf kenmerken: ongewenst gewichtsverlies, zelfgerapporteerde vermoeidheid, verminderde spierkracht (knijpkracht), vertraagde loopsnelheid en verminderde fysieke activiteit [10]. Geriatrische frailty wordt inmiddels herkend als een risicofactor voor slechtere uitkomsten na chirurgie. Het is een opkomende methode om risico's in te schatten met een groeiende wetenschappelijk ondersteunde basis [11-14].

\section{Sarcopenie}

Sarcopenie is een syndroom dat gekarakteriseerd wordt door het verlies van spiermassa en spierfunctie. Deze verandering in lichaamssamenstelling is in recente jaren steeds meer onderzocht in chirurgische patiënten als voorspeller voor ongunstige uitkomsten. Zo is sarcopenie geassocieerd met slechte korte en lange termijn uitkomsten na pancreas- (alvleesklier-) en leverchirurgie [15-17].

\section{Doelen van dit proefschrift}

Het eerste doel van dit proefschrift is een overzicht geven van de literatuur dat inzicht geeft in de vooruitgang die geboekt is in de zorg rondom maagkankerchirurgie. Deel één van dit proefschrift zal een overzicht geven van de vooruitgang en vernieuwingen in het intra-operatieve en postoperatieve traject alsmede vooruitgang in de regionale organisatie van maagkankerchirurgie. 
Het tweede doel van dit proefschrift is gericht op het onderzoeken van factoren die mogelijk nuttig kunnen zijn in het beter voorspellen van complicaties en mortaliteit door chirurgie. In deel twee van dit proefschrift zijn twee studies opgenomen. Zij kijken naar geriatrische frailty, voedingsstatus en sarcopenie als mogelijke voorspellers voor problemen na maagkankerchirurgie.

Introductie van nieuwe technieken leidt onvermijdelijk tot een vergelijking met de traditionele aanpak. Het doel van deel drie van dit proefschrift is het vergelijken van laparoscopische maagresectie met traditionele open maagresectie waarbij de twee technieken op het gebied van kosten met elkaar vergeleken zullen worden. Het laatste doel van dit proefschrift is inzicht krijgen in de impact van maagkankerchirurgie op de kwaliteit van leven van patiënten, dit vormt deel vier.

\section{Deel 1. Vooruitgang en innovatie in maagkankerchirurgie}

Met betrekking tot maagkankerchirurgie is er de laatste jaren het een en ander gebeurd om de uitkomsten voor patiënten te verbeteren. In hoofdstuk 2 van dit proefschrift is een overzicht gegeven van een aantal van deze verbeteringen. Deze hebben betrekking op de chirurgische aspecten van maagkanker behandeling. Daarmee vallen een paar van de meest belangrijke verbeteringen in recente jaren buiten beschouwing van dit proefschrift. Misschien wel de meest belangrijke zijn de resultaten van perioperatieve chemotherapie in het verbeteren van de overlevingskansen van maagkankerpatiënten.

Bij het bespreken van een grote operatie zoals een maagresectie, is een inschatting van de risico's en afweging ten opzichte van de voordelen erg belangrijk. Risico's inschatten is erg lastig. Dus om chirurgische zorg te verbeteren zou het goed zijn om ons vermogen om risico's in te schatten te verbeteren. De ASA-physical status, Charlson Comorbidity Index (CCl) zijn voorbeelden van classificaties die voor risicoinschatting gebruikt kunnen worden. Hogere scores zijn gerelateerd aan hogere operatierisico's. Leeftijd op zichzelf moet geen factor zijn waarop beslissingen gebaseerd worden. Comorbiditeit en algemene fysieke conditie zijn veel belangrijker zoals ook uit de volgende delen in dit proefschrift zal blijken. Verdere verbetering van risico-inschatting is mogelijk door het gebruiken van voedingsstatus en geriatrische frailty in de preoperatieve beoordeling van de patiënten.

De stadiëringslaparoscopie met spoelvocht cytologie is ingevoerd om peritoneale metastasen (buikvlies uitzaaiingen) veel beter te kunnen detecteren. Laparoscopische chirurgie, ook wel kijkoperatie genoemd, behoort inmiddels tot de standaardbehandeling in veel onderdelen van de chirurgie. Studies, voornamelijk in Azië uitgevoerd, hebben aangetoond dat laparoscopische chirurgie 
bij maagkankerpatiënten gepaard gaat met langere operatieduur, maar met minder bloedverlies en sneller herstel van de patiënt.

Verder worden in hoofdstuk 2 de lymfklierdissectie, vroegtijdig herkennen en behandelen van naadlekkages en organisatie van zorg door middel van centralisatie en audits als belangrijke onderwerpen in de behandeling van maagkankerpatiënten besproken.

\section{Deel 2. Risico-inschatting}

In hoofdstuk drie van het proefschrift werd gekeken of geriatrische frailty en voedingsstatus kunnen helpen bij het identificeren van patiënten met een verhoogd risico op complicaties en overlijden. Dit werd met behulp van twee vragenlijsten onderzocht. Resultaten lieten zien dat van de patiënten met drie of meer punten op de geriatrische frailty vragenlijst, 23,3\% overleed binnen een maand na de operatie ten opzichte van $5,2 \%$ van de patiënten met een lagere score. Een vergelijkbaar resultaat werd gevonden met betrekking tot ondervoede patiënten. Van de patiënten die geen risico op ondervoeding hadden, dus nul punten op de voedingsvragenlijst overleed slechts 3,2\% binnen een maand. $\mathrm{Bij}$ patiënten die wel een risico op ondervoeding hadden en dus één of meer punt op de vragenlijst hadden gescoord overleed $13,3 \%$ binnen een maand aan complicaties. Deze resultaten bleken los van leeftijd en kankerstadium belangrijke voorspellers te zijn voor complicaties en overlijden na een maagkankeroperatie. Dit kan helpen bij het beter inschatten van patiënten en ze daarmee ook beter voor te lichten.

In hoofdstuk vier van dit proefschrift is een studie gepresenteerd die met behulp van CT-scan beelden verlies van spiermassa, oftewel sarcopenie, in kaart heeft gebracht bij maagkankerpatiënten. Het doel van deze studie was ten eerste te analyseren hoe vaak verlies van spiermassa, sarcopenie, bij maagkankerpatiënten voorkomt. Daarnaast werd gekeken of sarcopenie ook als voorspeller voor overlijden of complicaties gebruikt zou kunnen worden. Uit de gegevens van deze studie bleek dat sarcopenie veel voorkomt bij maagkankerpatiënten, maar liefst in $57,7 \%$ van de patiënten. Dit is veel hoger in vergelijking van andere patiëntgroepen bijvoorbeeld patiënten met dikkedarmkanker of leverkankerpatiënten.

In deze studie in hoofdstuk vier werd geen verschil gezien in complicaties of overlijden na maagkankerchirurgie tussen patiënten die sarcopenie hadden en patiënten met een normale spiermassa. Hieruit kon dus niet geconcludeerd worden dat sarcopenie een goede voorspeller is voor complicaties. 


\section{Deel 3. Laparoscopie en kosten}

Om de gezondheidszorg op de lange termijn toegankelijk te houden is het belangrijk dat kosten beheersbaar blijven. Daarom is het bij introductie van nieuwe technieken van belang deze af te zetten tegen de oude manier. De gedachte dat iets nieuws vaak ook betekent dat het duurder is, kan soms een drempel vormen. Het doel is om voor de patiënt een voordeel te bieden en daarbij liever niet (veel) duurder uit te zijn. Laparoscopische chirurgie, kijkoperatietechniek, poogt dit te doen. Alhoewel het voordeel hiervan bij Westerse maagkankerpatiënten nog niet onomstotelijk vast staat zoals uit deel één bleek is dit wel aannemelijk. Hoofdstuk vijf beschrijft een studie waarbij de kosten geanalyseerd zijn tijdens de introductie van laparoscopie voor maagkanker.

De belangrijkste resultaten van de eerste 52 laparoscopische ingrepen waren als volgt. De operatie zelf, met andere woorden het gebruik van materialen en operatiekamerbezetting, is bij laparoscopie aanzienlijk duurder dan bij een klassieke open operatie. Dit kwam vooral door de langere operatieduur en meer gebruik van relatief dure wegwerpmaterialen bij laparoscopie. Echter, er waren minder kosten aan de opname in het ziekenhuis verbonden door een kortere opnameduur en minder ligdagen op de Intensive Care bij de laparoscopisch geopereerde patiënten. Hierdoor waren de totale kosten vergelijkbaar tussen de laparoscopisch en open geopereerde patiënten. Bovendien herstelden laparoscopisch geopereerde patiënten sneller en hadden zij over het algemeen minder complicaties.

\section{Deel 4. Kwaliteit van leven}

De studie in hoofdstuk zes van dit proefschrift heeft in zeven Nederlandse ziekenhuizen alle aan maagkanker geopereerde en overlevende patiënten geïdentificeerd. Aan deze 274 patiënten werden een tweetal vragenlijsten opgestuurd over hun kwaliteit van leven. Hiervan stuurde 222 (81\%) de vragenlijsten ingevuld terug.

De eerste vragenlijst betrof de algemene kwaliteit van leven vragen. Deze zogenaamde European Organization for Research and Treatment of Cancer (EORTC) QLQ-C30 vragenlijst is ook in een gezonde populatie afgenomen door een andere studiegroep. Hierdoor konden de resultaten van de maagkankerpatiënten met de resultaten van deze gezonde mensen vergeleken worden. De andere vragenlijst die afgenomen werd was EORTC QLQ-STO22 en deze vragenlijst bevat ook vragen over maagkanker specifieke klachten.

Zoals te verwachten lieten de uitkomsten zien dat de maagkankerpatiënten meer klachten ervaren dan gezonde personen. Vooral in functionele schalen zoals fysiek, 
cognitief- en sociaal functioneren. Opvallend is dat maagkankerpatiënten hun globale kwaliteit van leven helemaal niet veel slechter beoordelen dan gezonde personen.

Dit fenomeen wordt reconceptualisatie genoemd en dit ziet men ook in andere populaties van patiënten die kanker hebben overleefd. Hierbij stelt men zijn referentiekader bij met als gevolg dat ondanks de aanwezigheid van symptomen men toch een redelijk hoge mate van algehele tevredenheid ervaart, men neemt de klachten als het ware voor lief.

\section{Discussie en toekomstperspectieven}

Maagkanker is een ziekte die vooral oudere patiënten treft. Omdat ouderen vaak meer kwetsbaar zijn, is het van belang in te kunnen schatten hoe kwetsbaar ze zijn. Studies die hier gepresenteerd zijn hebben laten zien dat geriatrische frailty (kwetsbaarheid bij ouderen), voedingsstatus en spiermetingen goed mogelijk zijn. De belangrijke vraag is hoe we deze informatie moeten gebruiken.

Als een operatie zeer risicovol blijkt, dan is de vraag of een dergelijke operatie de beste oplossing is voor het probleem van de patiënt. Daarom zal informatie van risico-inschatting gebruikt kunnen worden om in sommige gevallen af te zien van operatief ingrijpen. In zulke situaties is zorg gericht op symptoombestrijding mogelijk beter.

Daarnaast geeft risico-inschatting waardevolle aanvullende informatie die gebruikt kan worden om patiënten beter te informeren. Met name over de ingreep, wat hen te wachten staat en welke risico's er aan zijn verbonden. Overleving is vaak de hoofduitkomst van wetenschappelijke studies, echter dit is voor patiënten niet altijd het belangrijkste doel van behandeling. Behoud of verbetering van kwaliteit van leven kan vanuit de patiënt gezien een veel belangrijker doel van behandeling zijn. Verbetering in risico-inschatting gericht op de individuele patiënt en daarmee verbeterde informatievoorziening moet ervoor zorgen dat de patiënten behandelkeuzes kunnen maken gericht op wat zij belangrijk vinden in hun leven. De derde manier waarop risico-inschatting informatie gebruikt kan worden, is om aangrijpingspunten te identificeren waarop voor de operatie ingegrepen kan worden om risico's te verminderen. Dat wil zeggen of bepaalde risico's die gezien worden teruggedraaid kunnen worden. Neem bijvoorbeeld de voedingsstatus. Bij een ondervoede patiënt is het raadzaam om de voedingsstatus te verbeteren met bijvoeding voor de operatie.

Toekomstige studies zullen zich erop moeten richten om nog beter en het liefst ook gemakkelijker kwetsbaarheid van patiënten in te schatten. Het identificeren van punten waarop ingegrepen kan worden om risico's te verkleinen is ook van belang. De tijd die interventies nodig hebben om een effect te hebben zorgen echter voor een extra uitdaging. Wanneer men bij een patiënt met sarcopenie eerst 
spiermassa zou willen opbouwen kost het tijd om dat doel te bereiken met sport en dieetinterventies. Deze tijd die je nodig hebt resulteert wel in vertraging van de behandeling (operatie). Vertraging in behandeling is ook niet wenselijk en potentieel nadelig, daarom moeten effecten van eventuele interventies wel opwegen tegen de mogelijke vertraging.

Prehabilitatie oftewel de patiënt trainen voor een operatie, zowel fysiek als mentaal, klinkt als een potentieel veelbelovende strategie. Het idee is om de patiënt op een fysiek en mentaal hoger niveau te krijgen om zo beter bestand te zijn tegen de aanslag op het lichaam, die de operatie en eventuele complicaties zijn. Een belangrijke uitdaging en mogelijk struikelblok zal timing zijn.

\section{Conclusie}

In het kort zijn er de laatste jaren veel onderzoeken verschenen die verbetering in de chirurgische zorg van maagkanker hebben laten zien. Daarnaast lijken geriatrische frailty (kwetsbaarheid) en voedingsstatus goed bruikbaar te zijn als voorspellers voor slechtere uitkomsten na maagkankerchirurgie. Sarcopenie oftewel spierverlies komt vaak voor bij Westerse maagkankerpatiënten, maar lijkt niet voorspellend te zijn voor slechtere korte termijn uitkomsten. Laparoscopie (kijkoperaties) voor maagkanker lijkt in eerste instantie niet perse duurder te zijn dan open chirurgie als gekeken wordt naar kosten van operatiemateriaal en ziekenhuisopname. Ten slotte waarderen de overlevende maagkankerpatiënten hun algehele kwaliteit van leven niet slechter dan die van een gezonde vergelijkbare populatie Nederlanders. Ondanks dat maagkankerpatiënten wel degelijk klachten blijven ervaren, ook in de jaren na de operatie. 


\section{Referenties}

1. Torre LA, Siegel RL, Ward EM, and Jemal A, Global Cancer Incidence and Mortality Rates and Trends-An Update. Cancer Epidemiol Biomarkers Prev, 2016. 25(1): p. 16-27.

2. Integral Cancer Center of the Netherlands (IKNL IKN. Gastric cancer incidence report. 201710 April 2017]; Available from: http://www.cijfersoverkanker.nl/.

3. Eddes E TR, Wouters M. Dutch Institute for Clinical Auditing, Year Report 2015 (DICA Jaarrapportage 2015). 2015; Available from: https://www.dica.nl/jaarrapportage-2015.

4. Bartlett EK, Roses RE, Kelz RR, Drebin JA, Fraker DL, and Karakousis GC, Morbidity and mortality after total gastrectomy for gastric malignancy using the American College of Surgeons National Surgical Quality Improvement Program database. Surgery, 2014. 156(2): p. 298-304.

5. Dikken JL, van Sandick JW, Allum WH, Johansson J, Jensen LS, Putter H, Coupland VH, Wouters MW, Lemmens VE, van de Velde CJ, van der Geest LG, Larsson HJ, Cats A, and Verheij M, Differences in outcomes of oesophageal and gastric cancer surgery across Europe. Br J Surg, 2013. 100(1): p. 83-94. 6. Park DJ, Lee HJ, Kim HH, Yang HK, Lee KU, and Choe KJ, Predictors of operative morbidity and mortality in gastric cancer surgery. Br J Surg, 2005. 92(9): p. 1099-102.

7. Dewys WD, Begg C, Lavin PT, Band PR, Bennett JM, Bertino JR, Cohen MH, Douglass HO, Jr., Engstrom PF, Ezdinli EZ, Horton J, Johnson GJ, Moertel CG, Oken MM, Perlia C, Rosenbaum C, Silverstein MN, Skeel RT, Sponzo RW, and Tormey DC, Prognostic effect of weight loss prior to chemotherapy in cancer patients. Eastern Cooperative Oncology Group. Am J Med, 1980. 69(4): p. 491-7.

8. Mariette C, De Botton ML, and Piessen G, Surgery in esophageal and gastric cancer patients: what is the role for nutrition support in your daily practice? Ann Surg Oncol, 2012. 19(7): p. 2128-34.

9. Awad S, Tan BH, Cui H, Bhalla A, Fearon KC, Parsons SL, Catton JA, and Lobo DN, Marked changes in body composition following neoadjuvant chemotherapy for oesophagogastric cancer. Clin Nutr, 2012. 31(1): p. 74-7.

10. Fried LP, Tangen CM, Walston J, Newman AB, Hirsch C, Gottdiener J, Seeman T, Tracy R, Kop WJ, Burke G, McBurnie MA, and Cardiovascular Health Study Collaborative Research G, Frailty in older adults: evidence for a phenotype. J Gerontol A Biol Sci Med Sci, 2001. 56(3): p. M146-56.

11. Dasgupta M, Rolfson DB, Stolee P, Borrie MJ, and Speechley M, Frailty is associated with postoperative complications in older adults with medical problems. Arch Gerontol Geriatr, 2009. 48(1): p. $78-83$.

12. Robinson TN, Eiseman B, Wallace JI, Church SD, McFann KK, Pfister SM, Sharp TJ, and Moss M, Redefining geriatric preoperative assessment using frailty, disability and co-morbidity. Ann Surg, 2009. 250(3): p. 449-55.

13. Lee DH, Buth KJ, Martin BJ, Yip AM, and Hirsch GM, Frail patients are at increased risk for mortality and prolonged institutional care after cardiac surgery. Circulation, 2010. 121(8): p. 973-8.

14. Makary MA, Segev DL, Pronovost PJ, Syin D, Bandeen-Roche K, Patel P, Takenaga R, Devgan L, Holzmueller CG, Tian J, and Fried LP, Frailty as a predictor of surgical outcomes in older patients. J Am Coll Surg, 2010. 210(6): p. 901-8.

15. Peng PD, van Vledder MG, Tsai S, de Jong MC, Makary M, Ng J, Edil BH, Wolfgang CL, Schulick RD, Choti MA, Kamel I, and Pawlik TM, Sarcopenia negatively impacts short-term outcomes in patients undergoing hepatic resection for colorectal liver metastasis. HPB (Oxford), 2011. 13(7): p. 439-46.

16. Peng P, Hyder O, Firoozmand A, Kneuertz P, Schulick RD, Huang D, Makary M, Hirose K, Edil B, Choti MA, Herman J, Cameron JL, Wolfgang CL, and Pawlik TM, Impact of sarcopenia on outcomes following resection of pancreatic adenocarcinoma. J Gastrointest Surg, 2012. 16(8): p. 1478-86.

17. van Vledder MG, Levolger S, Ayez N, Verhoef C, Tran TC, and Ijzermans JN, Body composition and outcome in patients undergoing resection of colorectal liver metastases. Br J Surg, 2012. 99(4):

p. 550-7. 


\section{Valorisation addendum}

\section{Introduction}

In daily clinical activities decisions are largely governed by habits and previous experiences, so we continue to solve the same problems with the same solutions hopefully resulting in the same outcome or preferably better. The goal of medical science is to improve outcome and to provide evidence to change our approach in daily practice. But the magnitude of impact depends several factors. The magnitude of the study, i.e., level of evidence, determined by size of study, quality of the data acquisition and risk of bias for instance. And also how closely it relates to daily practice. For example, laboratory studies and animal studies, which are extremely important for understanding basic knowledge of health and disease. They rarely have a significant direct impact on daily clinical practice because it many steps need to be takes to introduce this knowledge in clinical practice. On the other hand, large scale randomized controlled trials comparing two treatment strategies have both magnitude as well as close relationship with daily practice. These can therefore result in a change in daily practice sometimes soon after publication. So to translate these concepts to the studies presented in this thesis one might say although this thesis is comprised of clinical studies, these studies are not very large. Indeed, studies of up to 180 patients in a single center and more than 200 patients in a multi centre study may be relatively small statistically speaking. For Western gastric cancer populations however, these are of a fair size. Even more so, magnitude of study results does not need to be singular and can be cumulative. For example the growing number of studies that are published on, for instance, geriatric frailty in surgical patients all add cumulatively to the total mass of the evidence. This is also true for other concepts presented in this thesis (sarcopenia, laparoscopic surgery and Quality of Life). To illustrate this one can type the following search terms into the Pubmed search engine: "geriatric", "frailty" and "surgery". This results in 'just' 335 hits, the first study dates from 1993 and the authors call out for implementation of geriatric assessment. The next studies do not appear until ten years later. After this a veritable explosion occurred of increasing number of published articles on this subject occurs.

The work in this thesis may not alter the daily practice in a groundbreaking way. It did help on a smaller scale to improve the results of this single centre by reducing the morbidity and mortality of gastric cancer surgery. Key concepts which are important to the treatment of gastric cancer patients are highlighted in this thesis and add to the already existing evidence that inevitably will affect treatment of gastric cancer and perhaps other patients. 


\section{Socioeconomic relevance}

Medical studies, especially clinically focused studies, are inherently more broadly relevant than just scientifically. They are of interest to daily clinical practice and to patients, and by extension therefore of importance to their social network, the population as a whole, health insurance providers and healthcare administrators.

From a social and moral standpoint the question arises what level of risk is acceptable to perform surgery? If one could be able to reliably identify high risk patients, which level of risk would be considered too great to be acceptable? And who is to decide this threshold? Is it patients themselves, medical professionals or even health insurance providers? These questions are yet unanswered, but they suggest that studies aimed to help identify patients who are at an increased risk can potentially have far-reaching implications. For the moment frailty and nutritional status help us identify patients who are at risk. This information can be explained to patients and families and they can make treatment decisions together with physicians. These decisions take more into account such as a person's own frame of reference and other factors such as comorbidities. Perhaps in the future when risk assessment tools further improve the medical profession and society in general might have to deal with these, rather difficult, questions.

With health care costs seemingly ever expanding, gaining more insight in cost aspects of treatment is essential. This is not only to monitor costs but also to identify points at which costs can be reduced without deleterious effects on patient wellbeing or outcome. Managing costs is important to keep health care affordable and ensure the stable safety net our current healthcare system provides. The study in this thesis provides an insight into hospital related costs. These might be especially important when planning to negotiate implementation of laparoscopic surgery, which is discussed in the section below. This is because laparoscopic surgery is more expensive but may lead to cost reduction in other aspects of health care. On the other hand, more aspects come into play when considering cost-effectiveness of treatment. This will have to be further explored in other studies and will be a part of the Dutch LOGICA trial which compares open versus laparoscopic surgery for gastric cancer in a randomized controlled trial. 


\section{Implementing current results}

Frailty and nutritional status have shown to be important predictors of outcome in a lot of studies. The difficulty is to determine in what way they should influence decision making. That still has to be determined. What can be implemented is the use of questionnaires to screen for elements of frailty and nutritional depletion. They can be administered by health care professionals and supporting nursing staff, but can also be administered on paper. This can also easily be performed prior to outpatient clinic visits. Although fraught with some difficulty, especially in elderly patients, these questionnaires can even be administered digitally either at the clinic or at home. However this last option will probably often rely on support from others and might therefore not always guarantee optimal results.

The implementation of how the information is obtained as described above is one aspect. The other important aspect of implementation is how this information should be used. Based on current results from studies in this thesis and other literature it is far too early to make treatment decisions based on frailty and nutritional status. However, the results underline the importance of screening for malnutrition and offering nutritional support when needed is paramount. Frailty can based on these results ad to preoperative decision making and informed consent. It can help identify high-risk patients and informing patients of these risks can help them and their families to make better decisions for themselves. Some patients might refrain from invasive surgery if it carries high risks and therefore decide not to undergo a procedure. Others might choose to proceed with surgery despite increased risk of adverse events, but their choice would be based on more complete information.

It has not yet come to a stage where measuring muscle mass and sarcopenia should be routinely performed on preoperative imaging. How sarcopenia impacts clinical outcome and how it may influence daily practice should first be elucidated further. However this thesis shows that the use of cheap open-source software such as Osirix to assess sarcopenia and muscle mass is well suited for research purposes. It is easy to use and has valid test characteristics (e.g., low inter-observer variability) as shown in other studies.

The implementation of laparoscopic surgery is already increasing. Laparoscopic surgery has been used as an approach for many surgically treatable diseases. After increased usage in the East the West is now also increasingly using laparoscopic surgery in gastric cancer patients. One major hurdle of implementing this new technique is that aside from safety aspects, dealt with in numerous previous studies, health-care administrators might be wary because of fears of increased 
costs. Hopefully this thesis provides some evidence that this is not necessarily the case. There were no significant differences in costs between open and laparoscopic surgery. Major difference was increased cost related to the surgery itself (e.g., operating room and material usage) but this was compensated by a reduction in ICU and hospital stay resulting in similar overall costs. Although local prices and costs vary and are often dependent on volume and negotiated pricing of products, the general idea remains the same. New techniques do not always inherently introduce more expenses.

Quality of life remains very important and is becoming more and more recognized as an outcome parameter in recent years. The results from the study in this thesis can most easily be implemented in daily practice in the information patients receive regarding their surgical procedure. Gastric cancer surgery is intrinsically high risk not only as far as complications are concerned but especially with its influence on daily living. For instance, change dietary habits will occur as the gastrointestinal tract is altered by the surgery. Knowledge about the impact on daily living before the operation will improve the understanding and acceptance by patients. Other complaints such as pain, fatigue and dyspnoea may also be affected. An important finding of the quality of life study presented in this thesis is the fact that despite these complaints they tend to value their overall Quality of Life almost equal to healthy people. 


\section{Dankwoord}

Dit werk is af, gelukkig! Een proefschrift voltooien is niet mogelijk zonder de hulp, steun en inspanningen van talloze mensen om je heen. Hiervoor oneindige dank, want zonder jullie was dit proefschrift er niet geweest. Het lukt niet om in een dankwoord iedereen recht te doen. Dus wie hier niet aan bod komt, maar mij toch geraakt heeft: mijn dank is groot.

Allereerst, Kees Dejong dank voor het vervullen van de promotor rol. Een bijzondere rol aangezien je geen enkele auteursrol hebt gekregen van ons in de studies in dit boek. Toch heb je dit hele boek en een aantal stukken voor het submitten willen voorzien van verhelderend commentaar. Waarvoor veel dank. Je nodigde me uit om op de 11e van de 11e de 11e stelling te bedenken en dat is gelukt (in de weekenddienst).

De spil in het research verhaal mijn co-promotor en mentor: Jan Stoot, a.k.a Johnny Punch! Jouw ongeremde enthousiasme maakte dat ik elke keer, als er weer een researchmeeting bij jullie thuis achter de rug was, met een 'go get 'm' attitude door kon met mijn werk. Je begon al te strooien met de woorden 'boekje' en 'promotie' in het vliegtuig naar Orlando voor mijn eerste congres. lets wat ik zeker in het begin met de nodige korrels zout genomen heb. Eerst zien dan geloven. Nu is dan toch dat moment gekomen, jouw eerste promovendus als co-promotor. Oneindig veel dank voor al je uren werk dat je aan ons studenten hebt gespendeerd en ons gepusht hebt om te laten zien wat er mogelijk is, ook zonder geld en ook zonder fulltime tijd.

Speciale dank aan de leden van leescommissie voor het beoordelen van ons werk en voorzien van nuttig commentaar. In het bijzonder professor Nicole Bouvy als voorzitter en de overige leden prof. dr. H. Grabsch, prof. dr. M. Weijenberg, prof. dr. R. van Hilligersberg en dr. B. Wijnhoven, die helaas niet allen bij de verdediging aanwezig kunnen zijn.

Michiel de Maat jij nu als eerst, want jij hebt me geholpen bij het zetten van mijn eerst stappen in onderzoek. Toen ik zo groen als gras aankwam als vijfdejaars student heb je ervoor gezorgd dat ik terecht kon met vragen en voor advies. Jan was de aanstichter, maar van jou heb ik geleerd onderzoek te doen en vooral hoe het netjes op te schrijven. Onwijs bedankt daarvoor! 
Vanaf het eerste moment was ook jij Ton Hoofwijk intensief betrokken bij het onderzoek. Maar ook buiten het onderzoek heb je in de afgelopen jaren veel voor mij betekend. Je bent altijd eerlijk en rechtdoorzee, zowel in nakijken van de papers, op de werkvloer en daarbuiten. Als ik onaangekondigd me opeens bij jou moest melden wist ik nooit of ik iets verprutst had en dat te horen kreeg of dat je iets leuks positiefs wilde terugmelden. Gelukkig was het meestal het laatste. Mede dankzij jouw steun ben ik in opleiding in het mooiste vak dat er is. Ik heb veel bewondering voor jou als chirurg en vooral als mens. Dank is niet goed in worden te vatten, maar toch: heel erg veel bedankt!!!

Leden van de LOGICA trial groep, in het bijzonder Hylke Brenkman en Maarten Seesing. Bedankt voor jullie samenwerking, mij scherp te houden bij data op tijd invoeren. Minder dank voor de veel te vroege bijeenkomsten op de vrijdagochtend bij de chirurgendagen. Dank aan alle leden voor de nog steeds voortdurende samenwerking zowel in de LOGICA trial als in de vervolg- en side-studies.

Dank aan de semi's die meegedaan hebben aan alle studies in dit boek en daarbuiten. Elk hun eigen weg ingeslagen, promotietraject, opleiding etc. Jeroen van Vugt, een van onze eerste congressen in Helsinki en elkaars CT's meten. Die van jou waren er trouwens veel meer dan die van mij! Gefeliciteerd met je onwijs dikke boek en natuurlijk de opleiding. Patrick de Hoogt, Charlotte Silvius, Frederique Spauwen en de huidige onderzoekers Thaís Tweed en Kees de Mooij. Als je maar wil, kan het!

Natuurlijk niet te vergeten de vakgroep chirurgie Zuyderland, Maatschap Heelkunde Zuid-Limburg. Dank voor de steun in het onderzoek die ik gekregen heb van de groep en uiteraard ook dat jullie van mij een goed chirurg proberen te maken.

Speciale dank aan mijn goede vrienden en paranimfen Jasper Kox en Luuk Theelen. Met één meeting aan de keukentafel was alles geregeld, althans dat dachten jullie. Ik dank jullie voor jullie vriendschap. Jasper 'Foxy Koxie' Kox voor je altijd irritante weerwoord en intellectueel aftroeven. Luuk die nog steeds niet weet dat hij de eerste orthopeed-intensivist gaat worden. Dat we tot die tijd nog maar regelmatig naar de Muziekgieterij mogen gaan.

Vrienden die studententijd gemaakt hebben tot wat het was: Gijs Boereboom, Koen Dullaert, Sander Huisman, Jasper Kox, Denny Maessen, Luuk Theelen en Bart Wagemans. In de uren die we samen in de Mensa gespendeerd hebben, hadden we allemaal een complete promotie kunnen afronden. Om de uren die we in de tuin aan de Bloemenweg of op de stoep aan de Wilhelminasingel hebben zitten barbecueën er nog maar niet bij op te tellen. ledereen is op zijn pootjes terecht 
gekomen of het nou bij defensie, als huisarts of specialist in opleiding is. Zelfs Koen Dullaert zonder wie ik niet terecht was gekomen bij Jan Stoot. Als jij niet te 'lui' was geweest om onderzoek te gaan doen had ik aan dit proefschrift nooit kunnen beginnen.

Collega's assistenten chirurgie in Zuyderland, Maastricht en in de regio. Een mooie assistententijd maak tenslotte je samen. Of dat op de werkvloer is of op de bühne van de chirurgendagen maakt niet uit. Het is fijn om de regio met jullie te delen.

Een niet wetenschappelijke maar persoonlijke dank aan de verpleging op de SEH in Zuyderland Sittard 2013-2014 (toen nog Orbis). Inmiddels zijn heel aantal van jullie er niet meer werkzaam, ambulance, ander ziekenhuis of ander werk. De mooie leerzame tijd van mijn eerste jaar als assistent op de SEH heb ik bij jullie mogen doorbrengen. Het is heel goed en vormend voor een jonge arts om in en klein team intensief samen te werken in mooie en soms ook donkere tijden. Dank voor jullie, hulp, steun en gezelligheid in het begin, maar zeker ook daarna nog als assistent chirurgie.

Pap en mam, jullie hebben letterlijk en figuurlijk aan de wieg gestaan. Zij die mij samen met mijn broer en zus (Sten en Jossie) groot gebracht hebben in een warm en liefdevol thuis. Dankzij jullie heb ik alle eigenschappen meegekregen die nodig zijn om dit boekwerk te voltooien en chirurg te kunnen worden. Nieuwsgierig, handig, leergierig, niet zeuren en hard werken (en 'aet door')! Hiervoor kan ik jullie niet genoeg bedanken! Ik weet dat we druk zijn en dat ik niet zo vaak thuis ben als ik graag zou willen zijn. Maar onthoud dat ik er altijd zal zijn als het nodig is. Ik hou van jullie!

Elsbeth, mijn vriendin én, ook al vind ik het nog wat raar klinken, mevrouw TegelsRouers tegenwoordig. Mijn bewondering voor jou is immens! Hoe je het volhoudt, snap ik niet. Het is niet gemakkelijk, jouw werk in Utrecht, mijn werk hier, allebei een promotie, de zorg voor je moeder en nog een privé leven erop nahouden naast dit alles. Ik vind het bijzonder. Het is een balanceeract die we al geruime tijd volhouden. Gelukkig kun je de laatste tijd wat meer tijd in Maastricht werken zodat we niet alleen op papier samenwonen maar ook écht in de praktijk samenwonen in ons eigen ( $\mathrm{t}$ )huis. Ik hoop dat in de nabije toekomst je gegund wordt wat je het allerliefste wil: in opleiding tot kinderarts. Geen twijfel mogelijk dat je dat vak glansrijk zult vervullen! Want in vergelijking met wat je nu doet is in opleiding zijn een eitje. Lieverd ik hou ontzettend veel van je!!!

Om af te sluiten: "Soms is et baeter iets moeis te verleeze, baeter verleeze den det ge 't noeit het gehad". De tekst van Jack Poels uit het lied Heilige Antonius van het album Water, Lucht, Liefde uit 1997 is zeer treffend. ledereen heeft wel iets of 
iemand waar je na het lezen hiervan aan denkt. Dank ook aan hen die er niet meer zijn in wat ze voor ons betekend hebben en nog steeds voor ons betekenen. Dat we allemaal van tijd tot tijd een moment mogen nemen om aan hen te denken. Voor allen die Limburg vreemd zijn en een handje hulp nodig hebben de vertaling: het is stelling 11 van dit proefschrift. 


\section{Publications in this thesis}

Brenkman HJF, Tegels JJW, Ruurda JP, Luyer MDP, Kouwenhoven EA, Draaisma WA, van der Peet DL, Wijnhoven BPL, Stoot J, van Hillegersberg R, Group Logica Study. Factors influencing health-related quality of life after gastrectomy for cancer. Gastric cancer : official journal of the International Gastric Cancer Association and the Japanese Gastric Cancer Association. 2018;21(3):524-32.

Tegels JJ, Silvius CE, Spauwen FE, Hulsewe KW, Hoofwijk AG, Stoot JH. Introduction of laparoscopic gastrectomy for gastric cancer in a Western tertiary referral centre: A prospective cost analysis during the learning curve. World J Gastrointest Oncol. 2017;9(5):228-34.

Tegels JJ, van Vugt JL, Reisinger KW, Hulsewe KW, Hoofwijk AG, Derikx JP, Stoot $\mathrm{JH}$. Sarcopenia is highly prevalent in patients undergoing surgery for gastric cancer but not associated with worse outcomes. Journal of surgical oncology. 2015;112(4):403-7.

Tegels JJ, De Maat MF, Hulsewe KW, Hoofwijk AG, Stoot JH. Improving the outcomes in gastric cancer surgery. World journal of gastroenterology : WJG. 2014;20(38):13692-704.

Tegels JJ, de Maat MF, Hulsewe KW, Hoofwijk AG, Stoot JH. Value of geriatric frailty and nutritional status assessment in predicting postoperative mortality in gastric cancer surgery. J Gastrointest Surg. 2014;18(3):439-45; discussion 45-6. 


\section{Publications not in this thesis}

Tweed T, van Eijden Y, Tegels JJ, Brenkman H, Ruurda J, van Hillegersberg R, Sosef $\mathrm{MN}$, Stoot JH. Safety and efficacy of early oral feeding for enhanced recovery following gastrectomy for gastric cancer: A Systematic Review. Surgical Oncology (accepted)

van de Pas JM, Tegels JJW, van Vugt R, Vissers YLJ, de Loos ER. Posture-dependent thoracic outlet syndrome due to a inferiorly and dorsally angulated clavicle fracture. ANZ J Surg. 2018.

de Hoogt PA, Reisinger KW, Tegels JJW, Bosmans J, Tijssen F, Stoot J. Functional Compromise Cohort Study (FCCS): Sarcopenia is a Strong Predictor of Mortality in the Intensive Care Unit. World journal of surgery. 2018;42(6):1733-41.

Tegels JJ, Stoot JH. Way forward: Geriatric frailty assessment as risk predictor in gastric cancer surgery. World J Gastrointest Surg. 2015;7(10):223-5.

Tegels JJ, Hulsewe KW, Sosef MN, Stoot JH. Morbidity and mortality after total gastrectomy for gastric malignancy: do not forget about geriatric frailty and nutrition. Surgery. 2015;157(2):406-7.

van Vugt JL, Tegels JJ, Derikx JP, Visschers RG, Stoot JH. First experiences with the Radial Reload with Tri-staple technology in low rectal surgery. International journal of surgery. 2015;14:23-7.

Reisinger KW, van Vugt JL, Tegels JJ, Snijders C, Hulsewe KW, Hoofwijk AG, Stoot JH, Von Meyenfeldt MF, Beets GL, Derikx JP, Poeze M. Functional compromise reflected by sarcopenia, frailty, and nutritional depletion predicts adverse postoperative outcome after colorectal cancer surgery. Ann Surg. 2015;261(2):34552. 


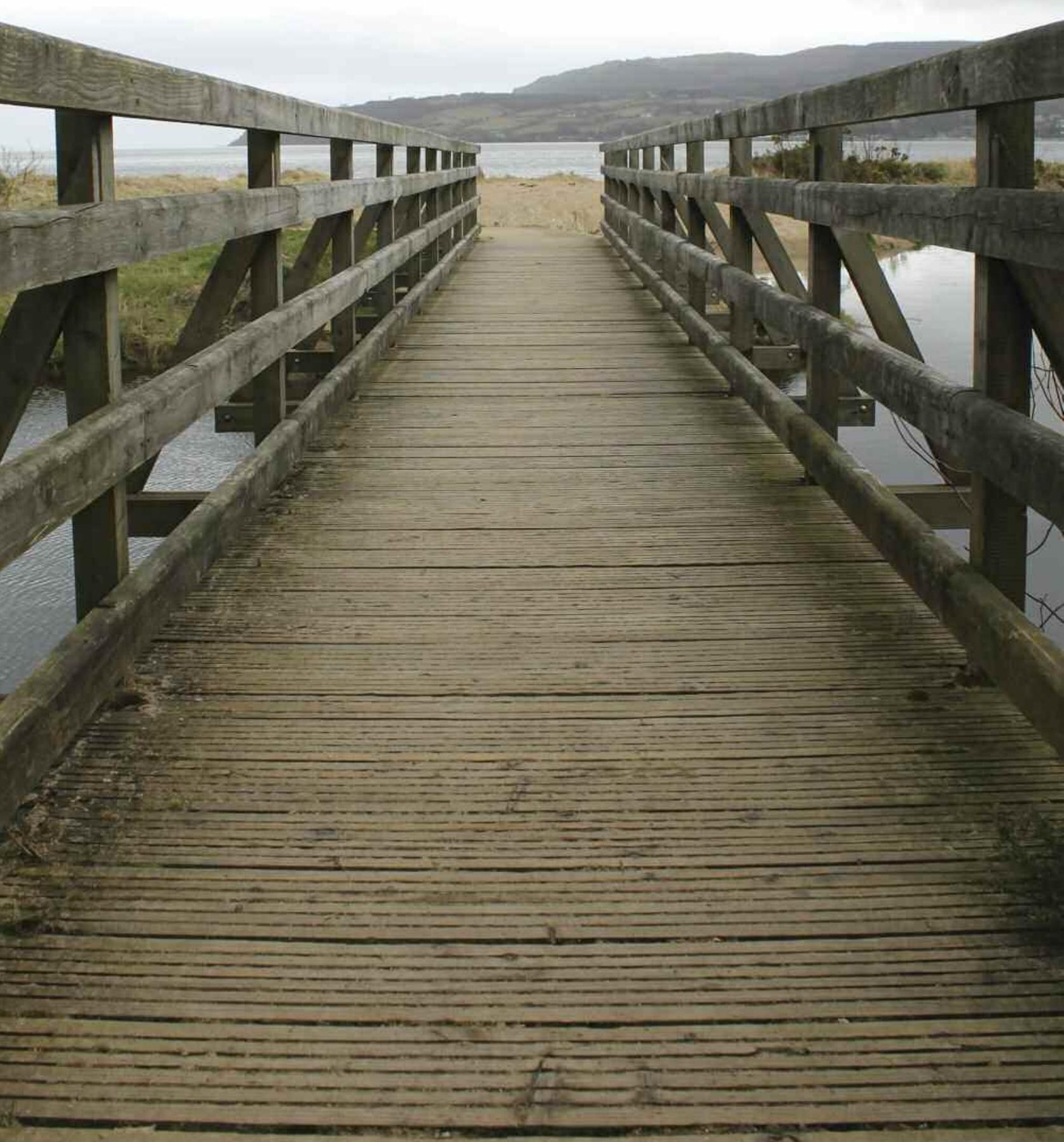


Juul Tegels was born on the August 25th 1988 in his childhood home in Swalmen, the Netherlands. In this town he grew up with his parents and younger twin brother and sister. After graduating from the Bisschoppelijk College Broekhin in Roermond he went on to study Medicine at the Maastricht University in 2007.

During the last years of medical school he started doing research in what was then named Orbis Medical Centre in Sittard under the supervision of Jan Stoot. This formed a beginning of the work in this thesis.

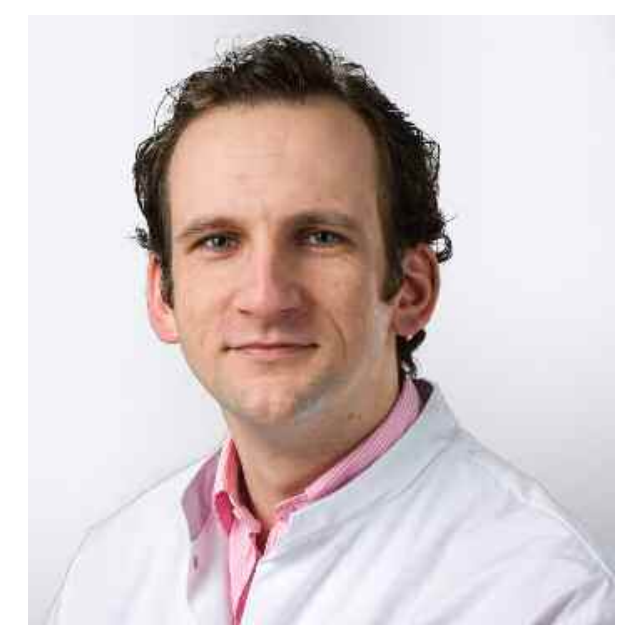

He graduated in juli 2013 after completing both his research and clinical rotations at the department of surgery in Sittard. After graduation he started his first job as a resident not in training at the Emergency department of the Orbis Medical Centre. In May 2014 he got to present his first study results at the Digestive Disease Week in Orlando (FL, U.S.) with the help of a van Walree grant.

In June 2014 he continued as resident not in training in the surgical department of the same hospital. Meanwhile continuing to work on his thesis. In July 2015 he started his surgical training in Sittard under dr. Ton Hoofwijk and later also in Heerlen under dr. Meindert Sosef. This was due to the hospital merger between Orbis Medical Centre and Atrium Medical Centre to form Zuyderland medical centre. At this time the thesis was also under supervision of professor dr. C.H.C. Dejong (Maastricht University medical centre). Currently he is continuing his surgical training in the Maastricht University medical centre under the supervision of prof. L.P.S. Stassen. After his time there he will return by the end of 2019 to the Zuyderland medical centre for the final years of his surgical training.

In september 2018 Juul got happily married to Elsbeth Rouers. They live in Maastricht, the city where they met. 


\section{Improving outcomes in gastric cancer surgery}

\section{Juul Tegels}

1. Geriatrische frailty is een belangrijke voorspeller van morbiditeit en mortaliteit na maagkankerchirurgie - Dit proefschrift

2. Sarcopenie komt vaak voor bij maagkankerpatiënten, maar lijkt geen voorspeller voor morbiditeit of mortaliteit - Dit proefschrift

3. Laparoscopie als nieuwe techniek lijkt niet duurder te zijn dan de traditionele open chirurgie voor maagkanker - Dit proefschrift

4. Patiënten die maagkanker overleefd hebben ervaren meer symptomen en presteren slechter in algeheel functioneren, echter zij ervaren hun globale kwaliteit van leven als ongeveer even hoog als die van gezonde personen - Dit proefschrift

5. Preoperatieve risico-inschatting door middel van bepaling van geriatrische frailty, voedingsstatus en sarcopenie is van belang om een goed geïnformeerd preoperatief gesprek te voeren met de patiënt en familie - Valorisatie

6. Neither a referring physician nor an assessing surgeon should deny patients surgery purely on the basis of age. - Preston et al. J R Soc Med. 2008 Aug 1; 101(8): 409-415.

7. Trauma experienced by geriatric patients is much different from that experienced by young trauma patients. - M. Zenilman, JAMA Surg. 2014;149(4):327-328

8. Premature infants are at increased risk of vaccine-preventable diseases compared with term infants. - Kent et. al. Pediatrics. 2016 Sep;138(3)

9. The day will come when man will have to fight noise as inexorably as cholera and the plague - Robert Koch, arts en microbioloog, Nobelprijswinnaar 1905

10. Human beings, who are almost unique in having the ability to learn from the experiences of others, are also remarkable for their apparent disinclination to do so Douglas Adams

11. Soms is het beter iets moois te verliezen, beter verliezen dan dat je het nooit hebt gehad - Jack Poels (Rowwen Hèze), Heilige Antonius (Album: Water, Lucht, Liefde) - 1997 